UNIVERSIDADE DE SÃo PAULO

Faculdade de Medicina de Ribeirão Preto

Departamento de Neurociências e Ciências do Comportamento

Ingrid de Miranda Esteves

\title{
Caracterização das alterações na via hipocampo-córtex pré-frontal medial em modelo farmacológico da doença de Alzheimer
}



Ingrid de Miranda Esteves

\section{Caracterização das alterações na via hipocampo-córtex pré-frontal medial em modelo farmacológico da doença de Alzheimer}

Tese apresentada à Faculdade de Medicina de Ribeirão Preto da Universidade de São Paulo, como parte das exigências para a obtenção do título de Doutor em Ciências.

Área de concentração: Neurociência

Orientador: Prof. Dr. João Pereira Leite Co-orientador: Prof. Dr. Rodrigo Neves Romcy-Pereira

Versão original

Ribeirão Preto, SP 
AUTORIZO A REPRODUÇÃO E DIVULGAÇÃO TOTAL OU PARCIAL DESTE TRABALHO, POR QUALQUER MEIO CONVENCIONAL OU ELETRÔNICO, PARA FINS DE ESTUDO E PESQUISA, DESDE QUE CITADA A FONTE.

Esteves, Ingrid de Miranda

Caracterização das alterações na via hipocampo-córtex préfrontal medial em modelo farmacológico da doença de Alzheimer/ Ingrid de Miranda Esteves

Ribeirão Preto, 2010.151p.

Orientador João Pereira Leite

Tese (Doutorado) - Faculdade de Medicina de Ribeirão Preto

da Universidade de São Paulo. Área de concentração: Neurosciênicias

1. Alzheimer. 2. Estreptozotocina. 3. Nicotina. .4. Sinapse. 5. Sinapse. 6. LTP 
Esteves, Ingrid de Miranda. Caracterização das alterações na via hipocampocórtex pré-frontal medial em modelo farmacológico da doença de Alzheimer. Tese apresentada à Faculdade de Medicina de Ribeirão Preto da Universidade de São Paulo, como parte das exigências para a obtenção do título de Doutor em Ciências. Área de concentração: Neurociências.

\section{Aprovado em:}

\section{Banca examinadora}

Prof. Dr.: Instituição:

Julgamento: Assinatura:

Prof. Dr.: Instituição:

Julgamento: Assinatura:

Prof. Dr.: Instituição:

Julgamento: Assinatura:

Prof. Dr.: Instituição:

Julgamento: Assinatura:

Prof. Dr.: Instituição:

Julgamento: Assinatura: 

Dedico meu doutorado aos meus filhos Isabela e Gabriel, Que sequer existiam quando começei a realizar este trabalho. Espero que um dia eles venham a compreender a importância da ciência para a humanidade e pro planeta que vivem. 



\section{Agradecimentos}

Agradeço em primeiro lugar a Deus e a meus pais, porque a eles eu devo o simples fato de estar aqui.

Ao Dr. João por ter me dado voto de confiança e ter me aceito no seu laboratório, ao Cleiton por ter sido a pessoa que me introduziu ao grupo e também por ser o grande mentor deste trabalho e ao Rodrigo por ter aceito ser o meu coorientador.

Agradeço também a todos os colegas do laboratório, que de forma direta ou indireta contribuíram na execuçáo desta tese, e em especial aos colaboradores deste trabalho: o Matheus e o Rafael (que ajudaram na coleta e discussão dos dados) a Ludy e a Mari (que realizaram as análises histológicas e imunoistoquímicas) e finalmente à Ana Clara (pela contribuição nas análises e discussẽs dos dados e principalmente pelo apoio nos momentos mais difíceis e obscuros nesta reta final).

Sou grata de todo o meu coração ao Ricardo pelo seu amor e compreensão durante as minhas isoladas e intermináveis madrugadas de trabalho e também aos meus filhos, que apesar de serem os grandes responsáveis pelo atraso na conclusão desta tese, eles completam a minha vida, me proporcionam uma alegria sem par e me fornecem motivos pra seguir adiante.

Deixo também aqui toda a minha gratidão aos meus queridos irmãos, que só o fato de existirem faz com que a minha vida seja mais feliz.

Registro também meu agradecimento a todo o suporte técnico e competente apoio oferecidos pela Renata Caldo Scandiuzzi no HC, pelo Renato Meirelles no anexo e pela Silvia Lo Turco na secretaria da pós-graduação, que fizeram com que a execução deste trabalho se tornasse viável.

Por fim, sou grata ao CNPq pelo financiamento do projeto. 



\section{Resumo}

ESTEVES, I. M. Caracterização das alterações na via hipocampo-córtex préfrontal medial em modelo farmacológico da doença de Alzheimer. 2016. 151p. Tese (Doutorado) - Faculdade de Medicina de Ribeirão Preto - Universidade de São Paulo, Ribeirão Preto, 2016.

Severas alterações no metabolismo energético, no consumo de glicose e na sinalização de insulina cerebral estão presentes na doença de Alzheimer (DA). O modelo animal da DA obtido pela administração intracerebroventricular de estreptozotocina (STZ-icv) em ratos induz um estado de resistência à insulina no cérebro associado à disfunções colinérgicas e a déficits cognitivos, tornando-o um dos poucos modelos experimentais da forma esporádica da DA. Este trabalho tem como objetivo caracterizar, neste modelo, as disfunções sinápticas na via hipocampo - córtex pré-frontal medial (CA1-CPFm) e testar se o tratamento com nicotina é capaz de prevenir as disfunções sinápticas e reverter os prejuízos cognitivos induzido pelo STZ-icv. Para isso, ratos Wistar receberam STZ e foram submetidos a 20 dias de tratamento com nicotina. Dois dias depois, foram realizados nos animais teste de campo aberto e de reconhecimento de objeto. Em seguida os animais foram anestesiados com uretana para que os registros eletrofisiológicos fossem realizados. Um eletrodo foi utilizado para estimular CA1 com pulso pareado e potenciais de campo pós-sinápticos $\left(\mathrm{fPSP}_{1}\right)$ e sua facilitação $\left(\mathrm{fPSP}_{2}\right)$ foram registradas por um eletrodo no CPFm. Após 30 minutos de linha de base, uma estimulação em alta frequência foi aplicada para induzir a potenciação de longa duração (LTP), seguido de mais quatro horas de registro. Outro grupo experimental foi realizado para avaliar o efeito de longo prazo da STZ-icv e do tratamento com nicotina. Neste grupo, testes comportamentais e eletrofisiológicos foram realizados 60 dias após o fim do tratamento. Independentemente do tempo, os resultados indicam que a STZ produziu uma redução na indução e na manutenção da LTP, mas a facilitação por pulso pareado $\left(\mathrm{PPF}=\mathrm{fPSP}_{2} / \mathrm{fPSP}_{1}\right)$ mostra que a $\mathrm{STZ}$ prejudica a plasticidade pré-sináptica apenas a curto prazo. O tratamento com nicotina atenua a disfunção na LTP induzida pela STZ. Além disso, apenas o tratamento de nicotina também é capaz de reduzir a plasticidade pré-sináptica no grupo controle dois dias após o fim do tratamento. Estes resultados também estão associados com os dados comportamentais, uma vez que a nicotina reverteu os déficits de memória de reconhecimento nos animais STZ mas manteve o comportamento exploratório reduzido. Sugerimos com isso que o sistema colinérgico, que desempenha um papel importante em funções cognitivas e na LTP, está afetado nos animais injetados com STZ e o tratamento crônico com nicotina consegue reduzir os danos na plasticidade sináptica e comportamentais, induzidos pela STZ.

Palavras-chave: Alzheimer. Estreptozotocina. Nicotina. Sinapse. LTP. 



\section{Abstract}

ESTEVES, I. M. Characterization of changes in the medial prefrontal cortexhippocampal pathway in a pharmacological model of Alzheimer's disease. 2016. 151p. Tese (Doutorado) - Faculdade de Medicina de Ribeirão Preto - Universidade de São Paulo, Ribeirão Preto, 2016.

Severe abnormalities in brain glucose/energy metabolism and insulin signaling have been documented to play an important role in early stage of alzheimer disease (AD) pathology. Intracerebroventricular administration (icv) of streptozotocin (STZ) in rats can induce an insulin-resistant brain state associated with cholinergic dysfunctions and memory impairments, which make it a suitable experimental model of the sporadic form of AD. The present work aimed to extend the characterization of this model by probing synaptic plasticity dysfunctions in the medial prefrontal cortex (mPFC)- hippocampal (CA1) pathway and test if nicotine can prevent synaptic dysfunction and revert cognitive impairment induced by icv STZ. Here, Wistar rats received bilateral microinjection of STZ and were submitted to 20 days of nicotine treatment. After 2 days of withdrawing the subjects were submitted to open field and object recognition tests. After that, animals were anesthetized with urethane for electrophysiological tests. A twisted bipolar electrode was used to stimulate posterior-dorsal hippocampus (CA1/subiculum) with paired-pulse. Basal field post-synaptic potentials $\left(\mathrm{fPSP}_{1}\right)$ and facilitated responses $\left(\mathrm{fPSP}_{2}\right)$ were recorded by a monopolar electrode in the medial mPFC. After 30min of baseline, high frequency stimulation was applied to induce long-term potentiation (LTP) and additional four hours of electrophysiological recordings was performed. Another experimental group was performed to evaluate the long term effect of both icv STZ and nicotine treatment. In this group behavioral and electrophysiological tests were performed with 60 days after chronic treatment. Independently of time, our results indicate that STZ produced a significant decrease in the induction and maintenance of LTP, but paired pulse facilitation (PPF = $\left.\mathrm{fPSP}_{2} / \mathrm{fPSP}_{1}\right)$ shows that only the short-term pre-synaptic plasticity was impaired after STZ injection. The nicotine treatment attenuates the STZ-induced LTP dysfunction in the CA1-mPFC pathway. However, just the nicotine treatment (in control group) can reduce pre-synaptic plasticity two days after chronic treatment. These results are also associated with behavioral data, since nicotine treatment reversed the deficits in recognition memory of STZ animals but maintained the reduced exploratory behavior. We suggest that the brain cholinergic system, which plays a role in cognition function and LTP, is affected in STZ injected animals and chronic treatment with nicotine can attenuate the STZ-induced synaptic plasticity and behavioral dysfunctions.

Keywords: Alzheimer. Streptozotocine. Nicotine. Synapse. LTP. 



\section{Lista de Figuras}

Figura $1-$ Paradigma experimental . . . . . . . . . . . . . . . 45

Figura 2 - Esquema das seções de micro-injeção . . . . . . . . . . . . . . . . 48

Figura 3 - Histologia do ventrículo . . . . . . . . . . . . . . . . . . . . 49

Figura 4 - Arena do Campo Aberto . . . . . . . . . . . . . . . . 50

Figura 5 - Protocolo do Reconhecimento de Objetos . . . . . . . . . . . . 51

Figura 6 - Foto mostrando a realização do Reconhecimento de Objetos . . . . 52

Figura 7 - Regiões de registro e estimulação . . . . . . . . . . . . . . . . 53

Figura 8 - Esquema do sistema de aquisição . . . . . . . . . . . . . . . . 55

Figura $9-$ Protocolo de estimulação . . . . . . . . . . . . . . . . 57

Figura 10 - Análise da plasticidade sináptica . . . . . . . . . . . . . 59

Figura 11 - LFP característico de um animal anestesiado com uretana . . . . . 60

Figura 12 - Espectrograma característico de um animal anestesiado com uretana 61

Figura 13 - Seleção dos estados Ativos e Inativos . . . . . . . . . . . . . . 63

Figura 14 - Atividade locomotora dos grupos com diferentes doses de nicotina 68

Figura 15 - Reconhecimento de objeto com diferentes doses de nicotina . . . . 69

Figura 16 - Características dos potenciais registrados da via CA1-CPFm dos grupos tratados com diferentes doses de nicotina e CTR . . . . . . 71

Figura 17 - fPSPs e PPF dos grupos com diferentes doses de nicotina . . . . . 73

Figura 18 - Distância total de locomoção dos grupos do Experimento 1 . . . . 75

Figura 19 - Treino e teste dos grupos do Experimento 1 . . . . . . . . . 76

Figura 20 - Índice de Reconhecimento e Tempo Total de Exploração dos grupos do Experimento 1 . . . . . . . . . . . . . . . . . . . . . . 77 
Figura 21 - Características dos potenciais registrados da via CA1-CPFm durante o Experimento 1 . . . . . . . . . . . . . . . . . 79

Figura 22 - fPSP e PPF dos grupos do Experimento $1 \ldots \ldots$. . . . . . . 81

Figura 23 - fPSP e PPF dos grupos STZ tratados e não tratados do Experi-

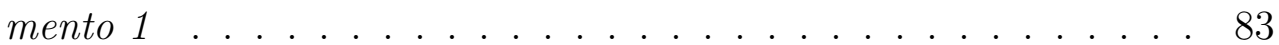

Figura 24 - Potência das LFPs Ativas e Inativas do CPFm do Experimento 1.85

Figura 25 - Potência das LFPs Ativas e Inativas do hipocampo do Experimento 1. . . . . . . . . . . . . . . . . 87

Figura 26 - Correlações entre as análises de potência e dados eletrofisiológicos 88

Figura 27 - Coerência de amplitude CA1-CPFm do Experimento 1 . . . . . 89

Figura 28 - Locomoção dos grupos do Experimento 2 . . . . . . . . . . . . . 91

Figura 29 - Treino e teste 1 mês após a injeção dos grupos do Experimento 2 . 92

Figura 30 - Treino e teste 3 meses após a injeção dos grupos do Experimento 293

Figura 31 - Tempo total de exploração e índice de reconhecimento dos grupos do Experimento 2 . . . . . . . . . . . . . . . . . . . . . . . . . . . 94

Figura 32 - Características dos potenciais registrados da via CA1-CPFm durante o Experimento 2 . . . . . . . . . . . . . . . . . . 96

Figura 33 - fPSP e PPF dos grupos do Experimento $2 \ldots \ldots$. . . . . . . . 98

Figura 34 - fPSP e PPF dos grupos STZ tratados e não tratados do Experimento 2 . . . . . . . . . . . . . . . . . . 100

Figura 35 - Potência das LFPs ativas e inativas do CPFm do Experimento 2. . 102

Figura 36 - Potência das LFPs ativas e inativas do hipocampo do Experimento 2. . . . . . . . . . . . . . . . . . . . . . 104

Figura 37 - Coerência de amplitude CA1-CPFm do Experimento 2 . . . . . 106

Figura 38 - Marcação neuronal por HE nos animais do Experimento 1 e Experimento $2 \ldots \ldots \ldots \ldots$. . . . . . . . . . . . . . 108

Figura 39 - Densidade Neuronal 1 mês e 3 meses após a injeção de STZ . . . . 110

Figura 40 - Marcação da área imunorreativa para BDNF nos animais do Experimento 1 . . . . . . . . . . . . . . . . . . 112 
Figura 41 - Expressão de BDNF nos grupos do Experimento 1 . . . . . . . . 113

Figura 42 - Correlações com a expressão de BDNF . . . . . . . . . . . . . . 113

Figura 43 - Marcação da área imunorreativa para BDNF nos animais do Ex-

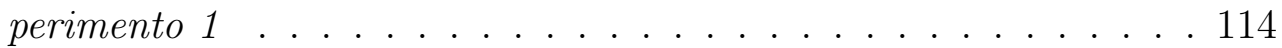

Figura 44 - Expressão de TrkB nos grupos do Experimento 1 . . . . . . . . . . 115

Figura 45 - Correlações com a expressão de TrkB . . . . . . . . . . . . . . . 115 



\section{Lista de Tabelas}

1 Grupos Experimento $1 \ldots \ldots \ldots$. . . . . . . . . . . 46

2 Grupos Experimento $2 \ldots \ldots \ldots \ldots$

3 Resultados dos testes comportamentais . . . . . . . . . . . . . . 116

4 Resultados da plasticidade sináptica . . . . . . . . . . . . . . . . 116

$5 \quad$ Resultados da análise espectral no CPFm . . . . . . . . . . . . . . 116

6 Resultados da análise espectral no CA1 . . . . . . . . . . . . . . . 117

7 Resultados histológicos e imunohistoquímicos . . . . . . . . . . . . . 117 



\section{Sumário}

1 Introdução 23

1.1 Demência . . . . . . . . . . . . . . . . . . . 23

1.2 A Doença de Alzheimer . . . . . . . . . . . . . . . . . . . . . 24

1.3 Modelo Animal da DA . . . . . . . . . . . . . . . . . . . . . . 28

1.4 Alterações no metabolismo energético na DA e no modelo de Estreptozotocina-

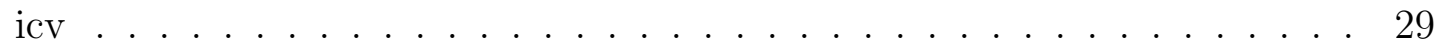

1.5 Alterações na plasticidade sináptica na DA . . . . . . . . . . . . . . 33

1.6 Sistema Colinérgico e DA . . . . . . . . . . . . . . 35

1.7 Via CA1-CPFm . . . . . . . . . . . . . . . 36

$\begin{array}{llr}2 & \text { Justificativa } & 39\end{array}$

$\begin{array}{lll}3 & \text { Objetivos } & 41\end{array}$

3.1 Objetivo Geral . . . . . . . . . . . . . . . . . . . 41

3.2 Objetivos Específicos . . . . . . . . . . . . . . . . . 42

4 Metodologia $\quad 43$

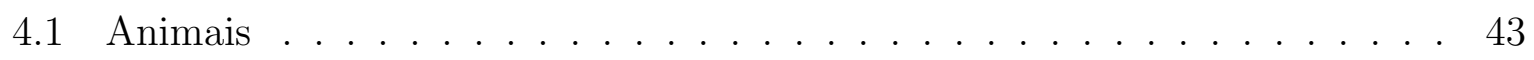

4.2 Desenho Experimental . . . . . . . . . . . . . . . . . . . . 43

4.3 Microinjeção . . . . . . . . . . . . . . . . . . . . . 46

4.4 Tratamento Crônico . . . . . . . . . . . . . . . . . . . . . . . . . 49

4.5 Testes Comportamentais . . . . . . . . . . . . . . . 50

4.5.1 Campo Aberto . . . . . . . . . . . . . . . . 50 
4.5.2 Reconhecimento de Objeto . . . . . . . . . . . . . 51

4.6 Eletrofisiologia . . . . . . . . . . . . . . . . . . 52

4.6.1 Regiões de registros e estimulação . . . . . . . . . . . . . . . 52

4.6 .2 Sistema de Aquisição . . . . . . . . . . . . . . . . . . . . . . 54

4.6.3 Protocolo de Estimulação . . . . . . . . . . . . . . . . . . . . 56

4.6 .4 Análise da Plasticidade Sináptica . . . . . . . . . . . . . . . . 58

4.7 Análises Oscilatórias . . . . . . . . . . . . . . . . . . . . . 60

4.8 Análises Histológicas e Imunohistoquímicas . . . . . . . . . . . . . . . . 64

4.8.1 Densidade Neuronal . . . . . . . . . . . . . . . . . 64

4.8.2 Imunohistoquímica . . . . . . . . . . . . . . . . . 65

4.9 Análise Estatística . . . . . . . . . . . . . . . . . 66

$\begin{array}{lll}5 & \text { Resultados } & 67\end{array}$

5.1 Padronização da dose do tratamento crônico de nicotina . . . . . . . . . 67

5.1.1 Ambas as doses de nicotina reduzem a atividade locomotora . . . . 68

5.1.2 Apenas a nicotina na dose de $3 \mathrm{mg} / \mathrm{kg}$ gera déficit no Reconhecimento de Objeto . . . . . . . . . . . . . . . . . . . 69

5.1.3 A dose de $1 \mathrm{mg} / \mathrm{kg}$ gera um aumento na eficiência da transmissão basal ........................ . . . 70

5.1.4 A nicotina na dose de $3 \mathrm{mg} / \mathrm{kg}$ gera déficit na LTP . . . . . . . . . . 72

5.2 Experimento1: Efeitos a curto prazo da STZ . . . . . . . . . 74

5.2.1 A curto prazo a STZ e a nicotina reduz na locomoção . . . . . . . 74

5.2.2 A curto prazo a STZ gera déficit no RO e o tratamento com nicotina reverte este déficit . . . . . . . . . . . . . . . . . 75

5.2.3 Propriedades dos potenciais evocados na via CA1-CPFm nos grupos do Experimento 1: A nicotina melhora a eficiência na transmissão

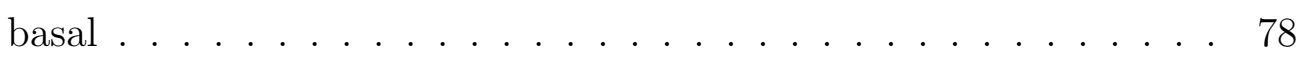


5.2.4 A curto prazo a nicotina reduz os déficit gerados pela STZ na plasticidade sináptica . . . . . . . . . . . . . . . . 80

5.2.5 A curto prazo a STZ aumenta a potência de Gama Alto em CA1 e a nicotina aumenta a amplitude do pico em Teta 2 no CPFm . . . . 84

5.2.6 A curto prazo STZ e o tratamento de nicotina não alteram a coerência CA1-CPFm . . . . . . . . . . . . . . . . . . 89

5.3 Experimento 2: Efeitos a longo prazo da STZ e do tratamento de nicotina 90

5.3.1 A longo prazo existe uma redução da locomoção em todos os grupos 90

5.3.2 A longo prazo a STZ gera déficit no RO e a nicotina novamente reverte este déficit . . . . . . . . . . . . . . . . . 92

5.3.3 Propriedades dos potenciais evocados na via CA1-CPFm nos grupos do Experimento 2 . . . . . . . . . . . . . . . . . . . . . . . . 95

5.3.4 A longo prazo a nicotina reduz os déficits gerados pela STZ na LTP 97

5.3.5 A longo prazo a STZ reduz a amplitude do pico em Teta 2 e a nicotina reverte este efeito . . . . . . . . . . . . . . . 101

5.3.6 A longo prazo a STZ reduz a coerência CA1-CPFm em Gama Baixo no estado Inativo . . . . . . . . . . . . . . . . . . . . . 105

5.4 Análises Histológicas . . . . . . . . . . . . . . . . . . . . . . 107

5.4.1 A STZ reduz a densidade neuronal no ENT a curto prazo e a nicotina aumenta a densidade neuronal em CA1 a longo prazo . . . . . 107

5.4.2 A STZ reduz a expressão de BDNF no PL e a nicotina reverte este efeito . . . . . . . . . . . . . . . . . . 111

5.4.3 O tratamento com nicotina aumenta a expressão de TrkB em CA1 e no ENT . . . . . . . . . . . . . . . . . . . . 114

5.5 Resumo dos resultados . . . . . . . . . . . . . . . . . 116

6 Discussão

6.1 Análises comportamentais . . . . . . . . . . . . . . . . . . 119

6.2 Alterações na plasticidade sináptica . . . . . . . . . . . . . . . . . . . . 122 
6.3 Análises oscilatórias . . . . . . . . . . . . . . . . . . . 125

6.4 Resultados histológicos e imunohistoquímicos . . . . . . . . . . . . 127

7 Conclusões 


\section{Introdução}

\subsection{Demência}

A demência é um termo geral utilizado para doenças progressivas em decorrência de danos no cérebro, caracterizada pelo declínio de funções cognitivas e comportamentais (REITZ; BRAYE; MAYEUX, 2011). Ela afeta principalmente as pessoas mais velhas, sendo que entre 2 e $10 \%$ dos casos de demência começam antes dos 65 anos e a prevalência dobra a cada cinco anos (Alzheimer's Disease International, 2009).

Segundo o relatório de 2015 da Alzheimer Disease International, existe um novo caso de demência a cada $3 \mathrm{~s}$. O mesmo relatório estima que no mundo existem 46,8 milhões de pessoas com demência e esse número irá praticamente triplicar em 2050 (131,5 milhões). O custo global para cuidar de pessoas com demência passou de US\$ 604 bilhões em 2010 para US\$ 818 bilhões em 2015. Este valor inclui a prestação de cuidados de saúde e serviços sociais, assim como a redução ou perda de rendimentos das pessoas com demência e dos seus cuidadores (Alzheimer's Disease International, 2015).

Há quase 900 milhões de pessoas com 60 anos ou mais vivendo no mundo e as Nações Unidas estima que em 2050 a população mundial com idade superior a 60 será de 2 bilhões (United Nations, 2013). O aumento da prevalência da demência devido ao aumento da expectativa de vida da população fez com que a Organização Mundial de Saúde (OMS) publicasse em 2012 o relatório "Demência: Uma Prioridade de Saúde Pública" onde pede aos governos de todo o mundo desenvolverem um Plano Nacional para as Demências com soluções e abordagens que impulsionem o diagnóstico precoce, sensibilizem a opinião pública sobre a doença, reduzam o estigma e proporcionem um melhor atendimento e mais apoio aos cuidadores (World Health Organization; Alzheimer's Disease International, 2012). 


\subsection{A Doença de Alzheimer}

Entre as demências, a Doença de Alzheimer (DA) é a mais prevalente, chegando a abranger cerca de $80 \%$ dos casos. Ela é uma doença neurodegenerativa que gera uma perda progressiva da memória e da capacidade de aprender, a longo prazo ela pode gerar dificuldades em se locomover, em se comunicar, desorientação espacial e alterações comportamentais (KUMAR; SINGH; EKAVALI, 2015) (Alzheimer's Association, 2014). Nos EUA ela atinge 5,3 milhões de americanos, gerando um custo pra nação de US $\$ 226$ bilhões. Em 2050 está estimado que este custo chegue a US\$1,1 trilhão. Ela ocupa a sexta posição no ranking das causas de morte. Enquanto morte por outras causas maiores vem diminuindo significativamente, entre 2010 e 2013 as mortes atribuídas à DA aumentaram 70\%. Além disso ela é a única doença entre as dez maiores causas de morte nos EUA que não pode ser nem prevenida e nem curada(Alzheimer's Association, 2014).

A DA também gera uma tremenda carga emocional e financeira para a família do paciente e da comunidade, através da prestação de cuidados e perda de salários. Cerca de $60 \%$ dos cuidadores de pacientes de demência classificam o estresse emocional na execução da tarefa como sendo alto ou muito alto e $40 \%$ deles sofrem de depressão, gerando um custo adicional à saúde pública.(LEWCZUK et al., 2015).

Uma importante divisão clínica da doença é realizada de acordo com a idade do aparecimento dos sintomas. A DA de início precoce tipicamente inicia entre os 30 e 60 anos e corresponde a aproximadamente $5 \%$ do total de casos. Cerca de $13 \%$ dos casos precoces da doença de Alzheimer são tipo familiar (DAf) e têm origem na predisposição genética para a doença (CAMPION et al., 1999). O tipo mais comum da doença é a DA esporádica (DAs), de inicio tardio, na qual os sintomas clínicos podem ser observados após os 65 anos e cuja duração pode superar dez anos.

Independente da forma como ela se manifesta, esta doença é caracterizada pelo surgimento de lesões devido ao acúmulo extracelular de proteínas beta-amilóides (chamadas de placas amilóide ou senis) e intracelular de uma forma anormal da proteína tau hiperfosforilada (chamados de emaranhados neurofibrilar-NFT). Com a progressão da doença, a transmissão sináptica apresenta falhas, o número de sinapses diminui e os neurônios morrem, levando a uma perda neuronal generalizada no cérebro e, especificamente, a uma atrofia do hipocampo e do cortex (DUYCKAERTS; DELATOUR; POTIER, 2009). Os mecanismos que desencadeiam as alterações citadas acima ainda são desconhecidos, sendo 
que estas lesões ocorrem de forma gradativa e iniciam por volta de 20 anos antes de parecer os sintomas da doença (VILLEMAGNE et al., 2013).

A idéia de que o peptídeo amilóide e a Tau fosforilada são patológicos está lentamente mudando, pois aparentemente eles estão mais relacionados com uma estratégia adaptativa da célula ao estresse oxidativo que ocorre na DA. Além disso, a doença apresenta vários outras disfunções, tais como: inflamação, desequilíbrio da concentração de cálcio, disfunção mitótica, desequilíbrio hormonal e fatores genético que desempenham um papel no desencadeamento da doença (ANAND; GILL; MAHDI, 2014).

Coma as excessão dos raros casos de DA causados por mutação genética, acredita-se que esta doença é desencadeada devido a múltiplos fatores. Entre eles pode-se citar:

- A idade: A maior parte das pessoas dignosticadas com a doença possuem mais de 65 anos (Alzheimer's Disease International, 2015)(Alzheimer's Association, 2014).

- Gene ApoE- $\epsilon$ : Este gene está relacionado com o transporte de colesterol na corrente sanguínea e pesquisas estimam que entre 40 a $65 \%$ dos portadores de DA possuem o alelo $\epsilon 4$ do gene (FARRER et al., 1997).

- Comprometimento Cognitivo Leve (MCI - do inglês Mild Cognitive Impairment): Pessoas com desvios cognitivos leves, principalmente associados à memória, estão mais propensos a desenvolver DA. Porém MCI não necessariamente leva à demência (ALBERT et al., 2011).

- Doenças Cérebrovascular: Acidente vascular cerebral (AVC) hemorrágico ou isquêmico estão intimamente relacionados com demência. O AVC, além de poder lesionar áreas diretamente relacionada com a memória, pode induzir processos inflamatórios que desencadeiam a demência (PENDLEBURY; ROTHWELL, 2013).

- Doenças Cardiovasculares: A saúde do cérebro está intimamente ligada à saúde geral do coração e dos vasos sanguíneos. Estas doenças podem afetar diretamente áreas relacionadas com a memória, desencadear processos inflamatórios e aumentar o depósito de proteínas beta-amilóide que podem levar à demência (JEFFERSON et al., 2015).

- Pressão Sanguínea: Hipertensão na meia idade compromete a integridade da barreira hematoencefálica (BBB) resultando em extravasamento de proteínas pro cérebro que pode acarretar em disfunção sináptica, danos neuronal, apoptose (KALARIA, 2010). 
- Injuria Traumática Cerebral (TBI): Existe evidências que uma injúria de moderada a severa no cérebro pode desencadear uma maior produção da Proteína Precursora de Amilóide (APP) e da proteína Tau, aumentando o risco de desenvolver DA ou outras demências (PLASSMAN et al., 2010).

- Diabetes Mellitus Tipo 2: Esta doença chega a aumentar em 54\% o risco de desenvolver Alzheimer (LEIBSON et al., 1997). A enzima que degrada a insulina (IDE) é a mesma responsável por degradar a beta-amilóide, no caso de hiperinsulinemia que acompanha a diabetes, a insulina pode competir com a beta-amilóide pela enzima degradadora propiciando a formação de placas (CRAFT, 2007).

Tendo como base estes fatores de risco não é possível prever quem irá desenvolver DA. No entanto, a relevância destas correlações reside em que os fatores de risco dão pistas sobre mecanismos da doença. O diagnóstico da DA é quase sempre confirmado quando a doença está em um estagio avançado, baseado em exames laboratoriais e clínicos que visam detectar sintomas como a presença de declínio cognitivo progressivo, déficits de memória e outras disfunções neuropsicológicas. Até o momento, o diagnóstico incontestável da doença pode ser fornecido apenas com exames detalhados post-mortem do cérebro (KHAN; ALKON, 2013). Existem biomarcadores que podem ajudar a diagnosticar a doença na fase prodrômica (estágio da DA onde os critérios para o diagnóstico da demência ainda não estão preenchidos) o que irá permitir um tratamento mais precoce (GAUTHIER et al., 2013). Estes biomarcadores são divididos em dois tipos: os de beta-amilóide e os da proteína Tau e podem ser quantificadas no liquor de forma confiável. Com a morte neuronal a Tau fosforilada é eliminada no liquor, aumentando sua concentração, e o acúmulo de beta-amilóide no cérebro faz com que sua concentração no liquor seja reduzida (LEWCZUK et al., 2015).

Existem também exames de imagem com marcador para beta-amilóide utilizando tomografia por emissão de pósitrons (PET) porém esses exames são pouco acessíveis (JACK; HOLTZMAN, 2013). Ainda é necessário estudos adicionais de padronização dos biomarcadores para que eles sejam de fato implementados na clínica. Não está claro se esta técnica permitirá diferenciar no futuro a DA das outras demências, no estágio inicial, o que tornaria o tratamento da doença mais eficaz (KHAN; ALKON, 2013).

Devido aos múltiplos mecanismos envolvendo a patogenia da DA e a dificuldade de realizar um diagnóstico precoce da doença há uma grande dificuldade em produzir uma terapia eficaz. Atualmente existem apenas cinco drogas aprovadas pela FDA (US Food and Drug Administration) para serem utilizadas para o tratamento da DA. Todas elas 
modulam a neurotransmissão e agem de forma sintomática, nenhuma delas é capaz de impedir a progressão da doença (ANAND; GILL; MAHDI, 2014). Entre os sistemas neurotransmissores, o sistema colinérgico é o mais severamente afetado, principalmente em áreas límbicas, seja pela redução de enzimas relacionadas à produção da acetilcolina ou pela sua degradação (RACCHI et al., 2004). Por este motivo, quatro destas drogas são inibidores da colinesterase (ChE): Tacrina, Donezepil, Rivastigmina e Galantamina, sendo que a primeira raramente é prescrita devido aos seus efeitos colaterais (hepatotoxicidade). Estas drogas agem aumentando a disponibilidade de acetilcolina no cérebro, induzem uma melhora no perfil cognitivo do paciente e são eficazes no estagio inicial da doença (RACCHI et al., 2004). A quinta droga aprovada pela FDA, é a Memantina, um antagonista não-competitivo de moderada afinidade dos receptores NMDA. Ela permite a ativação fisiológica dos receptores durante os processos de formação da memória, porém bloqueia sua ativação patológica. Das cinco, ela é a droga mais eficaz no estagio avançado da doença, sendo a única que possui caráter neuroprotetor contra a ativação excitotóxica dos receptores de glutamato (LIPTON, 2005).

Novas abordagens no tratamento da AD estão sendo intensamente investigadas e testadas, tais como:

- Imunoterapia anti-amilóide (RAFII; AISEN, 2015)

- Terapias anti-Tau (ROSENMANN, 2013)

- Bloqueadores de canais de cálcio (SARAVANARAMAN; CHINNADURAI; BOOPATHY, 2014)

- Redução do estresse oxidativo (NICOLAKAKIS et al., 2008)

- Terapias anti-inflamatórias (JAVED et al., 2012)

Apesar dos avanços no que se refere a compreensão dos processos patológicos que ocorrem no cérebro durante a DA, encontrar terapias que tratem a causa e não os sintomas continua sendo um desafio (ZEMEK et al., 2014). Inúmeras estratégias terapêuticas apresentaram resultados positivos em modelos animais da doença, proporcionando informações valiosas para entender os mecanismos patogênicos e propor possíveis tratamentos (DUYCKAERTS; DELATOUR; POTIER, 2009). Porém ainda existe um déficit em pesquisas translacionais para que esses resultados sejam aplicados na clínica. A análise dos motivos que diferentes abordagens reduzem as disfunções cognitivas e a neurodegeneração 
em ratos irão certamente acelerar as pesquisas translacionais e intervenções médicas mais eficazes (FRANCO; CEDAZO-MINGUEZ, 2013).

\subsection{Modelo Animal da DA}

A DA tem sido estudada de forma intensa nos últimos 20 anos e modelos animais da doença contribuíram para uma melhor compreensão dos mecanismos patogênicos associados a ela (DUYCKAERTS; DELATOUR; POTIER, 2009).

A maior parte dos modelos são com animais transgênicos. O conhecimento das mutações genéticas associadas com as mudanças patológicas que ocorrem no cérebro durante a evolução da doença (principalmente na DAf) permitiram que cientistas desenvolvessem animais transgênicos (normalmente camundongo) com mutações que conseguiram reproduzir as lesões da DA (DUYCKAERTS; POTIER; DELATOUR, 2008). Através dos estudo destes animais, com doenças tipo-DA, cientistas esperam conseguir extrapolar para o que realmente ocorre nos humanos (CAVANAUGH; PIPPIN; BARNARD, 2014).

Mutações dos genes que codificam a APP (Precursor da Proteína Amilóide) e a Presenilina 1 e 2 tem sido associados ao desenvolvimento da DAf (GOATE, 2006). Porém, animais com mutação apenas no gene APP acabam desenvolvendo ao longo da vida depósitos extracelular de peptídeos amilóide (MUCKE et al., 2000).

A dupla mutação de genes codificadores da APP com os genes da Presenilina-PS1 ou da BACE1 (enzimas que fazem parte do processamento da beta-amilóide) fazem com que os camundongos desenvolvam a lesão de forma mais acelerada (BODENDORF et al., 2002). Ao contrário do que era esperado, os camundongos duplo transgênicos não apresentaram emaranhados neurofibrilares. Neste contexto surgiu o camundongo triplo transgênico (3xTgAD), para reproduzir as duas lesões presentes na DA. Além de expressar genes codificadores da proteína APP, da Presenilina-AP1, o genoma destes camundongos apresenta também gene humano mutado da proteína Tau (ODDO et al., 2003).

Apesar dos ratos serem os animais mais utilizados no campo da neurosciência, existe uma maior dificuldade em fazer com que ratos transgênicos (com mutações semelhantes às presentes em camundongo) apresentem lesões. Mas recentemente foi desenvolvido com sucesso um modelo transgênico com ratos (TgF344-AD) que consegue desenvolver placas 
amilóide e NFT (sendo a última sem mutação) e pode vir a ser um modelo promisor para se realizar pesquisas translacionais (COHEN et al., 2013).

A utilização dos animais transgênicos para pesquisar a DA possui a vantagem de conseguir reproduzir característica neuropatológicas, cognitivas e comportamentais semelhantes à doença. Com isso é possível intervir com tratamentos antes do início das patologias. Porém estes modelos em geral não apresentam perda neuronal, o que o torna inadequado para estudar mecanismos de neuroproteção. Também não são os mais adequados para estudar a forma mais comum de DA que é a esporádica, onde as lesões geralmente não causadas por mutações (FRANCO; CEDAZO-MINGUEZ, 2013).

\subsection{Alterações no metabolismo energético na DA e no modelo animal de injeção intracerebroventri- cular de Estreptozotocina (STZ-icv)}

Existem evidências que sugerem que a deficiência energética e a redução do metabolismo da glicose no sistema nervoso central são eventos reversíveis iniciais que desencadeiam a DA esporádica (FRöLICH et al., 1998; HOYER, 2002). Estudos mostram que antes do declínio cognitivo característico na DAe existe uma desensibilização dos receptores de insulina neuronal - similar à que ocorre na Diabetes Mellitus tipo 2 (DMt2) - junto com uma redução de concentração de insulina cerebral (HOYER, 2004; DE LA MONTE; WANDS, 2005). Esta resistência à insulina cerebral fez com que a DA fosse considerada uma DMt2 encefálica ou uma Diabetes Mellitus tipo 3 (HOYER, 1998, 2002; DE LA MONTE, 2014).

A DMt2 apresenta resistência insulínica periférica, caracterizada por níveis elevados de insulina no plasma, baixa quantidade de insulina no liquor e baixa disponibilidade de glicose (WATSON; CRAFT, 2003). A DA apresenta um quadro de resistência insulínica central, caracterizado por baixo fluxo de glicose, baixa concentração de insulina no liquor e desensibilização de seus receptores no cérebro (FRöLICH et al., 1999; WATSON; CRAFT, 2004). Estas anormalidades no metabolismo energético e na sinalização da insulina, que ocorre na DAe, levaram à criação do modelo farmacológico da doença através da injeção intracerebroventricular de uma droga diabetogênica - a estreptozotocina (LANNERT; 
HOYER, 1998).

A estreptozotocina (STZ) é uma glicosamina derivada de nitrosouréia normalmente utilizada para criar o modelo experimental de DMt2 em ratos. Ela é uma droga seletivamente tóxica às células $\beta$ do pâncreas quando aplicada de forma sistêmica e em altas doses (>65mg/kg, i.p.), gerando uma resistência insulínica periférica (TAKADA et al., 2007). Porém, quando a STZ é administrada de forma intracerebroventricular (STZ-icv) e em baixas doses (1 - $3 \mathrm{mg} / \mathrm{kg}$, icv) ela não é capaz de alterar o nível basal da glicose sanguínea - consequentemente não induz a DM - mas no cérebro ela consegue alterar o metabolismo da glicose e gerar uma resistência insulínica (SALKOVIC-PETRISIC; HOYER, 2007). Este estado de resistência de insulina cerebral, induzido pela STZ central, vem sendo associado às mudanças morfológicas, moleculares e comportamentais que ocorrem na DAe (LESTER-COLL et al., 2006). Uma vez que gera uma deterioração tanto do metabolismo encefálico como do sistema cognitivo de forma progressiva. Também está associado a um aumento da expressão da proteína beta-amilóide, da fosforilação da proteína Tau e apresenta processos de neurodegeneração, principalmente entre os neurônios colinérgicos (SALKOVIC-PETRISIC et al., 2013). Estas características típicas da DA, adquiridas pela administração da STZ em doses subtóxicas no sistema nervoso, vem fazendo com que a STZ-icv seja considerada um dos poucos modelos que permite o estudo da DA esporádica. (CORREIA et al., 2011; DE LA MONTE; WANDS, 2005).

Perifericamente, a toxicidade da STZ se da basicamente por dois mecanismos, após ser internalizadas pelas células $\beta$ do pâncreas. Um dos mecanismos é devido a metilação de bases nitrogenadas do DNA, causando um distúrbio no consumo de ATP. O outro seria por meio de alterações do estado nitro-oxidativo celular. Ambos os mecanismos iniciam um processo de estresse oxidativo e de fragmentação do DNA, deletérios à célula (SZKUDELSKI, 2001). No sistema nervos, contudo, ainda é necessário mais estudos para compreender todos os mecanismos pelo qual a STZ gera resistência insulínica em doses subdiabetogênicas. Porém acredita-se que o mecanismo da STZ no cérebro seja semelhante ao que ocorre no sistema periférico e que a STZ entra na célula através do transportador de glicose GLUT2 (GRüNBLATT et al., 2007; SALKOVIC-PETRISIC; HOYER, 2007).

De forma geral, a glicose atravessa a barreira hemato-encefálica utilizando o transportador GLUT1 (GRAY; MEIJER; BARRETT, 2014). Quando alcança o meio extracelular do cérebro ela é internalizadas pelos neurônios e glias por distintos transportadores - tais como o GLUT4 - e a insulina, junto com seus os receptores, desempenham um papel importante nesta internalização (SHAH; DESILVA; ABBRUSCATO, 2012). 
Além do metabolismo da glicose, a insulina possui no cérebro ação neuroendócrina, neuroprotetora, neuromodulatoria e seu receptor possui um papel fundamental na regulação gênica e na plasticidade sináptica em importantes regiões do cérebro (APOSTOLATOS et al., 2012; CHIU; CHEN; CLINE, 2008). Sendo que tanto a insulina quanto os receptores de insulina podem ser encontrados em várias regiões do encéfalo associadas ao desempenho de funções cognitivas - tais como o córtex cerebral e o hipocampo (WATSON; CRAFT, 2004; HOYER, 2002).

Cascatas de sinalização ativadas por receptores de insulina são responsáveis por regular - além do metabolismo energético - fator de crescimento celular, sobrevivência neuronal, estresse oxidativo e expressão de genes de receptores colinérgicos (DE LA MONTE; WANDS, 2008). Uma das principais cascatas de sinalização que a insulina está envolvida é a da via fosfaditilinositol-3-quinase (PI3-K). A ativação desta via tem como principal função promover sobrevivência neuronal ao inibir eventos pró-apoptóticos (DE LA MONTE; TONG, 2014). Nesta via a insulina consegue ativar seu receptor tirosina quinase (RI), via fosforilação, que aumenta a atividade da proteína quinase B (AKt/PKB). Por sua vez, a AKt/PKB recruta GLUT4 para que este internalize glicose na célula. Adicionalmente, a $\mathrm{AKT} / \mathrm{PkB}$ também é responsável por inativar (mediante fosforilação) duas formas citosólicas da enzima GSK-3: a GSK-3 $\alpha$ e a GSK-3 $\beta$ (SALKOVIC-PETRISIC; TRIBL; SCHMIDT M. HOYER, 2006; CORREIA et al., 2011). Sendo que a GSK-3 $\beta$ regula a fosforilação da proteína Tau (CHENG et al., 2005) e a GSK-3 $\alpha$ está associada com a formação do peptídeo beta-amilóide (PHIEL et al., 2003). Além do mais, a insulina também regula a liberação e o tráfego de peptídeos solúveis de APP (através de sinalização da PI3-K) e interfere na degradação do peptídeo beta-amilóide através da mesma enzima que degrada a insulina - IDE (WATSON; CRAFT, 2003). Neste contexto, as principais lesões e a neurodegeneração que ocorre na DA seriam desencadeadas pela resistência à insulina, uma vez que a ativação dos seus receptores conseguem estimular fatores de sobrevivência, controlar a fosforilação da proteína Tau e a produção do peptídeo beta-amilóide (mediante a ativação do PI3-K) além de promover sua degradação (HOYER, 2004; DE LA MONTE; WANDS, 2005).

Outra consequência fisiopatológica do metabolismo alterado da glicose, gerada pela resistência à insulina, é a redução de aproximadamente $50 \%$ da produção de ATP no início da DAe e esta redução continua aumentando com a progressão da doença (SHAH; DESILVA; ABBRUSCATO, 2012). A deficiência energética gerada pela menor disponibilidade de ATP no cérebro desencadeia um processo de estresse oxidativo e também pode ativar cascatas de sinalização que levam à apoptose (DE LA MONTE; TONG, 2014). 
Além da redução da ATP, o déficit de glicose no cérebro acarreta redução da produção da acetilcoenzima-A (Acetil-CoA) que, além de ser uma fonte de energia celular, é materia prima para a produção da acetilcolina (HOYER, 2004). Desta forma, o sistema colinérgico também é afetado diretamente pela disfunção energética que ocorre na DA e pode ser um dos mecanismo biológico para a redução da capacidade de memória e aprendizado na doença, visto que este sistema neurotransmissor está intimamente relacionado com processos cognitivos (DE LA MONTE; WANDS, 2008).

Assim como na DA, a administração de STZ-icv também inibe a fosforilação do resíduo tirosina do RI, reduz a produção de ATP, a atividade da AKT/PkB-GSK-3 no hipocampo e aumenta a fosforilação da proteína Tau (HOYER, 2002; HOYER; LANNERT, 2007; SALKOVIC-PETRISIC; TRIBL; SCHMIDT M. HOYER, 2006; GRüNBLATT et al., 2007). Além disso, este modelo apresenta um aumento na expressão do peptídeo betaamilóide em várias regiões do cérebro e depósitos do peptídeo dentro de vasos sanguíneos, porém, apenas com a administração de STZ icv não foi constatado a presença de placas amilóide no tecido (SALKOVIC-PETRISIC et al., 2011).

Vários estudos também comprovaram a presença de déficit cognitivo após a STZ icv. Teste com labirinto em cruz elevado, labirinto aquático de Morris, esquiva passiva e reconhecimento de objeto já foram utilizados para comprovar, assim como na DA, a presença de déficits de memória de longo e curto prazo neste modelo (LANNERT; HOYER, 1998; GRüNBLATT et al., 2007; AGRAWAL et al., 2011; ISHRAT et al., 2009; ESPINOSA et al., 2013) e estes resultados parecem ser independentes da dose de STZ ou do número de injeções aplicada (MEHLA; PAHUJA; GUPTA, 2013). Estudos sobre os processos envolvidos na perda de memória neste modelo sugerem que ela é causada principalmente pela deficiência do metabolismo energético nos neurônios colinérgicos (LESTER-COLL et al., 2006; GRüNBLATT et al., 2007; TOTA et al., 2011). Uma possível base biológica para justificar este declínio na cognição seria que a deficiência do metabolismo energético e a menor disponibilidade de ATP no cérebro, gerada pela STZ icv, é responsável pela menor produção tanto da Acetil-CoA quanto da colina-acetiltransferase (ChAT) - responsáveis pela produção da acetilcolina - levando a um prejuízo dos mecanismos relevantes para a formação da memória devido a uma redução na transmissão sináptica (BLOKLAND; JOLLES, 1993; SZUTOWICZ et al., 2013).

Por fim, a dificuldade na aquisição e retenção de memória neste modelo provavelmente está associada com a existência de processo neurodegenerativos e com a menor expressão dos receptores de insulina na região do hipocampo e do cortex (GRüNBLATT et al., 2007). 
Juntando este fato com todas as características em comum que o modelo STZ-icv possui com a DA esporádica, este modelo se tornou uma ferramenta útil para compreender os processos que envolvem a etiologia e a progressão da doença, permitindo que estratégias terapêuticas mais eficazes sejam testadas e possam vir a ser aplicadas na clínica.

\subsection{Alterações na plasticidade sináptica na DA}

O hipocampo e o neocortex são áreas do cérebro essenciais para o processo de formação de memória (DUDAI; MORRIS, 2013). O conceito da sinapse e o seu papel no aprendizado foi constatado pioneiramente por Ramon y Cajal em 1894. Ele observou que o número de neurônios no cérebro não se alteram significativamente durante o curso da vida e constatou como sendo improvável que novas memórias fossem geradas pelo surgimento de novos neurônios. Este fato o levou a propor que o provável mecanismo para a formação da memória estava nas alterações das conexões de redes neurais já existentes (JONES, 1994). Mais tarde, Hebb expandiu este conceito ao postular que padrões de atividade neuronal eliciados por experiências relevantes ou repetitivas seriam capazes de induzir eventos metabólicos que modificariam de forma permanente a conexão entre dois neurônios (HEBB, 1949). Neste contexto, alterações na eficiência da plasticidade sináptica passou a ser reconhecido como o principal substrato do processo de aprendizagem e memória, podendo ser subdividido em duas categorias: plasticidade sináptica de longa duração, que pode perdurar de horas a dias, e plasticidade sináptica de curta duração que vai da ordem de milissegundos a minutos (CITRI; MALENKA, 2008).

O estudo da plasticidade sináptica de curta duração pode ser feito através da aplicação de dois estímulos pareados em um neurônio pré-sináptico, apresentando proximidade temporal suficiente para gerar facilitação (PPF - do inglês paires-pulse-facilitation) ou depressão (PPI - do inglês paires-pulse-inhibition) da resposta do neurônio pós-sináptico. Este tipo de plasticidade desempenha um papel importante nas adaptações de curto prazo em vias sensoriais, mudanças comportamentais transitórias e formas de memória de curta duração (CITRI; MALENKA, 2008).

A plasticidade sináptica de longa duração pode ser estudada através de dois mecanismos, a potencialização de longa duração (LTP - do inglês long-term potentiation) e a depressão de longa duração (LTD - do inglês long-term depression). A LTP é ob- 
servada experimentalmente, quando estímulos repetitivos ou tetânicos são aplicados em alta frequência, provocando a potencialização sustentada dos potenciais pós sinápticos de campo (fPSPs - do inglês field postsynaptic potentials) (BLISS; LOMO, 1973). Ela geralmente requer a ativação de receptores de glutamato do tipo N-metil-D-aspartato (NMDA), um alto influxo de $\mathrm{Ca}^{2+}$ no citoplasma da espinha dendrítica pós-sináptica e uma maior expressão de receptores AMPA, desencadeando a ativação de cascatas de proteínas cinases e segundos mensageiros intracelulares que acarretam na formação de novas espinhas dendríticas (BLISS; COLLINGRIDGE; MORRIS, 2003). Já a LTD pode ser induzida quando os neurônios recebem estimulação prolongada de baixa frequência produzindo uma depressão dos fPSPs (ITO; KANO, 1982). Assim como a LTP, a indução de LTD hipocampal também exige ativação de receptores do tipo NMDA porém o baixo influxo de $\mathrm{Ca}^{2+}$ mobiliza, preferencialmente, proteínas fosfatases, acarretando uma internalização dos receptores AMPA que reduz a sensibilidade com que o terminal pós-sináptico responde ao glutamato (COLLINGRIDGE et al., 2010). A LTP e a LTD permitiram uma compreensão molecular dos processos que acarretam o fortalecimento e enfraquecimento de sinapses a longo prazo e ambas são sensíveis à aprendizagem (MARTIN; MORRIS, 2002). Atualmente muitas evidências reforçam a ideia de que a LTP é um mecanismo celular de fortalecimento sináptico e formação de memórias (BLISS; COLLINGRIDGE, 1993). Em contrapartida, a LTD parece desempenhar um papel importante no processo de eliminação de memórias (COLLINGRIDGE et al., 2010).

Apesar da neurodegeneração progressiva ser uma das principais patologias da DA, a redução progressiva de sinapses e espinhas dendríticas em várias regiões do cérebro associadas ao aprendizado e à memória - tais como o hipocampo e o neocortex - é o que melhor se correlaciona com o declínio cognitivo progressivo presente na DA (POOLER; NOBLE; HANGER, 2014; SCHEFF et al., 2006). A redução na transmissão sináptica ocorre no estágio inicial da doença e estudos mostram que a morte neuronal no início não é suficientemente grande para explicar a perda sináptica. Isto sugere que, em pacientes com DA, existe uma disfunção sináptica que antecede à neurodegeneração (ARENDT, 2009). Sendo que esta disfunção sináptica não é caracterizada apenas pela redução do número de sinapses, mas também por uma atividade anormal de redes neurais que podem interferir nos mecanismos de aprendizagem e também podem levar a uma hiperestimulação excitotóxica que contribui com processos neurodegenerativos (PALOP; MUCKE, 2010; VERRET et al., 2012). Estas observações mencionadas acima sugerem que a neurodegeneração presente na DA é precedida por uma disfunção na plasticidade sináptica seguida por uma redução no número de sinapses e a redução na plasticidade sináptica é 
o principal responsável pelo declínio cognitivo da doença (HUANG; MUCKE, 2015).

\subsection{Sistema Colinérgico e Doença de Alzheimer}

Os neurônios colinérgicos estão presentes em várias regiões do sistema nervoso e são responsáveis por modular atividades cognitivas relacionadas com memória e aprendizado. Além disso, desempenham um papel crítico no desenvolvimento cortical, no controle do fluxo sanguíneo no cérebro e no ciclo sono-vigília (SCHLIEBS; ARENDT, 2006).

O sistema colinérgico possui dois tipos de receptores: os nicotínicos e os muscarínicos. Os receptores colinérgicos muscarínicos são metabotrópicos de ação duradoura e são subdivididos em cinco subtipos $\left(\mathrm{M}_{1}\right.$ a $\left.\mathrm{M}_{5}\right)$. Cada subtipo de receptor está associado a uma classe distinta de proteína $\mathrm{G}$, que modula a abertura de canais iônicos, níveis de $\mathrm{Ca}^{2+}$ intracelular e a atividade de diversas proteínas (NATHANSON, 2008). Já os receptores colinérgicos nicotínicos possuem esse nome pela sua sensibilidade à nicotina e são canais iônicos ativados por ligante de ação rápida constituído por uma estrutura pentamérica com cinco subunidades protéicas. Nos neurônios, as subunidades presente são: $\alpha(2-6)$ e $\beta(2-4)$, e as combinações mais comuns do encéfalo no mamífero são a heteromérica $\alpha 4 \beta 2$ e a homomérica $\alpha 7$ (MIWA; FREEDMAN; LESTER, 2011). Quando ativado eles induzem uma despolarização da membrana através do influxo de $\mathrm{Ca}^{2+}$. A alta concentração de cálcio intracelular contribui para que neurotransmissores sejam liberados na fenda sináptica e gera uma facilitação do potencial pós-sináptico. Desta forma, a nicotina age no terminal pré-sináptico aumentando a influxo de cálcio que aumenta a eficácia da transmissão sináptica (DANI; BERTRAND, 2007).

Os neurônios colinérgicos do prosencéfalo basal sofrem alterações degenerativas durante o processo normal de envelhecimento. Esta degradação resulta em uma hipofunção colinérgica que está relacionada com o progressivo déficit de memória associado à velhice. A perda de neurônios colinérgicos do prosencéfalo basal também é uma característica marcante na DA e é reconhecida como sendo uma patologia que explica, pelo menos em parte, a progressiva disfunção cognitiva da doença (SCHLIEBS; ARENDT, 2006). Correlação entre níveis de demência com a redução de marcadores colinérgicos tais como a acetilcolina (ACh), a colina-acetiltransferase (ChAT) e receptores colinérgicos (AchR) muscarínicos e nicotínicos levaram à formulação da hipóteses colinérgica de déficit de memória nos 
idosos e na DA (BARTUS, 2000). A morte de neurônios colinérgicos é predominantemente encontrada em casos de envelhecimento patológico, tal como a DA, enquanto que o envelhecimento normal é acompanhado por uma perda gradual da função colinérgica causada por degeneração dendrítica, sináptica, e axonal. Na DA de início precoce e nos estágios avançados da DA de início tardio existe uma grave perda de inervações colinérgicas corticais, enquanto que em pacientes com comprometimento cognitivo leve (MCI), ou em estágios iniciais da AD, não existe neurodegeneração e sim uma perda da função colinérgica (SCHLIEBS; ARENDT, 2011).

Tendo em vista o importante papel que o sistema colinérgico desempenha nos processos funcionais que levam à DA, uma das estratégias de tratamento sintomático da DA mais comum consistem em aumentar os níveis de acetilcolina na fenda sináptica reduzindo o seu metabolismo com inibidores da enzima acetilcolinesterase - AChE (ANAND; GILL; MAHDI, 2014). A modulação direta dos receptores colinérgicos (muscarínico ou nicotínico) também pode ser outra abordagem considerável no tratamento da DA. No hipocampo, a expressão dos receptores colinérgico estão presentes tanto em terminais pré-sinápticos quanto pós-sinápticos e quando eles são ativados existe um aumento na potencialização de longa duração (LTP) (DREVER; RIEDEL; PLATT, 2011). Existem estudos in vivo que mostram que agonistas muscarínicos são capazes de reverter déficits cognitivos, reduzir a fosforilação da proteína Tau e também reduzir o processamento da proteína beta-amilóide em modelos transgênicos da DA (FISHER, 2012). Agonistas nicotínicos também conseguem gerar uma melhora no desempenho de testes cognitivos, indicando que esses receptores também desempenham um papel importante em tarefas relacionadas com a memória (LEISER et al., 2009; LEVIN, 2012).

\subsection{Via CA1-CPFm}

As conexões entre o hipocampo e o cortex pré-frontal desempenham um papel fundamental em uma série de funções cognitivas, tais como a consolidação de memórias, o processamento da memória de trabalho, o refinamento da tomada de decisão e o controle de comportamentos preservativos (LAROCHE; DAVIS; JAY, 2000). A existência de uma via direta monossináptica da região CA1 ventral do hipocampo e subiculum a áreas específicas do córtex pré-frontal medial (CPFm) fornece um modelo útil para conceituar as 
formas de comunicação entre o hipocampo e o cortex no processo de aprendizagem e na consolidação de memória (DAMASIO, 1989; LAROCHE; JAY; THIERRY, 1990). Estudos utilizando modelos animais de memória revelam que a transmissão de informação entre o hipocampo e o CPFm é necessária quando uma informação espacial de curta duração é usada para gerar estratégias comportamentais prospectivas (SEAMANS; FLORESCO; PHILLIPS, 1995; FLORESCO; SEAMANS; PHILLIPS, 1997).

A via CA1-CPFm é glutamatérgica, sua resposta excitatória é dependente de receptores AMPA e esta via é capaz de desenvolver LTP e LTD (JAY; BURETTE; LAROCHE, 1995; TAKITA et al., 1999). Por meio desta via o CPFm - que é inervado por fibras colinérgicas do prosencéfalo basal e tronco encefálico - modulam a atividade neuronal e a plasticidade sináptica em resposta ao hipocampo. A ativação colinérgica muscarínica é capaz de facilitar a indução tanto da LTP quanto da LTD nesta via (LOPES-AGUIAR et al., 2008, 2013). Esta facilitação sináptica no CPFm, sob ativação colinérgica, pode ser justificada pelo aumento da acetilcolina em áreas corticais durante tarefas de memória de trabalho (HIRONAKA et al., 2001) e condiz com o mecanismo de integração e armazenamento de informações que ocorrem durante a execução destas tarefas (HASSELMO, 2005; MARTIN; MORRIS, 2002). Isto sugere que o sistema colinérgico também é importante para regular de maneira bidirecional a plasticidade sináptica no CPFm. Porém, ainda falta esclarecer o papel da ativação colinérgica nicotínica nas conexões entre o hipocampo e o neocórtex em doenças neurodegenerativas como Alzheimer. 


\section{$2 \quad$ Justificativa}

Devido ao aumento da expectativa de vida da população mundial a doença de Alzheimer está se tornando uma epidemia global. Ela está entre as maiores causas de morte entre os idosos, porém, é a única que não possui cura e cuja incidência vem crescendo exponencialmente. Apesar dos avanços obtidos nas pesquisas que procuram melhor compreender os mecanismos básicos que envolvem a DA, existem inúmeros desafios que dificultam a tradução destes conhecimentos para uma abordagem clínica. Os medicamentos obtidos pela pesquisa de base, e aprovados para uso clínico, têm enormes limitações no que diz respeito à sua eficácia e não conseguem prevenir ou reverter os processos neurodegenerativos relacionados com a DA.

A maioria dos modelos utilizados para estudar a DA são com animais transgênicos. Estes modelos são adequados para estudar o tipo familiar da doença mas falham em não permitir uma compreensão sobre a etiologia do tipo mais prevalente que é a esporádica - que não é causada por mutações e não apresenta uma predisposição genética. Neste contexto, a existência de modelos que permitam o estudo do tipo esporádico da doença que é o de maior prevalência - como o utilizado neste trabalho (STZ icv), é necessária para a melhor compreensão do caráter multifatorial da doença e para propor novas estratégias terapêuticas.

Além do mais, pouco se sabe sobre a modulação da plasticidade sináptica na via CA1-CPFm em modelos experimentais de Alzheimer. Uma investigação mais detalhada poderá fornecer novos dados sobre os mecanismos de processamento envolvidos na neurodegeneração progressiva, na deterioração cognitiva e na consolidação/processamento de memórias durante a progressão da doença. A intervenção farmacológica realizada neste trabalho utilizando a nicotina visa esclarecer a relação existente entre a DA e o sistema colinérgico - que é um dos sistemas neurotransmissores afetado em pacientes com DA - em uma via relevante para a consolidação e manutenção da memória, que é a CA1-CPFm. Sendo que estas informações poderão contribuir no futuro para o surgimentos de novas terapias e também na realização de um diagnóstico mais rápido e preciso da DA. 


\section{Objetivos}

\subsection{Objetivo Geral}

O objetivo desde trabalho foi realizar uma caracterização das alterações eletrofisiológicas, oscilatórias, comportamentais e histológica no modelo farmacológico da DA esporádica utilizando a STZ icv. Além disso, foi realizado intervenção farmacológica, no sistema colinérgico utilizando a nicotina, para tentar reduzir a progressão dos principais sintomas da DA, presentes neste modelo. 


\subsection{Objetivos Específicos}

1. Caracterizar as disfunções na plasticidade sináptica de curta e longa duração na via que conecta a região CA1 do hipocampo ao CPFm em modelo farmacológico de DA - ratos Wistar submetidos a injeção de STZ-icv;

2. Promover intervenção farmacológica crônica por meio injeções intraperitoneais com nicotina, com o objetivo de atenuar as principais alterações eletrofisiológicas, comportamentais e moleculares caracterizadas previamente no modelo experimental citado no item 1 ;

3. Correlacionar os principais achados eletrofisiológicos com os resultados dos testes comportamentais e com as marcações imunohistoquímicas; 


\section{Metodologia}

\subsection{Animais}

Os animais utilizados nos experimentos foram ratos Wistar machos com pesos iniciais entre 140-160 g, com aproximadamente 40 dias, fornecidos pelo Biotério Central da Universidade de São Paulo do campus de Ribeirão Preto.

Eles foram alojados em grupos de 2 a 3 animais em caixas de polipropileno medindo 40x33x18 cm, acamadas com serragem e com livre acesso à ração e água. Durante todo o período de experimentação os animais foram submetidos a ciclo claro/escuro de $12 \mathrm{~h}$ com o período de claro iniciando 7:00 h.

Para a execução deste trabalho foi necessário utilizar 183 animais, sendo que desses $120(65,5 \%)$ foram incluídos nas análises aqui apresentadas e os outros 63 animais tiveram que ser descartados por algum tipo problema tais como morte durante a cirurgia, erros no posicionamento dos eletrodos, ruídos.

Este trabalho teve todos os procedimentos experimentais aprovados pela Comissão de Ética em Experimentação Animal (CETEA) da FMRP-USP sob o protocolo 088/2010.

\subsection{Desenho Experimental}

A figura 1 ilustra os desenhos experimentais 1 e 2 realizados neste trabalho. No experimento 1 (Fig. 1-A), os animais foram anestesiados no primeiro dia para receber uma microinjeção intracerebroventricular (icv) de líquido cerebrospinal artificial (aCSF) com ou sem a STZ diluída. Os animais que receberam a microinjeção com a STZ foram utilizados neste trabalho como modelo animal farmacológico da doença de Alzheimer 
(LESTER-COLL et al., 2006; SALKOVIC-PETRISIC; HOYER, 2007) e os que receberam apenas o aCSF serviram como controle.

Após dois dias de recuperação os animais passaram por 20 dias de tratamento crônico com nicotina que foi dissolvida em solução salina e aplicada via intraperitoneal. Os animais que serviram de controle do tratamento receberam o mesmo volume de salina porém sem a nicotina diluída.

Os testes comportamentais foram realizados entre os dia 25 e 27, dois dias após o fim do tratamento crônico, garantindo assim que os animais não estivessem mais sob efeito agudo da nicotina. No primeiro dia de teste os animais tiveram sua locomoção monitorada no paradigma de Campo Aberto, e em seguida (segundo e terceiro dias), sua memória de reconhecimento foi avaliada no teste de Reconhecimento de Objetos.

No dia 28 foi realizado o teste eletrofisiológico que consiste em registrar o hipocampo (CA1) e o cortex pré-frontal medial (CPFm) do animal anestesiado com uretana. Este registro foi realizado $30 \mathrm{~min}$ antes e $240 \mathrm{~min}$ depois de estimular a via CA1-CPFm com estímulos de alta frequência (HFS - do inglês High Frequency Stimulation). Ao final do registro os animais tiveram seus encéfalos perfundidos para fixação e posterior avaliação de morte neuronal e de neurotrofinas.

O paradigma do experimento 2 (Fig. 1-B) é idêntico ao do experimento 1 até o teste comportamental. Após um intervalo de 60 dias, do primeiro teste comportamental, os animais são submetidos aos mesmos testes comportamentais novamente (entre os dias 88 a 90), e no dia 91 também realizam o teste eletrofisiológico e a perfusão.

No experimento 1 foi possível observar os efeitos a curto prazo tanto da STZ quanto do tratamento crônico e o experimento 2 foi realizado para observar os efeitos a longo prazo, visto que nele houve um intervalo de 3 meses entre a microinjeção da STZ e o registro eletrofisiológico e no experimento 1 este intervalo foi de 1 mês. 


\section{A $\quad$ Exp.1}

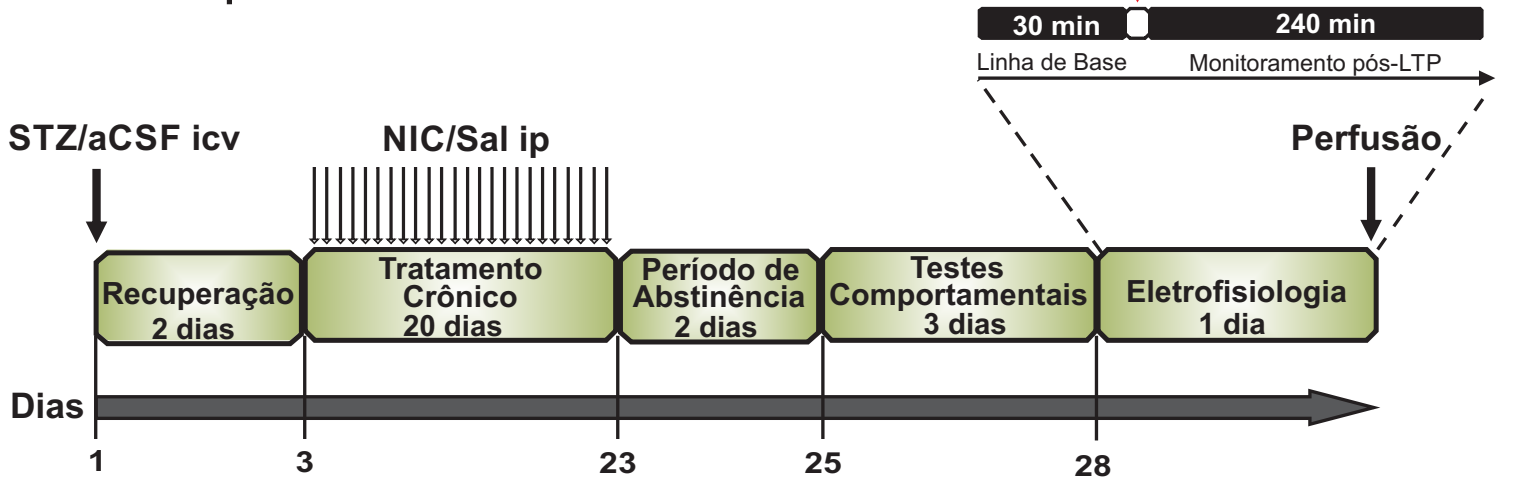

\section{B Exp.2}
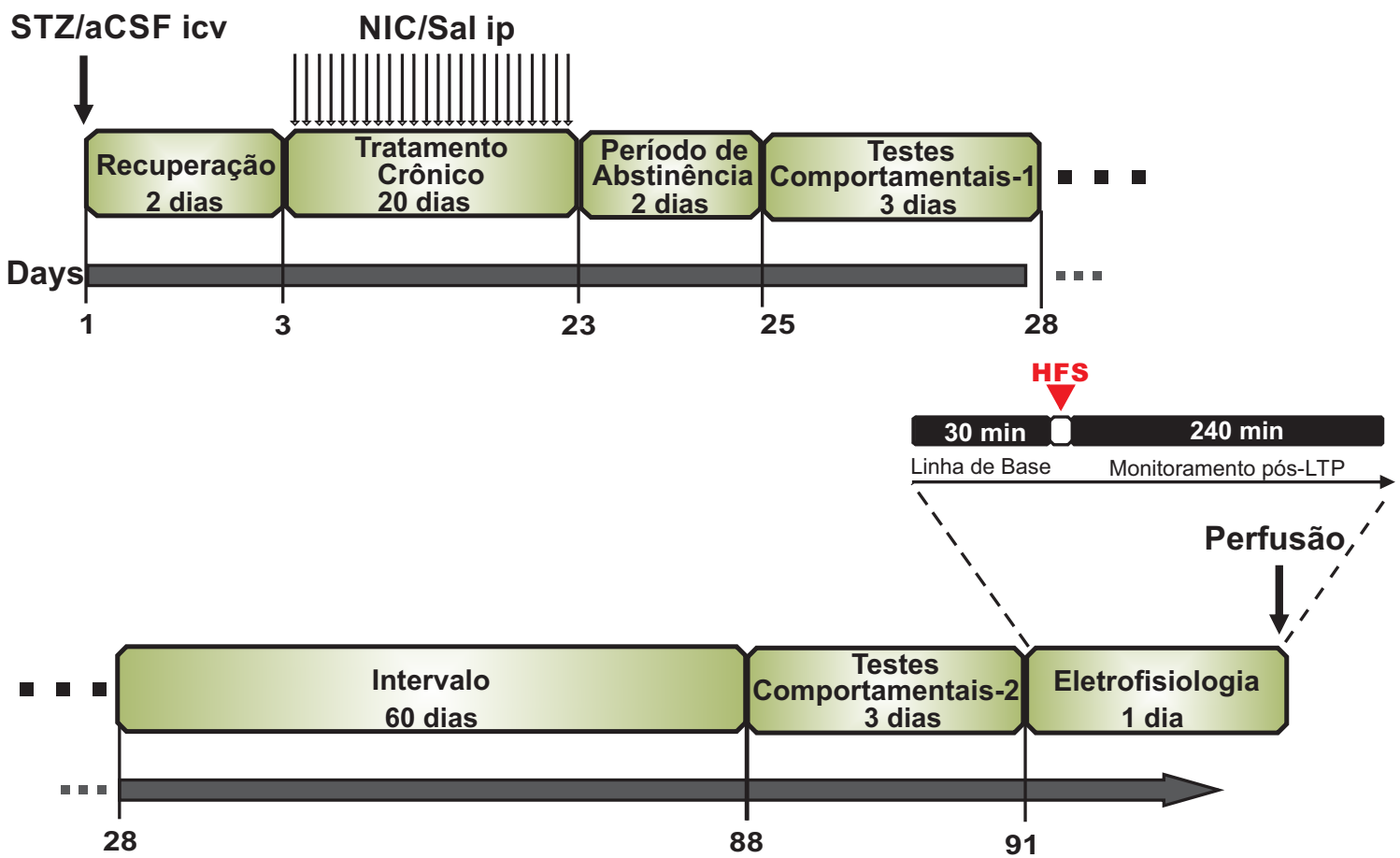

Figura 1 - Paradigma experimental dos dois experimentos. (A) Os animais do experimento 1 receberam a microinjeção de STZ/aCSF icv e após 2 dias de recuperação receberam 20 dias de tratamento crônico de nicotina ou salina. Do dia 25 ao 27, dois dias depois do fim do tratamento, foram realizados os testes comportamentais de Campo Aberto e Reconhecimento de Objetos. No dia 28, um mês após a injeção de STZ/aCSF, foram realizados os registros eletrofisiológicos e a perfusão. (B) O paradigma do experimento 2 possui uma segunda seção de testes comportamentais após um intervalo de 60 dias da primeira seção, do dia 88 ao 90, e os registros eletrofisiológicos foram realizados no dia 91 (três meses após a injeção da STZ/aCSF icv). 
As Tabelas 1 e 2 reúnem as abreviaturas utilizadas neste trabalho dos grupos experimentais, respectivamente dos experimentos 1 e 2. Em ambos os experimentos foram necessários 4 grupos, sendo que dois deles receberam STZ e dois apenas aCSF. Dos grupos que receberam STZ, um deles recebeu tratamento com nicotina e o outro com salina (chamados de STZnic e $S T Z$, respectivamente). No caso dos grupos controles, que receberam aCSF, os animais $C T R$ foram tratados com salina e os animais CTRnic foram tratados com nicotina.

Tabela 1 - Grupos Experimento 1

\begin{tabular}{l|l} 
GRUPO & INTERVENÇÃO \\
\hline $1-C T R_{1}$ (1 mês) & Salina \\
2- STZ $Z_{1}$ (1 mês) & Salina \\
3- $C T R$ Ric 1 mês) & Nicotina $1 \mathrm{mg} / \mathrm{kg}$ \\
4- $S T Z n i c_{1}$ (1 mês) & Nicotina $1 \mathrm{mg} / \mathrm{kg}$
\end{tabular}

Tabela 2 - Grupos Experimento 2

\begin{tabular}{l|l} 
GRUPO & INTERVENÇÃO \\
\hline $1-C T R_{3}$ (3 meses) & Salina \\
2- STZ $Z_{3}(3$ meses $)$ & Salina \\
3- $C T R n i c_{3}$ (3 meses) & Nicotina $1 \mathrm{mg} / \mathrm{kg}$ \\
$4-S T Z n i c_{3}$ (3 meses) & Nicotina $1 \mathrm{mg} / \mathrm{kg}$
\end{tabular}

As próximas seções terão como finalidade descrever em detalhes cada passo realizado no desenho experimental.

\subsection{Microinjeção}

Para a microinjeção icv os animais receberam injeção sistêmica de cloridratos de cetamina (100 mg/kg, i.p. em $\mathrm{NaCl} 0,15 \mathrm{M})$ e xilazina (10 mg/kg, i.p. em $\mathrm{NaCl} 0,15 \mathrm{M})$ visando a anestesia geral, verificado por meio do pinçamento da cauda. Após a tricotomia do escalpo, a cabeça do animal foi fixada no aparelho estereotáxico (KOPF, KOPF instruments; EUA/Insight; Brasil). O escalpo foi então higienizado com álcool iodado, e localmente anestesiado com injeção subcutânea de lidocaína. 
Logo após à incisão longitudinal, o escalpo foi limpo com peróxido de hidrogênio 10 \% até que a superfície do crânio ficasse exposta. Em seguida, tendo o bregma como referência ântero-posterior (AP) e médio-lateral (ML), foram feitos dois orifícios com as seguintes coordenadas, seguindo o atlas Paxinos e Watson (PAXINOS; WATSON, 2007):

- Ventrículo Direito: AP -0,5 mm; ML -1,4 mm;

- Ventrículo Esquerdo: AP -0,5 mm; ML +1,4 mm;

Nos orifícios foram introduzidas duas cânulas de aço inoxidável de $14 \mathrm{~mm}$, feitas a partir de uma agulha comum (calibre $23 \mathrm{G}$ ). A extremidade da cânula foi posicionada $4 \mathrm{~mm}$ abaixo do nível do osso do crânio fazendo com que ambas chegassem no limite superior dos ventrículos (Fig. 2). Utilizando a cânula como guia, foram introduzidas duas agulhas gengivais $(30 \mathrm{G}$ ) dobradas de forma que a ponta da agulha ultrapassasse em 1 mm a ponta inferior da cânula.

Cada agulha foi conectada previamente a uma microsseringa de $10 \mu \mathrm{L}$ (Hamilton, EUA) através de um tubo flexível de polietileno contendo $2 \mu \mathrm{L}$ de aCSF com ou sem STZ diluída na dose de $3 \mathrm{mg} / \mathrm{kg}$ (Streptozotocin; Sigma-Aldrich, USA), conforme o grupo do animal. O aCSF é uma solução aquosa de sais (em mM: $\mathrm{CaCl}_{2} 1,2 ; \mathrm{KCl} 2,7 ; \mathrm{MgCl}_{2}$ 1,0; $\mathrm{NaCl}$ 135,0) com pH 7,3 a temperatura ambiente (BARILAR et al., 2015).

Os $2 \mu \mathrm{L}$ de cada ventrículo foram vagarosamente injetados em uma velocidade de $0,5 \mu \mathrm{L} / \mathrm{min}$. Depois da microinjeção as duas cânulas foram retiradas para realizar a sutura do escalpo e no final do procedimento todos os animais foram tratados com um antibiótico (Pentabiótico; 0,4 ml via intramuscular) e um antipirético analgésico(Banamine; 0,3 ml via subcutânea). 


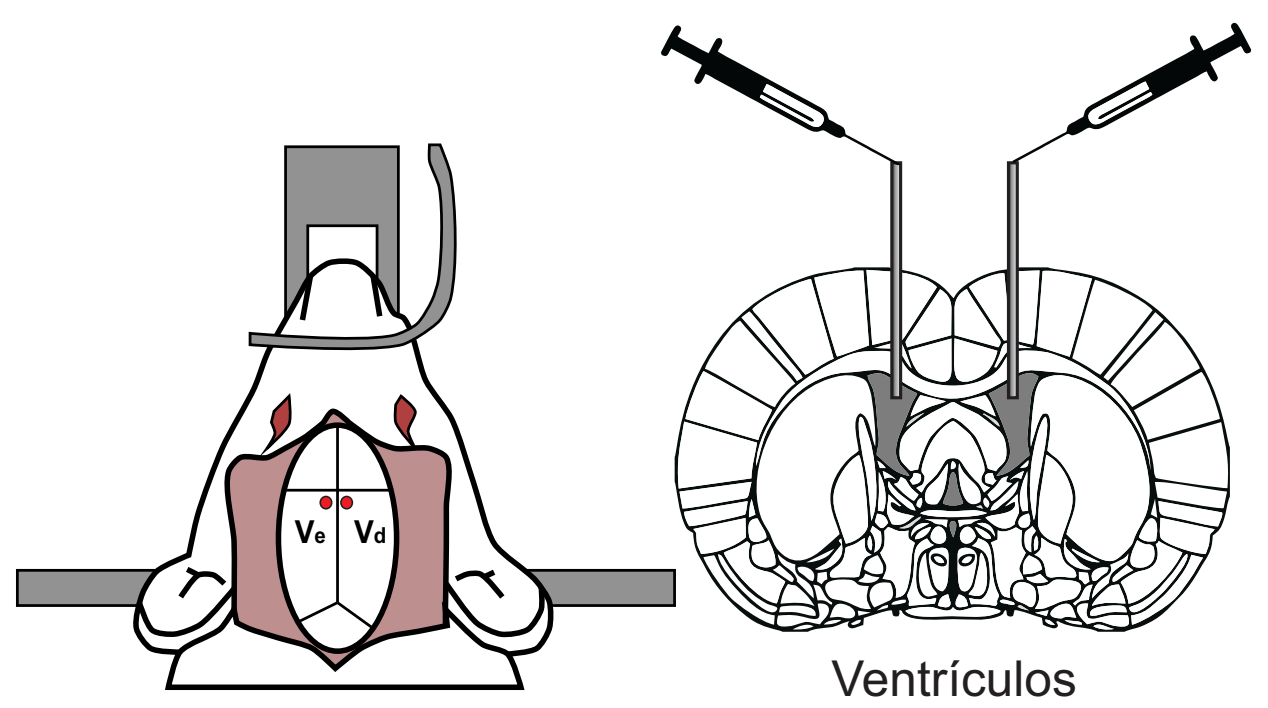

Figura 2 - Esquema das seções de micro-injeção. A figura à esquerda mostra a região do crânio onde foram realizados os furos para ter acesso aos ventrículos direito e esquerdo. A figura à direita mostra o corte coronal da região onde foram realizadas as injeções da STZ.

As coordenadas utilizadas na microinjeção foram padronizadas em um experimento piloto, que foi realizado para garantir que a droga injetada chegasse ao ventrículo. Nesse experimento foi realizado o procedimento descrito acima porém com azul de metileno no lugar do aCSF e o animal foi decapitado logo após a injeção. O cérebro foi removido e fixado por $24 \mathrm{~h}$ em paraformaldeído (PFA) $4 \%$ e posteriormente em sacarose $20 \%$ durante mais $48 \mathrm{~h}$ a $4{ }^{\circ} \mathrm{C}$. Logo em seguida o cérebro foi congelado a $-20{ }^{\circ} \mathrm{C}$ para fatiamento coronal em criostato $(30 \mu \mathrm{m})$ da região de interesse fossem obtidas utilizando um criostato. Estas fatias foram montadas em lâminas gelatinizadas e posteriormente coradas com Hematoxilina-Eosina para que a região onde as cânulas se encontravam fossem fotografadas (Fig. 3). 


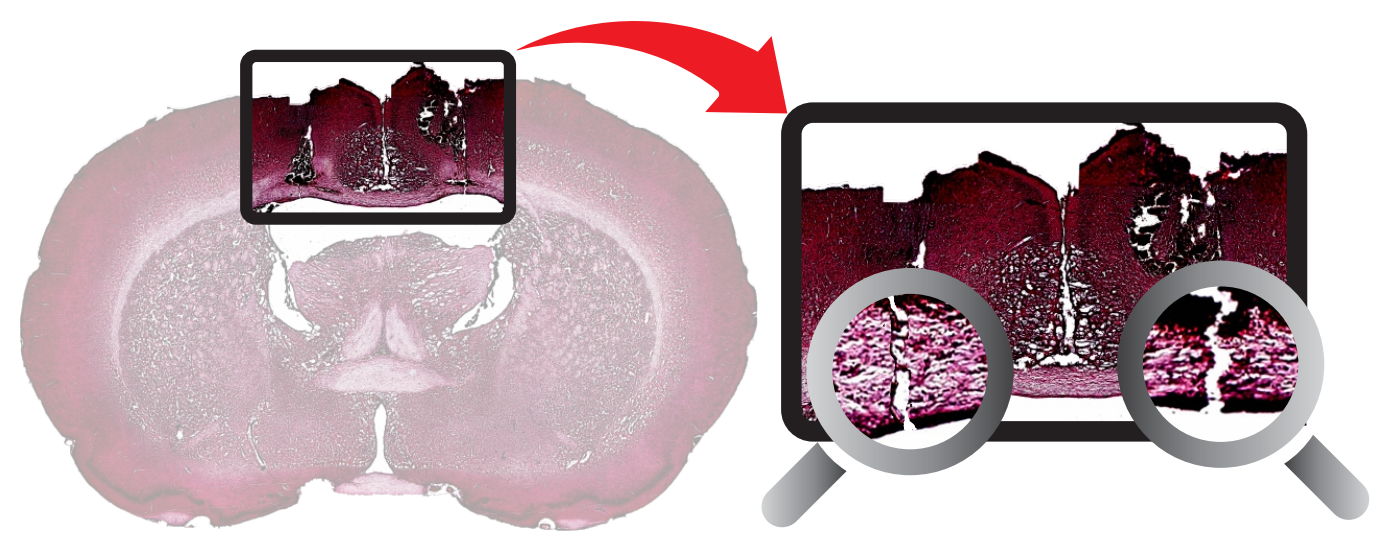

Figura 3 - Histologia do ventrículo. Seção coronal do ventrículo mostrando a padronização das coordenadas utilizadas na microinjeção da STZ.

\subsection{Tratamento Crônico}

O tratamento crônico foi realizado durante 20 dias consecutivos com injeções ip do agonista nicotínico, NIC, dissolvido em solução salina ( $\mathrm{NaCl}$ 0,9\%) na dose de $1 \mathrm{mg} / \mathrm{kg}$. Os grupos que serviram como controle do tratamento receberam o mesmo volume de salina sem NIC diluída.

A NIC utilizada foi na forma de hidrogeno_tartarato de [-]-nicotina (Sigma Aldrich, EUA). Esta droga foi escolhida pelos resultados obtidos na literatura que apontam para o efeito neuroprotetor da nicotina devido à manutenção da atividade mitocondrial (SAXENA; PATRO; NATH, 2011). Duas doses foram experimentalmente testadas. A primeira foi $3 \mathrm{mg} / \mathrm{kg}$ por ser uma dose, apresentada na literatura, que aumenta a sensibilidade dos receptores de insulina (XU et al., 2012). A segunda concentração foi de $1 \mathrm{mg} / \mathrm{kg}$, concentração que na literatura se revelou como uma dose que previne a redução de receptores nicotínico (ALKADHI et al., 2012).

A opção de escolher a dose de $3 \mathrm{mg} / \mathrm{kg}$ nos experimentos foi descartada por ser uma dose extremamente alta, quando aplicada de forma intraperitonial causou clonia das patas dianteiras e traseiras, hiperventilação e salivação nos ratos. A NIC na concentração de 1 $\mathrm{mg} / \mathrm{kg}$ não apresentou as reações adversas mencionadas acima, e como não se encontrava entre as doses mais elevadas e nem entre as mais baixas presentes na literatura, ela pareceu ser a concentração mais adequada para ser testada nos experimentos. 


\subsection{Testes Comportamentais}

Foram realizados dois testes comportamentais no intervalo de 3 dias. No primeiro foi realizado o Campo Aberto para verificar a atividade locomotora do animal e nos próximos dois dias foi realizado o Reconhecimento de Objeto, que consiste um teste comportamental capaz de avaliar a memória de reconhecimento.

\subsubsection{Campo Aberto}

O Campo Aberto foi realizado em uma arena de acrílico (46 x 46 x 46cm) com sensores infravermelhos posicionados em suas paredes (Fig. 4). Durante o intervalo que os animais permaneceram na arena os sensores detectaram as posições do animal em blocos de 3 min durante 15 min. Os dados eram enviados a um computador e registrados por um software dedicado (Insight, Brasil) para serem analisados posteriormente. Para cada animal foi possível computar a distância percorrida em cada bloco de 3 min ou a distância total percorrida durante todo o experimento.
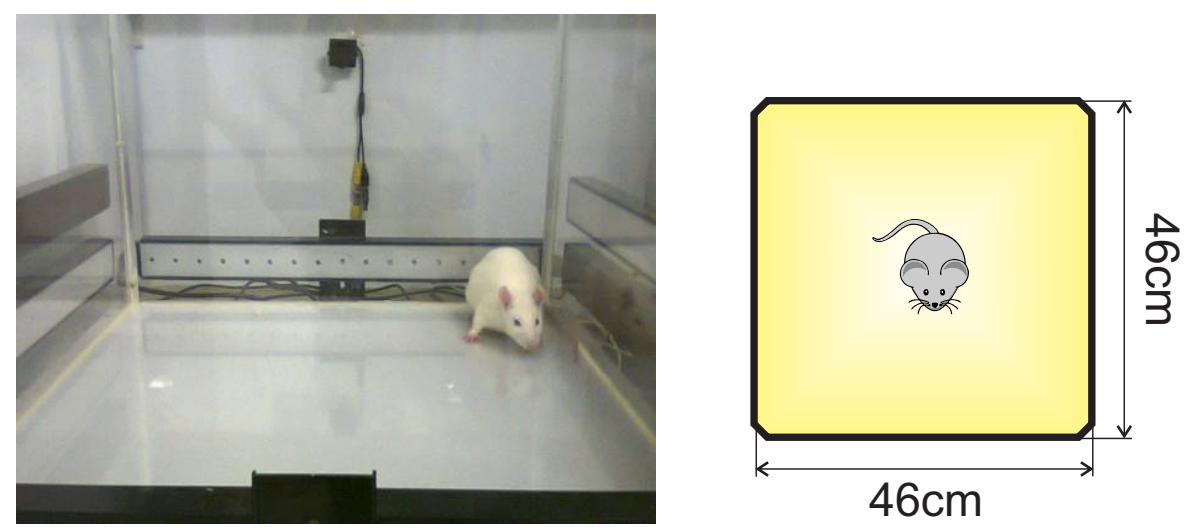

Figura 4 - Foto da arena onde foi realizado o teste de Campo Aberto. À esquerda uma foto durante a realização do Campo Aberto e a esquerda um esquemático com as dimensões da arena. 


\subsubsection{Reconhecimento de Objeto}

O Reconhecimento de Objetos foi realizado em dois dias. No primeiro dia foi realizada a habituação do animal à caixa e no segundo dia foi realizado o treino e o teste propriamente dito (Fig.5). Na habituação o animal ficou 30 min dentro da caixa vazia e no dia seguinte se deu início ao treino, que consiste em colocar o animal na caixa para explorar dois objeto idênticos (A e A) localizados nos cantos por 4 min. Após um intervalo de 20 min um dos objetos é trocado (B e A) e o animal retorna à caixa para realizar o teste que consiste em explorar por mais 4 min esses dois objetos (WARBURTON et al., 2003).

Em cada etapa, todos os objetos e a caixa foram limpos com álcool $70 \%$ para evitar que cheiros influenciassem o teste de forma indesejada e todos os procedimentos foram filmado por uma camera localizada no topo da caixa fornecendo uma imagem como a mostrada na figura 6.

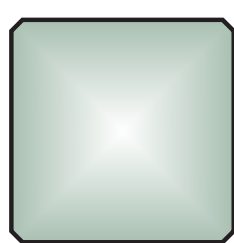

Habituação

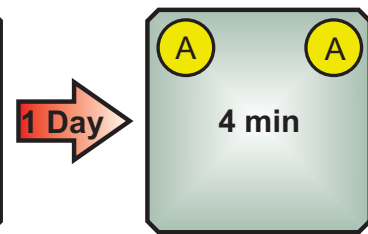

Treino

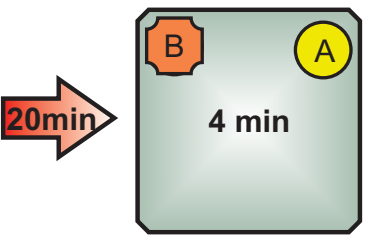

Teste

Figura 5 - Representação esquemática do Reconhecimento de Objetos. Um dia antes dos testes o animal é colocado na caixa por 30 min para que seja realizada a habituação ao local. Após $24 \mathrm{~h}$ o animal é inserido novamente na caixa por $4 \mathrm{~min}$ com dois objetos idênticos - A e A. Depois de um intervalo de 20 min o animal retorna à caixa por mais 4 min com um dos objetos trocados, B e A.

Pelos vídeos registrados foram quantificados o tempo que o animal explorou cada objeto, tanto durante o treino quanto durante o teste. Para cada vídeo foi quantificado o índice de reconhecimento e a Taxa de Discriminação. No teste, o índice de reconhecimento consiste no tempo em que o animal explorou o objeto novo divido pelo tempo total de exploração, neste caso, um índice de $50 \%$ indica que o animal explorou por igual ambos os objetos. A Taxa de Discriminação é a diferença entre o tempo de exploração do objeto novo e o tempo de exploração do objeto velho, tudo divido pelo tempo total. Esta taxa revela a proporção do tempo total de exploração que o animal passou explorando o objeto novo (GOH; MANAHAN-VAUGHAN, 2012). 


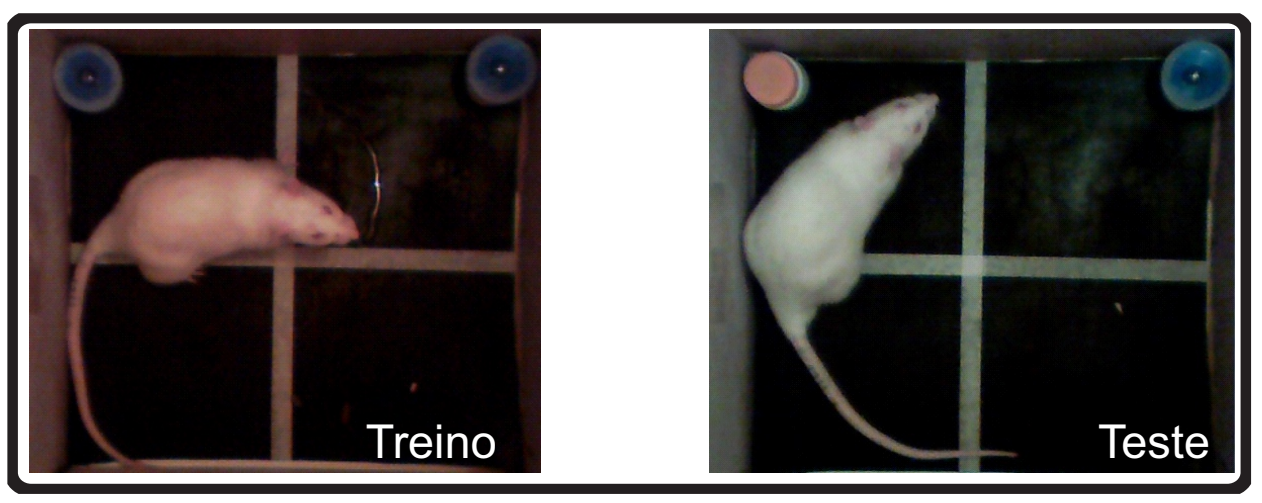

Figura 6 - Foto mostrando a realização do Reconhecimento de Objetos durante o treino (esquerda) e teste (direita).

O tempo de exploração foi computado quando o rato estava cheirando o objeto a uma distância de pelo menos $2 \mathrm{~cm}$ (ou com o nariz encostado ou com a cabeça direcionada ao objeto). Casos em que o animal se sentou, parou ou subiu no objeto não foram considerados.

\subsection{Eletrofisiologia}

A eletrofisiologia foi realizada com os animais anestesiados de forma permanente com uretana ip (Sigma Aldrich, EUA) na dose de 1,2 mg/kg dissolvidos em salina ( $\mathrm{NaCl}$ 0,9\%) na concentração de 50\%. Os procedimentos estereotáxicos foram idênticos aos da cirurgia de microinjeção (seção 4.3), com a diferença que para realizar a eletrofisiologia o animal permaneceu sobre uma placa aquecedora (Insight, Brasil) e sua temperatura foi mantida em $37 \pm 0,5{ }^{\circ} \mathrm{C}$, monitorada via termômetro retal.

\subsubsection{Regiões de registros e estimulação}

Com o crânio exposto, foram realizados três orifícios ipsilaterais, para o implante dos dois eletrodos monopolar de registro e o bipolar de estimulação, com as seguinte coordenadas seguindo o atlas (PAXINOS; WATSON, 2007): 
- $\mathbf{R} 1$ (CPFm, pré-límbico): AP +3,0 mm; ML -0,5 mm; DV -3,3 mm

- $\mathbf{R 2}$ (CA1 do hipocampo): AP -4,2 mm; ML -4,0 mm; DV -2,5 a -2,8 mm

- S (CA1 do hipocampo): AP -5,7 mm; ML -4,4 mm; DV -2,5 a -2,8 mm

Um quarto orifício foi realizado sobre o cortex parietal contralateral, sem precisão estereotáxica, e nele foi fixado de forma superficial um microparafuso com fio e conector para servir de aterramento e referência (Fig 7).
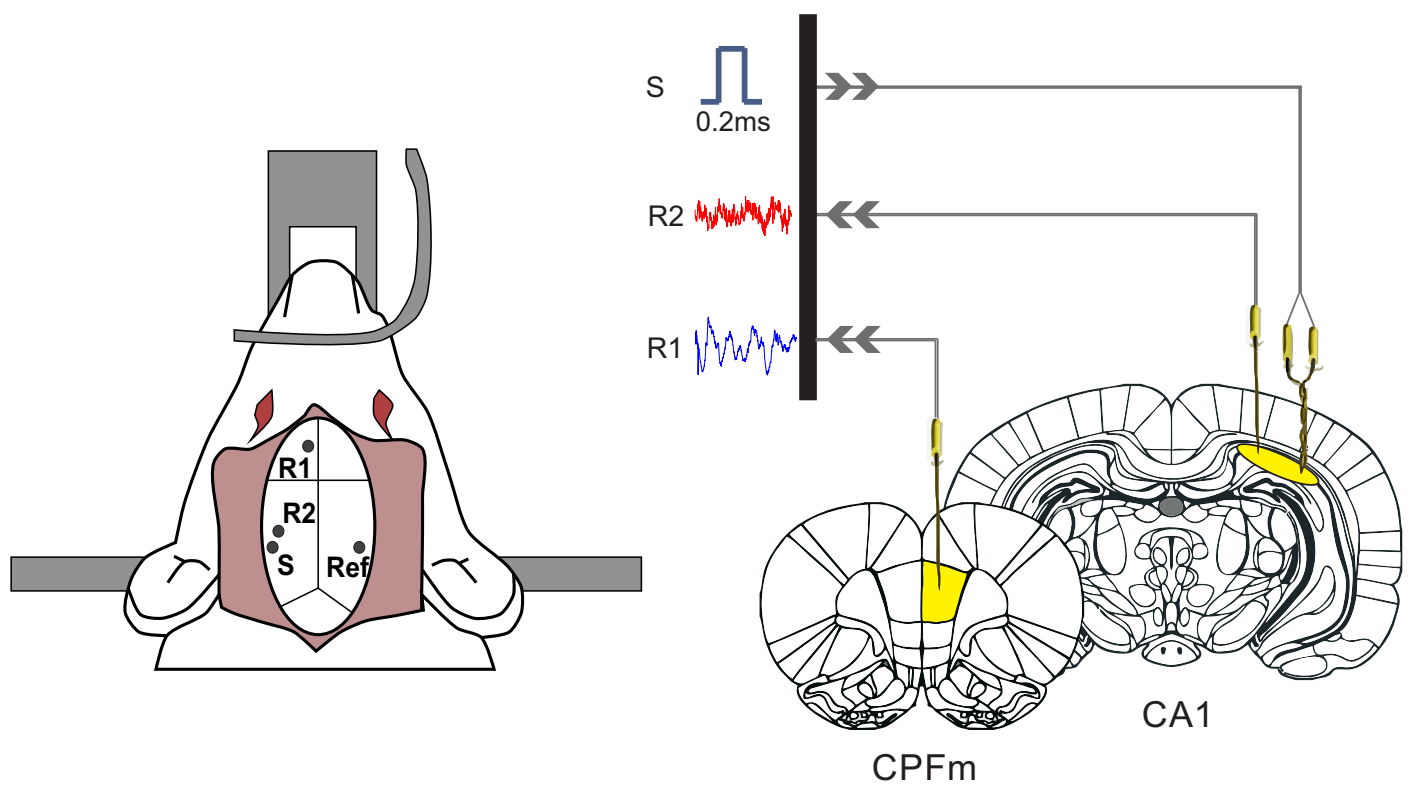

Figura 7 - Regiões de registro e estimulação. A figura à esquerda mostra a região do crânio onde foi realizado os furos para ter acesso às regiões de estímulo $(\mathrm{S})$, de registro $(\mathrm{R} 1$ e R2) e a de referência/terra (Ref). A figura à direita mostra as seções coronais das regiões onde foram inseridos os eletrodos monopolares de registro R1 e R2 (CPFm e CA1, respectivamente) e o bipolar de estímulo (região dorsal posterior do CA1) 
Os eletrodos foram preparados manualmente utilizando fios de tungstênio isolados com teflon (60 $\mu \mathrm{m}$ de diâmetro; A-M Systems, EUA). Os eletrodos monopolares foram obtidos a partir de um fio único soldado a um conector. Os bipolares foram obtidos a partir de pares de fios de tungstênio trançados, cada um soldado a um conector. As extremidades das pontas implantadas de cada eletrodo bipolar foram separadas em aproximadamente $0,5 \mathrm{~mm}$.

O primeiro eletrodo implantado foi o R1 e, logo em seguida, cimentado junto ao crânio com acrílico auto-polimerizável. Com isso, foi possível utilizar os braços da armação estereotáxica para o implante dos outros dois eletrodos. O implante do R2 foi realizado com monitoramento em tempo real dos potenciais de campo locais (LFPs - do inglês Local Field Potential), tanto por audio (Model 3300, A-M Systems, Inc) quanto por vídeo. Quando um eletrodo atinge uma camada neuronal densa, como o CA1 hipocampal, visualiza-se e ouve-se um aumento da manifestação espontânea de espículas. O último eletrodo implantado foi o de estímulo (S) e o seu alvo foi alcançado com a ajuda de pulsos monofásicos de $0.2 \mathrm{~ms}$ de duração e com intensidade variando entre 150 a $300 \mu \mathrm{A}$ aplicados a cada $20 \mathrm{~s}$. As coordenadas eram ajustadas até que os pulsos aplicados em CA1 (S) eliciassem no CPFm (R1) potenciais de campo pós-sinápticos (fPSPs) típicos da região: com amplitude maior que $250 \mu \mathrm{V}$ e primeira deflexão negativa com latência de 15 a 17 ms para o primeiro vale (LAROCHE; JAY; THIERRY, 1990).

\subsubsection{Sistema de Aquisição}

A figura 8 ilustra os equipamentos utilizados para estimular e registrar os dados durante os experimentos eletrofisiológicos.

Os estímulos elétricos (S) foram gerados por um estimulador digital S88X (Grass Technologies, EUA) e transmitidos a uma unidade de isolamento de corrente (PSIU6X, Grass Technologies, EUA) antes de sua aplicação intracerebral. Tal isolamento serviu para garantir a regularidade dos pulsos monofásicos. Os parâmetros de estimulação serão descritos na seção abaixo.

O sinal biológico, captado por ambos os eletrodos de registro (R1 e R2), foi amplificado em 100 vezes e filtrado na faixa de $0,3 \mathrm{~Hz}$ a $1 \mathrm{kHz}$ por dois pré-amplificadores analógicos P55 (Grass Technologies, EUA), sendo um para cada eletrodo. Após passar pelos pré- 
amplificadores, os sinais analógicos foram digitalizados a uma taxa de amostragem de 10 $\mathrm{kHz}$ por um conversor analógico-digital de 16 bits (PowerLab, ADInstruments, Austrália) e finalmente foram armazenados em um computador através do software LabChart 7.2 (ADInstrumentos, Austrália).

Para sincronizar o estímulo com o registro, o estimulador aciona um sinal de "trigger"no padrão TTL (Transistor-Transistor Logic) que é enviado ao conversor via cabo BNC sempre que o estimulo for gerado.

Todos os dados registrados, salvos pelo LabChart, foram exportados para a extensão .mat e analisados no Matlab (Mathwork, EUA).

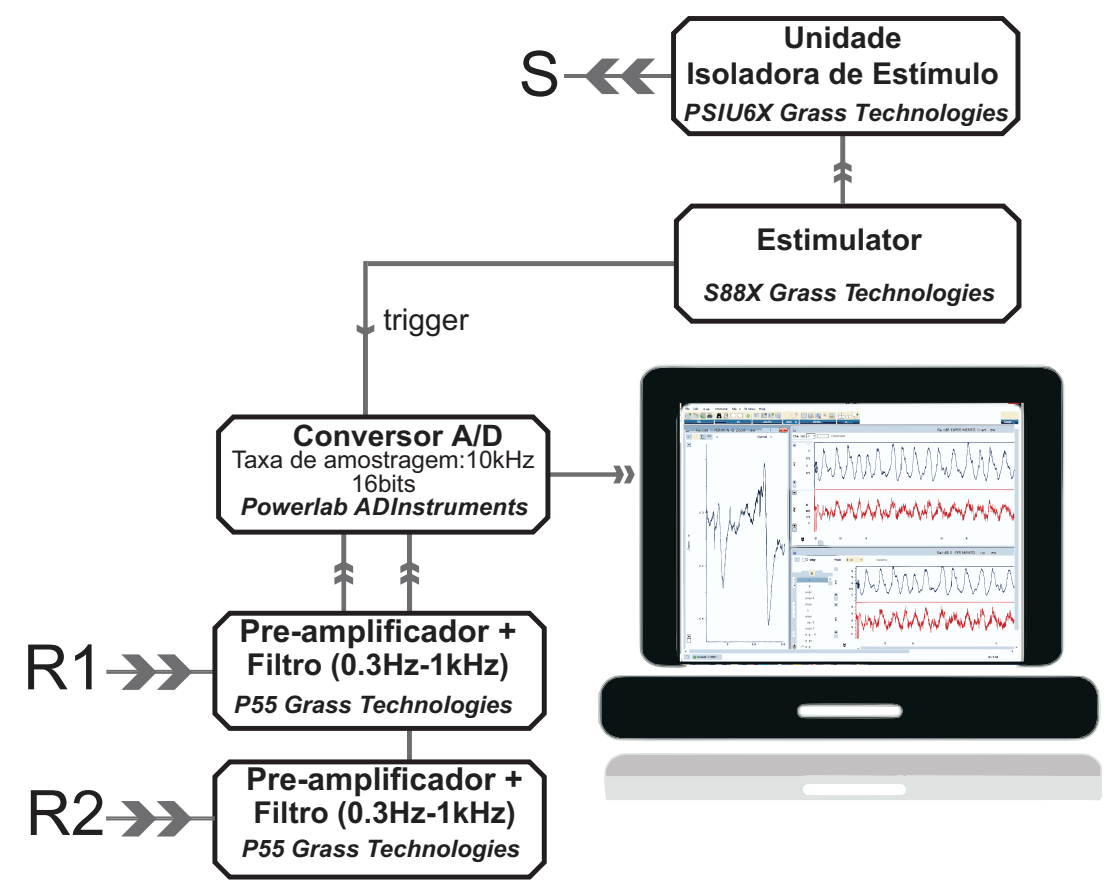

Figura 8 - Esquema do sistema de aquisição. O estimulador (S88X) gera ao mesmo tempo o estímulo e o trigger, que sincroniza o tempo do estímulo com o registro. O estímulo gerado passa por um isolador de corrente (PSIU6X) antes de ser enviado ao eletrodo bipolar (S-CA1). Os pré-amplificadores (P55) recebem os sinais dos eletrodos (R1CPFm e R2-CA1) os amplifica 100 vezes, filtra na banda de $0,3 \mathrm{~Hz}$ a $1 \mathrm{kHz}$ e os envia ao conversor A/D (Powerlab). O conversor digitaliza o sinal a uma taxa de $10 \mathrm{kHz}$ e um computador com o software LabChart 7.2 é utilizado para registrar esses dados. 


\subsubsection{Protocolo de Estimulação}

De forma geral, o paradigma do registro eletrofisiológico consiste basicamente em: (1) Registro de 30 min de linha de base (LB); (2) Indução da LTP por meio de estimulação de alta frequência (HFS); (3) Registro de 240 min pós-LTP. Junto com os registros dos LFPs dos trechos (1) e (3), a via também foi monitorada utilizando pulsos pareados para se obter os fPSPs e o PPF durante todo o registro (Fig. 9-A).

Porém, antes de iniciar o registro da LB, foi obtido para cada animal a curva de Entrada/Saída (E/S) para determinar a intensidade do estímulo a ser utilizada durante todo o experimento. Esta curva foi obtida aumentando gradualmente a intensidade dos pulsos monofásicos aplicados em CA1, conforme a sequência: 608090100120150200 $300400500 \mu \mathrm{A}$. Para cada intensidade, foram realizadas as médias de 3 fPSPs do CPFm. A intensidade da estimulação utilizada no resto do experimento foi aquela capaz de eliciar fPSPs com aproximadamente $50 \%$ da amplitude máxima da curva de E/S. Tal intensidade busca evocar fPSP com regularidade, mas sem saturar o recrutamento axonal e, portanto, sem impedir a expressão da plasticidade sináptica.

Após 30 min de monitoramento da via no estado basal, durante a LB, a indução da LTP foi realizada por meio de uma estimulação de alta frequência (HFS) - Fig. 9-C. Esta estimulação consiste em duas séries de 10 trens de estímulos separadas por 10 min. Cada trem de estímulo é composta por 50 pulsos a $250 \mathrm{~Hz}(200 \mathrm{~ms})$ aplicados a cada $10 \mathrm{~s}$ (JAY; BURETTE; LAROCHE, 1995; ROMCY-PEREIRA; PAVILDES, 2004; LOPES-AGUIAR et al., 2008), em seguida a via foi monitorada por mais $240 \mathrm{~min}$.

Os 270 min de registro de cada animal foi dividido em 810 épocas de 19,5 s amostradas a $10 \mathrm{kHz}$. O monitoramento da via foi realizado durante todo o experimento utilizando pulsos pareados de 0,2 ms com intervalo inter-pulsos (IIP) de $80 \mathrm{~ms}$ no início de cada época. Este IIP é capaz de eliciar dois fPSPs com a maior facilitação por PPF na via CA1-CPFm (ROMCY-PEREIRA; PAVILDES, 2004; KISS T.AND HOFFMANN; HAJóS, 2011) e o $\mathrm{PPF}$ foi obtido pela razão do segundo pelo o primeiro $\left(f P S P_{2} / f P S P_{1}\right)$. Além dos $f P S P_{1}$ e $f P S P_{2}$ também foram registrados os 19,5 s de LFPs das 810 épocas tanto do CPFm quanto do CA1 ao longo de todo experimento com o objetivo de monitorar também a atividade oscilatória de cada animal (Fig. 9-B). 


\section{A Paradigma Eletrofisiológico}

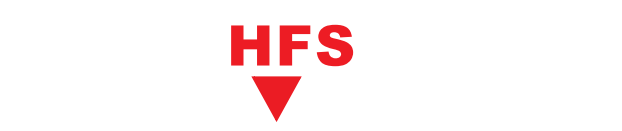

$30 \mathrm{~min}$

$240 \mathrm{~min}$

Linha de Base

Monitoramento pós-LTP

\section{B Registros: fPSPs e LFPs}

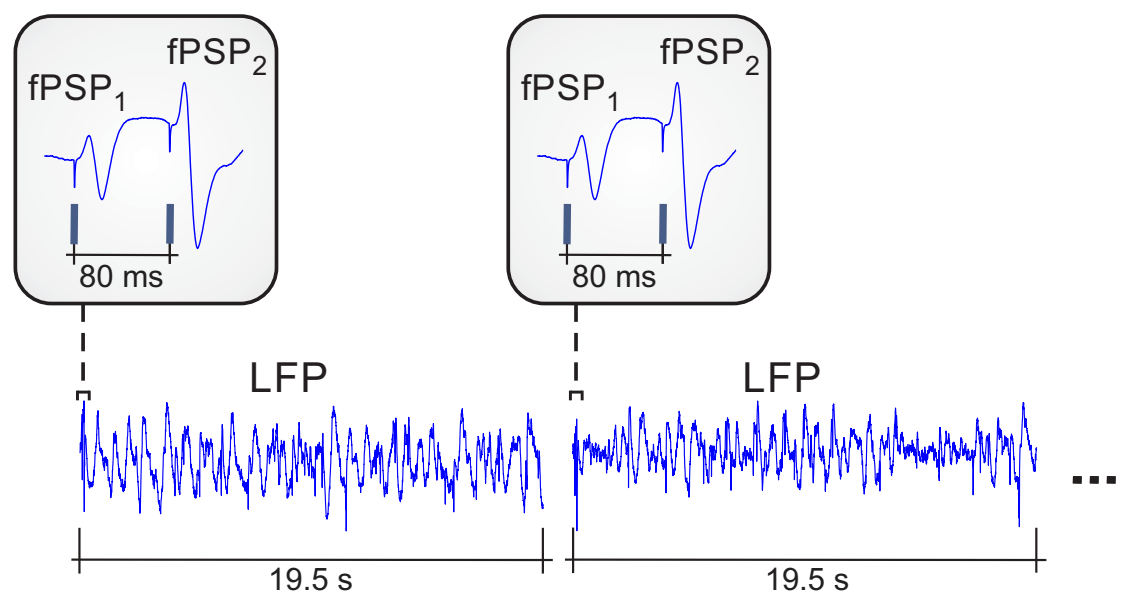

C HFS: Estimulação de Alta Frequência

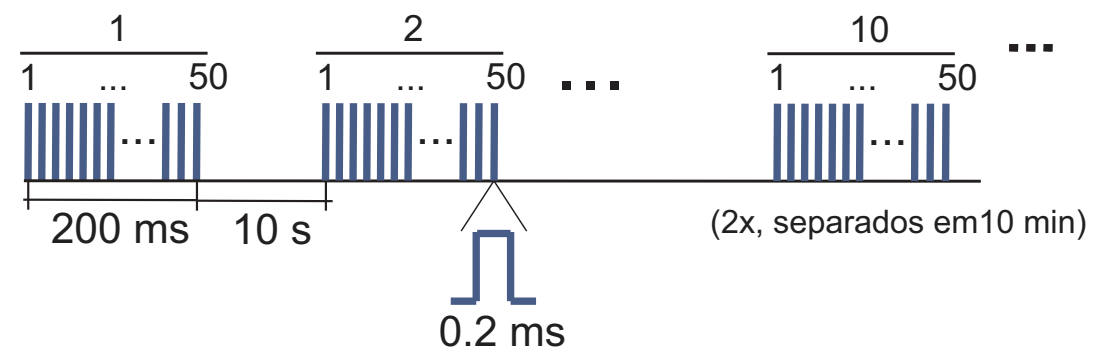

Figura 9 - Protocolo de estimulação elétrica. (A) O paradigma experimental eletrofisiológico consiste em primeiro monitorar a via no seu estado basal por $30 \mathrm{~min}$, em seguida, aplicar a estimulação de alta frequência (HFS) e monitorar a via por mais 240 min. (B) O monitoramento da via foi realizado mediante o registro de 810 épocas de 19,5 s dos LFPs durante os 270 min de experimento, sendo que no início de cada época foi aplicado um pulso pareado (que consiste em um par de pulsos de 0,2 ms espaçados entre si por $80 \mathrm{~ms}$ ) para que também fossem obtidos os fPSPs e o PPF. Esses pulsos são aplicados em CA1 e os potenciais evocados por eles ( $f P S P_{1}$ e $\left.f P S P_{2}\right)$ são registrados no CPFm. (C) A estimulação de alta frequência (HFS) consiste em duas séries de 10 trens de estímulos separados por $10 \mathrm{~min}$, sendo que os trens consistem em uma sequência de 50 pulsos a $250 \mathrm{~Hz}(200 \mathrm{~ms})$ aplicados a cada $10 \mathrm{~s}$. 
Posteriormente, esses dados foram importados para o Matlab e concatenados em uma matriz de forma que cada coluna representasse uma das 810 épocas do experimento. Para as análises da plasticidade sináptica foram utilizados apenas os primeiros $150 \mathrm{~ms}$ dessa matriz, de onde foi calculado a amplitude, a latência dos fPSPs e o PPF para cada época. Para as análises oscilatórias esta matriz foi reamostrada pra $500 \mathrm{~Hz}$, filtrada entre 0,5 e $250 \mathrm{~Hz}$ e removido os primeiro $150 \mathrm{~ms}$ por conter o artefato do estímulo e os fPSPs.

\subsubsection{Análise da Plasticidade Sináptica}

A figura 10 ilustra a maneira pela qual a análise da plasticidade foi realizada. Cada ponto do gráfico representa a amplitude média de 30 fPSPs, que corresponde a 10 min de registro. Os três primeiros pontos indicam a LB e os demais 24 pontos o monitoramento pós-LTP. Observa-se que após a aplicação da HFS ocorre um aumento da amplitude dos fPSPs e esse aumento persiste durante todo o experimento. Todos os valores foram divididos pela amplitude média da LB, inclusive os da própria linha de base. Desta forma, gráficos como o da figura 10 permite avaliar o aumento da amplitude dos fPSPs após a LTP em relação à linha de base. 


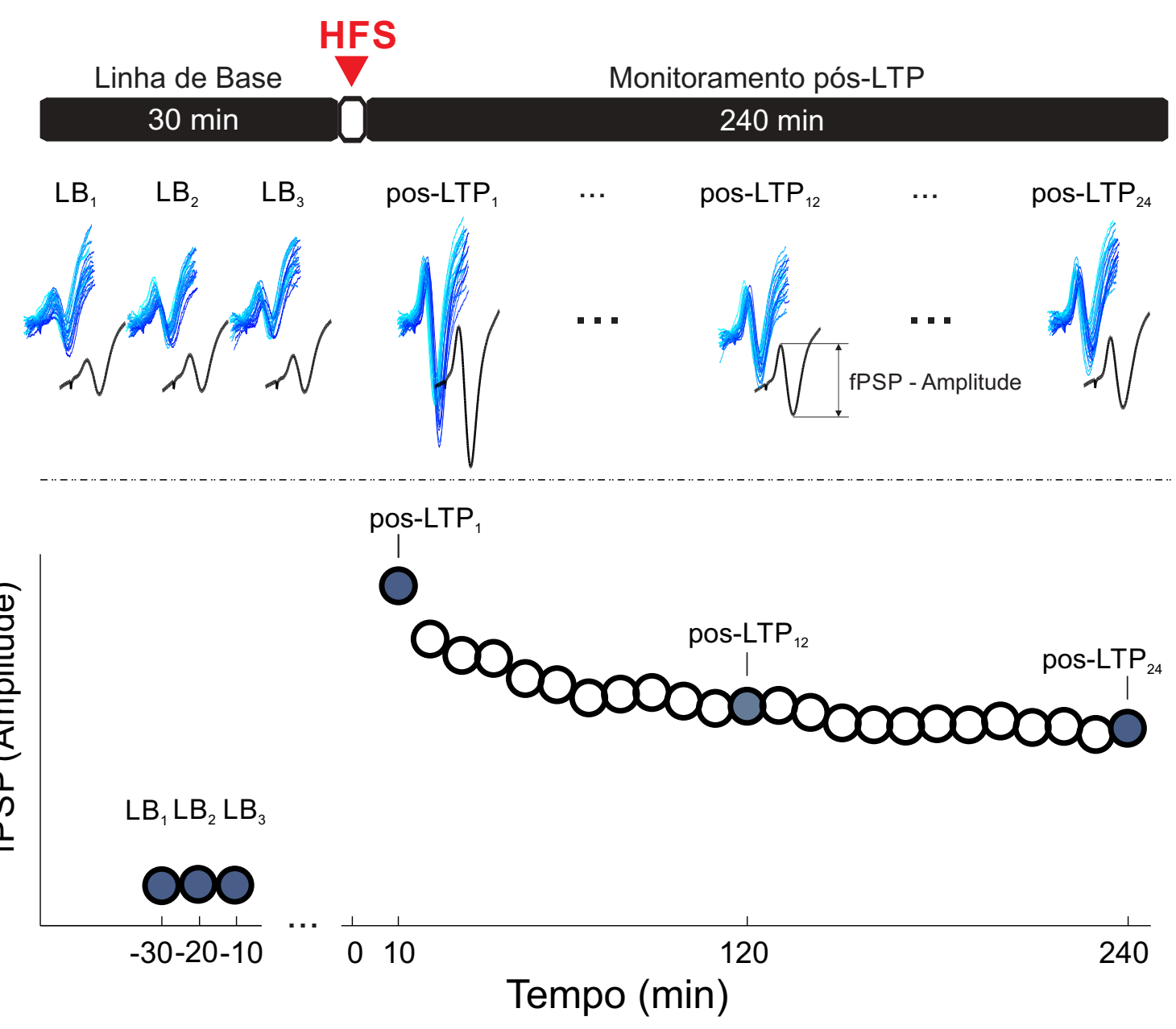

Figura 10 - Análise da plasticidade sináptica. No gráfico (Amplitude x tempo) cada ponto é obtido calculando o valor médio da amplitude de 30 fPSPs, sendo que os 3 primeiros pontos representam os PPSPs da linha base e os demais 24 pontos representam a amplitude média dos fPSPs após a aplicação da HFS. Observe que após a HFS ocorre a indução da LTP, onde a amplitude dos fPSPs aumentam sem retornar ao estado basal após $240 \mathrm{~min}$. 


\subsection{Análises Oscilatórias}

A uretana (anestesia utilizada durante a eletrofisiologia) promove alternâncias espontâneas no LFP entre estados cerebrais ativo e inativo que se assemelham às alterações do sono REM/nãoREM (do inglês Rapid Eye Movement) (CLEMENT et al., 2008). No estado inativo o LFP dos animais anestesiados com uretana, assim como no sono nREM, é caracterizado por uma elevada amplitude e oscilação lenta. No estado ativo, assim como no sono REM, o LFP apresenta baixa amplitude e oscilação rápida (CLEMENT et al., 2008) - Fig. 11.

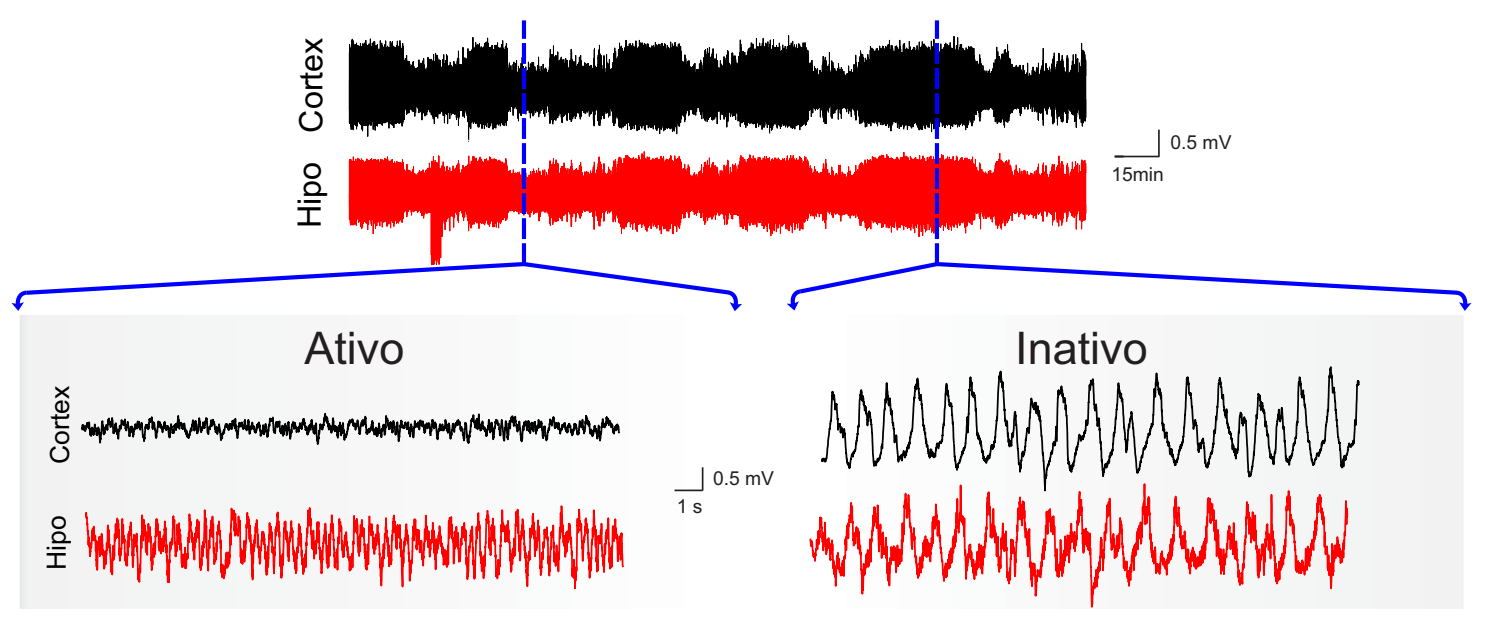

Figura 11 - LFP característico de um animal anestesiado com uretana. LFPs das 810 épocas concatenadas em um único vetor de um animal representativo evidenciando uma época (19,5 s) dos dois diferentes estados de um animal anestesiado com uretana no cortex e no hipocampo. Os traços azuis indicam o lugar onde o LFP foi expandido para mais detalhes. Ativo (à esquerda): LFP de baixa amplitude e oscilação rápida. Inativo (à direita): LFP de elevada amplitude e oscilação lenta.

O espectro de potência (PSD - do inglês Power Spectrum Density) de cada estado dos animais anestesiados com uretana também apresentam diferentes propriedades. A característica mais evidente no estado inativo, tanto do hipocampo quanto do cortex, é a elevada potência em Low Delta - $\approx 1$ Hz (Fig.12-A). Já no estado ativo o hipocampo apresenta um ritmo theta proeminente $-\approx 4 \mathrm{~Hz}$ (Fig.12-B). Esta oscilação também é conhecida como Theta tipo 2, que é uma oscilação sensível à atropina (um antagonista muscarínico) e surge durante estados de imobilidade ou em animais anestesiados com uretana (KISS et al., 2013a; LI; TOPCHIY; KOCSIS, 2007). 

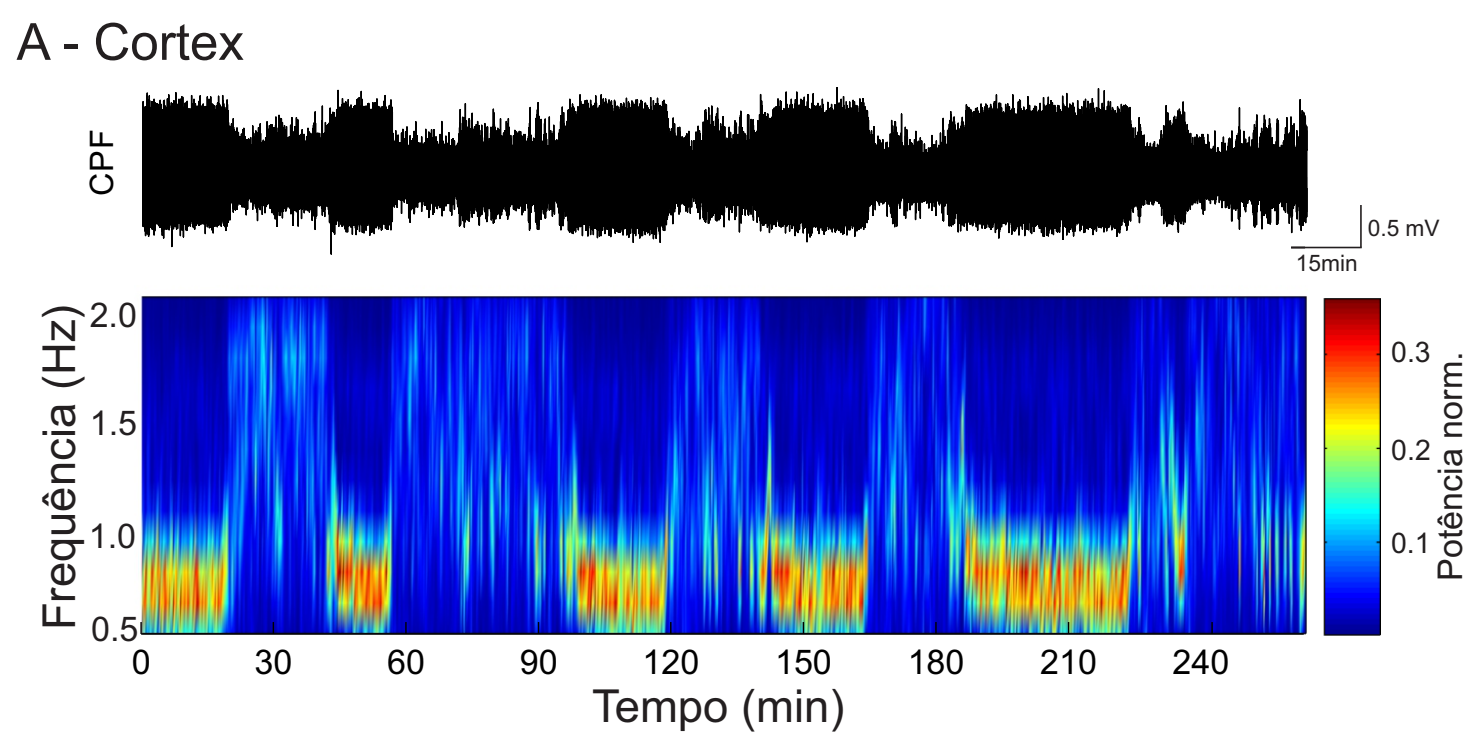

\section{B - Hipocampo}

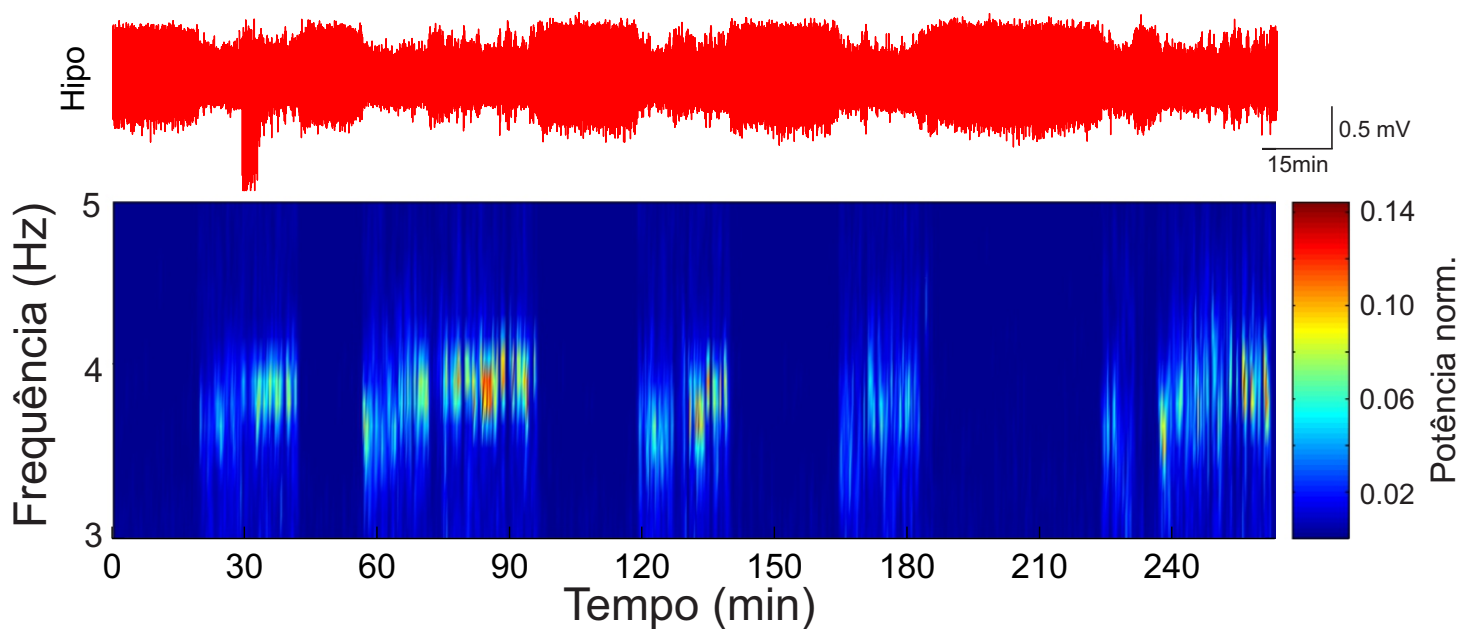

Figura 12 - Espectrograma característico de um animal anestesiado com uretana. (A) LFP e espectrograma do cortex típico de um animal anestesiado com uretana, que mostra o aumento da potência em Low Delta durante os estados inativos.(B) LFP e espectrograma mostrando o aumento da banda Tetha do hipocampo nos estados ativos. 
Antes de realizar as análises oscilatórias foi necessário localizar as épocas ativas e inativas nas 810 épocas registradas de cada animal para que as análises dos dois estados fossem realizadas de forma separada. Este processo foi realizado utilizando dois parâmetros: o cálculo da Raiz Média Quadrada (RMS - do inglês Root Mean Square) e da Taxa de Cruzamentos em Zero (ZCR - do inglês Zero Crossing Rate). Como as épocas inativas apresentam um LFP de alta amplitude seu valor RMS é elevado e como também apresentam oscilações lentas a taxa de cruzamentos em zero (ZCR) é reduzida. No caso das épocas ativas ocorre exatamente o oposto, como elas apresentam um LFP de baixa amplitude e oscilações rápidas seu RMS é baixo e o seu ZCR é elevado (Fig.13-A).

A classificação das 810 épocas de cada animal foi realizada utilizando o scatter plot dos valores ZCR pelo RMS. Nele foi selecionada, utilizando a função inpolygon() do Matlab, como inativa (em vermelho) as épocas com menor ZCR e maior RMS e como ativa (em verde) as épocas com maior ZCR e menor RMS. As épocas que permaneceram em preto são épocas não classificadas, normalmente por apresentar trechos dos dois estados e não foram utilizadas nas análises oscilatórias (Fig.13-B). Neste ponto vale ressaltar que o intuito deste método não é realizar uma seleção rigorosa de todas as épocas ativas e inativas do registro e sim possuir uma amostra fidedigna, com dados exclusivo de cada estado, sem nenhuma época classificada de forma incorreta (ou com trechos dos dois estados ou que não apresente características típicas do estado).

Após esta classificação foi possível calcular o PDS de cada estado de forma separada tanto do hipocampo quanto do CPFm e com isso observar as características que são típicas de cada estado no espectro de um animal anestesiado com uretana, como o mostrado na figura 13-C: ritmo Theta tipo 2 proeminente nas épocas ativas e uma maior potência na banda Low-Delta nas épocas inativas. 
A
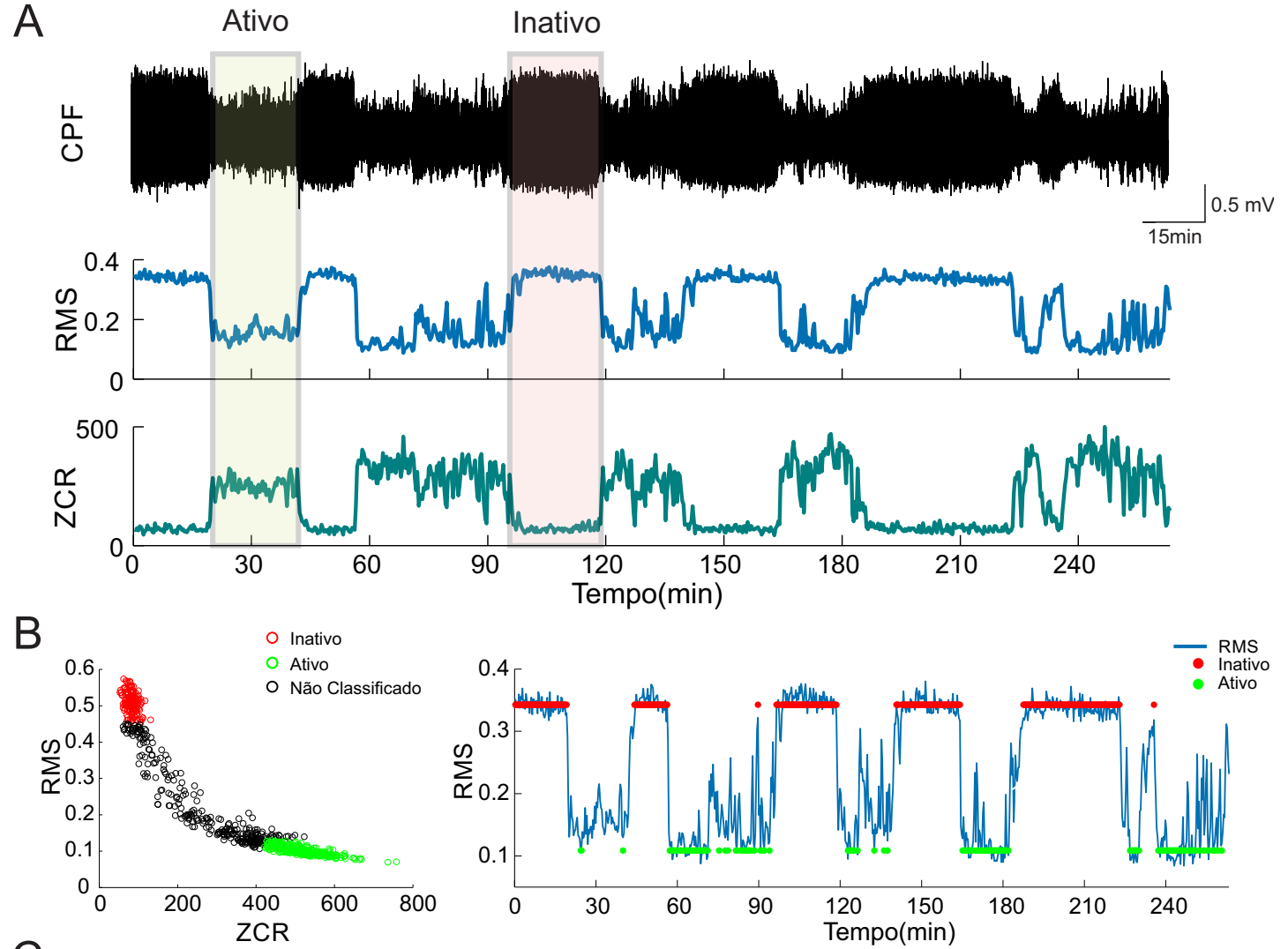

C
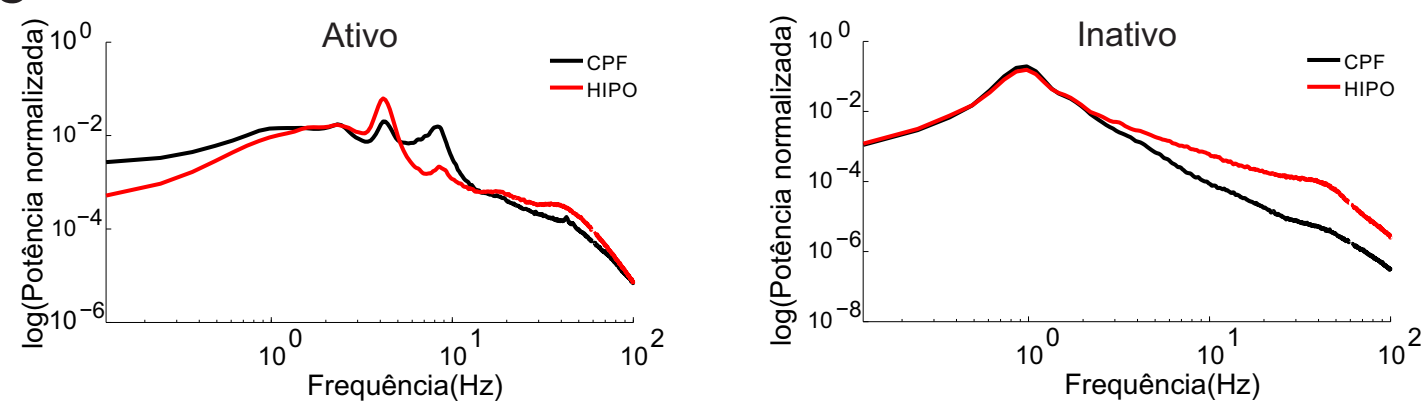

Figura 13 - Seleção de épocas nos estados Ativos e Inativos para realizar as análises oscilatórias. (A) LFP representativa de um animal seguido do cálculo do RMS e do ZCR. Um dos estados ativos está destacado em verde e um dos estados inativos está destacado em vermelho. Observa-se que o estado ativo apresenta um RMS baixo e um ZCR elevado e o estado inativo apresenta um RMS elevado e um ZCR baixo. (B) À esquerda - Scatter plot do RMS x ZCR utilizado para selecionar as épocas consideradas inativas e ativas, marcadas em vermelho e verde, respectivamente. As épocas não classificadas estão em preto. À direta - resultado da seleção no RMS: As épocas consideradas ativas e inativas estão marcadas no gráfico com suas respectivas cores. (C) PSDs médio de todas as épocas ativas (esquerda) e inativas (direita) do hipocampo e do CPF, selecionadas pelo scatter plot. Pode-se observar no PSD das épocas ativas uma maior potência na banda Theta tipo 2 e no PSD das épocas inativas uma maior potência na banda Low-Delta. 
Todos os PSDs apresentados neste trabalho foram calculados utilizando a função pwelch() do Matlab nos LFPs de cada época com frequência de amostragem de $500 \mathrm{~Hz}$, utilizando janela Hanning de 2500 pontos com sobreposição de 50\%. Após os cálculos, todos os PSD foram normalizados pela soma das potências.

Além dos PSDs foram calculados pro estado Ativo as potências nas seguintes bandas: Delta Baixo (Delta: 0,5 a $2 \mathrm{~Hz}$ ); Theta tipo 2 (Teta2: 3 a 5 Hz); Theta tipo 1 (Teta1: 5 a $10 \mathrm{~Hz}$ ); Gama Baixo (Gama: 30 a 55 Hz) e Gama Alto (Gama: 65 a $100 \mathrm{~Hz}$ ). Sendo que no estado Inativo apenas foi avaliada as bandas Delta Baixo e Gama Alto.

A análise de coerência de amplitude entre as duas regiões registradas foi realizada usando a função mscohere do Matlab, com janela de 4000 pontos e $75 \%$ de sobreposição.

\subsection{Análises Histológicas e Imunohistoquímicas}

As análises histológicas deste trabalho foram realizadas em colaboração com a pósdoc Ludmyla Kandratavicius e a doutoranda Mariana Monteiro. A avaliação da densidade neuronal foi realizada através da coloração de Hematoxilina-Eosina e também foi realizada imuno-histoquímica para detecção de BDNF, NGF, TrkA e TrkB nas seguintes regiões encefálicas: CA1, córtex entorrinal (ENT) e córtex pré-límbico (PL) da região pré-frontal.

\subsubsection{Densidade Neuronal}

Após o fim do registro, os animais receberam uma dose adicional de uretana para terem seus encéfalos perfundidos com $200 \mathrm{ml}$ de salina $0.9 \%$, seguido de $250 \mathrm{ml}$ de paraformaldeído (PFA) 4\%. Finalizada a perfusão os encéfalos foram removidos e imersos em PFA por 4 h e depois em etanol $70 \%$ por 1 dia para que depois fossem incluídos em parafina. Os blocos de parafina foram cortados em fatias coronais de $8 \mu \mathrm{m}$ de espessura, colocadas em lâminas gelatinizadas.

As secções das regiões encefálicas de interesse foram desparafinizadas em soluções de 
xilol, hidratadas e colocadas em uma solução de hematoxilina de Harris. Em seguida, as lâminas foram imersas em solução de álcool-ácido, que promove diferenciação de cor, e colocadas em solução de água amoniacal, que torna a púrpura em azul escuro. As lâminas foram então lavadas, parcialmente desidratadas e mergulhadas em solução de eosina alcoólica (1\% p/v em etanol 95\%). Concluído este procedimento, as lâminas foram enxaguadas repetidas vezes em etanol 70\%, desidratadas até etanol absoluto e finalmente diafanizadas em xilol.

\subsubsection{Imunohistoquímica}

O protocolo utilizado na imuno-histoquímica foi realizado seguindo o procedimento padronizado pelo nosso laboratório (KANDRATAVICIUS et al., 2013),(KANDRATAVICIUS et al., 2014) utilizando os seguintes anticorpos:

- Rabbit anti-NGF, Santa Cruz (sc-5634), diluído a 1:100 em blocking buffer

- Rabbit anti-BDNF IgG Chemicon, diluido a 1:40 em blocking buffer

- Rabbit anti-TrkA, Santa Cruz (sc-11), diluido a 1:50 em blocking buffer

- Rabbit anti-TrkB, Santa Cruz (sc-12), diluido a 1:50 em blocking buffer

Todos os anticorpos secundários utilizados foram o E0353, Dako, diluído a 1:200 em blocking buffer.

A primeira etapa da imuno-histoquímica foi a desparafinização das lâminas em estufa histológica e em solução de xilol-etanol absoluto. Após a desparifinização segue a etapa de hidratação, mergulhando as lâminas em soluções com concentrações decrescentes de álcoois. Depois foi realizada a recuperação antigênica, que resulta na exposição mais efetiva de epitopos protéicos do tecido. A próxima etapa foi o bloqueio dos grupamentos aldeídos livres, que tem por objetivo impedir a formação de compostos instáveis, o que impediria a ligação dos anticorpos primários aos sítios específicos. Em seguida, foi realizada a incubação com o anticorpo primário e o secundário. Após a revelação com diaminobenzidina (DAB, Sigma-Aldrich, USA), as lâminas foram desidratadas em soluções com concentrações crescentes de etanol, e finalmente xilol. 
As imagens digitais das seções foram obtidas no microscópio Zeiss Axio Imager acoplado a uma camera de alta resolução. Utilizando o programa AxioVision, com um aumento de 200x, as imagens foram digitalizadas e salvas em formato TIF para análise com o software Image J. Este programa nos permite selecionar, de forma padronizada, um limiar específico para a marcação da expressão de cada proteína analisada, sendo desprezadas as marcações de fundo.

\subsection{Análise Estatística}

Os dados neste trabalho que estão representados pelo valor médio e seu erro padrão de todos os grupos (ou valor médio e a dispersão de seus valores) foram submetidos à ANOVA de uma via seguida pelo teste post hoc de Bonferroni ou de Tukey.

Os resultados apresentados que possuem o tempo como uma das variáveis, como nas análises de plasticidade ( $f P S P_{1}, f P S P_{2}$ e PPF), no campo aberto ou no Treino $\mathrm{x}$ Teste do reconhecimento de objeto, foram submetidos à ANOVA de duas vivas com medidas repetidas seguida pelo teste post hoc de Bonferroni ou de Tukey. Nos dados moleculares a comparação da densidade neuronal ao longo do tempo para cada grupo foi realizada utilizando o teste t-student. Todos os testes estatísticos foram realizados utilizando o programa SigmaStat (Systat, EUA), tendo como critério de significância estatística o valor de $\mathrm{p}<0,05$.

Também foi testada a existência de correlações lineares entre os resultados obtidos neste trabalho. Os testes de correlação foi realizado utilizando o coeficiente linear de Pearson obtida pela função $[R H O, P V A L]=\operatorname{corr}(\ldots)$ do Matlab, utilizando $\mathrm{p}<0,05$ como critério de significância estatística. 


\section{$5 \quad$ Resultados}

\subsection{Padronização da dose do tratamento crônico de nicotina}

Os experimentos a seguir serviram para decidir a dose de nicotina no tratamento. Inicialmente, com base na literatura (XU et al., 2012), foi testada a dose de $3 \mathrm{mg} / \mathrm{kg}$. Porém esta dose aplicada intraperitonial gerou no inicio do tratamento espasmos, clonia nas patas, hiperventilação, além disso esses animais apresentaram uma maior dificuldade de cicatrização fazendo com que estivessem mais suscetíveis à infecções. Devido a esses efeitos colaterais esta dose não foi levada adiante no tratamento dos animais injetados com STZ, porém houve o esforço em fazer com que os animais que iniciaram o tratamento na dose de $3 \mathrm{mg} / \mathrm{kg}$ concluíssem o Experimento 1. Foram tratados 9 ratos nesta dose, um deles morreu com infecção no início do tratamento e apenas 6 conseguiram concluir o Experimento 1 até a eletrofisiologia, sendo que os dados de um deles teve que ser descartado por erro no posicionamento do eletrodo.

A segunda dose de nicotina testada foi de $1 \mathrm{mg} / \mathrm{kg}$. Os animais tratados com esta dose não apresentaram os efeitos agudos mencionados acima, apenas foi observado uma hiperlocomoção logo após a injeção em alguns ratos. Como a literatura apresenta vantagens da nicotina nesta dose (ALKADHI et al., 2012) foi decidido realizar o tratamento crônico com nicotina a $1 \mathrm{mg} / \mathrm{kg}$ nos animais injetados com STZ.

Esta Seção mostrará os resultados comportamentais e eletrofisiológico destas duas doses, $\mathrm{NIC}_{1 m g / k g}$ e $\mathrm{NIC}_{3 m g / k g}$, comparando com o grupo controle, CTR. 


\subsubsection{Ambas as doses de nicotina reduzem a atividade locomo- tora}

Ao avaliar a distância percorrida em blocos de 3 min (Fig. 14-A) houve uma redução significativa nos primeiros 3 min do grupo $\mathrm{NIC}_{1 m g / k g}$ em relação ao CTR e ao $\mathrm{NIC}_{3 m g / k g}$. Nos próximos 3 min tanto o $\mathrm{NIC}_{1 m g / k g}$ quanto o $\mathrm{NIC}_{3 m g / k g}$ foram diferentes em relação ao grupo controle [Interação tratamento x tempo: $F_{(8,132)}=2.797, \mathrm{p}<0.05$; ANOVA de duas vias com medidas repetidas, seguido teste post hoc de Bonferroni]. Porém, ao observar a locomoção total (Fig. 14-B), durante os 15 min monitorados, apenas o grupo $\mathrm{NIC}_{1 \mathrm{mg} / \mathrm{kg}}$ apresentou uma redução significativa, de $35 \%$, em relação ao controle $\left[F_{(2,32)}=4.806\right.$, $\mathrm{p}<0.05$; ANOVA de uma via simples, seguido teste post hoc de Bonferroni], também houve uma redução na locomoção do grupo $\mathrm{NIC}_{3 m g / k g}$ porém ela não foi significativa.

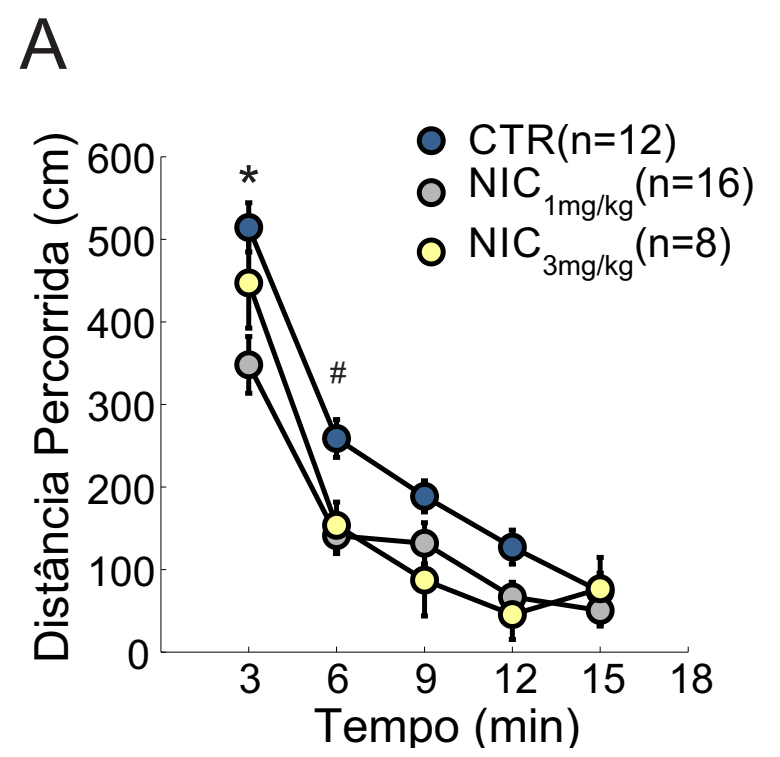

B

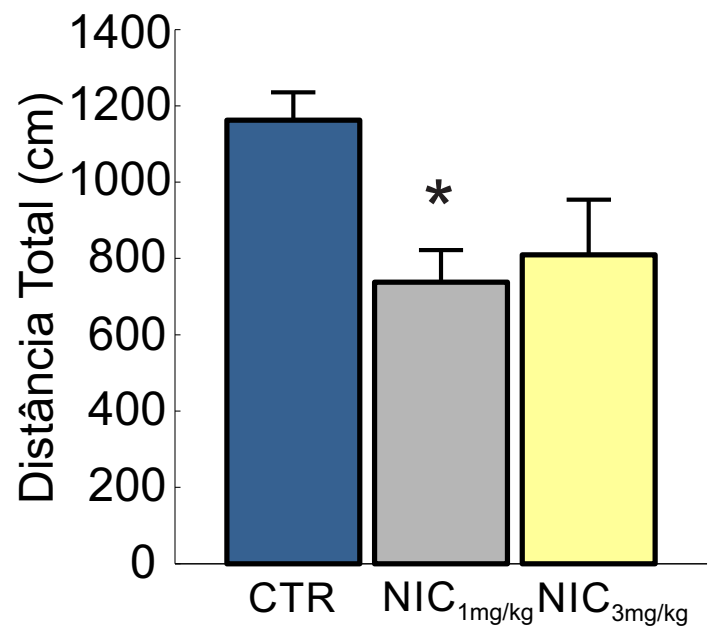

Figura 14 - Atividade locomotora dos grupos tratados com nicotina comparado com o controle. (A) Distância percorrida dos grupos medidos em blocos de 3 min. Houve uma diferença entre os grupos CTR vs. $\mathrm{NIC}_{1 m g / k g}$ e $\mathrm{NIC}_{3 m g / k g}$ vs. $\mathrm{NIC}_{1 m g / k g}$ nos primeiros $3 \mathrm{~min} ;{ }^{*} p<0.05$. No próximos 3 min os dois grupos tratados com nicotina se locomoveram menos que o grupo CTR; ${ }^{*} p<0.05$ CTR vs. $\mathrm{NIC}_{1 m g / k g}$ e CTR vs. $\mathrm{NIC}_{3 m g / k g}$ (ANOVA de duas vias medidas repetidas e teste post hoc de Bonferroni). (B) Comparação entre as distâncias medias totais dos grupos. A nicotina reduziu a locomoção total nas duas doses de nicotina porém apenas a dose de $1 \mathrm{mg} / \mathrm{kg}$ foi significativa; ${ }^{*} p<0.05 \mathrm{NIC}_{1 \mathrm{mg} / \mathrm{kg}}$ vs. CTR (ANOVA de uma via e teste post hoc de Bonferroni) . 


\subsubsection{Apenas a nicotina na dose de $3 \mathrm{mg} / \mathrm{kg}$ gera déficit no Re- conhecimento de Objeto}

Durante a tarefa de Reconhecimento de Objeto, apenas os grupos CTR e o $\mathrm{NIC}_{1 \mathrm{mg} / \mathrm{kg}}$ distinguiram o objeto novo durante a fase de teste (Fig. 15-A) [Comparação intra-grupo ao longo do treino/teste: $F_{(1,32)}=21.394, \mathrm{p}<0.001$; ANOVA de duas vias com medidas repetidas, seguido teste post hoc de Bonferroni]. Este resultado se torna claro ao comparar o Índice de Reconhecimento, durante o teste, dos três grupos (Fig. 15-B à esquerda) onde observa-se uma redução de aproximadamente $18 \%$ do Índice do grupo $\mathrm{NIC}_{3 m g / k g}$ em relação aos outros dois grupos [Interação tratamento x tempo: $F_{(2,32)}=14.240, \mathrm{p}<0.001$; ANOVA de duas vias com medidas repetidas, seguido teste post hoc de Bonferroni].

Ao analisar o tempo total de exploração (Fig. 15-B à direita) observa-se um redução de aproximadamente $48 \%$ no tempo dos animais tratados com nicotina, independente da dose utilizada $\left[F_{(2,32)}=6.064, \mathrm{p}<0.05\right.$; ANOVA de uma via simples, seguido teste post hoc de Bonferroni]. Porém, como mencionado acima, apenas o grupo $\mathrm{NIC}_{3 m g / k g}$ teve déficit no Índice de Reconhecimento e também não apresentou diferenças entre o treino e teste na Taxa de Discriminação (Fig. 15-C) [Comparação intra-grupo ao longo do treino/teste: $F_{(1,32)}=22.377, \mathrm{p}<0.001 ;$ ANOVA de duas vias com medidas repetidas, seguido teste post hoc de Bonferroni].
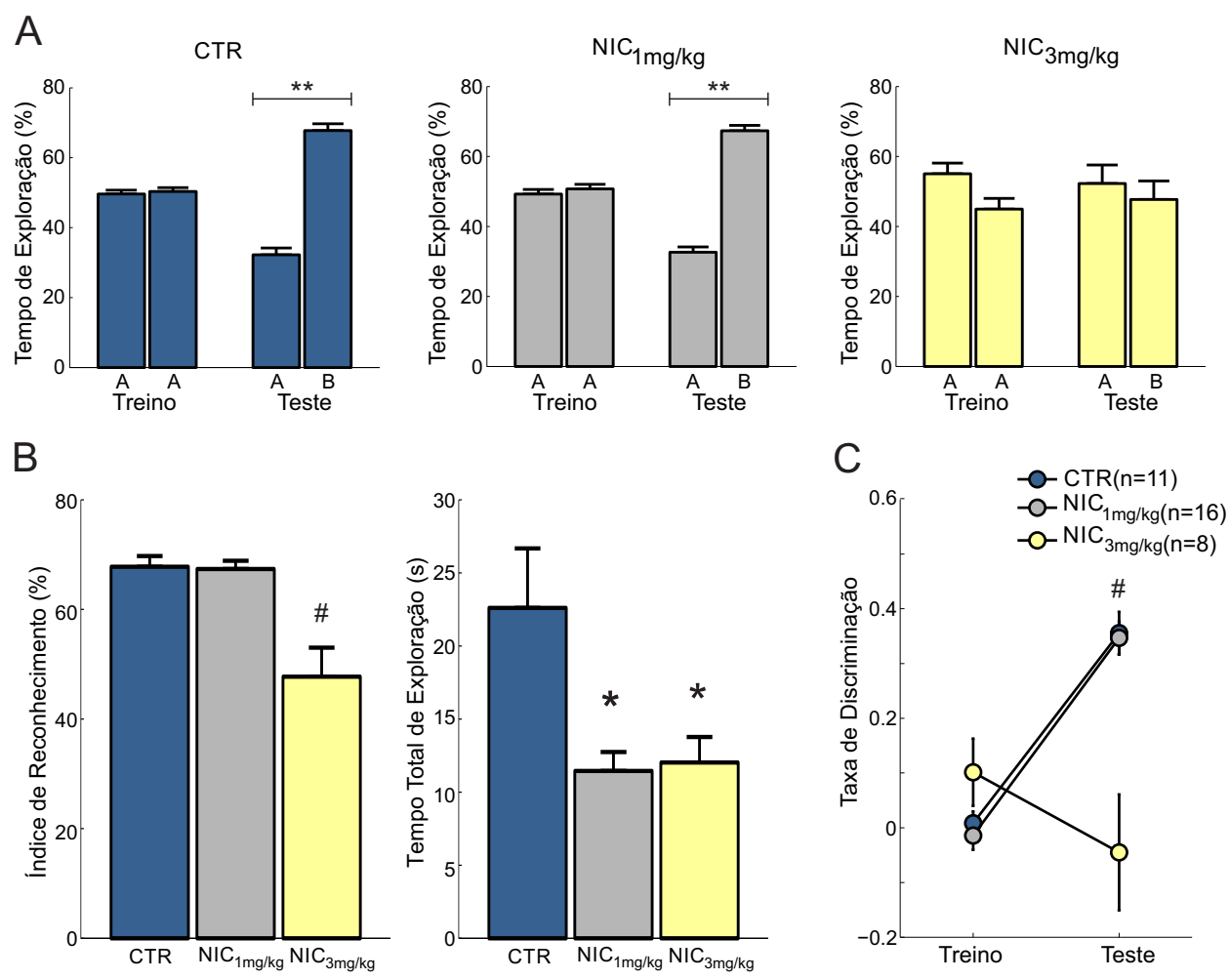
Figura 15 - Reconhecimento de objeto dos grupos tratados com nicotina. (A) Treino e teste dos grupos tratados com nicotina nas doses de $1 \mathrm{mg} / \mathrm{kg}$ e $3 \mathrm{mg} / \mathrm{kg}$ e do grupo controle. O grupo $\mathrm{NIC}_{3 m g / k g}$ não conseguiu reconhecer o objeto novo durante o teste; ${ }^{* *} p<$ $0.001 A_{\text {Teste }}$ vs. $A_{\text {Treino }}$ e $B_{\text {Teste }}$ vs. $A_{\text {Treino }}$; (ANOVA de duas vias com medidas repetidas e teste post hoc de Bonferroni). (B) Índice de reconhecimento e tempo total de exploração. Houve déficit no Índice de Reconhecimento do objeto novo apenas no grupo $\mathrm{NIC}_{3 m g / k g} ;{ }^{\#} p<0.01 \mathrm{NIC}_{3 m g / k g}$ vs. CTR e $\mathrm{NIC}_{1 m g / k g}$ (ANOVA de duas vias com medidas repetidas e teste post hoc de Bonferroni); Porém ao analisar o tempo total de exploração ambos os grupos tratados com nicotina exploraram menos que o grupo controle ${ }^{*} p<0.05 \mathrm{NIC}_{1 m g / k g}$ vs. CTR e $\mathrm{NIC}_{3 m g / k g}$ vs. CTR (ANOVA simples de uma via e teste post hoc de Bonferroni). (C) Taxa de Discriminação dos grupos com as duas doses de nicotina testadas e do grupo controle. Apenas o $\mathrm{NIC}_{3 m g / k g}$ não apresentou diferenças na Taxa de Discriminação entre o treino e teste; ${ }^{\#} p<0.001$ Treino vs. Teste do grupo CTR e $\mathrm{NIC}_{1 m g / k g}$ (ANOVA de duas vias com medidas repetidas e teste post hoc de Bonferroni).

\subsubsection{A dose de 1mg/ $\mathrm{kg}$ gera um aumento na eficiência da trans- missão basal}

A Figura 16 mostra as características dos potenciais evocados, na linha de base, de todos os animais incluídos nas análises eletrofisiológicas. As curvas de entrada e saída dos três grupos não apresentaram diferenças significativas entre si (Fig. 16 A).

Em relação à latência do primeiro pico negativo, os vaores médios obtidos tanto dos $f P S P_{1}$ quanto dos $f P S P_{2}$ estiveram entre 14.9 e 16.0ms (Fig. 16 B), valores típico da via CA1-CPFm como descrito em (LAROCHE; JAY; THIERRY, 1990). O valor médio das amplitudes do $f P S P_{1}$ entre 200 e $300 \mu \mathrm{V}$ e do $f P S P_{2}$ entre 500 e $750 \mu \mathrm{V}$ (Fig. $16 \mathrm{C}$ ). O PPF eliciado após o pulso pareado variou entre 2 e 2.5 (Fig. 16 D), também consistente com a literatura (KISS T.AND HOFFMANN; HAJóS, 2011).

Ao comparar as propriedades dos potenciais dos dois grupos tratados com nicotina e do grupo controle, apenas houve diferença significativa do grupo $\mathrm{NIC}_{1 \mathrm{mg} / \mathrm{kg}}$, em relação aos outros dois grupos, na amplitude do $f P S P_{1}\left[F_{(2,15)}=4.201, \mathrm{p}<0.05\right.$; ANOVA de uma via simples, seguido teste post hoc de Bonferroni $]$ e do $f P S P_{2}\left[F_{(2,15)}=4.631, \mathrm{p}<0.05\right.$; ANOVA de uma via simples, seguido teste post hoc de Bonferroni]. Os potenciais do $\mathrm{NIC}_{3 m g / k g}$ não apresentaram diferenças significativas em relação ao grupo controle. 


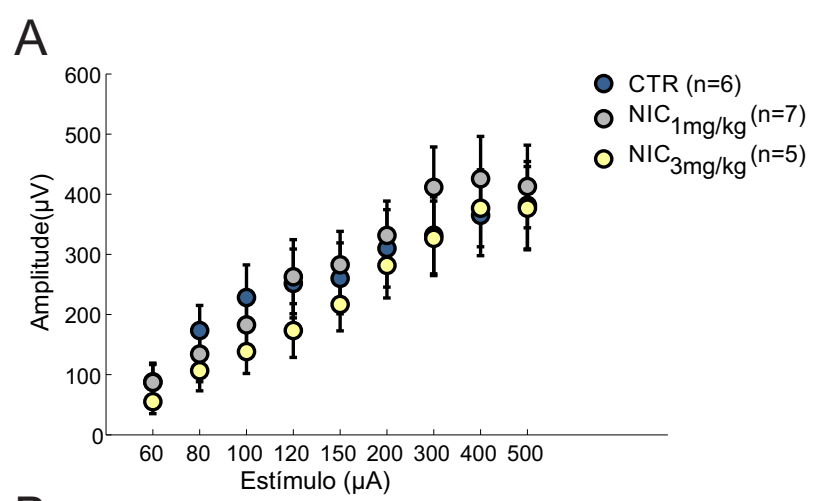

$\mathrm{B}$
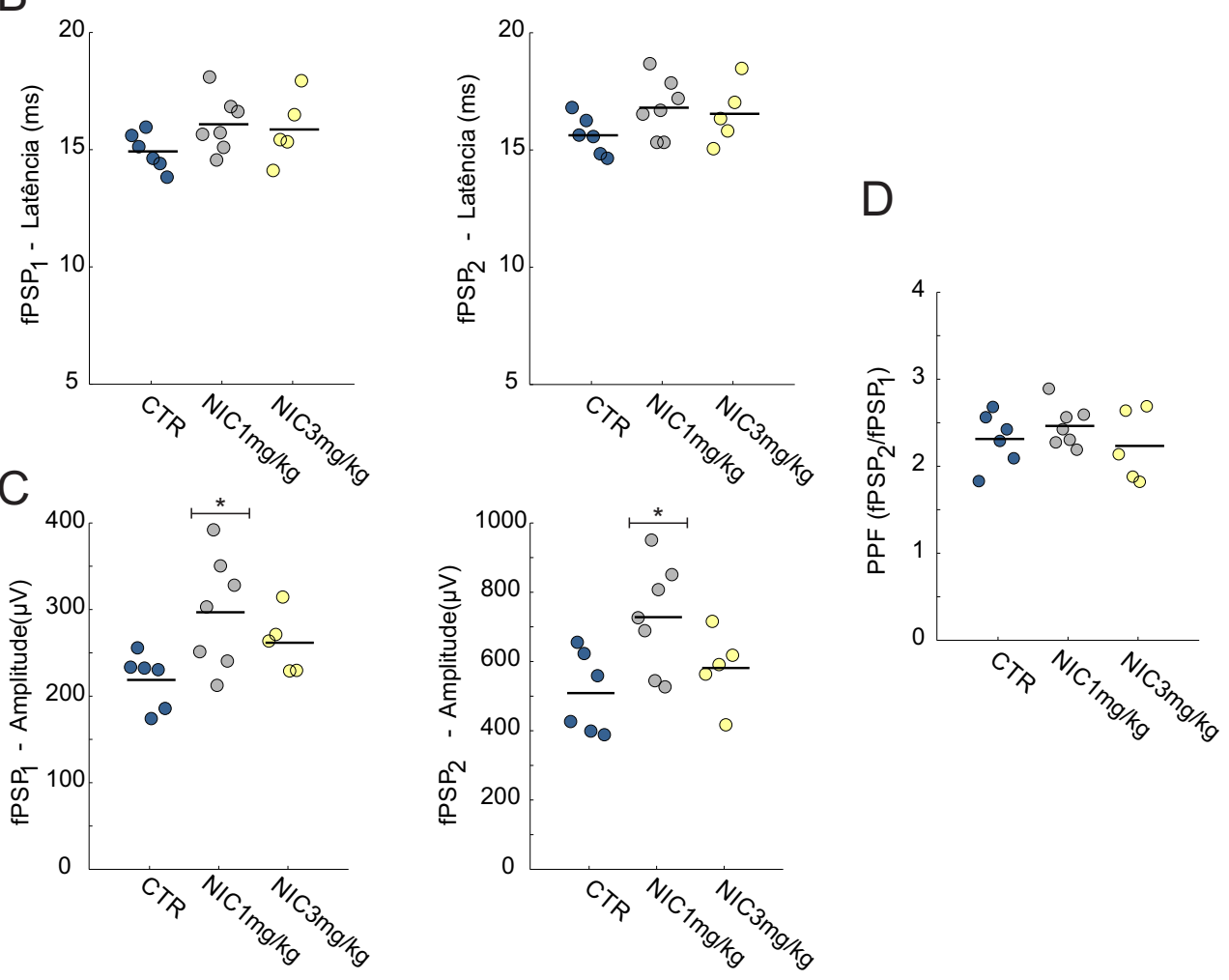

Figura 16 - Características dos potenciais registrados na linha de base dos grupos tratados com $\mathrm{NIC}_{1 m g / k g}, \mathrm{NIC}_{3 m g / k g}$ e CTR. (A) Curvas de entrada e saída (E/S) de todos os animais incluídos nas análises. Não foram encontradas diferenças significativas entre as curvas de $\mathrm{E} / \mathrm{S}$ dos grupos (ANOVA de duas vias medidas repetidas; $\mathrm{p}>0.05$ ), dados expressos como media +/- erro padrão. (B) Latência dos $f P S P_{1}$ e $f P S P_{2}$. (C) Amplitude dos $f P S P_{1}$ e $f P S P_{2}$. Apenas houve diferenças na amplitude dos $f P S P_{1}$ e $f P S P_{2}$ do grupo $\mathrm{NIC}_{1 \mathrm{mg} / \mathrm{kg}}$, em nenhum dos dados analisados houve diferenças significativas do grupo $\mathrm{NIC}_{3 m g / k g}$ comparado com o controle. (D) PPFs $\left(f P S P_{2} / f P S P_{1}\right)$ eliciado pelos potenciais evocados. Em $(\mathrm{B})(\mathrm{C})$ e $(\mathrm{D})$ dados expressos como media + dispersão dos valores; ${ }^{*} p<0.05 \mathrm{NIC}_{1 m g / k g}$ vs. CTR e $\mathrm{NIC}_{3 m g / k g}$ (ANOVA simples de uma via e teste post hoc de Bonferroni). 


\subsubsection{A nicotina na dose de $3 \mathrm{mg} / \mathrm{kg}$ gera déficit na LTP}

O efeito das duas doses de nicotina sobre a transmissão basal e sobre a plasticidade pré-sináptica na via CA1-CPFm pode ser observado na Figura 17. De forma global, existe um déficit na transmissão sináptica apenas do grupo $\mathrm{NIC}_{3 m g / k g}$, representada pela redução da amplitude do $f P S P_{1}$ [Tratamento: $F_{(2,15)}=6.975, \mathrm{p}<0.05$; ANOVA de duas vias com medidas repetidas, seguido teste post hoc de Tukey].

Além disso, as duas doses de nicotina geraram uma redução significativa tanto na indução quanto na manutenção da LTP no $f P S P_{2}$ durante praticamente as quatro horas monitoradas [Interação tratamento x tempo: $F_{(52,390)}=1.399, \mathrm{p}<0.05$; ANOVA de duas vias com medidas repetidas, seguido teste post hoc de Tukey]. Este resultado também pode ser confirmado ao observar apenas o efeito do tratamento, que mostra uma a redução de aproximadamente $20 \%$ na amplitude do $f P S P_{2}$ dos dois grupos tratados em relação ao controle [Tratamento: $F_{(2,15)}=8.334, \mathrm{p}<0.005$; ANOVA de duas vias com medidas repetidas, seguido teste post hoc de Tukey]. Porém o tratamento não foi capaz de gerar nenhuma alteração na plasticidade pré-sináptica da via, isso pode ser observado pelo fato de não haver diferenças significativas na amplitude do PPF em nenhum tempo específico (durante as quatro horas monitoradas) e nem de forma global. 

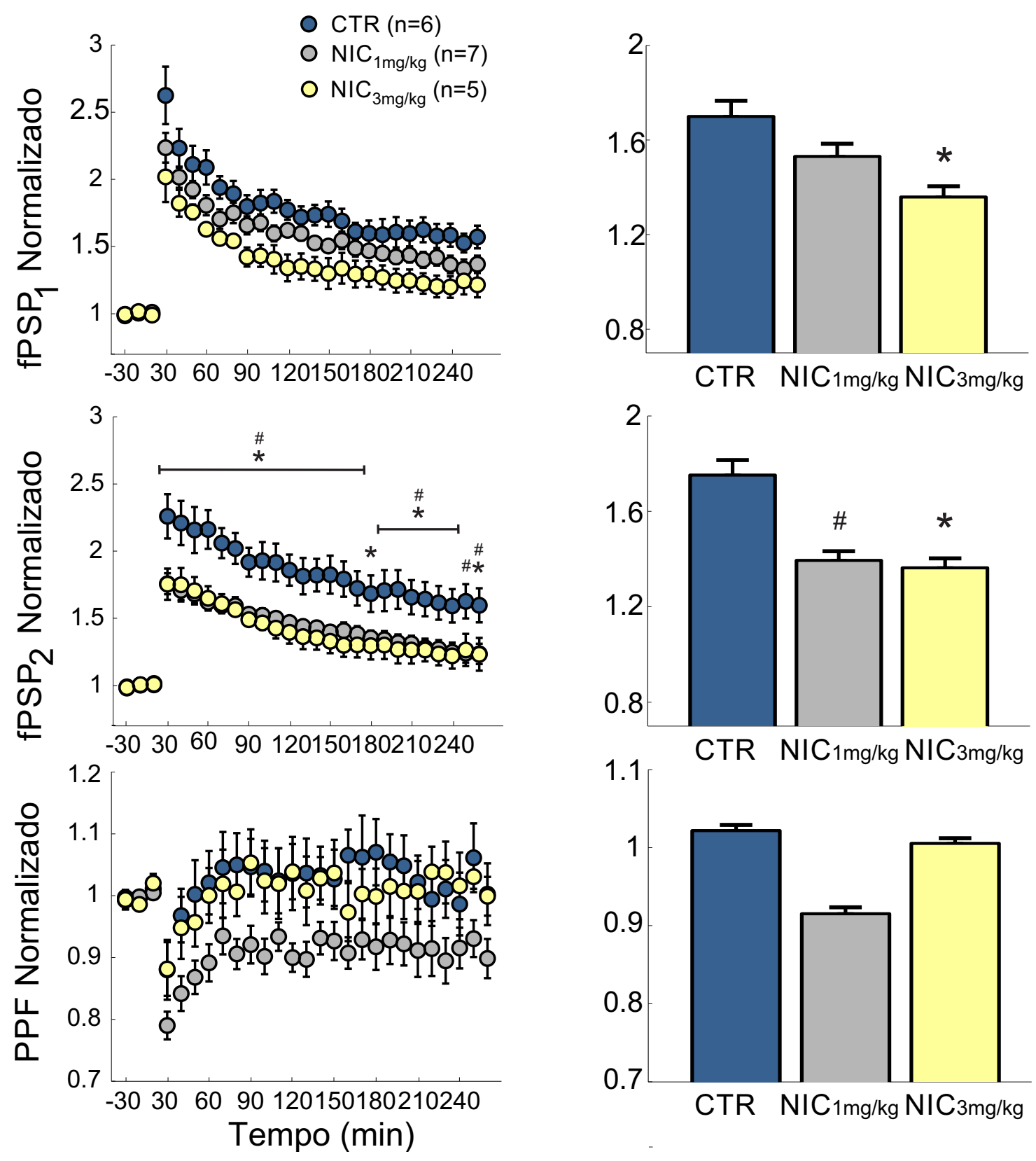

Figura 17 - fPSPs e PPF dos grupos tratado com as duas doses de nicotina e o controle. Ao analisar efeito do tratamento na amplitude do $f P S P_{1}$ observa-se uma redução significativa apenas do grupo $\mathrm{NIC}_{3 m g / k g}$, sem contudo apresentar diferenças significativas no teste post hoc. Na amplitude do $f P S P_{2}$ houve uma redução de ambos os grupos tratados com nicotina em praticamente em todo o tempo monitorado. $\mathrm{O}$ PPF não apresentou diferenças significativas devido ao tratamento, independente da dose. Dados expressos como média +/- erro padrão, separados em blocos de 10 min e normalizados pela média da linha de base; ${ }^{*} p<0.05$ CTR vs. $\mathrm{NIC}_{1 \mathrm{mg} / \mathrm{kg}}$; ${ }^{*} p<0.05$ CTR vs. $\mathrm{NIC}_{3 m g / k g}$ (ANOVA de duas vias com medidas repetidas, seguido de teste post hoc de Tukey). 


\subsection{Experimento1: Efeitos a curto prazo da STZ}

Esta Seção apresentará os resultados comportamentais e eletrofisiológicos do Experimento1, obtido com o grupo que recebeu a injeção icv. de STZ e o grupo STZ que foi tratado com nicotina (grupo STZnic). Junto a esses dois grupos serão apresentados os dados do grupos CTR e do NIC, que serviram de controles da injeção de STZ e do tratamento. Como foi mencionado na Seção 5.1, a dose escolhida para utilizar no tratamento de nicotina foi de $1 \mathrm{mg} / \mathrm{kg}$ por não ter gerado os déficits comportamentais e nem reduzir a eficiência na transmissão basal como ocorreu com a dose de $3 \mathrm{mg} / \mathrm{kg}$.

\subsubsection{A curto prazo a STZ e a nicotina reduz na locomoção}

Além do grupo apenas tratado com nicotina (grupo NIC), os animais injetados com STZ tratados ou não com nicotina (grupos STZ ou STZnic) se locomoveram menos no Campo Aberto comparado como controle (Fig. 18). Pode-se observar pela Figura 18-A que dos 15 min monitorados houve uma redução significativa dos três grupos (STZ, NIC e STZnic) em relação ao CTR durante os 6 min iniciais [Interação tratamento x tempo: $F_{(12,240)}=2.263, \mathrm{p}=0.01 ;$ ANOVA de duas vias com medidas repetidas, seguido teste post hoc de Bonferroni]. Ao avaliar a distância total de locomoção (Fig. 14-B) houve uma redução de aproximadamente $35 \%$ dos três grupos em relação ao CTR $\left[F_{(3,60)}=4.429\right.$, $\mathrm{p}<0.01$; ANOVA de uma via simples, seguido teste post hoc de Bonferroni]. 

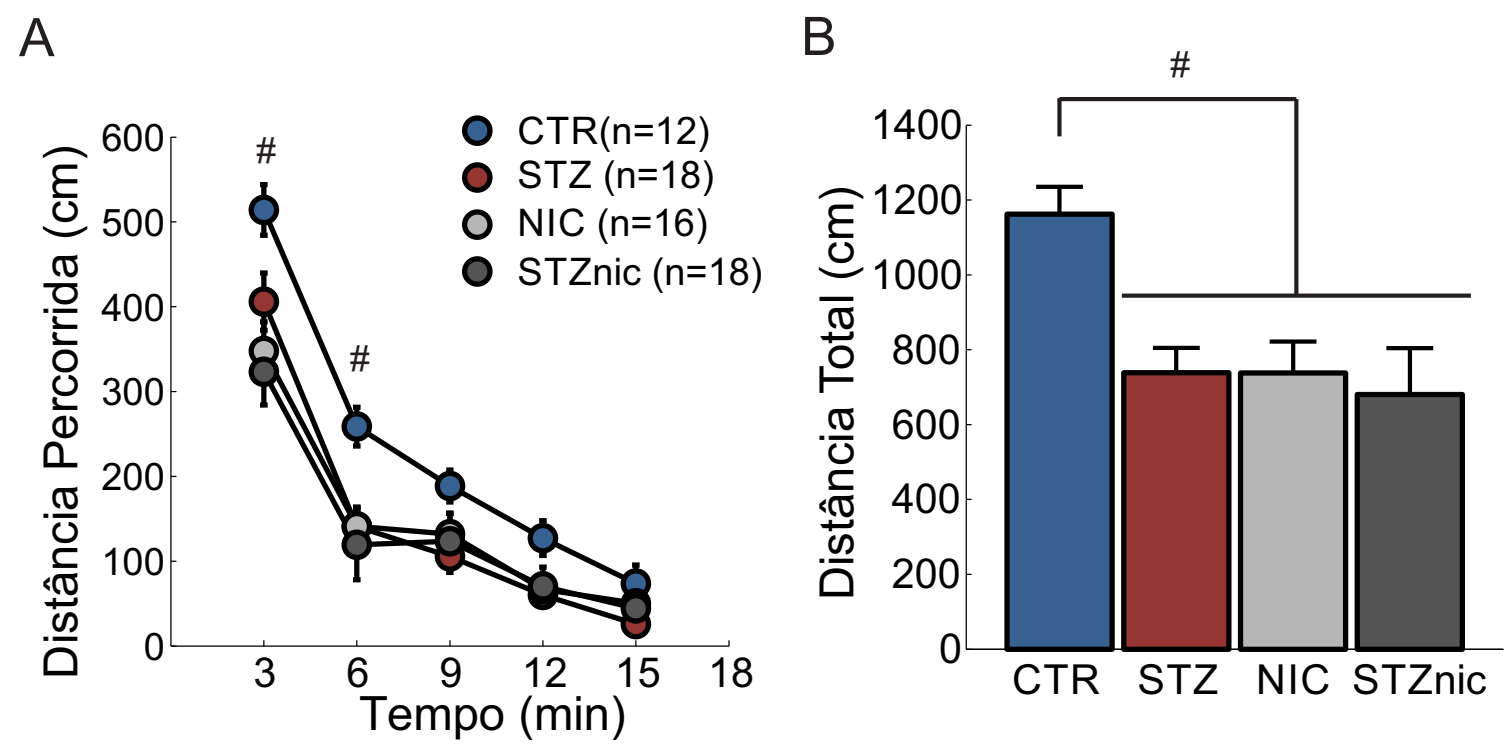

Figura 18 - Distância total de locomoção dos grupos do Experimento 1. (A) Distância percorrida dos grupos medidos em blocos de 3 min. Durante os seis minutos iniciais existe uma redução na atividade locomotora dos grupos STZ, NIC e STZnic em relação ao CTR; ${ }^{*} p<0.05$ CTR vs. STZ, NIC e STZnic em 3 min e 6 min (ANOVA de duas vias medidas repetidas, seguido de teste post hoc de Bonferroni). (B) Comparação entre as distâncias medias totais dos grupos. De forma global, a distância total dos três grupos (STZ, NIC e STZnic) também é significativamente menor que o CTR, ${ }^{\#} p<0.05$ (ANOVA simples de uma via, seguido de teste post hoc de Bonferroni).

\subsubsection{A curto prazo a STZ gera déficit no RO e o tratamento com nicotina reverte este déficit}

Na tarefa de Reconhecimento de Objeto do Experimento 1 apenas o grupo STZ não distinguiu o objeto novo do velho, ficando aproximadamente $50 \%$ do tempo total de exploração em cada objeto durante o teste (Fig. 19). O tratamento com nicotina conseguiu reverter este déficit visto que o grupo STZnic, e também o CTR e o NIC, ficaram aproximadamente $67 \%$ do tempo total de exploração no objeto novo [Comparação intra-grupo ao longo do treino/teste: $F_{(1,50)}=143.287, \mathrm{p}<0.001$; ANOVA de duas vias com medidas repetidas, seguido teste post hoc de Bonferroni]. Consequentemente, ao analisar a Taxa de Discriminação também pode-se observar que apenas o grupo STZ apresentou dificul- 
dades em discriminar o treino do teste [Comparação intra-grupo ao longo do treino/teste: $F_{(1,50)}=159.163, \mathrm{p}<0.001 ;$ ANOVA de duas vias com medidas repetidas, seguido teste post hoc de Bonferroni].
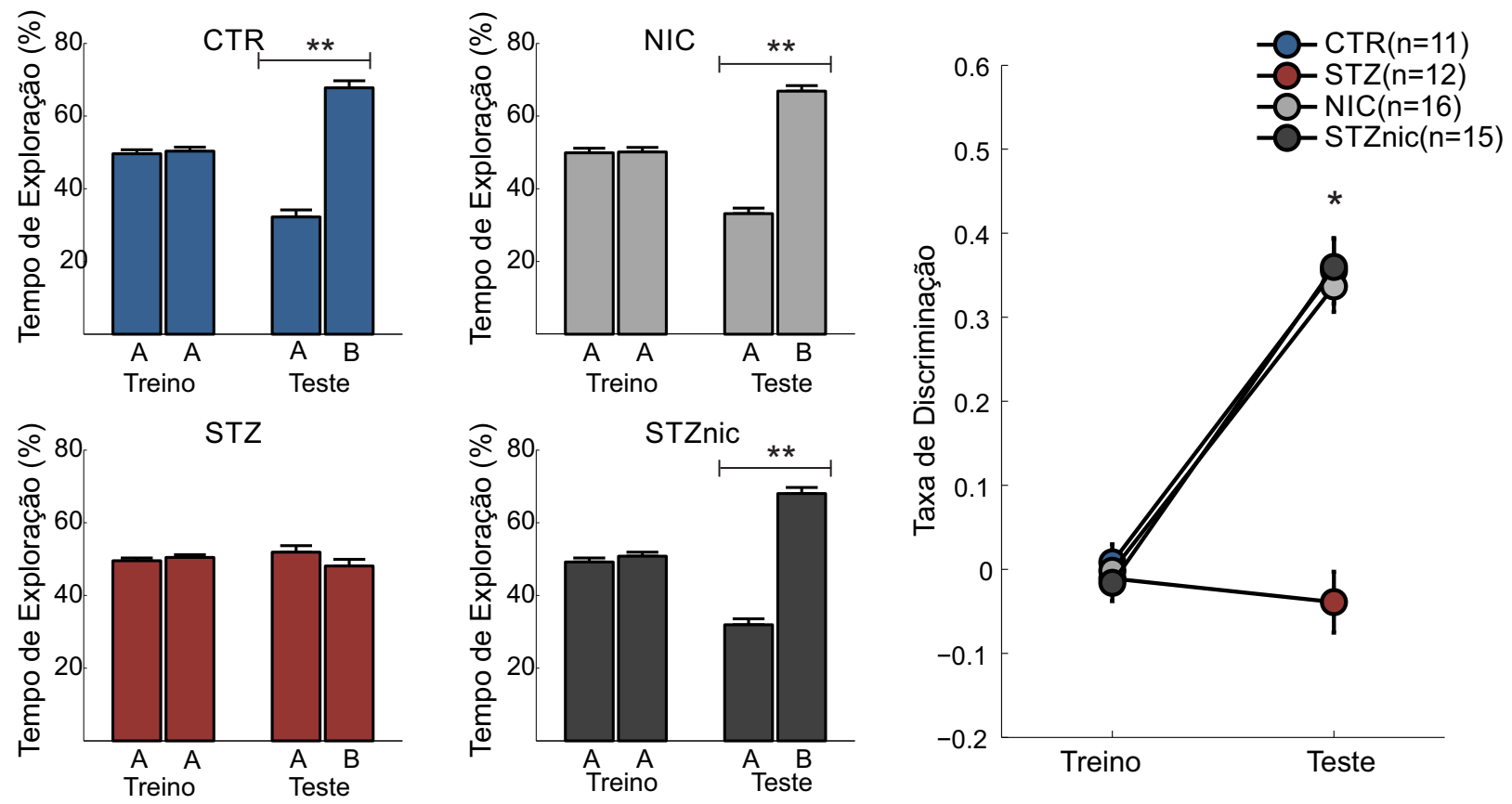

Figura 19 - Treino e teste 1 mês após a injeção de STZ/aCSF, dos grupos do Experimento 1. Os quatro gráficos da esquerda mostram a porcentagem do tempo de exploração que o grupo permaneceu em cada objeto durante o treino e o teste, apenas o grupo STZ apresentou déficit na memória de reconhecimento durante o teste, permanecendo durante o mesmo intervalo de tempo explorando o objeto novo e o velho. O gráfico da direita mostra a Taxa de Discriminação dos quatro grupos e indica que o único grupo que não discriminou o treino do teste foi o STZ; ${ }^{* *} p<0.001 A_{\text {Teste }}$ vs. $A_{\text {Treino }}$ e $B_{\text {Teste }}$ vs. $A_{\text {Treino }} ;{ }^{*} p<0.001$ Treino vs. Teste do grupo CTR, NIC e STZnic (ANOVA de duas vias com medidas repetidas, seguido de teste post hoc de Bonferroni). 
Este resultado fica ainda mais evidente ao comparar o Índice de Reconhecimento, durante o teste, dos quatro os grupos juntos (Fig. 20 à esquerda) onde pode-se observar uma redução de aproximadamente 30\% no Índice do grupo STZ comparado aos outros três [Interação tratamento x tempo: $F_{(3,50)}=18.470, \mathrm{p}<0.001$; ANOVA de duas vias com medidas repetidas, seguido teste post hoc de Bonferroni].

Em relação ao tempo total de exploração (Fig. 20 à direita) manteve-se apenas a redução do tempo do grupo NIC (mencionada na Seção 5.1), visto que a redução do grupo STZnic não foi significativa $\left[F_{(3,50)}=3.343\right.$, p $<0.05$; ANOVA de uma via simples, seguido teste post hoc de Bonferroni].
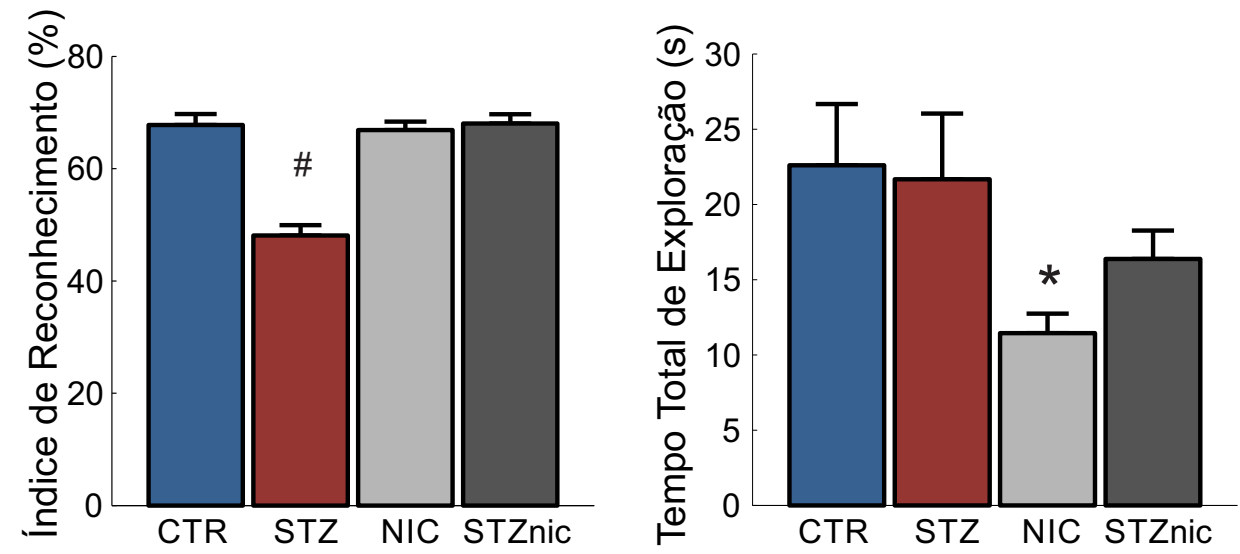

Figura 20 - Índice de Reconhecimento e Tempo Total de Exploração dos grupos do Experimento 1. No Índice houve redução apenas do grupo STZ, indicando um déficit na memória de reconhecimento deste grupo; ${ }^{\#} p<0.001$ STZ vs. CTR, NIC e STZnic. Em relação ao tempo total de exploração, apenas o grupo NIC apresentou uma redução significativa, porém sem acarretar em perda na memória de reconhecimento; ${ }^{*} p<$ 0.05, NIC vs. CTR (ANOVA simples de uma via, seguido de teste post hoc de Bonferroni). 


\subsubsection{Propriedades dos potenciais evocados na via CA1-CPFm nos grupos do Experimento 1: A nicotina melhora a efi- ciência na transmissão basal}

Assim como foi apresentado na Seção 5.1.3, a Figura 21 mostra as principais características dos potenciais na linha de base dos quatro grupos que foram submetidos ao Experimento 1. O valor médio da latência dos $f P S P_{1}$ e dos $f P S P_{2}$ se mantiveram entre 14.9 e $16.0 \mathrm{~ms}$ (Fig. 21-B), a média das amplitudes do $f P S P_{1}$ entre 190 e $300 \mu \mathrm{V}$ (Fig. 21 C) e o PPF eliciado após o pulso pareado continuou variando entre 2 e 2.5 (Fig. 21 D).

As quatro curvas de entrada e saída (Fig. 21-A), a latência e o PPF não apresentaram diferenças significativas entre os grupos [ANOVA de uma via simples, $\mathrm{p}>0.05]$. Porém ao avaliar a amplitude dos potenciais, manteve-se o aumento significativo do grupo NIC em relação aos demais três grupos do $f P S P_{1}\left[F_{(3,21)}=7.554, \mathrm{p}<0.05\right.$; ANOVA de uma via simples, seguido teste post hoc de Bonferroni $]$ e do $f P S P_{2}\left[F_{(3,21)}=6.260, \mathrm{p}<0.05\right.$; ANOVA de uma via simples, seguido teste post hoc de Bonferroni], indicando uma melhora na eficiência na transmissão basal gerada pelo tratamento de nicotina. 


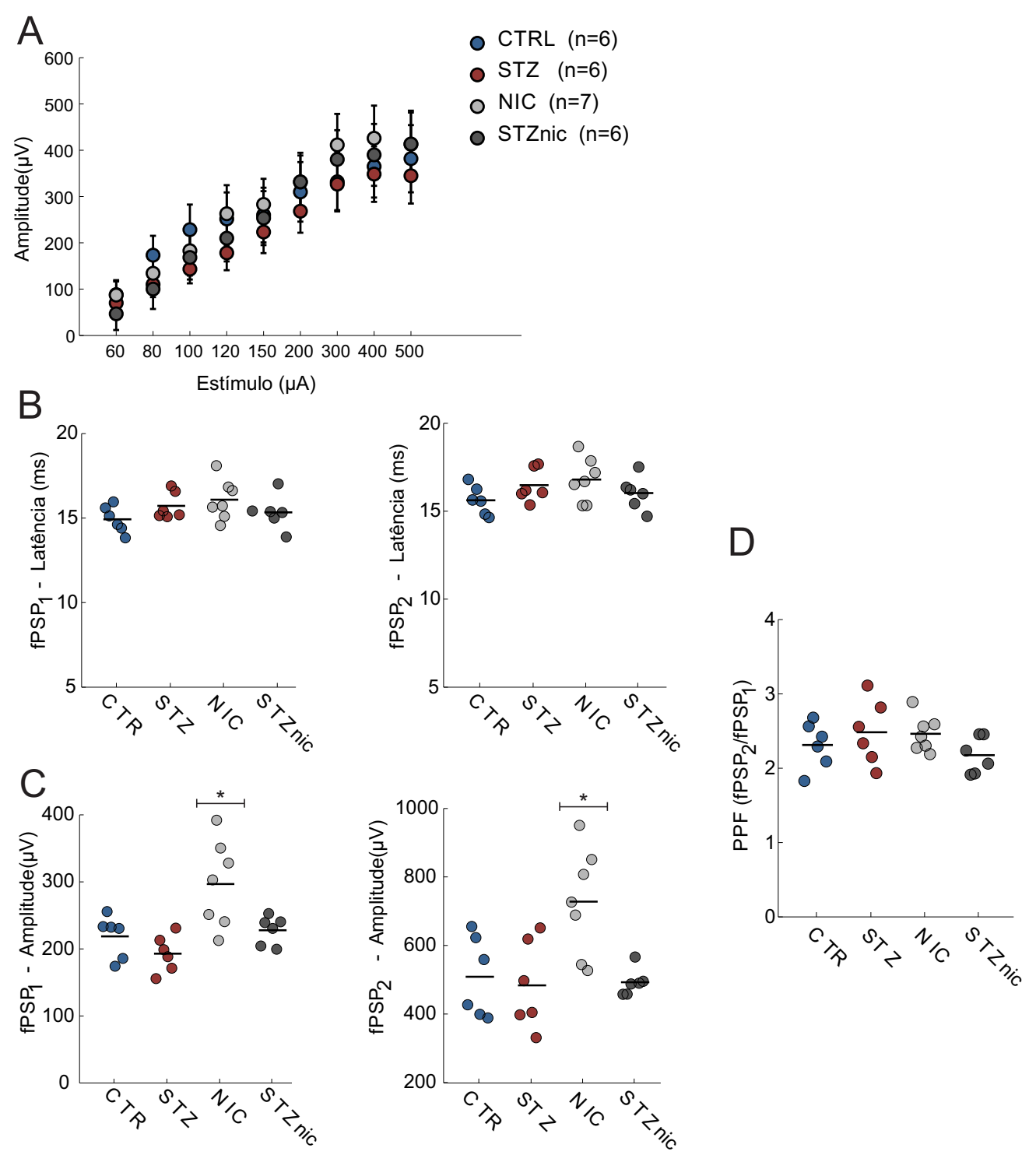

Figura 21 - Características dos potenciais registrados na linha de base durante o Experimento 1. (A) Curvas de entrada e saída (E/S) de todos os animais incluídos nas análises de potenciais. Não foram encontradas diferenças significativas entre as curvas de $\mathrm{E} / \mathrm{S}$ dos grupos (ANOVA de duas vias medidas repetidas; $\mathrm{p}>0.05$ ), dados expressos como media +/- erro padrão. (B) Latência dos $f P S P_{1}$ e $f P S P_{2}$. (C) Amplitude dos $f P S P_{1}$ e $f P S P_{2}$. Apenas foram encontradas diferenças significativa na amplitude dos $f P S P_{1}$ e $f P S P_{2}$ do grupo NIC comparado com os demais grupos. (D) PPFs eliciado pelos potenciais evocados. Em $(B)(C)$ e $(D)$ dados expressos como media + dispersão dos valores; ${ }^{*} p<0.05$ NIC vs. CTR, STZ e STZnic (ANOVA simples de uma via e teste post hoc de Bonferroni). 


\subsubsection{A curto prazo a nicotina reduz os déficit gerados pela STZ na plasticidade sináptica}

A próxima figura mostra os resultado das análises dos potenciais evocados dos grupos do Experimento 1, testados 1 mês após a injeção de STZ/aCSF. Na Figura 22 à direita o grupo STZ é comparado com o CTR, a partir dela pode-se observar que a STZ afeta tanto a indução quanto a manutenção da LTP do $f P S P_{1}$ e também do $f P S P_{2}$. No $f P S P_{1}$ existe uma redução de aproximadamente $26 \%$ na indução da LTP do grupo STZ e esta redução se mantém durante os 150 min iniciais [Interação tratamento x tempo: $F_{(26,260)}=$ 2.135, $\mathrm{p}<0.001$; ANOVA de duas vias com medidas repetidas, seguido teste post hoc de Tukey]. No $f P S P_{2}$ a redução da indução chega a aproximadamente $28 \%$ e se mantém significativamente menor durante as quatro horas monitoradas [Interação tratamento $\mathrm{x}$ tempo: $F_{(26,260)}=3.254, \mathrm{p}<0.001$; ANOVA de duas vias com medidas repetidas, seguido teste post hoc de Tukey]. Além de gerar uma redução na transmissão sináptica, a STZ também gera uma redução na plasticidade pré-sináptica da via. Este resultado pode ser confirmado pela queda significativa de aproximadamente $13 \%$ dos valores do PPF durante praticamente todo o tempo monitorado [Interação tratamento x tempo: $F_{(26,260)}=2.310$, $\mathrm{p}<0.001$; ANOVA de duas vias com medidas repetidas, seguido teste post hoc de Tukey].

O tratamento de nicotina nos animais injetados com STZ melhorou a eficiência na indução e manutenção da LTP da via e reverteu o déficit na plasticidade sináptica causada pela STZ. Este resultado é observado ao comparar o grupo STZnic com o CTR (Fig. 22centro), onde mostra que não existe diferenças na amplitude do $f P S P_{1}$ entre os dois grupos de forma global [Tratamento: $F_{(1,260)}=1.127, \mathrm{p}>0.05$; ANOVA de duas vias com medidas repetidas]. Porém a amplitude do $f P S P_{1}$ do grupo STZnic ainda apresenta uma queda significativa na indução da LTP, de aproximadamente 19\%, que acaba se igualando ao CTR 40 min após a indução [Interação tratamento x tempo: $F_{(26,260)}=1.992, \mathrm{p}<0.05$; ANOVA de duas vias com medidas repetidas, seguido teste post hoc de Tukey]. Em relação à amplitude do $f P S P_{2}$ e o PPF, o tratamento de nicotina conseguiu reverter os déficit presentes nos animais com STZ que não foram tratados, visto que o grupo STZnic não apresentou diferenças significativas em relação ao grupo controle nem no $f P S P_{2}$ e nem no PPF.

Ao comparar o grupo CTR com o NIC, que recebeu apenas o tratamento de nicotina (Fig. 22-direita) é possível observar que o tratamento crônico não alterou a amplitude do $f P S P_{1}$ [ $\mathrm{p}>0.05$; ANOVA de duas vias com medidas repetidas] porém reduz 
o $f P S P_{2}$ em aproximadamente $20 \%$ durante as 4 h de registro [Interação tratamento $\mathrm{x}$ tempo: $F_{(26,286)}=2.201, \mathrm{p}<0.05$; ANOVA de duas vias com medidas repetidas, seguido teste post hoc de Tukey]. O PPF do grupo NIC, apesar de existir uma tendência a redução devido ao tratamento de forma global [Tratamento: $F_{(1,260)}=4.530, \mathrm{p}=0.057$; ANOVA de duas vias com medidas repetidas], o teste post hoc mostra que houve reduções na maior parte do registro, indicado pela interação tratamento x tempo [Interação tratamento x tempo: $F_{(26,286)}=1.775, \mathrm{p}<0.05$; ANOVA de duas vias com medidas repetidas, seguido teste post hoc de Tukey]. Este resultado sugere que o tratamento crônico de nicotina a curto prazo não é capaz de alterar a LTP porém gera prejuízos na plasticidade pré-sináptica, indicada pela redução do PPF.

○ CTR $(n=6) \circ S T Z \quad(n=6)$
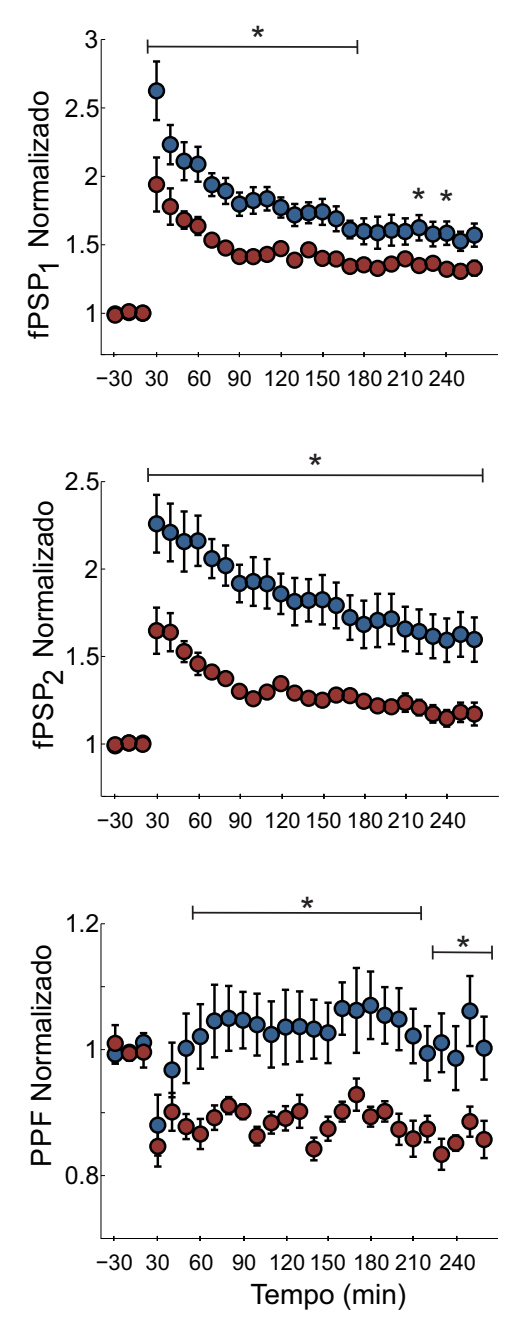

- CTR $(n=6) \circ$ STZnic $(n=6)$
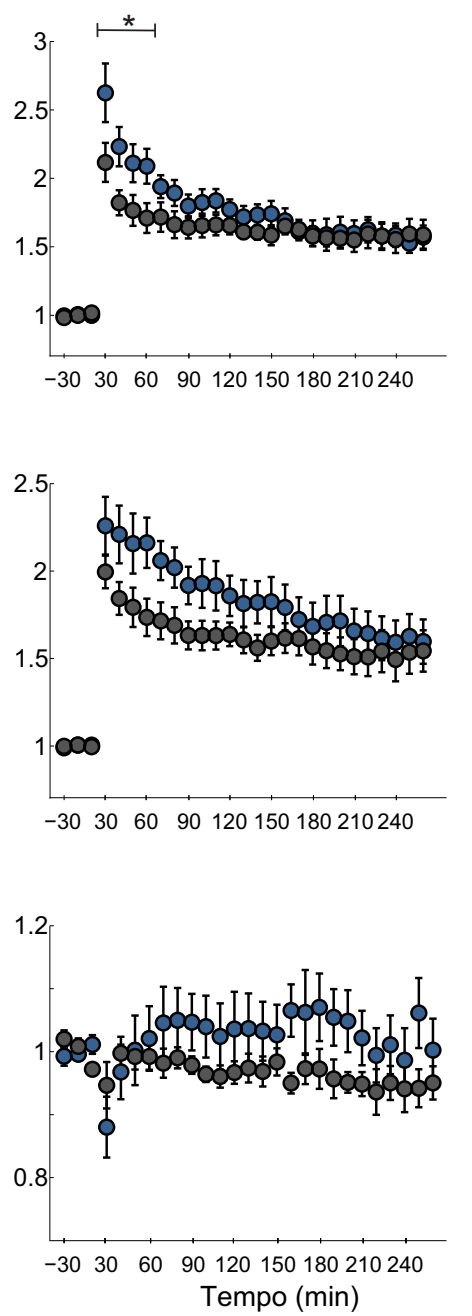

○TR $(n=6) \circ$ NIC $(n=7)$
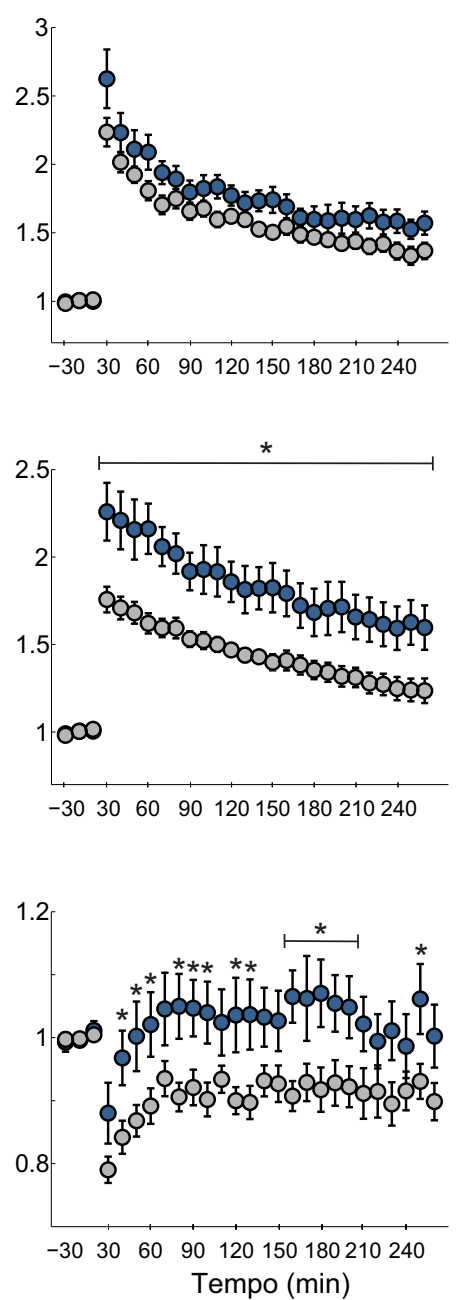

Figura 22 - fPSP e PPF dos grupos do Experimento 1. Ao comparar o grupo STZ com o CTR (à esquerda), observa-se que a STZ reduz de forma significativa a amplitude do $f P S P_{1}$ nos 150 min iniciais, do $f P S P_{2}$ durante as $4 \mathrm{~h}$ monitoradas e também do PPF praticamente durante todo o tempo monitorado. O tratamento com nicotina nos 
animais STZ reduziu as diferenças do $f P S P_{1}$ e reverteu o efeito da STZ no $f P S P_{2}$ e no PPF, visto que o grupo STZnic (centro) apresentou uma redução significativa na amplitude do $f P S P_{1}$ durante apenas 40 min após a indução da LTP e não apresentou diferenças nem no $f P S P_{2}$ e nem no PPF em relação ao CTR. Apenas o tratamento com nicotina, grupo NIC (à direita), não foi capaz de alterar a amplitude do $f P S P_{1}$. Porém o tratamento conseguiu reduzir a amplitude do $f P S P_{2}$ em relação ao grupo controle durante as $4 \mathrm{~h}$, o que acabou acarretando também em reduções no PPF em grande parte do registro. Dados expressos expressos como média +/erro padrão, separados em blocos de 10 min e normalizados pela média da linha de base; ${ }^{*} p<0.05$ (ANOVA de duas vias medidas repetidas, seguido de teste post hoc de Tukey).

Ao comparar os dois grupos injetados com STZ, tratado e não tratado com nicotina (Fig. 23), é possível constatar uma aumento global, do grupo STZnic em relação ao grupo STZ, de aproximadamente $22 \%$ na amplitude do $f P S P_{2}$ [Tratamento: $F_{(1,260)}=7.942$, p $>0.05$; ANOVA de duas vias com medidas repetidas, seguido teste post hoc de Tukey] e de $9 \%$ no PPF [Tratamento: $F_{(1,260)}=10.391, \mathrm{p}>0.05$; ANOVA de duas vias com medidas repetidas, seguido teste post hoc de Tukey]. O aumento do PPF confirma a melhora na plasticidade pré-sináptica ocasionada pelo tratamento. Apesar de existir um aumento na amplitude do $f P S P_{1}$ do grupo STZnic, ele não foi significativo e também não houve diferenças no teste post hoc em nenhum dos 3 casos. 

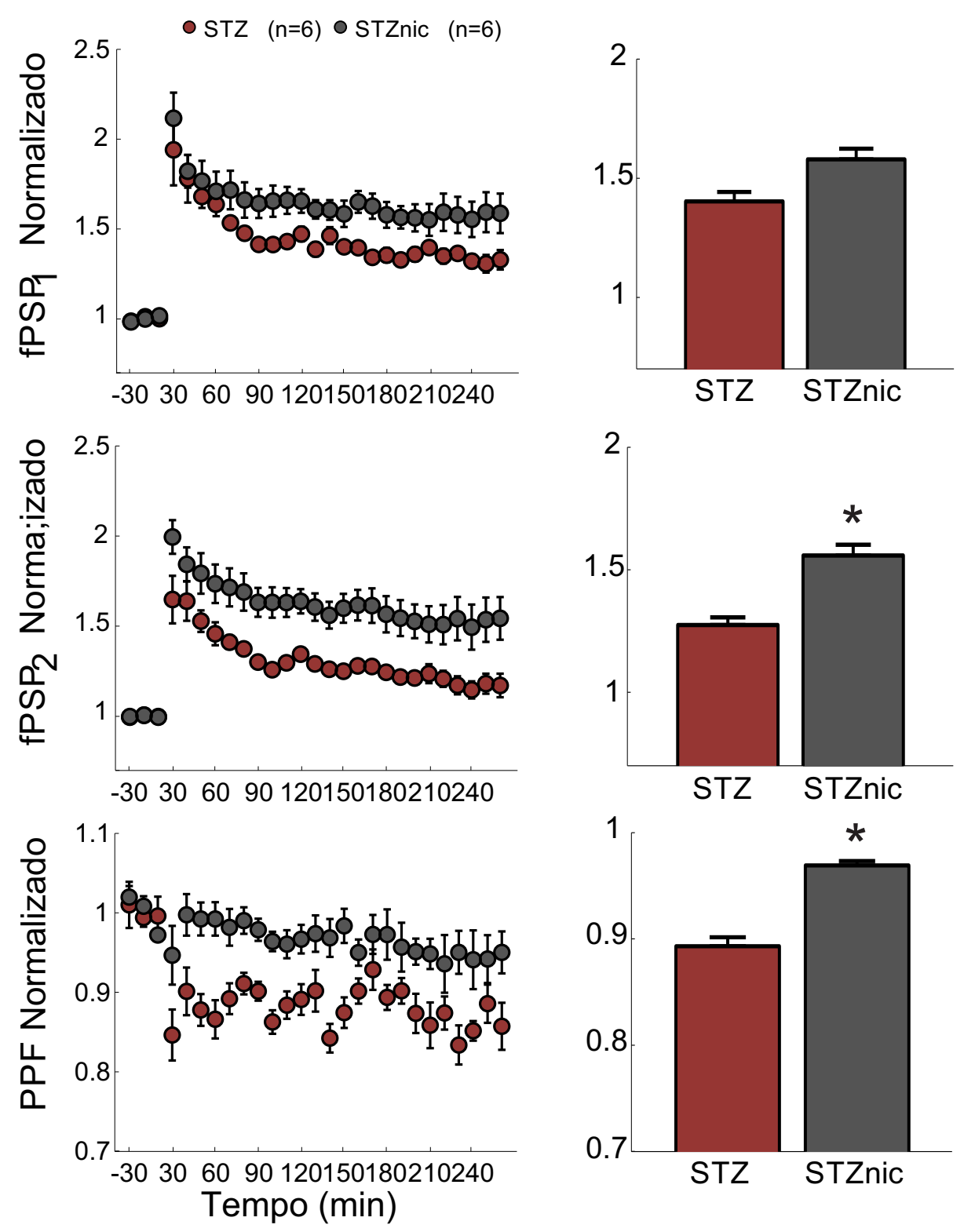

Figura 23 - fPSP e PPF dos grupos STZ tratados e não tratados do Experimento 1. Apenas houve aumento significativo na amplitude do $f P S P_{2}$ e do PPF de forma global do grupo STZnic em relação ao STZ, considerando apenas o tratamento. Nem os dois fPSPs e nem o PPF apresentaram diferenças no teste post hoc na interação tempo $\mathrm{x}$ tratamento. Dados expressos expressos como média +/- erro padrão, separados em blocos de 10 min e normalizados pela média da linha de base; ${ }^{*} p<0.05$ (ANOVA de duas vias medidas repetidas, seguido de teste post hoc de Tukey). 


\subsubsection{A curto prazo a STZ aumenta a potência de Gama Alto em CA1 e a nicotina aumenta a amplitude do pico em Teta 2 no CPFm}

As duas figuras a seguir mostram o espectro de potência (PSD) médio de cada grupo e o resultado das análises de potência realizadas nos animais do Experimento 1 nos dois estados - Ativos e Inativos - presentes nos animais anestesiados com uretana, como descrito em Métodos na Seção 4.7.

No CPFm pode-se observar que nas épocas Ativas os animais STZ tratados com nicotina apresentam uma redução da potência de Delta Baixo tanto em relação ao grupo CTR quanto ao grupo STZ $\left[F_{(3,20)}=6.882, \mathrm{p}<0.01\right.$; ANOVA de uma via simples, seguido teste post hoc de Tukey]. Na banda Teta 2 o efeito é exatamente o oposto visto que o grupo STZnic apresenta um aumento na potência desta banda quando comparado também com o grupo CTR e com o STZ $\left[F_{(3,20)}=4.866\right.$, p $<0.01$; ANOVA de uma via simples, seguido teste post hoc de Tukey]. Além disso, ao analisar as amplitudes do pico em Teta 2, presente nas épocas Ativas, houve uma aumento significativo dessa amplitude nos dois grupos tratados com nicotina (CTR-nic e STZ-nic) em relação ao CTR $\left[F_{(3,20)}=4.962\right.$, $\mathrm{p}<0.05$; ANOVA de uma via simples, seguido teste post hoc de Tukey]. Nas épocas Inativas nem as bandas Delta Baixo e Gama Alto apresentaram diferenças significativas [ p>0.05; ANOVA de uma via simples] (Fig. 24). 


\section{A - CPFm Inativo}
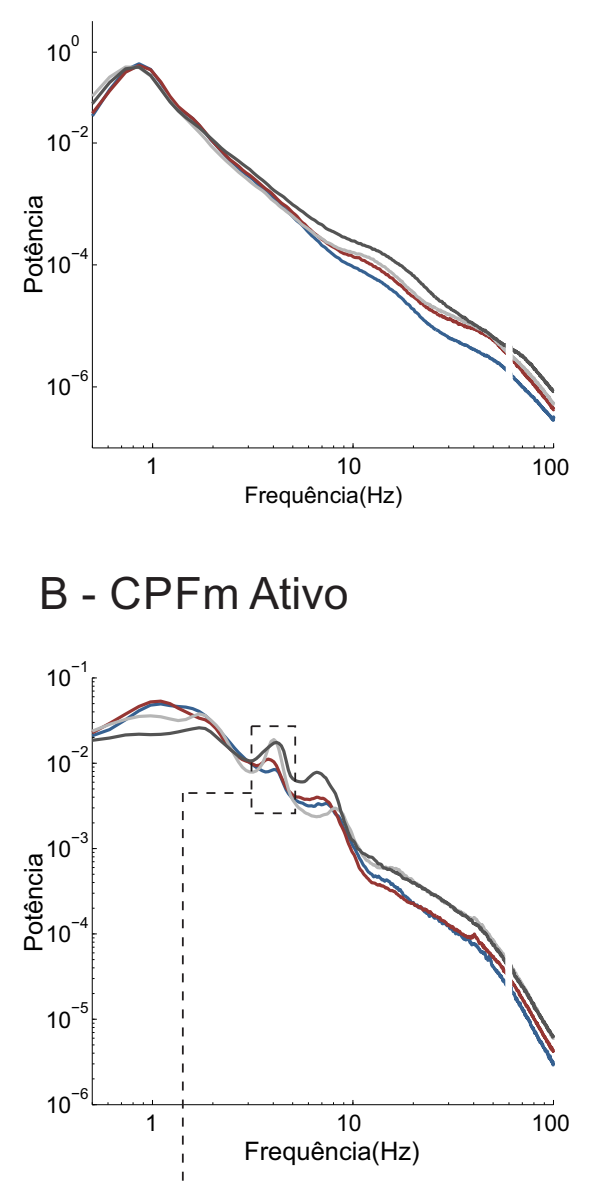
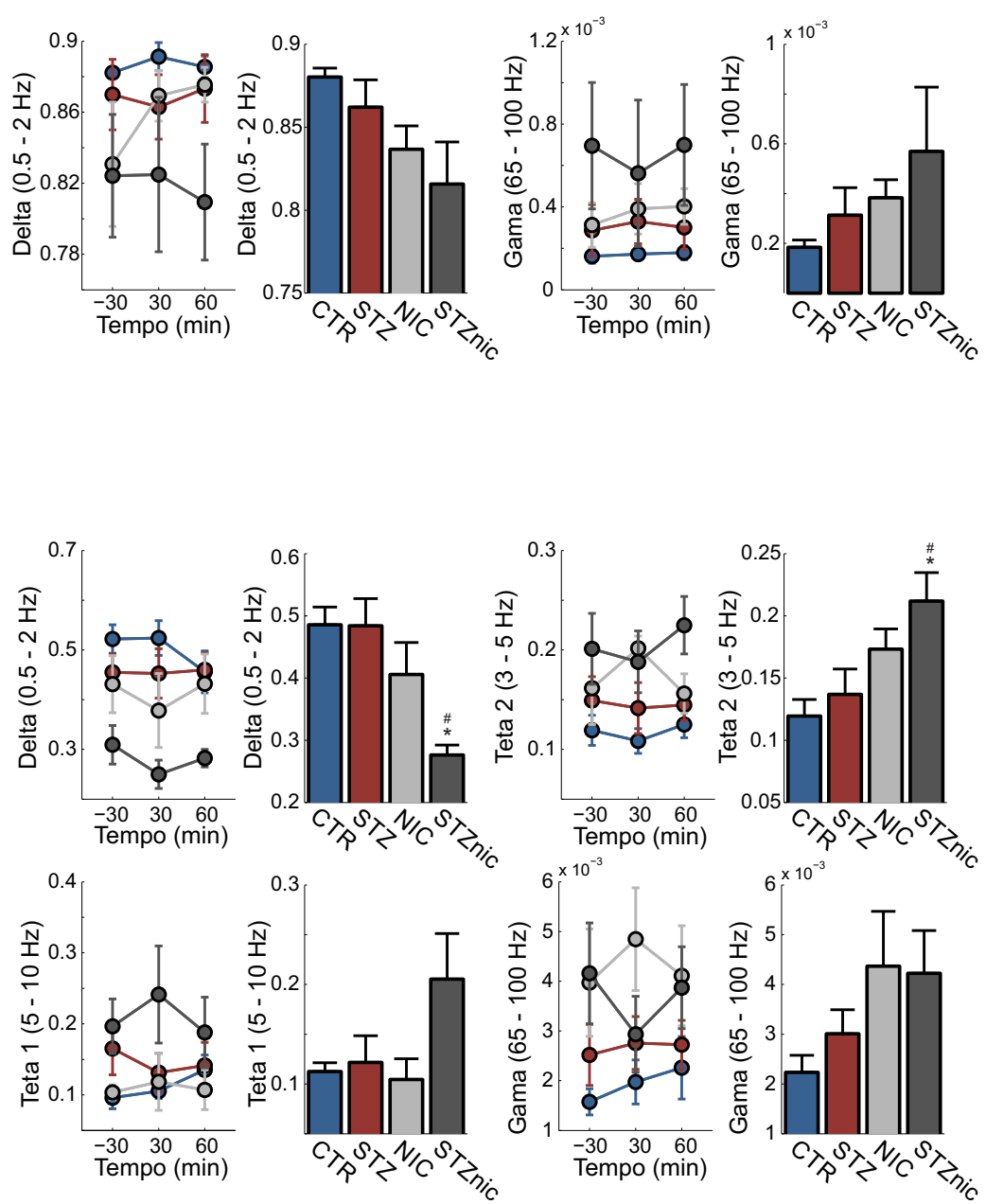
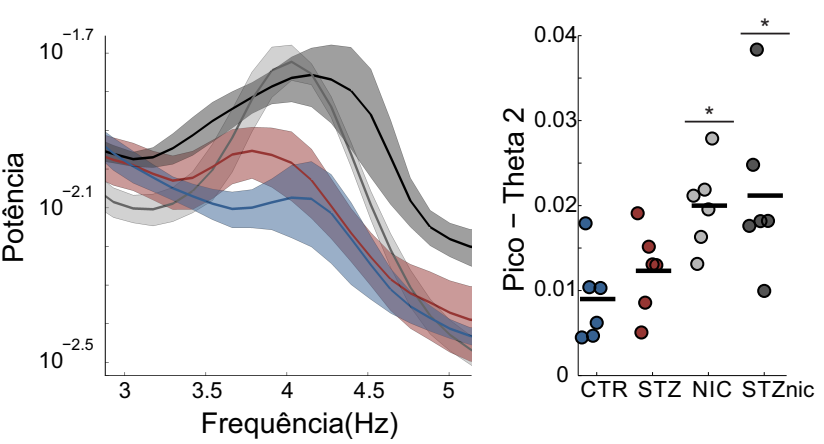

Figura 24 - Potência das LFPs Ativas e Inativas do CPFm dos grupos do Experimento 1. (A) à esquerda - PSD médio do CPFm dos quatro grupos no estado Inativo; à direta - potências média das duas bandas analisadas neste estado. (B) à esquerda - PSD médio do CPFm dos quatro grupos no estado Ativo; à direita - potências média das quatro bandas analisadas neste estado; em baixo - amplitude média do pico em Teta 2 e o PSD referente a esta banda. No estado Ativo, houve uma redução em 
Delta Baixo e um aumento significativo em Teta 2 do grupo STZnic em relação aos grupos CTR e STZ. A análise do pico em Teta 2 mostra um aumento da amplitude dos grupos NIC e STZnic em relação ao CTR. ${ }^{*} p<0.05$ vs. CTR; ${ }^{*} p<0.05$ vs. STZ (ANOVA simples de uma via, seguido de teste post hoc de Tukey).

Ao avaliar as potências das mesmas bandas no estado Inativo em CA1 (Fig. 25), houve um redução de todos os grupos em relação ao controle porém não significativa $\left[F_{(3,20)}=2.283, \mathrm{p}=0.061 ;\right.$ ANOVA de uma via simples $]$, pode-se observar também que a STZ aumenta significativamente a potência de Gama Alto quando se compara o grupo STZ com o CTR $\left[F_{(3,20)}=3.454, \mathrm{p}<0.05\right.$; ANOVA de uma via simples, seguido teste post hoc de Tukey]. No estado Ativo também houve aumento expressivo da potência de Gama Alto gerada pelo STZ e neste estado o grupo STZ é maior que o grupo CTR e NIC $\left[F_{(3,20)}=5.013, \mathrm{p}<0.05 ;\right.$ ANOVA de uma via simples, seguido teste post hoc de Tukey]. Além disso, houve uma redução da potência em Delta Baixo dos três grupos em relação ao CTR $\left[F_{(3,20)}=9.610, \mathrm{p}<0.05 ;\right.$ ANOVA de uma via simples, seguido teste post hoc de Tukey], um aumento da potência em Teta 1 também dos três grupos em relação ao CTR e também um aumento da potência do STZnic em relação ao NIC na mesma banda $\left[F_{(3,20)}=11.793, \mathrm{p}<0.05 ;\right.$ ANOVA de uma via simples, seguido teste post hoc de Tukey $]$. 
A - Ca1 Inativo

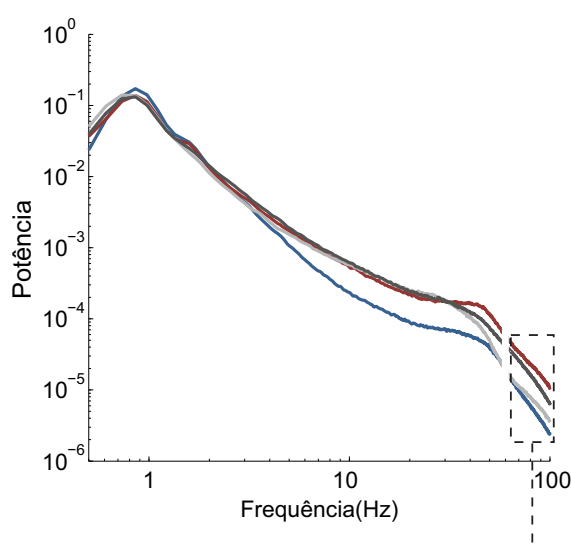

\section{B - Ca1 Ativo}

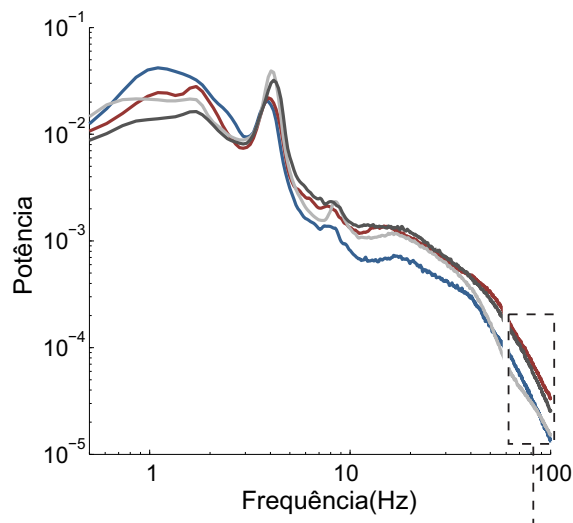

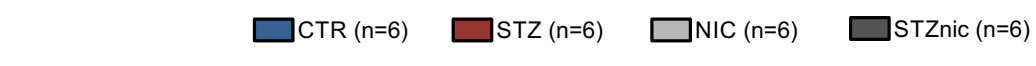
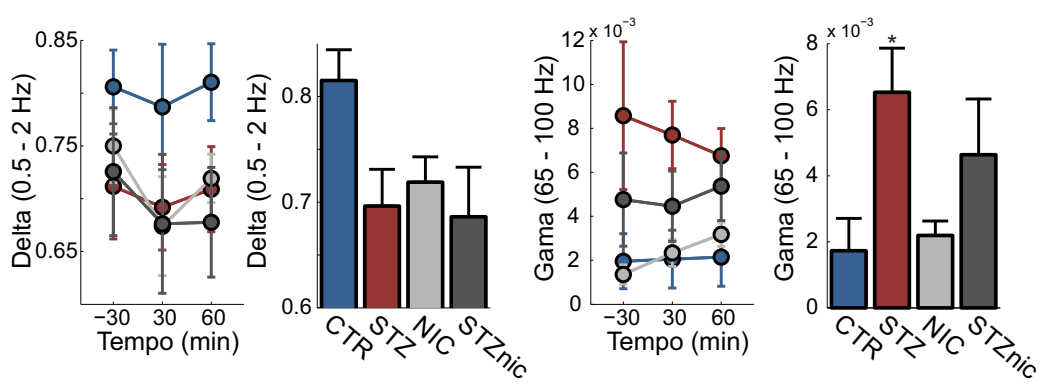
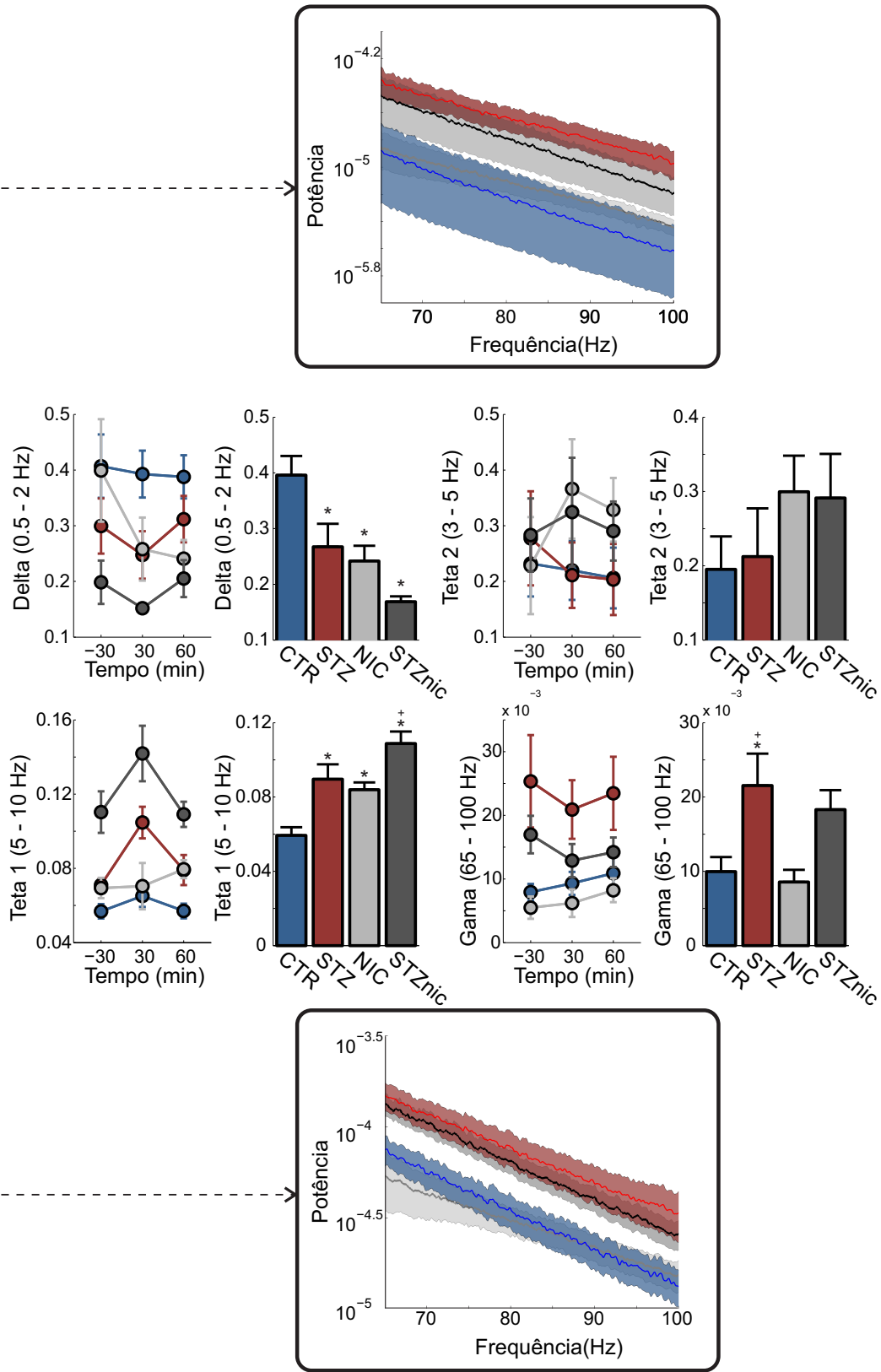

Figura 25 - Potência das LFPs Ativas e Inativas do hipocampo dos grupos do Experimento 1. (A) à esquerda - PSD médio do CA1 dos quatro grupos no estado Inativo; à direta - potências média das duas bandas analisadas neste estado; em baixo - PSD referente à banda Gama Alto no mesmo estado. (B) à esquerda - PSD médio do CA1 
dos quatro grupos no estado Ativo; à direita - potências média das quatro bandas analisadas neste estado; em baixo - PSD referente à banda Gama Alto. Houve um aumento significativo da potência em Gama Alto do grupo STZ em relação ao CTR nos dois estados. Também houve uma redução da potência em Delta Baixo e um aumento da potência de Teta 1 dos três grupos em relação ao grupo CTR. ${ }^{*} p<0.05$ vs. CTR ${ }^{+} p<0.05$ vs. NIC (ANOVA simples de uma via, seguido de teste post hoc de Tukey).

A Figura 26 mostra a correlação existente entre o pico em Teta 2 no CPF e Gama Alto no CA1 com os dados eletrofisiológicos. Existe uma correlação positiva ( $\mathrm{p}=0.028 ; \mathrm{R}=0.50)$ entre o pico em Teta 2 no CPFm com o PPF, indicando um aumento na plasticidade présináptica com o aumento da amplitude do pico em Teta 2. Além disso, foi encontrada um correlação negativa $(\mathrm{p}=0.025 ; \mathrm{R}=-0.51)$ entre Gama Alto do CA1 e a amplitude do primeiro potencial na linha de base o que mostra uma relação negativa entre a Gama Alto e a eficiência basal.
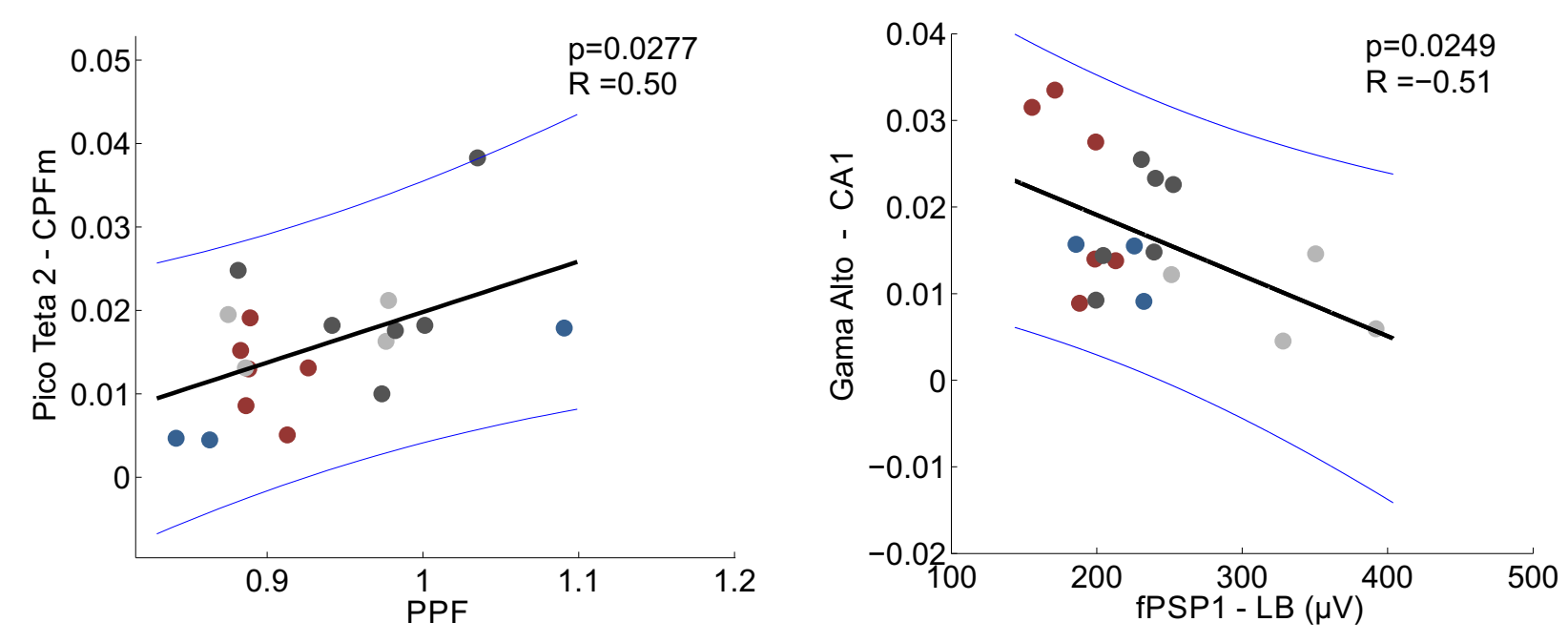

Figura 26 - Correlações entre as análises de potência e dados eletrofisiológicos. Esquerda Correlação positiva entre o pico de Teta 2 com o PPF ( $\mathrm{p}=0.028 ; \mathrm{R}=0.50)$. Direita - Correlação negativa entre Gama Alto com a amplitude do $f P S P_{1}$ durante a linha de base $(\mathrm{p}=0.025 ; \mathrm{R}=-0.51)$. 


\subsubsection{A curto prazo STZ e o tratamento de nicotina não alteram a coerência CA1-CPFm}

A análise de coerência de amplitude entre CA1 e o CPFm dos animais do Experimento 1 está apresentada na Figura 27. Nem a STZ e nem a nicotina geram alterações na sincronia entre estas duas regiões em nenhuma das bandas de oscilação analisada neste trabalho [p>0.05; ANOVA de uma via simples].
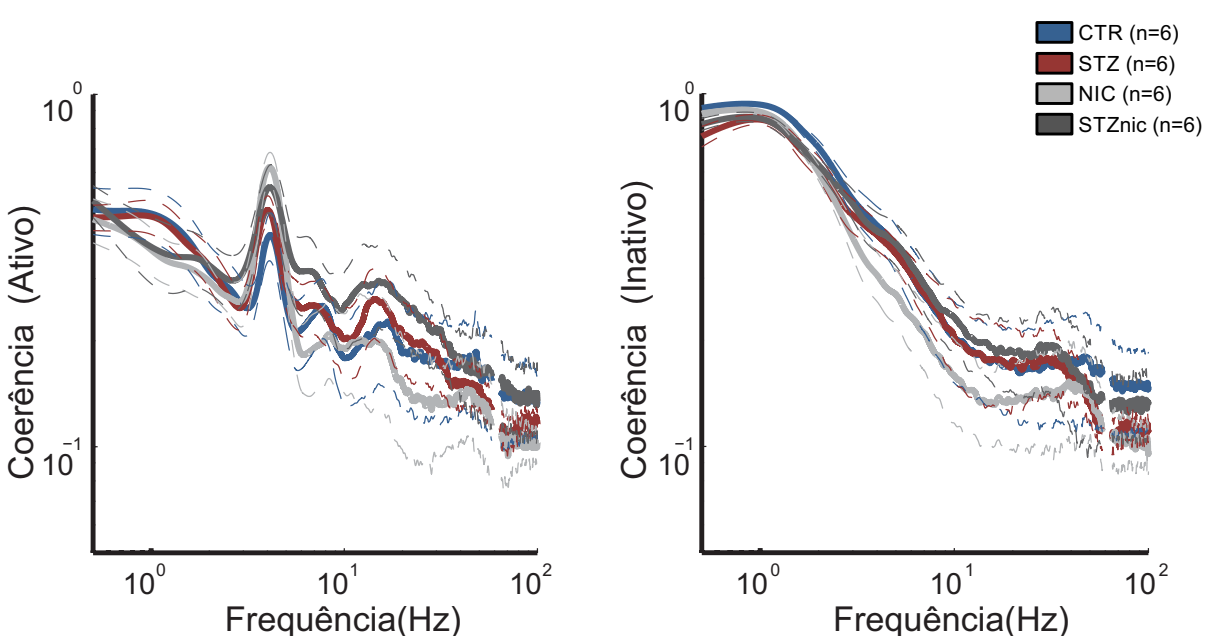

Figura 27 - Coerência de amplitude CA1-CPFm do Experimento 1. (Esquerda) Média da coerência de amplitude CA1-CPFm das épocas ativas dos quatro grupos. (Direita) Média da coerência de amplitude CA1-CPFm das épocas ativas dos quatro grupos. Não houve diferença significativa da coerência em nenhuma oscilação analisada. 


\subsection{Experimento 2: Efeitos a longo prazo da STZ e do tratamento de nicotina}

Nesta Seção serão apresentados os resultados dos quatro grupos que realizaram o $E x$ perimento 2. Estes animais realizaram os mesmos testes comportamentais que os grupos do Experimento 1 e depois de um intervalo de 60 dias os animais foram testados novamente. Os primeiros testes comportamentais foram realizados aproximadamente 1 mês após a injeção de STZ/aCSF e os segundos testes foram realizados 3 meses depois . Concluído todos os testes comportamentais estes grupos foram submetidos ao mesmo teste eletrofisiológico que os grupos do Experimento 1 para poder observar os efeitos a longo prazo tanto da injeção de STZ quanto do tratamento de nicotina.

\subsubsection{A longo prazo existe uma redução da locomoção em todos os grupos}

A Figura 28 mostra os resultados da locomoção no Campo Aberto nos dois distintos tempos em que os animais foram testados durante o Experimento 2. Observa-se que a curto prazo as diferenças obtidas na Seção 5.2.1 foram mantidas, visto que até o primeiro teste comportamental o paradigma do Experimento 1 é idêntico ao do Experimento 2, sendo então diferentes animais porém submetidos ao mesmo protocolo. Porém após um intervalo de 60 dias dos primeiros testes comportamentais tanto a STZ quanto a nicotina não alteram mais a locomoção, visto que a locomoção dos grupos se igualam.

Nos primeiros testes realizados (Fig. 28-A esquerda) houve uma queda significativa na locomoção nos 6 min inicias dos três grupos em relação ao $C T R_{1}$ [Interação tratamento $\mathrm{x}$ tempo: $F_{(12,200)}=3.820, \mathrm{p}<0.001$; ANOVA de duas vias com medidas repetidas, seguido teste post hoc de Bonferroni]. Porém a longo prazo (Fig. 28-A direita) estas diferenças deixam de existir [p>0.05; ANOVA de duas vias com medidas repetidas].

Ao avaliar a distância total percorrida dos quatro grupos a curto e a longo prazo (Fig. 14-B) verifica-se que, em relação ao $C T R_{1}$, houve uma redução de aproximadamente $30 \%$ nos três grupos $\left(S T Z_{1}, N I C_{1}\right.$ e $\left.S T Z n i c_{1}\right)$ na locomoção nos testes de 1 mês e uma redução de aproximadamente $50 \%$ na locomoção dos quatro grupos nos testes de 3 
meses $\left[F_{(7,83)}=10.851, \mathrm{p}<0.001 ;\right.$ ANOVA de uma via simples, seguido teste post hoc de Bonferroni].

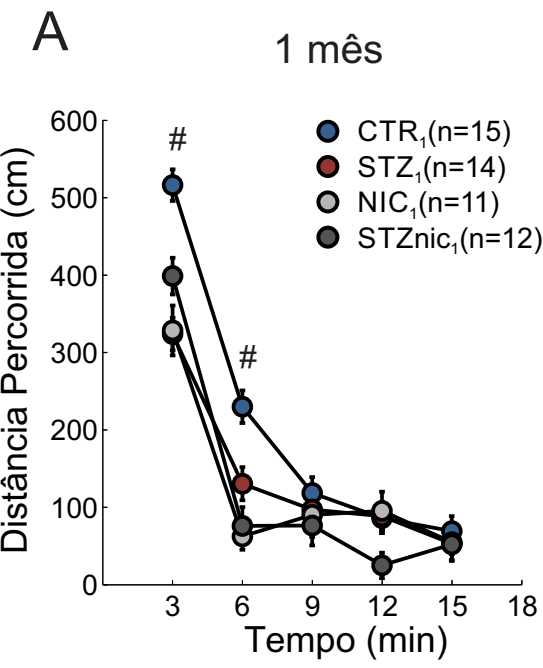

B

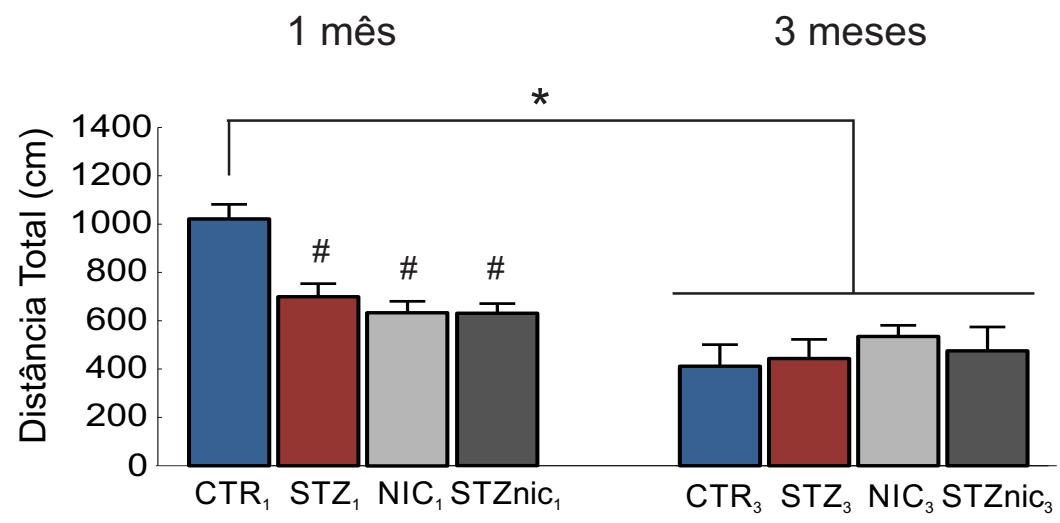

\section{3 meses}

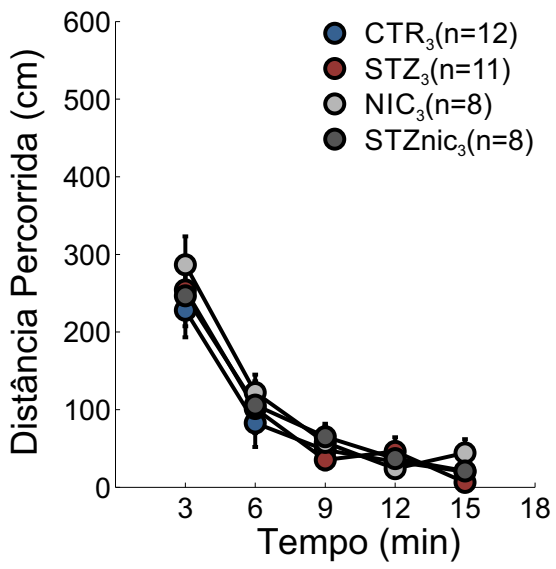

3 meses

Figura 28 - Distância total de locomoção 1 e 3 meses após a injeção de STZ/aCSF dos grupos do Experimento 2. (A) Distância percorrida dos grupos medidos em blocos de 3 min. A curto prazo, os grupos $S T Z_{1}, N I C_{1}$ e $S T Z n i c_{1}$ continuam se locomovendo menos nos seis primeiros minutos e a longo prazo (no teste de 3 meses) estas diferenças deixam de existir; ${ }^{*} p<0.05 C T R_{1}$ vs. $S T Z_{1}, N I C_{1}$ e $S T Z n i c_{1}$ em 3 min e 6 min (ANOVA de duas vias medidas repetidas, seguido de teste post hoc de Bonferroni). (B) Comparação entre as distâncias medias totais dos grupos. As distâncias percorridas pelos grupos $S T Z_{1}, N I C_{1}$ e $S T Z n i c_{1}$, nos testes de 1 mês, foram significativamente menores que o grupo $C T R_{1}$, porem 3 meses após a injeção de STZ/aCSF a locomoção dos quatro grupos se igualam e todos foram significativamente menores que o $C T R_{1} ;{ }^{*} p<0.01,{ }^{*} p<0.05$ comparado com $C T R_{1}$ (ANOVA simples de uma via, seguido de teste post hoc de Bonferroni). 


\subsubsection{A longo prazo a STZ gera déficit no RO e a nicotina no- vamente reverte este déficit}

Assim como no teste de Campo Aberto, a tarefa de Reconhecimento de Objetos também foi realizada duas vezes nos animais do Experimento 2, com um intervalo de 60 dias entre eles.

Os resultados do primeiro teste (Fig. 29) mostrou novamente que apenas o grupo $S T Z_{1}$ não conseguiu distinguir o objeto novo do velho, permanecendo aproximadamente o mesmo tempo explorando os dois objetos [Comparação intra-grupo ao longo do treino/teste: $F_{(1,40)}=61.688, \mathrm{p}<0.001 ;$ ANOVA de duas vias com medidas repetidas, seguido teste post hoc de Bonferroni]. Ao analisar a Taxa de Discriminação verifica-se também que somente o grupo $S T Z_{1}$ não conseguiu discriminar o treino do teste [Comparação intragrupo ao longo do treino/teste: $F_{(1,40)}=61.688, \mathrm{p}<0.001$; ANOVA de duas vias com medidas repetidas, seguido teste post hoc de Bonferroni]. Novamente, estes resultados reforçam os dados obtidos no Reconhecimento do Experimento 1 (Seção 5.2.2) uma vez que estes animais também foram submetidos ao mesmo protocolo experimental.
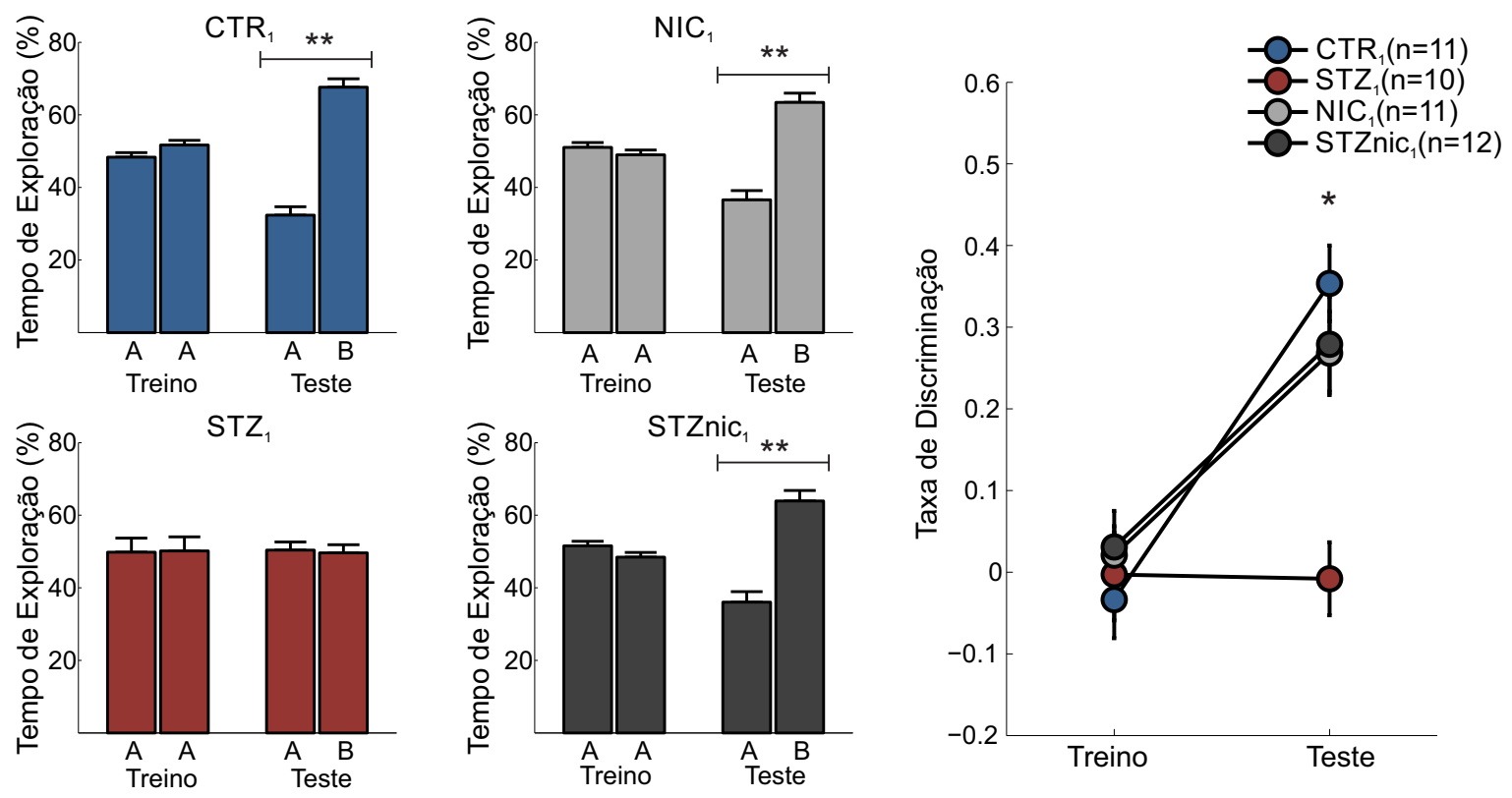

Figura 29 - Treino e teste 1 mês após a injeção de STZ/aCSF dos grupos do Experimento 2. Os quatro gráficos à esquerda mostram a porcentagem do tempo de exploração que o grupo permaneceu em cada objeto durante o treino e o teste. O gráfico à direita mostra a Taxa de Discriminação da tarefa de RO 1 mês após a injeção de 
STZ/aCSF. Apenas o grupo $S T Z_{1}$ apresentou dificuldades em reconhecer o objeto novo e também não conseguiu discriminar o treino do teste; ${ }^{* *} p<0.001 A_{\text {Treino }}$ vs. $A_{\text {Teste }}$ e $A_{\text {Treino }}$ vs. $B_{\text {Teste }} ;{ }^{*} p<0.001$ Treino vs. Teste dos grupos $C T R_{1}, N I C_{1} \mathrm{e}$ $S T Z n i c_{1}$ (ANOVA de duas vias com medidas repetidas, seguido de teste post hoc de Bonferroni).

As diferenças obtidas a curto prazo também foram mantidas ao testar os mesmos animais a longo prazo, após o intervalo de 60 dias (testes de 3 meses). Apenas o grupo injetado com STZ teve dificuldades em distinguir o objeto novo do velho durante o teste [Comparação intra-grupo ao longo do treino/teste: $F_{(1,40)}=31.413, \mathrm{p}<0.001$; ANOVA de duas vias com medidas repetidas, seguido teste post hoc de Bonferroni] e também, pela Taxa de Discriminação, observa-se que o $S T Z_{3}$ não conseguiu diferenciar o treino do teste [Comparação intra-grupo ao longo do treino/teste: $F_{(1,40)}=31.607, \mathrm{p}<0.001$; ANOVA de duas vias com medidas repetidas, seguido teste post hoc de Bonferroni] (Fig. 30).
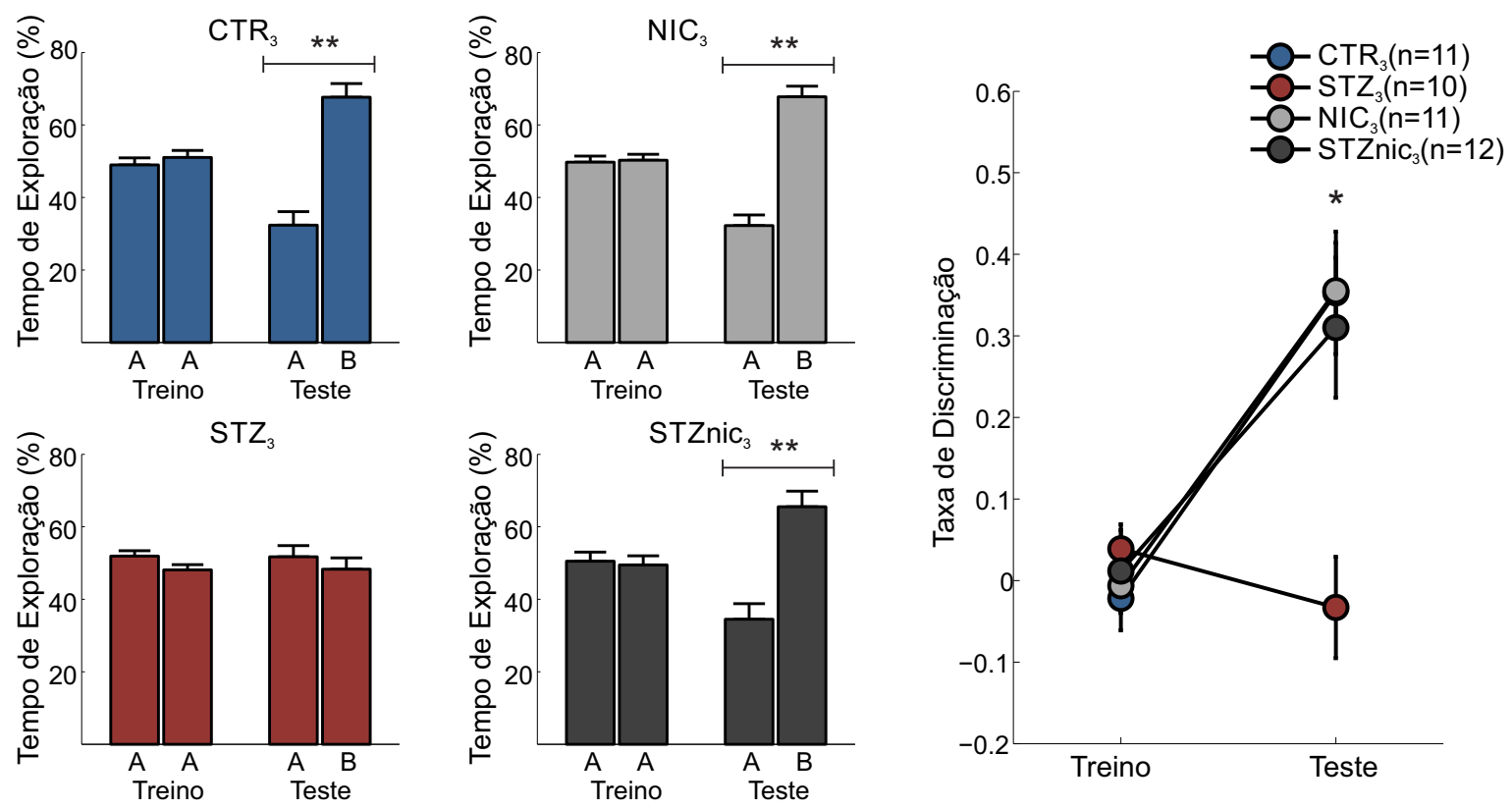

Figura 30 - Treino e teste 3 meses após a injeção de STZ/aCSF dos grupos do Experimento 2. Os quatro gráficos à esquerda indicam a porcentagem do tempo de exploração que o grupo permaneceu em cada objeto durante o treino e o teste na tarefa de 3 meses. Novamente, apenas o grupo $S T Z_{3}$ apresentou dificuldades de reconhecer o objeto novo durante o teste e também não conseguiu discriminar o treino do teste; ${ }^{* *} p<0.001 A_{\text {Teste }}$ vs. $A_{\text {Treino }}$ e $B_{\text {Teste }}$ vs. $A_{\text {Treino }} ;{ }^{*} p<0.001$ Treino vs. Teste dos grupos $\mathrm{CTR}_{3}, \mathrm{NIC}_{3}$ e $S T Z n i c_{3}$ (ANOVA de duas vias com medidas, seguido de teste post hoc de Bonferroni). 
Ao avaliar o Índice de Reconhecimento dos quatro grupos juntos observa-se novamente que o único grupo com déficit na memória de reconhecimento foi o STZ, tanto no teste de 1 mês [Interação tratamento x tempo: $F_{(3,40)}=8.031, \mathrm{p}<0.001$; ANOVA de duas vias com medidas repetidas, seguido teste post hoc de Bonferroni] quanto no teste de 3 meses [Interação tratamento x tempo: $F_{(3,40)}=5.665, \mathrm{p}<0.001$; ANOVA de duas vias com medidas repetidas, seguido teste post hoc de Bonferroni] (Fig. 31-A). Porém, ao avaliar o tempo total de exploração manteve-se a do $N i c_{1}$ em relação ao $C T R_{1}$ no primeiro mês e houve uma redução significativa do tempo total de exploração de todos os grupos no terceiro mês comparado com o $C T R_{1}\left[F_{(7,80)}=4.233, \mathrm{p}<0.001\right.$; ANOVA de uma via, seguido teste post hoc de Bonferroni].

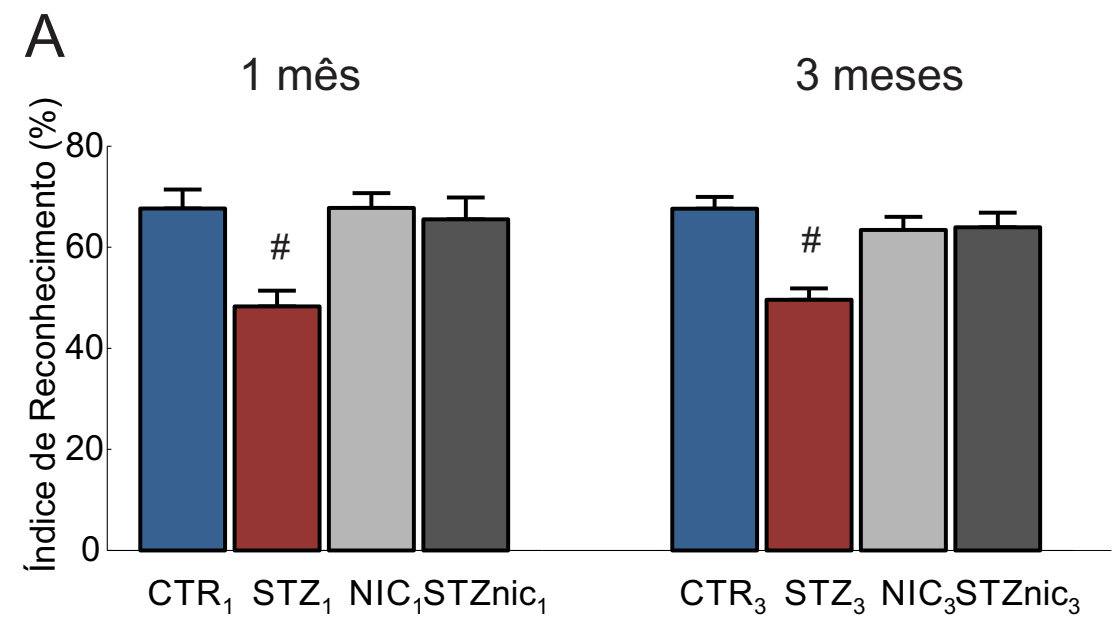

B 1 mês 3 meses

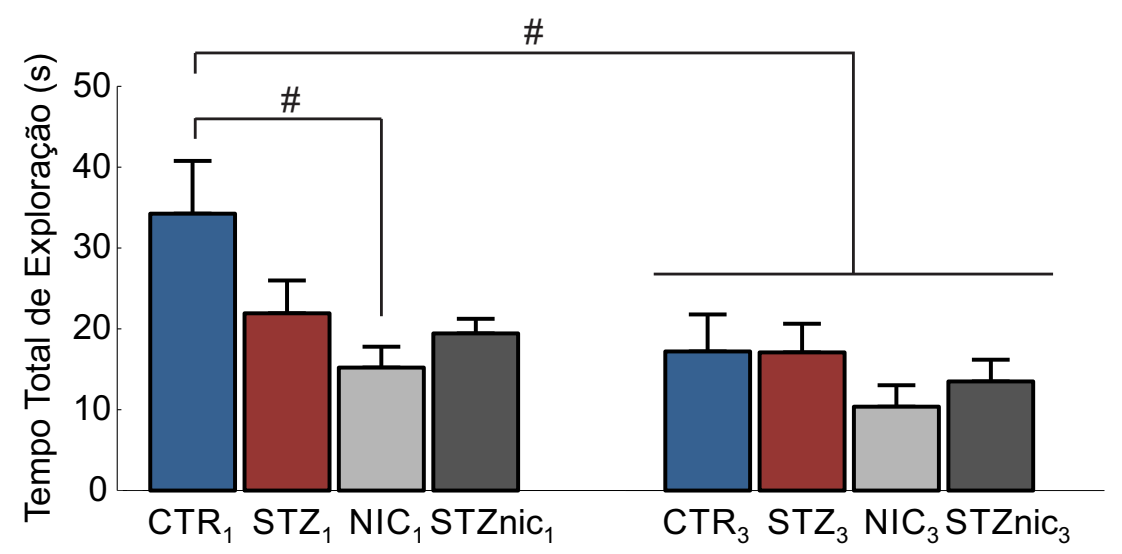

Figura 31 - Comparação dos dados da tarefa de RO entre os grupos no Experimento 2. (A) Índice de Reconhecimento dos grupos testados 1 mês e 3 meses após a injeção de STZ/aCSF. Em ambos os testes apenas o grupo STZ apresentou déficit no Índice de Reconhecimento; ${ }^{\#} p<0.01 S T Z_{1}$ vs. $C T R_{1}, N I C_{1}$ e $S T Z n i c_{1} ; S T Z_{3}$ vs. $C T R_{3}$, 
$N I C_{3}$ e $S T Z n i c_{3}$ (ANOVA de uma via, seguido de teste post hoc de Bonferroni). (B) Tempo total de exploração. A curto prazo o grupo $N I C_{1}$ apresentou um menor tempo de exploração e a longo prazo não houve diferenças entre os grupos, sendo que todos o grupos testados no terceiro mês apresentaram um tempo de exploração menor que o grupo $C T R_{1}$; ${ }^{\#} p<0.05$ (ANOVA de uma via, seguido de teste post hoc de Bonferroni).

\subsubsection{Propriedades dos potenciais evocados na via CA1-CPFm nos grupos do Experimento 2}

As principais características dos potenciais evocados dos grupos do Experimento 2 estão apresentados na Figura 32. Observa-se novamente que a longo prazo continua não existindo diferenças significativas entre as curvas E/S (Fig. 32-A), nem na latência (Fig. 32-B) e nem no PPF (Fig. 32-D). Além do mais, as diferenças existentes entre as amplitudes dos $f P S P_{1}$ e $f P S P_{2}$ do grupo tratado com nicotina em relação aos demais grupos deixaram de existir após um intervalo de 3 meses [ANOVA de uma via simples, p $>0.05]$. Os valores médios da latência continuou entre 14.9 e $16.0 \mathrm{~ms}$, os valores médios do PPF entre 2 e 2.7 e a amplitude média do $f P S P_{1}$ dos quatro grupos permaneceu entre 200 e $280 \mu \mathrm{V}$. 

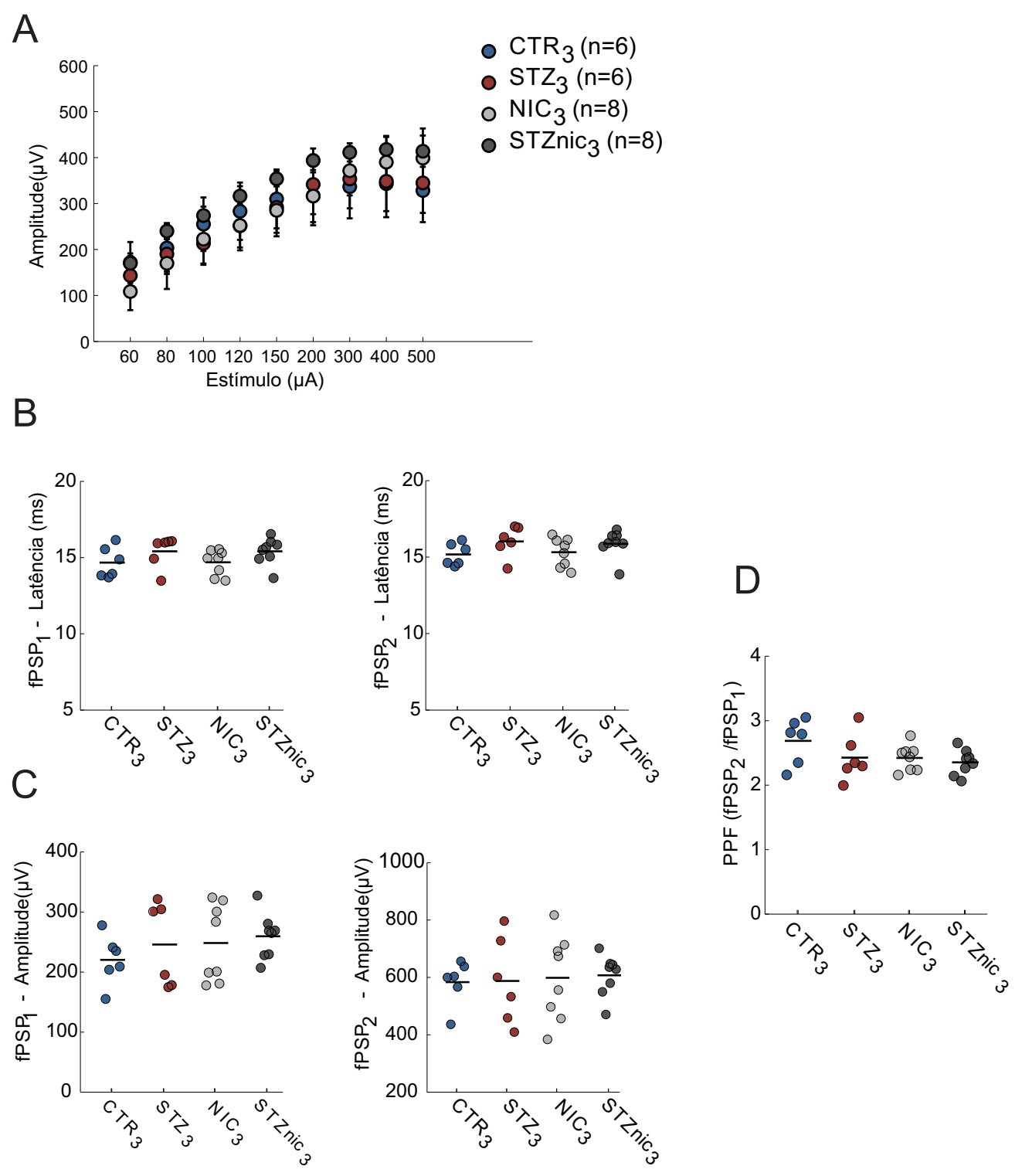

Figura 32 - Características dos potenciais registrados da via CA1-CPFm durante o Experimento 2. (A) Curvas de entrada e saída (E/S) de todos os animais incluídos nas análises de potenciais. Não foram encontradas diferenças significativas entre as curvas de E/S dos grupos (ANOVA de duas vias medidas repetidas; $\mathrm{p}>0.05$ ), dados expressos como media +/- erro padrão. (B) Latência dos $f P S P_{1}$ e $f P S P_{2}$. (C) Amplitude $\operatorname{dos} f P S P_{1}$ e $f P S P_{2}$. (D) PPFs eliciado pelos potenciais evocados. Em (B)(C) e (D) dados expressos como media + dispersão dos valores. Não foram encontradas diferenças significativas entre as médias das amplitudes, latências e PPF dos quatro grupos apresentados (ANOVA de uma via; $\mathrm{p}>0.05$ ). 


\subsubsection{A longo prazo a nicotina reduz os déficits gerados pela STZ na LTP}

O resultado a longo prazo tanto da injeção de STZ quanto do tratamento com nicotina na transmissão e na plasticidade sináptica é apresentado na próxima figura (Fig. 33).

Ao comparar o grupo $S T Z_{3}$ com o $C T R_{3}$ (Fig. 33 à direta), pode-se observar que a STZ, mesmo a longo prazo, continua reduzindo a eficiência na transmissão sináptica durante a LTP porém não chega a gerar déficits na plasticidade pré-sináptica. Este fato pode ser constatado uma vez que tanto a indução quanto a manutenção da LTP no $f P S P_{1}$ e no $f P S P_{2}$ do grupo $S T Z_{3}$ estão reduzidas, contudo o PPF não apresenta déficit em relação ao $C T R_{3}$. A amplitude do $f P S P_{1}$ do grupo $S T Z_{3}$ apresentou uma redução de aproximadamente $30 \%$ na indução da LTP e esta redução se mantém durante as quatro horas monitoradas [Interação tratamento x tempo: $F_{(26,260)}=3.605, \mathrm{p}<0.001$; ANOVA de duas vias com medidas repetidas, seguido teste post hoc de Tukey]. A redução do $f P S P_{2}$ do $S T Z_{3}$ na indução foi de aproximadamente $25 \%$ e aumenta para $30 \%$ no final das quatro horas [Interação tratamento x tempo: $F_{(26,260)}=2.763, \mathrm{p}<0.001$; ANOVA de duas vias com medidas repetidas, seguido teste post hoc de Tukey].

O tratamento com nicotina nos animais STZ a longo prazo conseguiu reduzir os déficit gerados pela STZ na indução e reverte os déficits da manutenção da LTP, pois ao comparar o grupo $S T Z n i c_{3}$ com o $C T R_{3}$ (Fig. 33-centro) observa-se que o grupo $S T Z n i c_{3}$ ainda apresenta uma redução na indução da LTP no $f P S P_{1}$, porém agora de aproximadamente $20 \%$, e esta diferença perdura por apenas 50 min [Interação tratamento x tempo: $F_{(26,312)}=2.796, \mathrm{p}<0.001 ;$ ANOVA de duas vias com medidas repetidas, seguido teste post hoc de Tukey]. Logo, a redução na indução do grupo STZnic 3 é $10 \%$ menor que a do grupo $S T Z_{3}$ e esta redução deixa de existir após 50 min registro, sendo que no grupo $S T Z_{3}$ ela permanece durante as quatro horas. Além disso, ao analisar a amplitude do $f P S P_{2}$ e do $\mathrm{PPF}$ do grupo $S T Z n i c_{3}$ não existe nenhuma diferença que seja significativa [Tratamento: $\mathrm{p}>0.05$; ANOVA de duas vias com medidas repetidas].

O efeito de apenas o tratamento com nicotina a longo prazo pode ser verificado ao comparar o grupo $N I C_{3}$ com o $C T R_{3}$ (Fig. 33-direta). O que se pode observar é que a nicotina por si só não é capaz de alterar a LTP e nem a plasticidade sináptica a longo prazo, pois não houve diferenças significativas nem nos fPSPs e nem no PPF [Tratamento: p>0.05; ANOVA de duas vias com medidas repetidas]. 

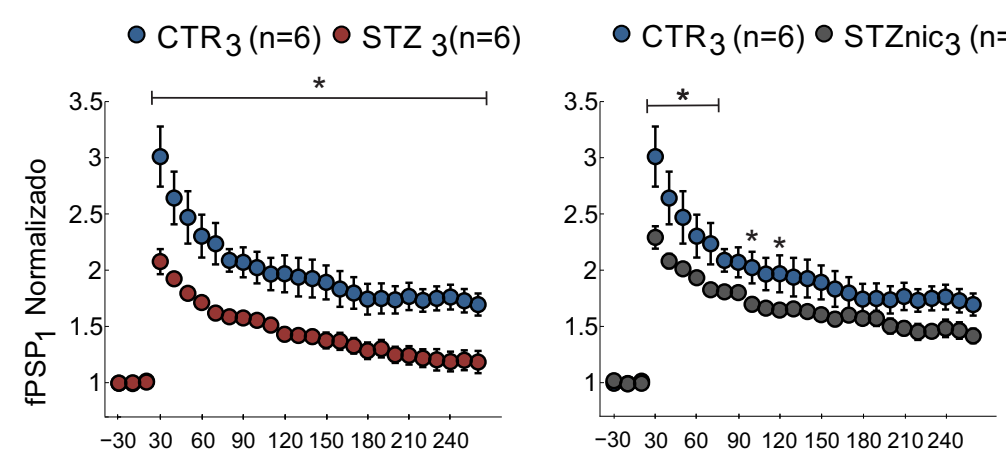

$\circ \mathrm{CTR}_{3}(n=6) \circ \mathrm{NIC}_{3}(\mathrm{n}=8)$
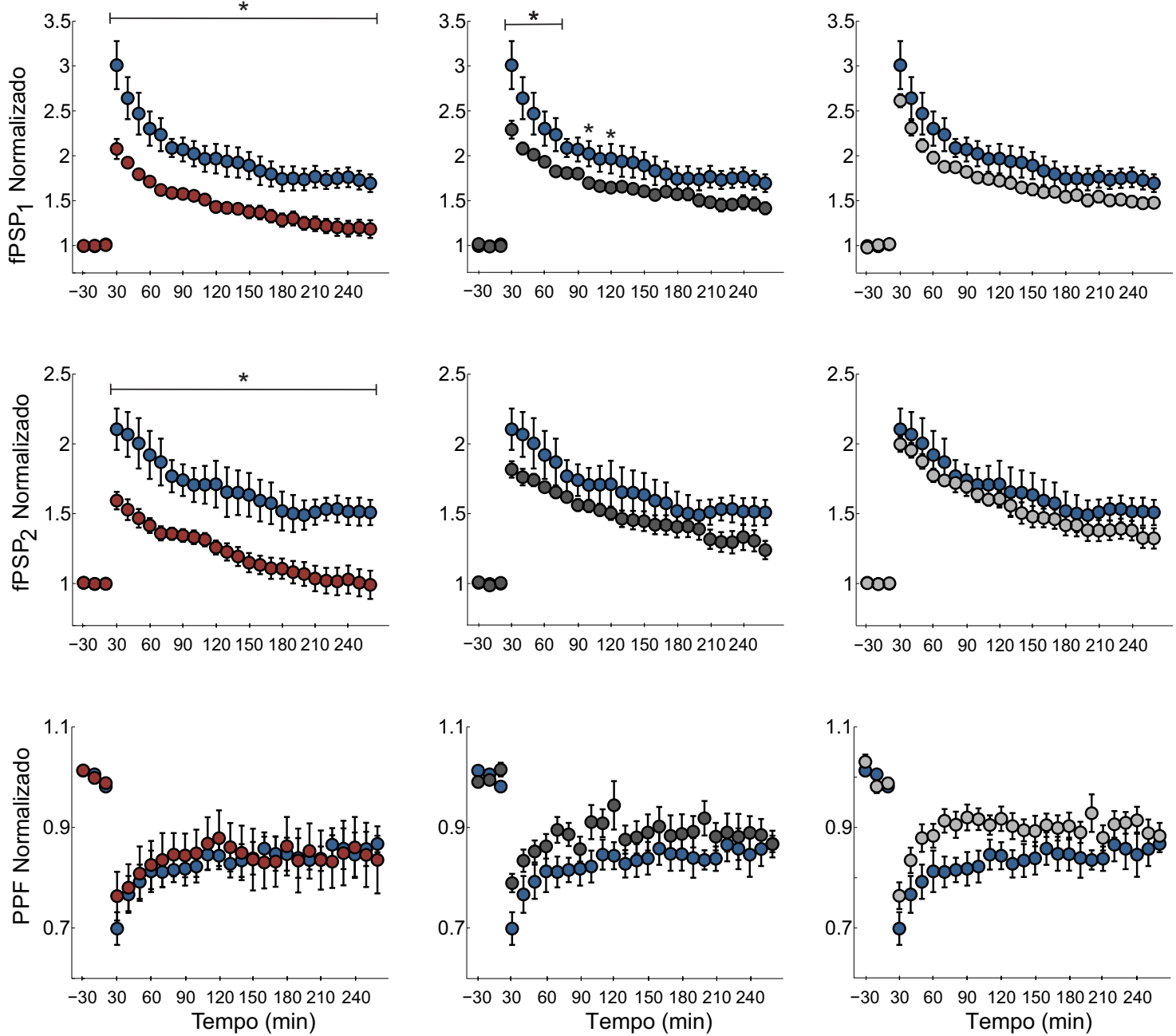

Figura 33 - fPSP e PPF dos grupos do Experimento 2. O grupo $S T Z_{3}$, comparado com o $C T R_{3}$ (à esquerda), mostra que o STZ a longo prazo gera uma redução significativa na amplitude do $f P S P_{1}$ e do $f P S P_{2}$ durante as $4 \mathrm{~h}$ monitoradas sem alterar o PPF. O tratamento com nicotina nos animais STZ a longo prazo continua reduzindo as diferenças do $f P S P_{1}$ e reverteu o efeito da $\mathrm{STZ}$ no $f P S P_{2}$. Este fato pode ser observado ao comparar o grupo $S T Z n i c_{3}$ com o $C T R_{3}$ (centro), onde ainda existe uma redução significativa da amplitude do $f P S P_{1}$ do grupo $S T Z n i c_{3}$ porém $10 \%$ menor que o grupo $S T Z_{3}$ e durante apenas 50 min. Além disso nem o $f P S P_{2}$ e nem o PPF apresentaram diferenças em relação ao $C T R_{3}$. O tratamento de nicotina a longo prazo, grupo $N I C_{3}$ (à direita), não apresentou diferenças em relação ao grupo $C T R_{3}$, a nicotina não foi capaz de alterar a amplitude do $f P S P_{1}$, do $f P S P_{2}$ e nem do PPF a longo prazo. Dados expressos expressos como média +/- erro padrão, separados em blocos de 10 min e normalizados pela média da linha de base; ${ }^{*} p<0.05$ (ANOVA de duas vias medidas repetidas, seguido de teste post hoc de Tukey). 
O efeito a longo prazo da STZ e do tratamento também pode ser avaliado ao comparar os grupos $S T Z_{3}$ e $S T Z n i c_{3}$ (Fig. 34). Ao realizar esta comparação observa-se a melhora na eficiência da indução e da manutenção da LTP gerada pelo tratamento e nenhuma alteração na transmissão pré-sináptica, confirmando o que foi constatado ao realizar as comparações com o grupo controle. De forma global, a amplitude do $f P S P_{1}$ do grupo STZnic 3 aumentou aproximadamente 15\% [Tratamento: $F_{(1,312)}=8.061$, p $<0.001$; ANOVA de duas vias com medidas repetidas, seguido teste post hoc de Tukey] e o f PSP2 aumentou $20 \%$ [Tratamento: $F_{(1,312)}=9.302, \mathrm{p}<0.001$; ANOVA de duas vias com medidas repetidas, seguido teste post hoc de Tukey]. No teste post hoc houve diferenças significativas apenas na amplitude $f P S P 2$ [Interação tratamento x tempo: $F_{(26,312)}=1.693$, $\mathrm{p}<0.001$; ANOVA de duas vias com medidas repetidas, seguido teste post hoc de Tukey] mostrando um aumento de aproximadamente $15 \%$ na indução do f PSP2 que se mantém por praticamente todo o tempo monitorado, chegando a $25 \%$ no final das quatro horas. Porém, ao avaliar a amplitude do PPF observa-se que o aumento do grupo STZnic 3 não foi significativo [Tratamento: $\mathrm{p}>0.05$; ANOVA de duas vias com medidas repetidas]. 

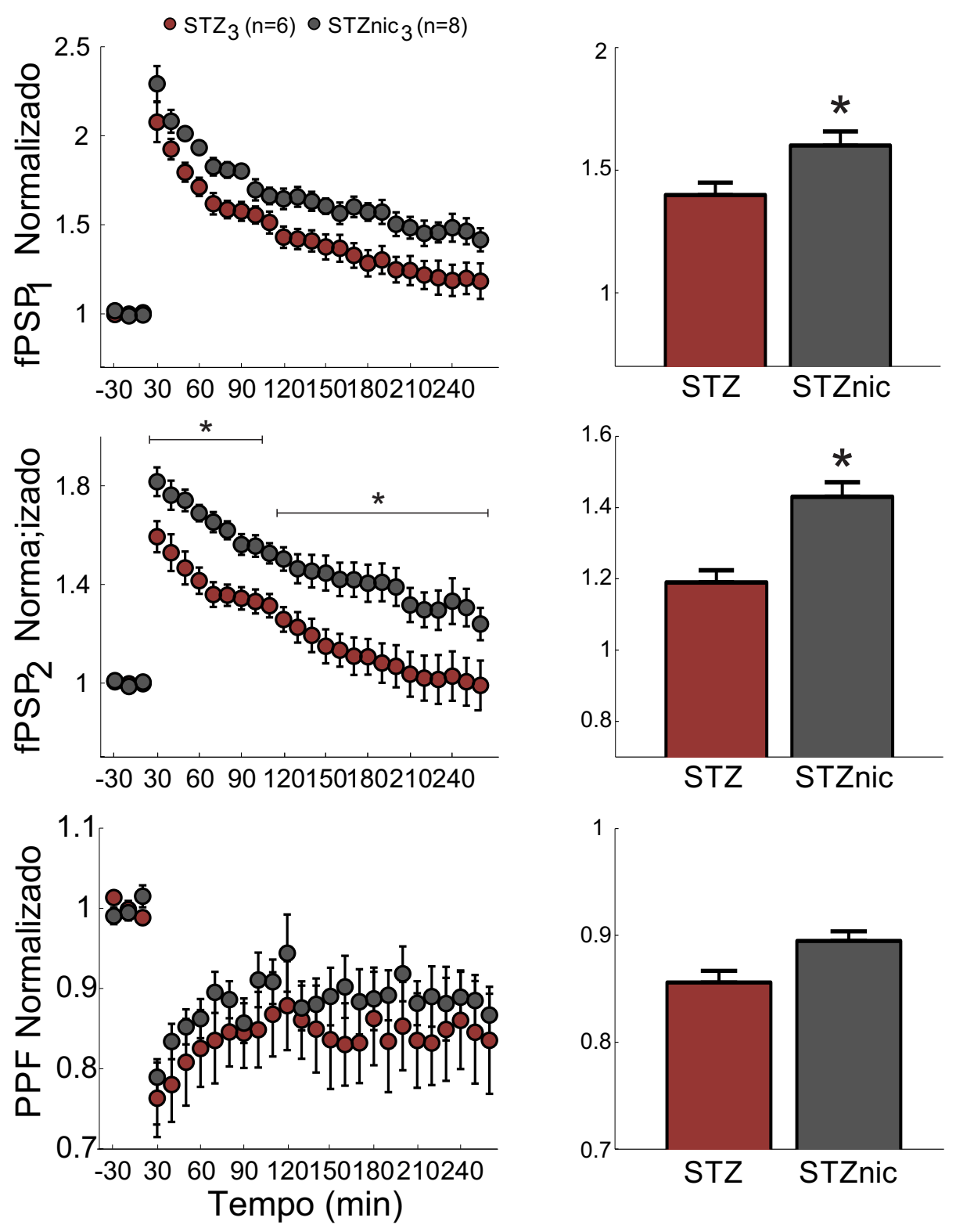

Figura 34 - fPSP e PPF dos grupos STZ tratados e não tratados do Experimento 2. A longo prazo, ao comparar com o $S T Z_{3}$ observa-se que existe um aumento global na amplitude dos dois $f P S P s$ e nenhuma alteração no PPF do grupo $S T Z n i c_{3}$. Apenas o $f P S P_{2}$ apresentou diferenças no teste post hoc na interação tempo x tratamento, mostrando que existe um aumento na amplitude do $f P S P_{2}$ do grupo $S T Z n i c_{3}$ durante praticamente as $4 \mathrm{~h}$ monitoradas. Dados expressos expressos como média +/erro padrão, separados em blocos de 10 min e normalizados pela média da linha de base; ${ }^{*} p<0.05$ (ANOVA de duas vias medidas repetidas, seguido de teste post hoc de Tukey) 


\subsubsection{A longo prazo a STZ reduz a amplitude do pico em Teta 2 e a nicotina reverte este efeito}

A Fig. 35 mostra o PSD e a análise de potência das bandas realizada nos animais do Experimento 2 no CPFm. No estado Inativo houve apenas uma tendência estatística de redução $(\mathrm{p}=0.056)$ da potência em Gama Alto do grupo NIC em relação ao CTR $\left[F_{(3,22)}=3.149, \mathrm{p}<0.05\right.$; ANOVA de uma via simples, seguido teste post hoc de Tukey]. Já no estado Ativo houve uma redução significativa dos três grupos em relação ao grupo CTR também na potência de Gama Alto $\left[F_{(3,22)}=5.256, \mathrm{p}<0.05\right.$; ANOVA de uma via simples, seguido teste post hoc de Tukey]. Ao analisar a amplitude do pico em Teta 2 presente no estado Ativo, pode-se observar que a STZ gerou uma redução da amplitude em relação aos grupos CTR e NIC e a nicotina conseguiu reverter este efeito no grupo STZnic $\left[F_{(3,20)}=4.516, \mathrm{p}<0.05\right.$; ANOVA de uma via simples, seguido teste post hoc de Tukey]. 


\section{A - CPFm Inativo}

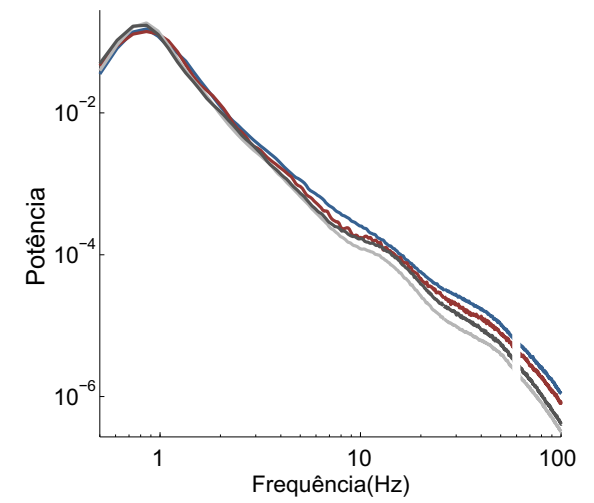

\section{B - CPFm Ativo}

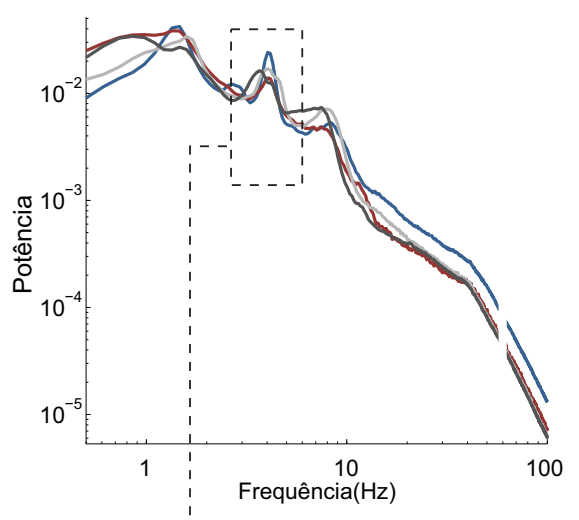

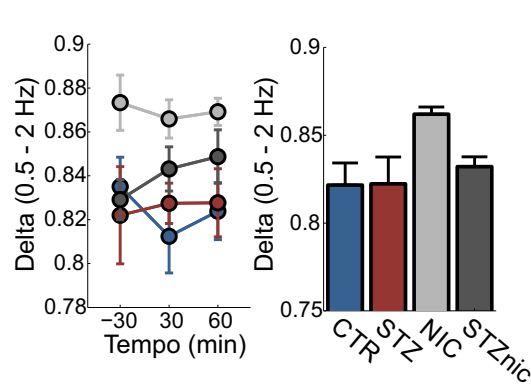
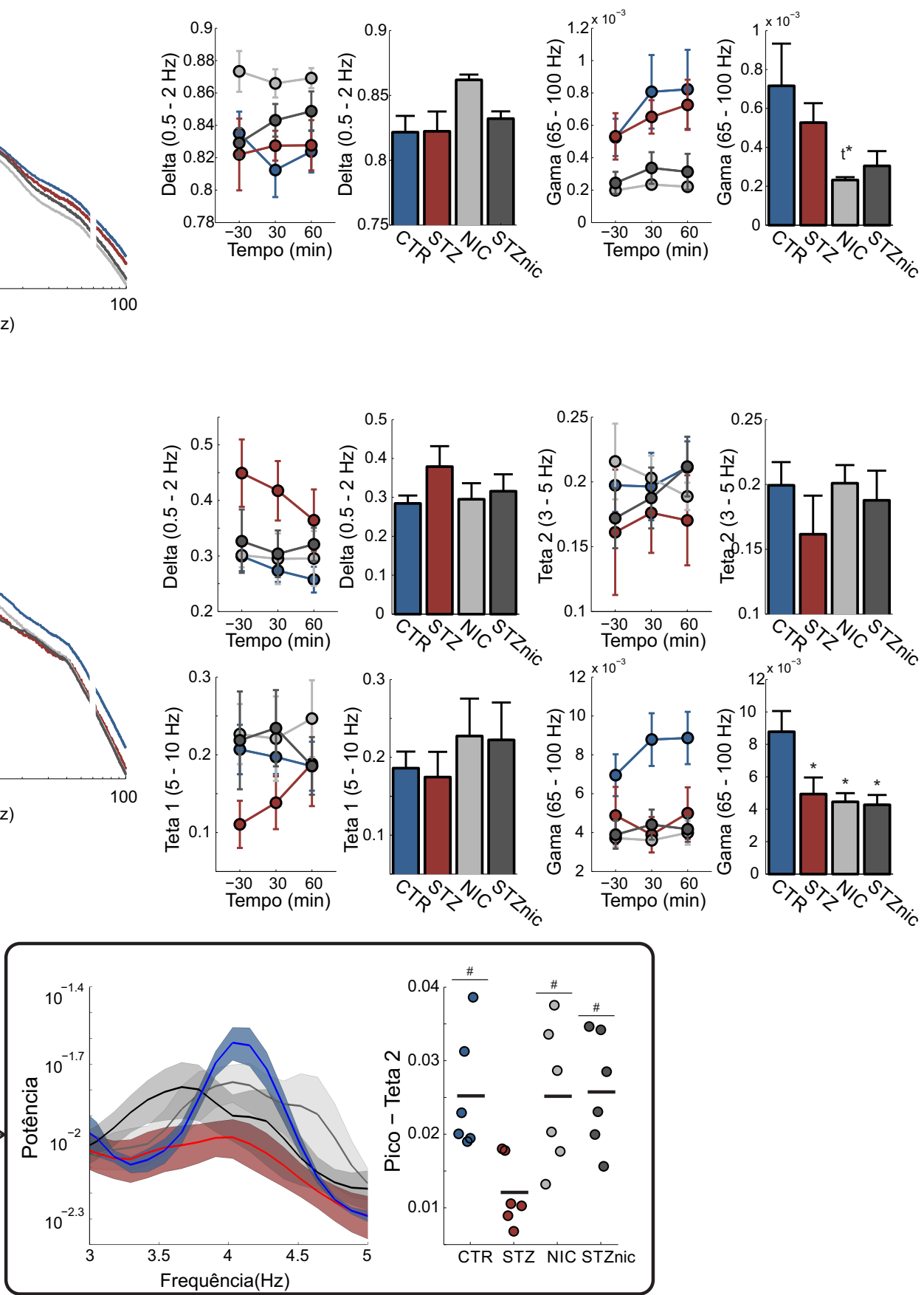

Figura 35 - Potência das LFPs ativas e inativas do CPFm dos grupos do Experimento 2.(A) à esquerda - PSD médio do CPFm dos quatro grupos no estado Inativo; à direta - potências média das duas bandas analisadas neste estado. (B) à esquerda - PSD médio do CPFm dos quatro grupos no estado Ativo; à direita - potências média das quatro bandas analisadas neste estado; em baixo - amplitude média do pico em Teta 
2 e o PSD referente a esta banda. No estado Inativo, houve uma tendência a redução em Gama Alto do grupo NIC em relação ao CTR. No estado Ativo a potência em Gama Alto dos três grupo foram significativamente menor que a do grupo CTR. A análise do pico em Teta 2 mostrou uma redução da amplitude do grupo STZ em relação aos grupos CTR, NIC e STZnic. ${ }^{*} p<0.05$ vs. CTR; $t^{*}(p=0.056)$ vs. CTR (ANOVA simples de uma via, seguido de teste post hoc de Tukey).

Ao avaliar as potências na região CA1 (Fig. 36) observa-se no estado Inativo que a STZ aumenta significativamente a potência em Delta Baixo do grupo STZ em relação ao CTR $\left[F_{(3,22)}=3.370, \mathrm{p}<0.05\right.$; ANOVA de uma via simples, seguido teste post hoc de Tukey] e reduz a potência em Gama Alto de ambos os grupos (STZ e STZnic) também em relação ao CTR $\left[F_{(3,22)}=4.536, \mathrm{p}<0.05\right.$; ANOVA de uma via simples, seguido teste post hoc de Tukey]. No estado Ativo também é possível observar o aumento da potência de Delta baixo do grupo STZ em relação ao grupo CTR e ao $\operatorname{NIC}\left[F_{(3,22)}=3.841, \mathrm{p}<0.05\right.$; ANOVA de uma via simples, seguido teste post hoc de Tukey] e em Gama Alto houve uma redução significativa do grupo STZnic em relação ao CTR $\left[F_{(3,20)}=3.051, \mathrm{p}<0.05\right.$; ANOVA de uma via simples, seguido teste post hoc de Tukey]. Ao analisar Teta 2 pode-se observar uma redução da potência do grupo STZ em relação aos demais grupos, porém ela não foi significativa. Mas o resultado que se obteve na análise do pico desta mesma banda foi aumento da amplitude acarretado pelo tratamento com nicotina do grupo STZnic em relação ao grupo STZ $\left[F_{(3,21)}=3.332, \mathrm{p}<0.05\right.$; ANOVA de uma via simples, seguido teste post hoc de Tukey]. 


\section{A - Ca1 Inativo}

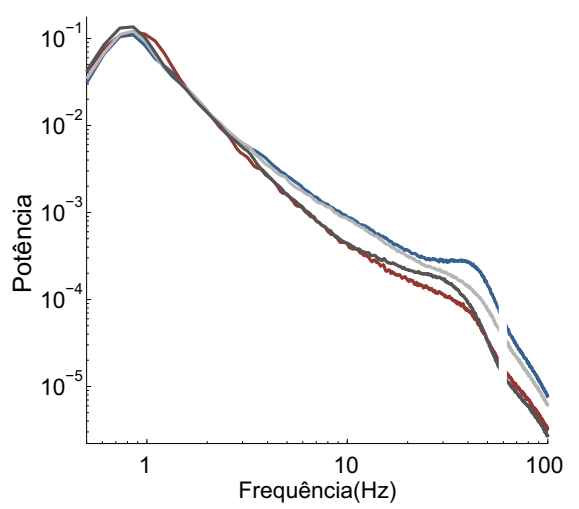

B - Ca1 Ativo

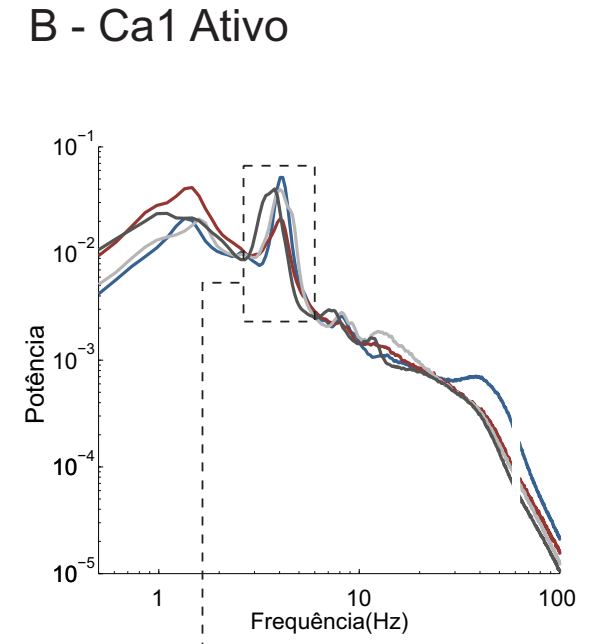

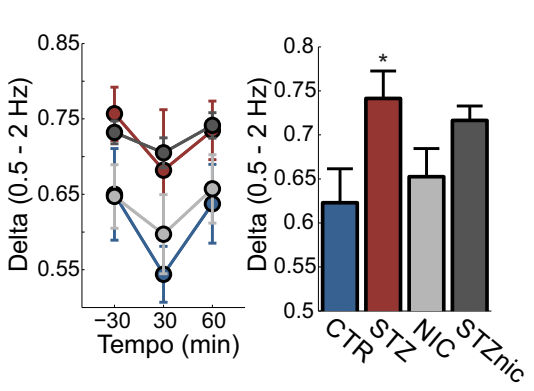
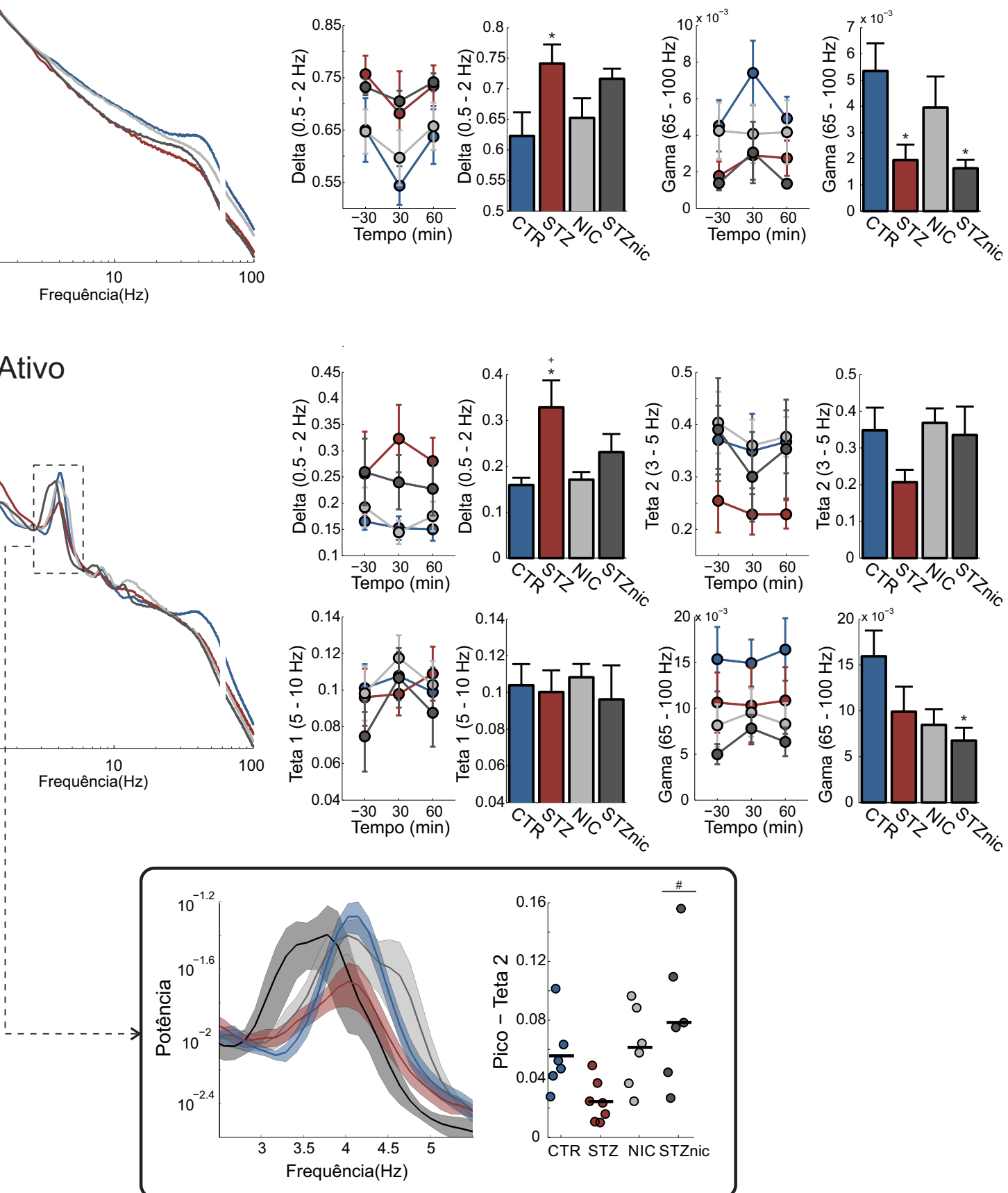

Figura 36 - Potência das LFPs ativas e inativas do hipocampo do Experimento 2. (A) à esquerda - PSD médio do CA1 dos quatro grupos no estado Inativo; à direta - potências média das duas bandas analisadas neste estado. (B) à esquerda - PSD médio do CA1 dos quatro grupos no estado Ativo; à direita - potências média das quatro bandas analisadas neste estado; em baixo - amplitude média do pico em Teta 2 e 
o PSD referente a esta banda. No estado Inativo, houve um aumento da potência em Delta Baixo do grupo STZ em relação ao CTR e uma redução dos grupos STZ e STZnic em Gama Alto também em relação ao CTR. No estado Ativo houve um aumento da potência em Delta Baixo do grupo STZ em relação ao CTR e ao NIC e a potência em Gama Alto do grupo STZnic foi significativamente menor que a do grupo CTR. A análise do pico em Teta 2 mostrou uma aumento da amplitude do grupo STZnic em relação ao grupo STZ. ${ }^{*} p<0.05$ vs. $\mathrm{CTR} ;{ }^{*} p<0.05$ vs. STZ; ${ }^{+} p<0.05$ vs. NIC (ANOVA simples de uma via, seguido de teste post hoc de Tukey).

\subsubsection{A longo prazo a STZ reduz a coerência CA1-CPFm em Gama Baixo no estado Inativo}

A análise de coerência de amplitude entre CA1 e o CPFm dos animais do Experimento 2 está apresentada na Figura 37. Apenas a STZ gerou alterações na sincronia entre estas duas regiões em Gama Baixo $\left[F_{(3,22)}=3.908, \mathrm{p}<0.05\right.$; ANOVA de uma via simples, seguido teste post hoc de Tukey], nas demais bandas não houve alterações significativas na coerência [p>0.05; ANOVA de uma via simples]. 

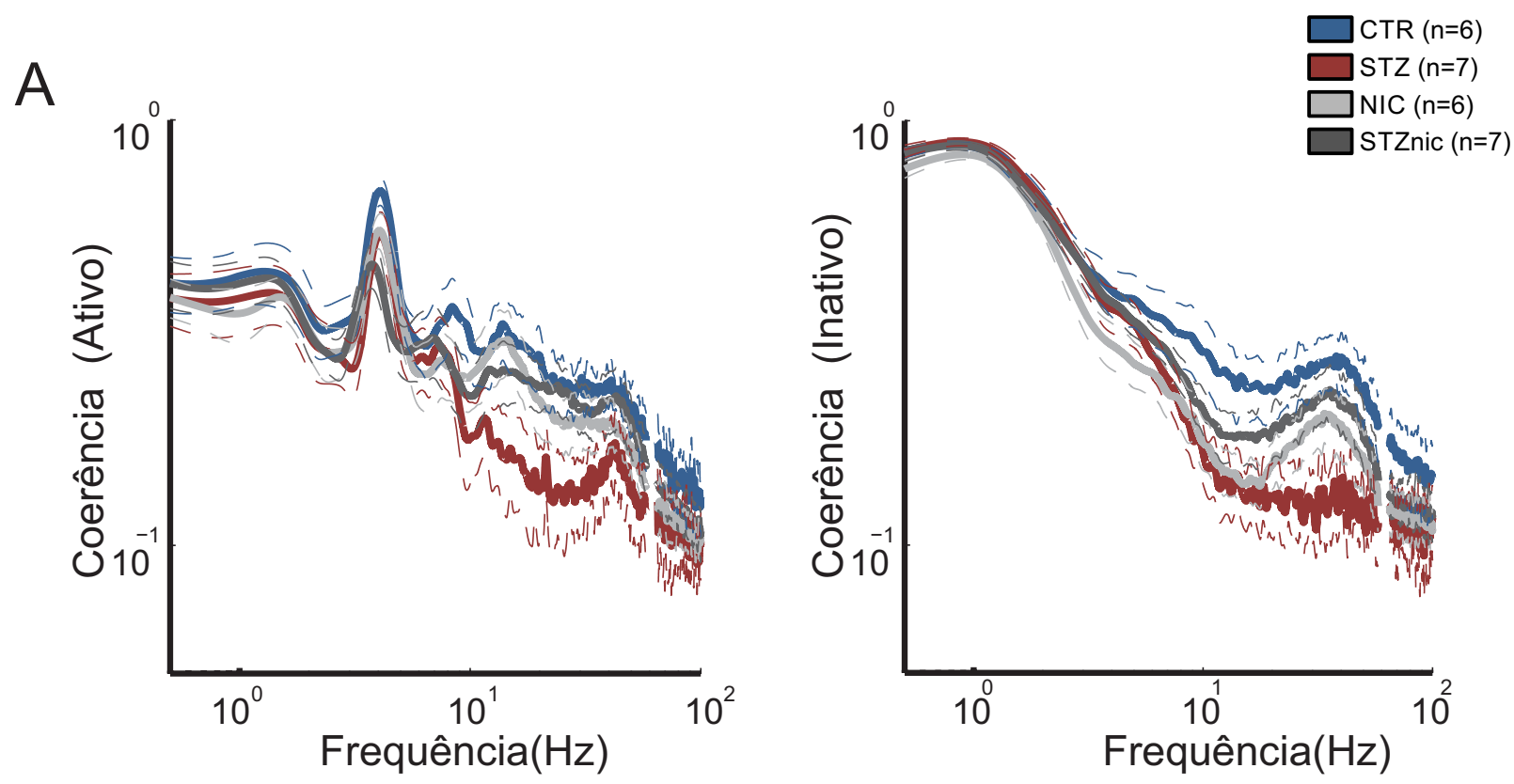

B
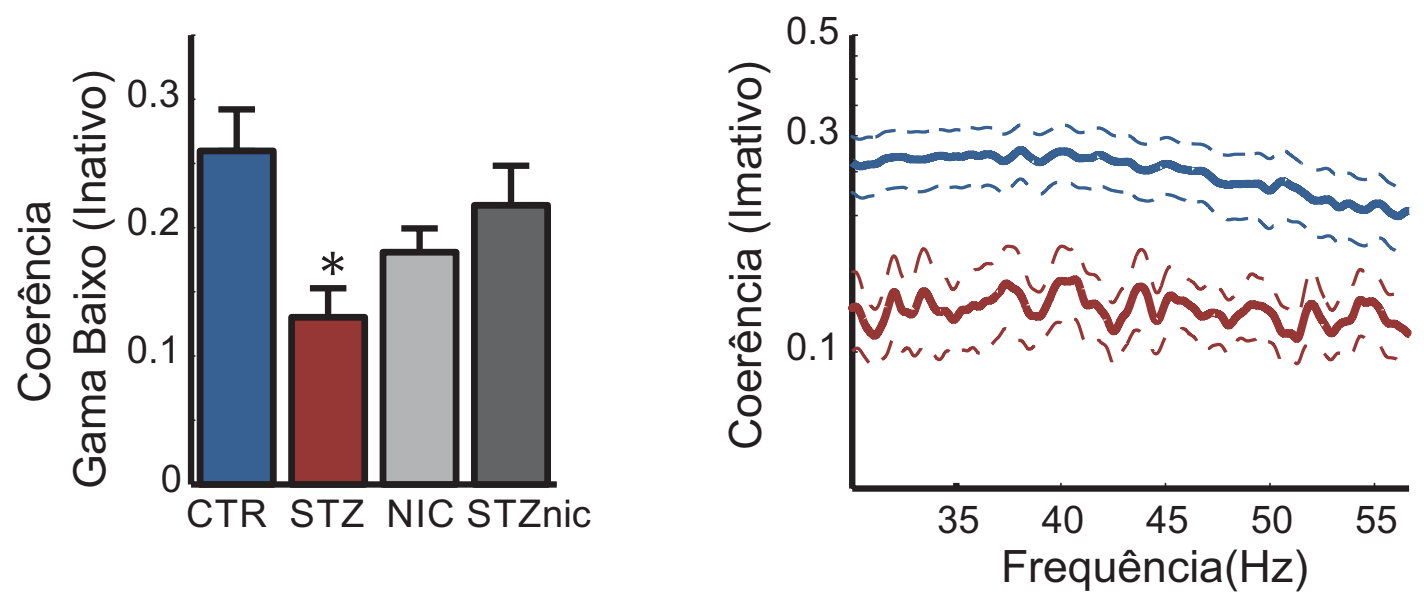

Figura 37 - Coerência de amplitude CA1-CPFm do Experimento 2. (Esquerda) Média da coerência de amplitude CA1-CPFm das épocas ativas dos quatro grupos. (Direita) Média da coerência de amplitude CA1-CPFm das épocas ativas. dos quatro grupos. Houve diferença significativa da coerência apenas Gama Baixo das épocas Inativas (ANOVA simples de uma via, seguido de teste post hoc de Tukey). 


\subsection{Análises Histológicas}

Esta seção apresentará os resultados das análises histológicas realizadas neste trabalho. Foram avaliadas a densidade neuronal, a expressão de BDNF e de TrkB nas regiões do, CA1, córtex entorrinal (ENT) e córtex pré-límbico (PL). Devido a problemas técnicos, a quantificação da expressão de BDNF e de TrkB dos animais de 3 meses não atingiram um $n$ suficiente para ser apresentado neste trabalho. Por este motivo, será apresentado do Experimento 2 (3 meses após a injeção de STZ/aCSF) apenas a quantificação da densidade neuronal.

\subsubsection{A STZ reduz a densidade neuronal no ENT a curto prazo e a nicotina aumenta a densidade neuronal em CA1 a longo prazo}

As próximas figuras mostram o resultado da densidade neuronal dos grupos de um mês e de três meses nas regiões avaliadas (Fig. ??). Na Figura 39 são apresentados o efeito da STZ e do tratamento de nicotina a curto e longo prazo pela quantificação da densidade neuronal. 


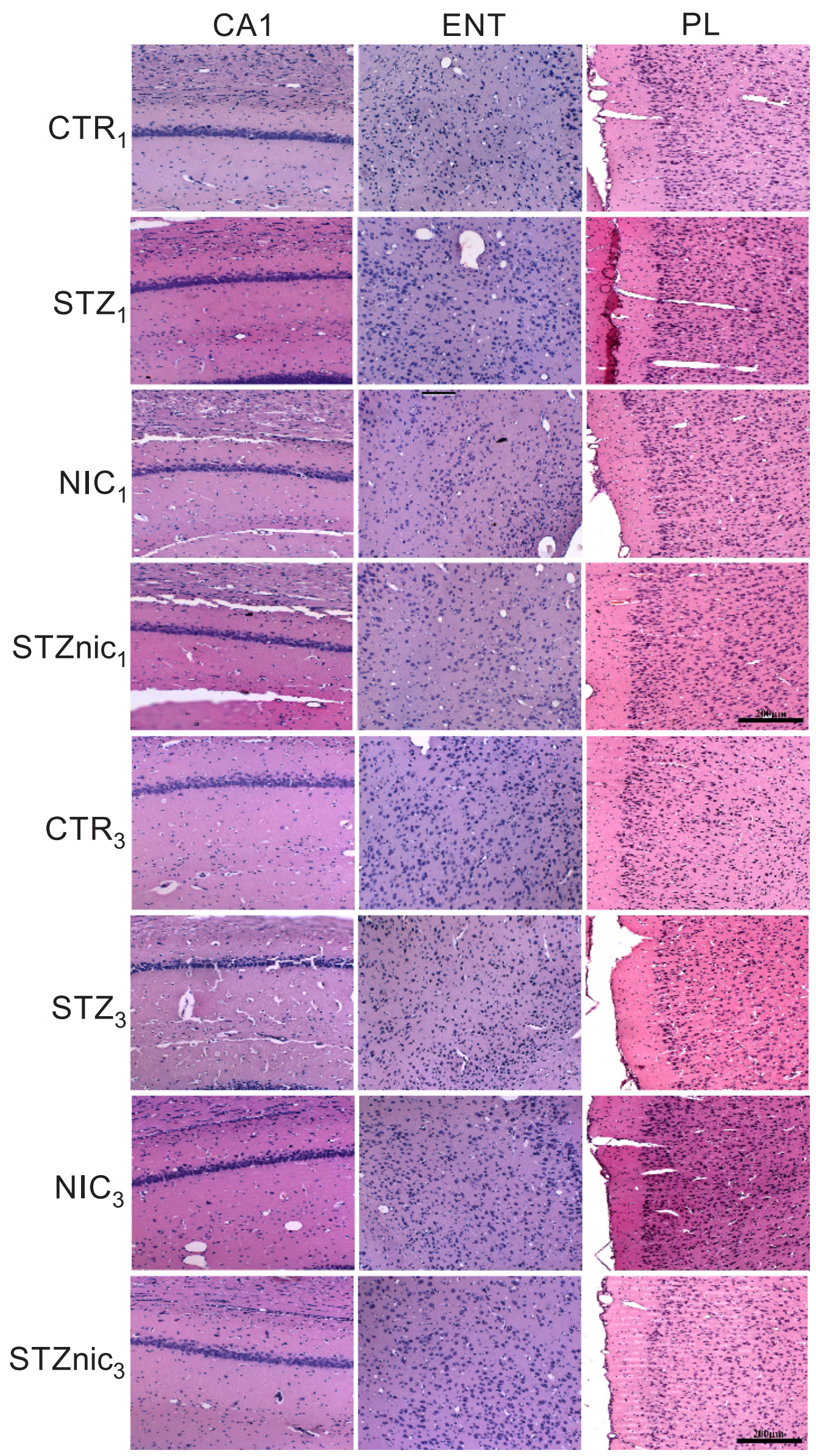


Figura 38 - Marcação neuronal por HE nos animais do Experimento 1 e Experimento 2 nas regiões CA1, córtex entorrinal (ENT) e córtex pré-límbico (PL).

A curto prazo resultados apontam que existe perda neuronal significativa do grupo $S T Z_{1}$ apenas no córtex entorrinal quando comparado ao grupo $C T R_{1}$, já a longo prazo a densidade neuronal do grupo $S T Z_{3}$ não se difere do $C T R_{3}$ em nenhuma região. Além disso, o tratamento com nicotina gerou uma redução generalizada na densidade neuronal nos animais de 1 mês (tanto no grupo CTRnic $c_{1}$ quanto no grupo STZnic $c_{1}$ ) sendo esta redução significativa em CA1 $\left[F_{(3,21)}=8.278, \mathrm{p}<0.05\right.$; ANOVA de uma via simples, seguido teste post hoc de Tukey] e no córtex entorrinal $\left[F_{(3,15)}=13.612, \mathrm{p}<0.05\right.$; ANOVA de uma via simples, seguido teste post hoc de Tukey]. A longo prazo, o efeito da nicotina se inverte em CA1, onde a contagem neuronal do grupo $\mathrm{NIC}_{3}$ foi significativamente maior que a dos demais grupos $\left[F_{(3,16)}=6.519, \mathrm{p}<0.05\right.$; ANOVA de uma via simples, seguido teste post hoc de Tukey]. No pré-límbico também houve um aumento da densidade neuronal do $\mathrm{NIC}_{3}$ em relação aos demais grupos, porém ela é significativa apenas em relação ao grupos $S T Z_{3}$ e $S T Z n i c_{3}\left[F_{(3,165)}=4.887, \mathrm{p}<0.05\right.$; ANOVA de uma via simples, seguido teste post hoc de Tukey]. 


\section{A Exp.1}
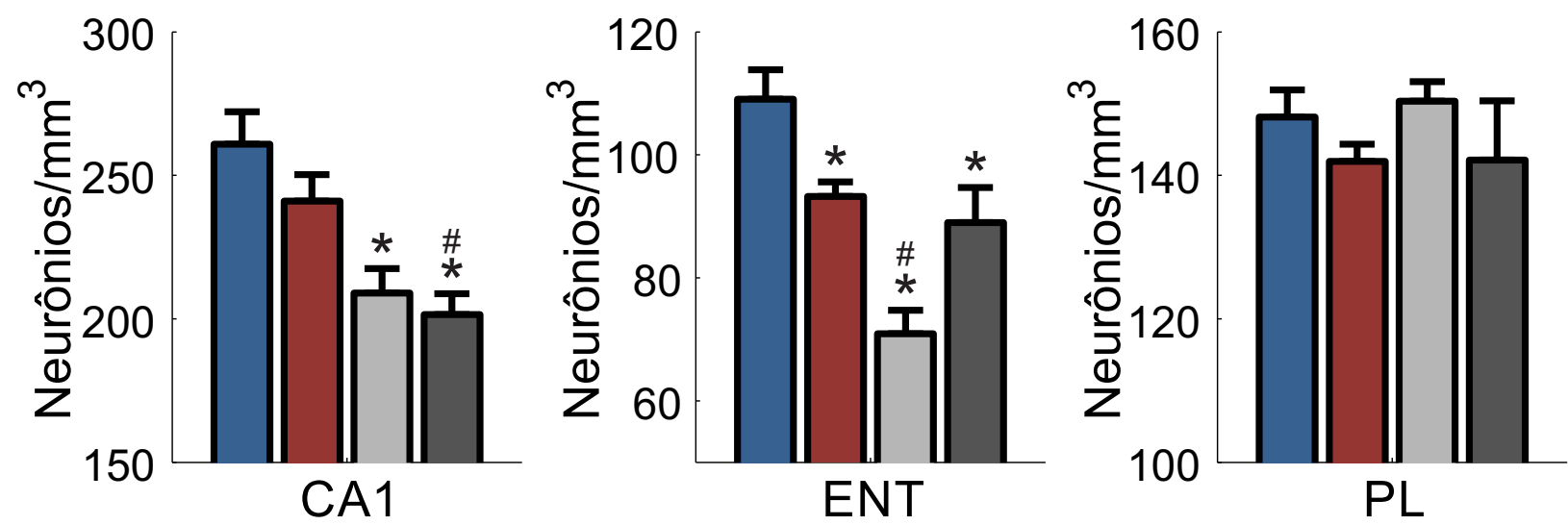

B Exp.2

$\square \mathrm{CTR}_{3} \square \mathrm{STZ}_{3} \square \mathrm{NIC}_{3} \square$ STZnic $_{3}$
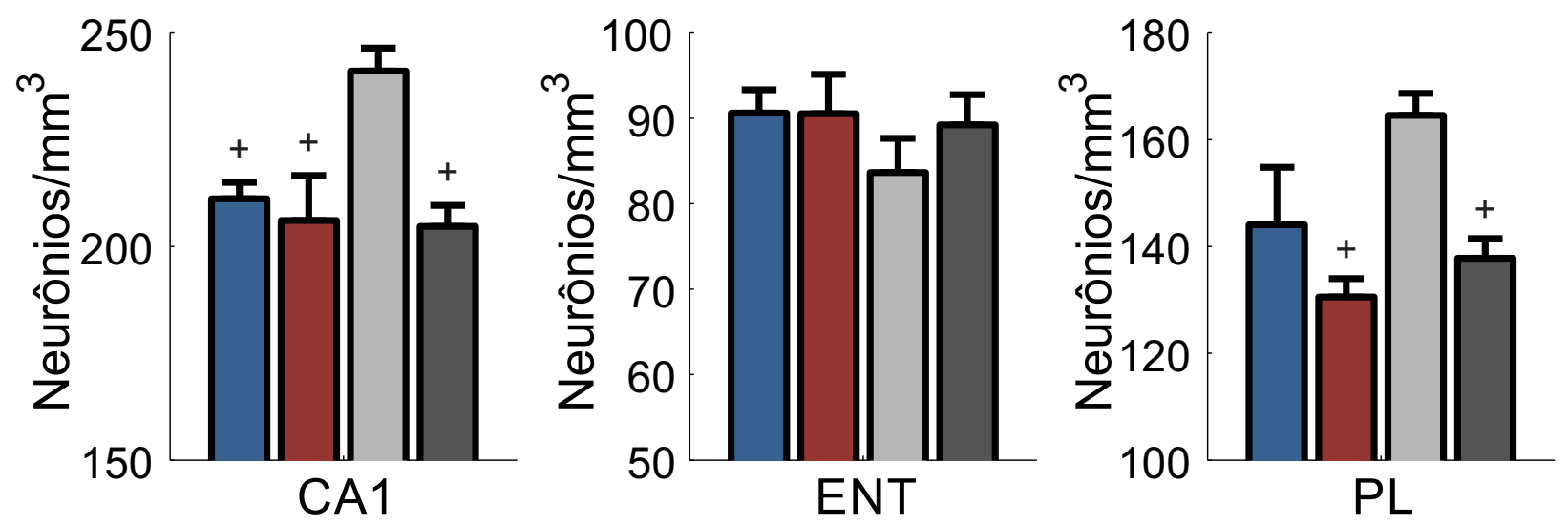

Figura 39 - Densidade Neuronal 1 mês e 3 meses após a injeção de STZ. (A) Nos animais do Experimento 1 houve em CA1 uma perda neuronal do grupo $N I C_{3}$ e $S T Z n i c_{1}$ em relação ao $C T R_{1}$ e também do $S T Z n i c_{1}$ em relação ao $S T Z_{1}$. No ENT todos os grupos apresentaram uma densidade menor em relação ao $C T R_{1}$ e o grupo $N I C_{1}$ também em relação ao $S T Z_{1}$. (B) No Experimento $2 \mathrm{O}$ grupo $N I C_{3}$ apresentou uma maior densidade neuronal em CA1 em relação aos demais grupos e no PL em relação ao $S T Z_{3}$ e $S T Z n i c_{3} .{ }^{*} p<0.05$ vs. CTR; ${ }^{\#} p<0.05$ vs. $\mathrm{STZ;}{ }^{+} p<0.05$ vs. NIC (ANOVA simples de uma via, seguido de teste post hoc de Tukey). 


\subsubsection{A STZ reduz a expressão de BDNF no PL e a nicotina reverte este efeito}

A avaliação da área imunorreativa para BDNF (Fig.40) mostra que em CA1 a nicotina, por si só, foi capaz de reduzir a expressão de BDNF, havendo uma redução significativa do grupo NIC em relação aos demais grupos $\left[F_{(3,18)}=6.000, \mathrm{p}<0.05\right.$; ANOVA de uma via simples, seguido teste post hoc de Tukey]. No córtex entorrinal houve um aumento da expressão de BDNF nos dois grupos tratados com nicotina (NIC e STZnic) porém a diferença foi significativa apenas em relação ao STZ $\left[F_{(3,18)}=6.563, \mathrm{p}<0.05\right.$; ANOVA de uma via simples, seguido teste post hoc de Tukey] e no pré-límbico a STZ reduziu a expressão de BDNF e a nicotina foi capaz de reverter esse efeito no grupo STZnic $\left[F_{(3,19)}=5.339, \mathrm{p}<0.05 ;\right.$ ANOVA de uma via simples, seguido teste post hoc de Tukey $]$ (Fig. 41). 


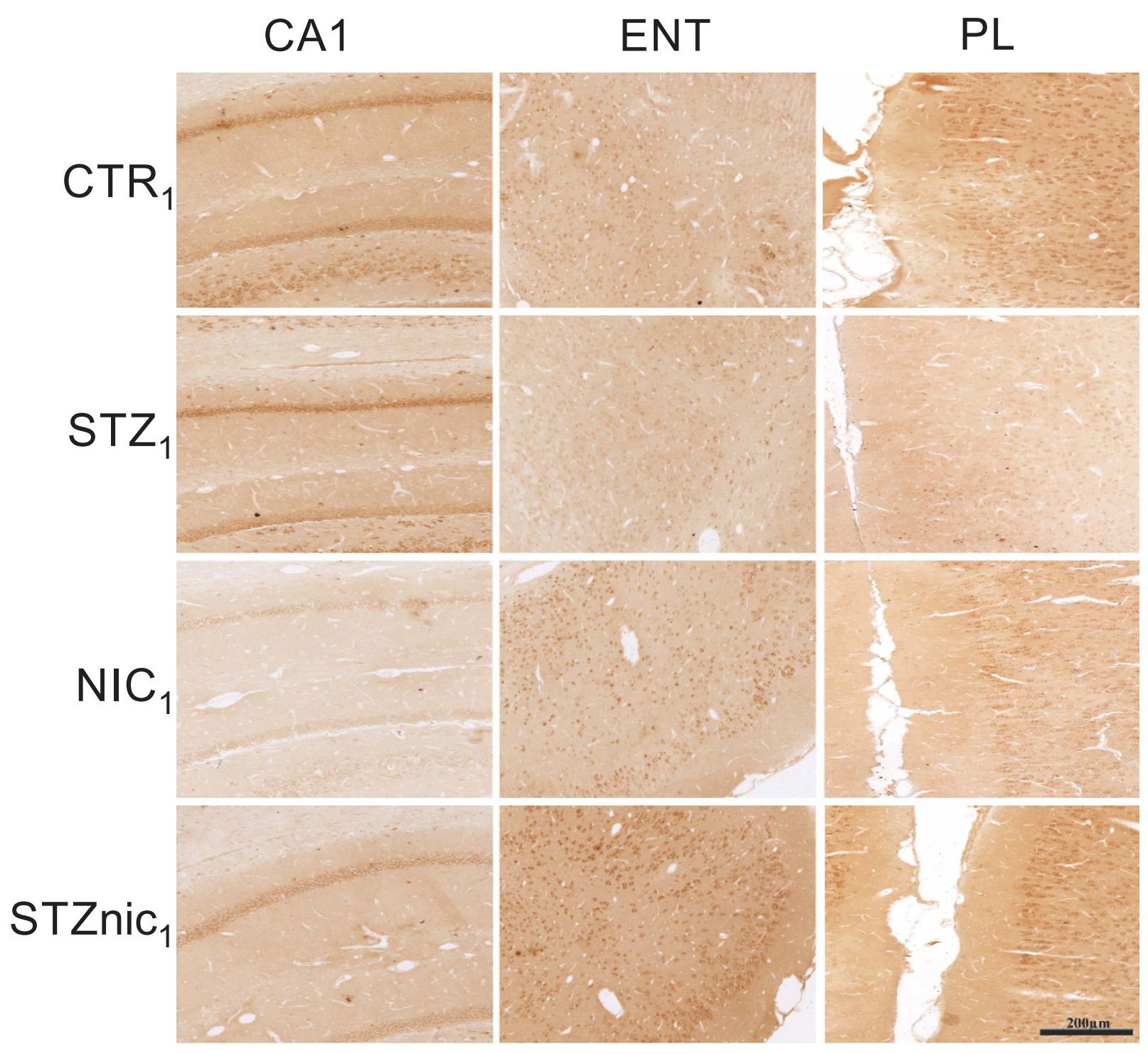

Figura 40 - Marcação da área imunorreativa para BDNF nos animais do Experimento 1 nas regiões CA1, córtex entorrinal (ENT) e Córtex pré-límbico (PL). 
$\square$ CTR $\square$ STZ $\square$ NIC $\square$ STZnic

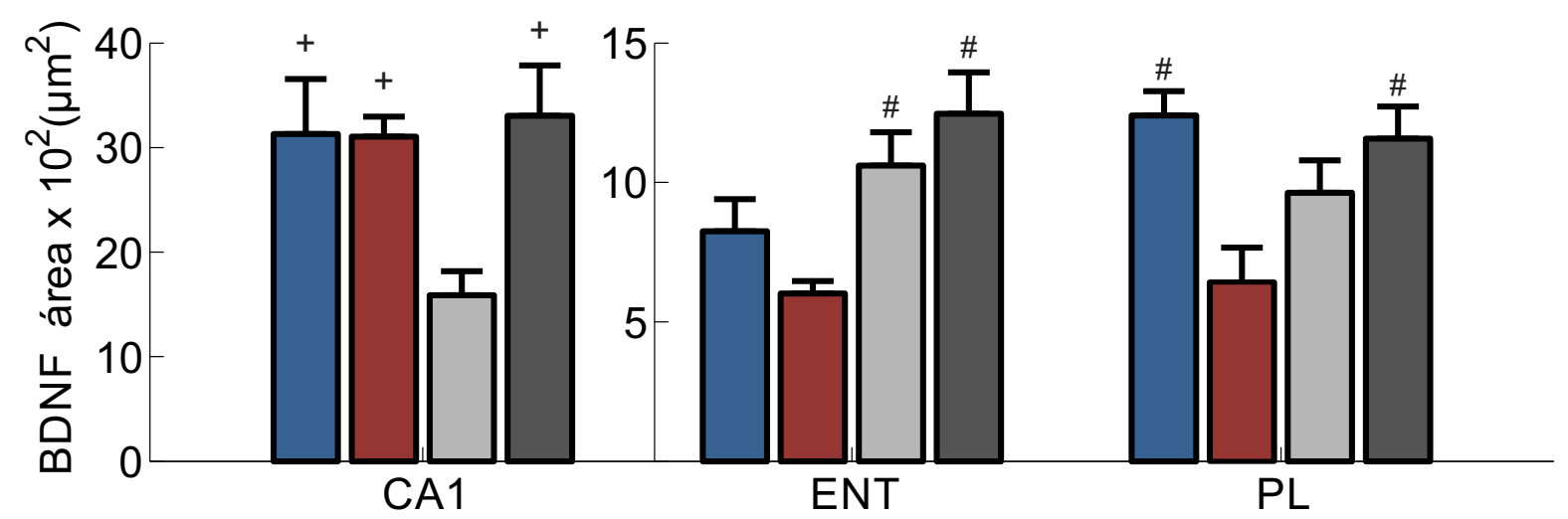

Figura 41 - Expressão de BDNF nos grupos do Experimento 1. Em CA1 a nicotina gerou uma redução de BDNF. No ENT ambos os grupos tratados com nicotina apresentaram um aumento na expressão de BDNF em relação ao STZ e no PL a STZ gerou uma redução na área imunorreativa para BDNF e a nicotina reverteu esse efeito no grupo STZnic. ${ }^{*} p<0.05$ vs. STZ; ${ }^{+} p<0.05$ vs. NIC (ANOVA simples de uma via, seguido de teste post hoc de Tukey)

A expressão de BDNF no pré-límbico apresentou correlação positiva com os dados eletrofisiológico (Fig. 42). Houve uma correlação positiva entre o BDNF no pré-límbico e o $f P S P_{1}(\mathrm{p}=0.03 ; \mathrm{R}=0.45)$, indicando também que a LTP está diretamente relacionada com a expressão de BDNF.

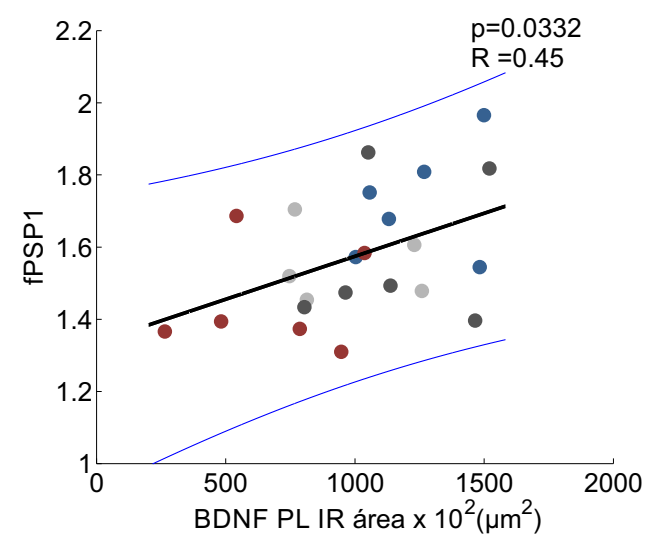

Figura 42 - Correlações com a expressão de BDNF. Correlação positiva entre BDNF no prélímbico e a amplitude normalizada do $f P S P_{1}(\mathrm{p}=0.03 ; \mathrm{R}=0.45)$. 


\subsubsection{O tratamento com nicotina aumenta a expressão de TrkB em CA1 e no ENT}

Ao avaliar a expressão de TrkB (Fig.43), nota-se que a nicotina acarretou um aumento da área imunorreativa no grupo NIC em relação aos demais três grupos tanto em CA1 $\left[F_{(3,15)}=9.172, \mathrm{p}<0.05 ;\right.$ ANOVA de uma via simples, seguido teste post hoc de Tukey] quanto no córtex entorrinal $\left[F_{(3,15)}=10.469, \mathrm{p}<0.05\right.$; ANOVA de uma via simples, seguido teste post hoc de Tukey]. No pré-límbico apenas o STZnic apresentou um aumento significativo em relação ao CTR $\left[F_{(3,17)}=3.870, \mathrm{p}<0.05\right.$; ANOVA de uma via simples, seguido teste post hoc de Tukey](Fig.44).

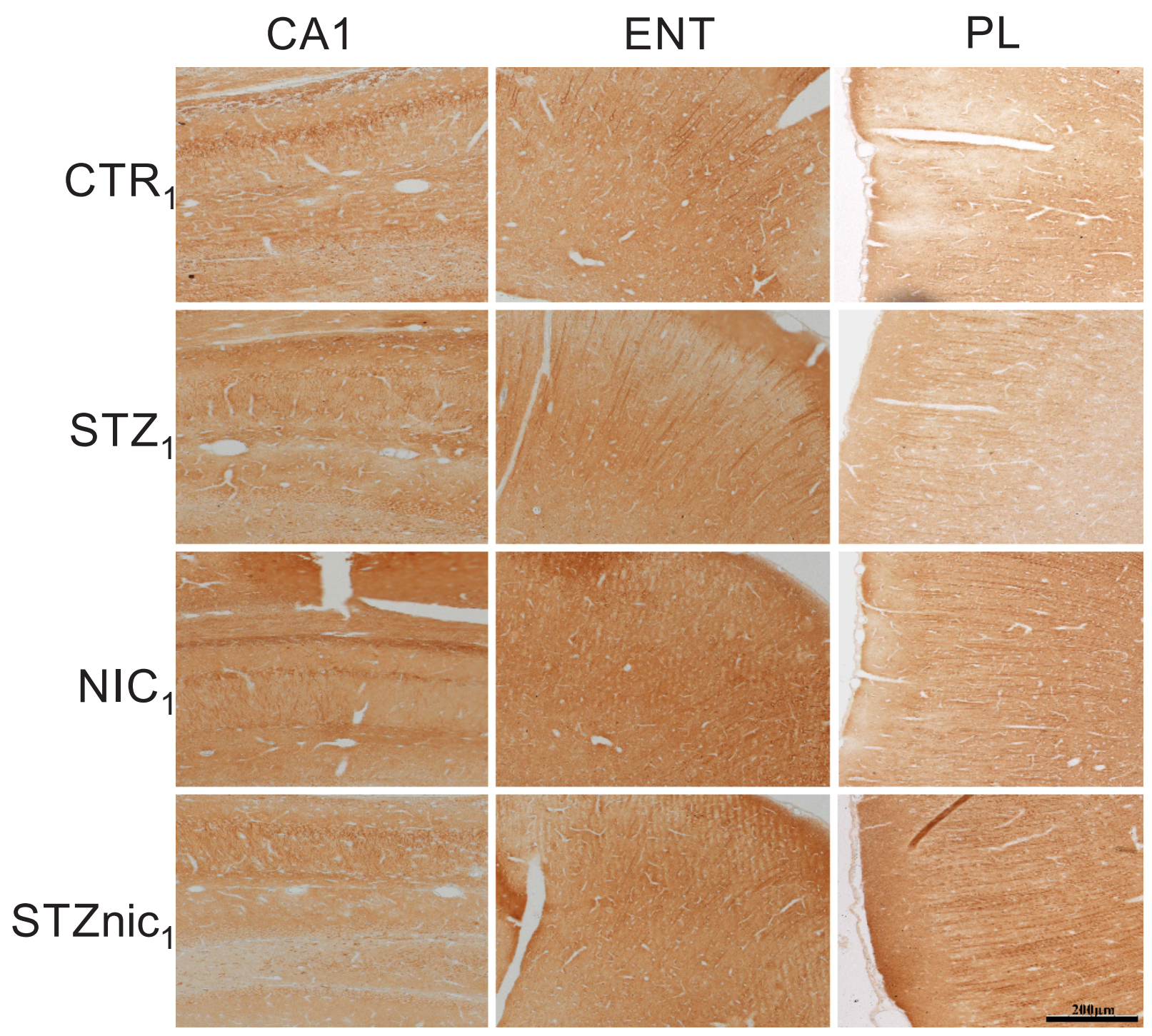


Figura 43 - Marcação da área imunorreativa para BDNF nos animais do Experimento 1 nas regiões CA1, córtex entorrinal (ENT) e Córtex pré-límbico (PL).

CCTR $\square$ STZ $\square$ NIC $\square$ STZnic

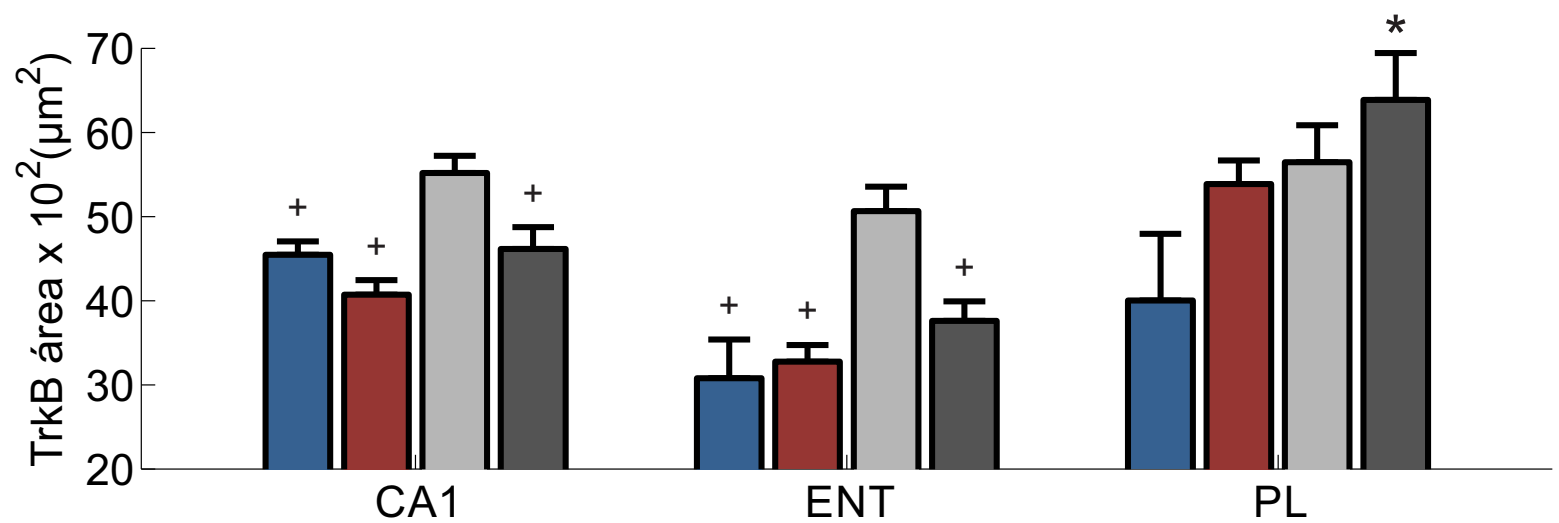

Figura 44 - Expressão de TrkB nos grupos do Experimento 1. A nicotina gerou um aumento na expressão de TrkB em CA1 e no ENT. No PL apenas a STZnic apresentou um aumento em relação ao CTR. ${ }^{*} p<0.05$ vs. $\mathrm{CTR} ;{ }^{+} p<0.05$ vs. NIC (ANOVA simples de uma via, seguido de teste post hoc de Tukey)

Teste de correlação indicaram uma relação direta entre a expressão de TrkB no Córtex Entorrinal com a amplitude do $f P S P_{1}$ durante a linha de base $(\mathrm{p}=0.0003 ; \mathrm{R}=0.72)$ e também entre a expressão de TrkB no pré-límbico com a amplitude do $f P S P_{1}$ durante a linha de base $(\mathrm{p}=0.014 ; \mathrm{R}=0.54)$. Indicando uma correlação entre o a expressão de TrkB no córtex e a eficiência na transmissão basal (Fig. 45).
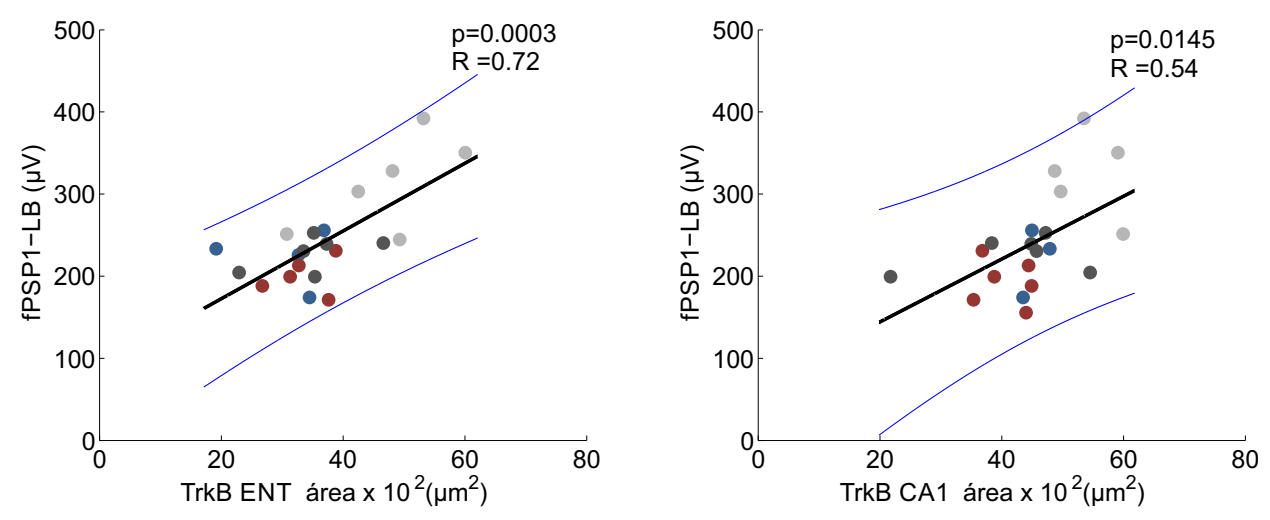

Figura 45 - Correlações com a expressão de TrkB. Esquerda - Correlação positiva entre TrkB no Córtex Entorrinal e a amplitude do $f P S P_{1}$ durante a linha de base $(\mathrm{p}=0.0003$; 
$\mathrm{R}=0.72$ ). Direita - Correlação positiva entre TrkB no CA1 e a amplitude do $f P S P_{1}$ durante a linha de base $(\mathrm{p}=0.014 ; \mathrm{R}=0.54)$.

\subsection{Resumo dos resultados}

Nesta Seção será apresentada tabelas resumindo todos os resultados deste trabalho. Para uma melhor visualização, setas em vermelho indicam alterações geradas pela STZ (comparando com o grupo CTR) e em azul as alterações geradas pela STZ associado com tratamento de nicotina no grupo STZnic (comparando com o grupo STZ). As células grifadas em ciano indicam os resultados em que a nicotina no grupo STZnic conseguiu reverter o o efeito da STZ e as células grifadas em amarelo indicam o efeito apenas do tratamento de nicotina.

Tabela 3 - Resultados dos testes comportamentais

\begin{tabular}{|c|c|c|c|c|c|c|}
\hline & \multicolumn{3}{|c|}{$\begin{array}{c}\text { Exp.1 } \\
\text { CA RO Explo. }\end{array}$} & \multicolumn{3}{|c|}{$\begin{array}{c}\text { Exp.2 } \\
\text { CA RO Explo. }\end{array}$} \\
\hline & $\downarrow$ & $\downarrow$ & - & - & $\downarrow$ & - \\
\hline STZnic - CTR & $\downarrow$ & - & - & - & - & - \\
\hline NIC - CTR & $\downarrow$ & - & $\downarrow$ & - & - & - \\
\hline STZnic - STZ & - & $\uparrow$ & - & - & $\uparrow$ & - \\
\hline
\end{tabular}

Tabela 4 - Resultados da plasticidade sináptica

\begin{tabular}{|c|c|c|c|c|c|c|}
\hline & $\mathrm{fPSP}$ & & $\mathrm{PF}$ & fPSP & & \\
\hline STZ - CTR & - & $\downarrow$ & $\downarrow$ & - & $\downarrow$ & - \\
\hline STZnic - CTR & - & - & - & - & - & - \\
\hline NIC - CTR & $\uparrow$ & - & $\downarrow$ & - & - & - \\
\hline STZnic - STZ & - & - & $\uparrow$ & - & $\uparrow$ & - \\
\hline
\end{tabular}

Tabela 5 - Resultados da análise espectral no CPFm

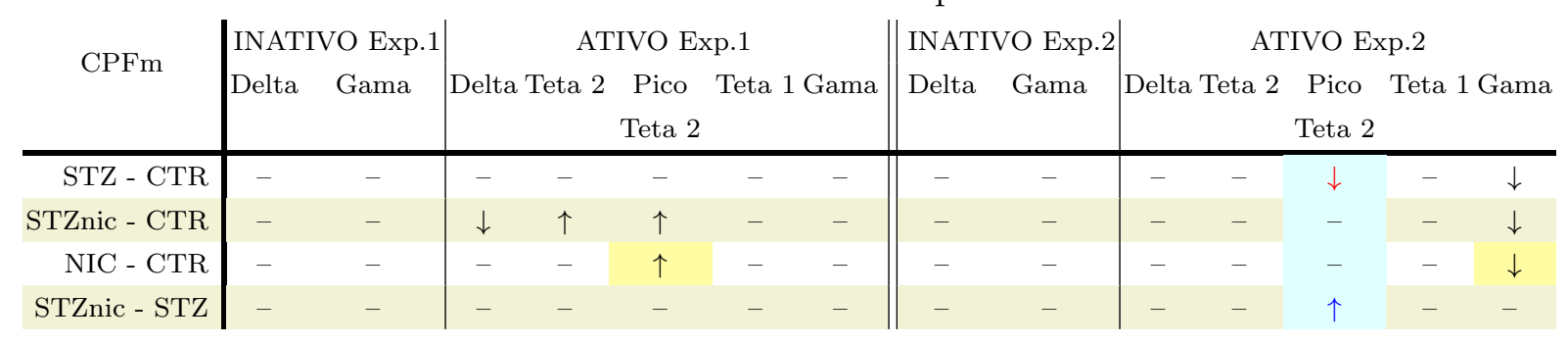


Tabela 6 - Resultados da análise espectral no CA1

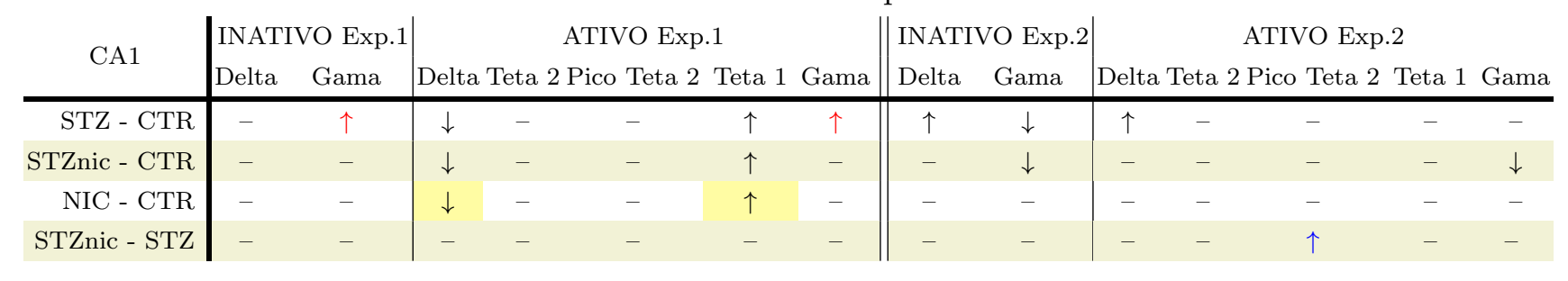

Tabela 7 - Resultados histológicos e imunohistoquímicos

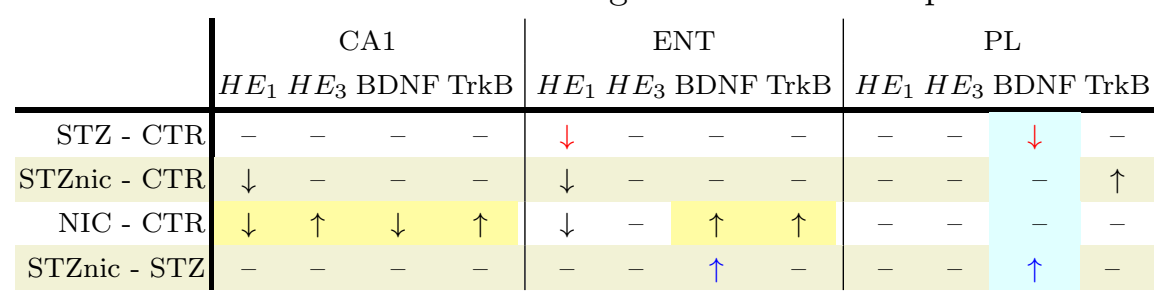




\section{Discussão}

Este trabalho é o primeiro estudo que caracteriza as propriedades eletrofisiológicas da via CA1-CPFm no modelo farmacológico da doença de Alzheimer e também é o primeiro a mostrar o efeito do tratamento crônico com nicotina neste modelo. Os principais resultados apresentados aqui mostram que a STZ-icv é capaz de induzir disfunções na memória de reconhecimento e gera um efeito prejudicial sobre a plasticidade sináptica na via CA1-CPFm in vivo. Além do mais, este trabalho mostra que o tratamento crônico com nicotina é capaz de prevenir os déficits induzidos pela STZ tanto na memória de reconhecimento quanto na plasticidade sináptica. Estes resultados, referentes às disfunções de plasticidade e de memória de reconhecimento, foram observados tanto nas análises de curto quanto nas de longo prazo. A seguir será realizada uma discussão mais detalhada sobre cada resultado tendo como referência as tabelas da Seção 5.5

\subsection{Análises comportamentais}

Os resultados comportamentais neste trabalho mostraram que tanto a STZ-icv quanto o tratamento com nicotina reduzem a locomoção a curto prazo. Além disso, apenas o grupo STZ apresentou déficits no teste de reconhecimento de objeto em ambos os tempos avaliados. Os animais tratados com nicotina, grupos NIC e STZnic, apresentaram hipolocomoção após o fim do tratamento, na literatura existem trabalhos que também observaram uma hipolocomoção logo após o fim do tratamento crônico com nicotina - semelhante ao apresentado neste trabalho tanto no grupo NIC quanto no grupo STZnic logo após o fim do tratamento do Experimento 1 (FUNG et al., 1996; NOMIKOS et al., 1999). FUNG et al. (1995) realizaram tratamento crônico com nicotina em ratos na dose de 1.5 $\mathrm{mg} / \mathrm{kg} /$ dia e $3 \mathrm{mg} / \mathrm{kg} /$ dia durante 14 dias. Após $24 \mathrm{~h}$ do fim do tratamento ambas as doses 
resultaram em redução da atividade locomotora e esta redução coincide com redução do nível de dopamina no estriado e no núcleo accumbens. Outro trabalho que estudou o efeito da abstinência da nicotina também constatou redução da atividade locomotora (NOMIKOS et al., 1999). Porém, os sintomas da abstinência foram obtidos por meio de injeções de um antagonista da subunidade $\alpha 7$ do receptor nicotínico (metilicaconitina). Além de constatarem hipolocomoção e alterações no sistema dopaminérgico do núcleo accubens, NOMIKOS et al. (1999) concluíram que a subunidade $\alpha 7$ está envolvida nas reações causadas pela retirada da nicotina. Como existem receptores nicotínicos nos terminais pré-sinápticos das células dopaminérgicas no corpo estriado, ambos os trabalhos reforçam o conceito de que neurônios desta região são capazes de influenciar o planejamento motor, tomada de decisão, motivação, recompensa e de terem um papel no desenvolvimento de dependência de droga (YAGER et al., 2015). Os resultados apresentados aqui indicam que também não houve alteração na atividade locomotora a longo prazo (no animais do Experimento 2). Este resultado corrobora o conceito de que a hipolocomoção gerada pela nicotina é um efeito colateral da abstinência da droga.

Além do grupo NIC e STZnic, neste trabalho também foi mostrado que o grupo STZ apresenta atividade locomotora reduzida a curto prazo e não apresenta diferenças a longo prazo. Na literatura não existe um consenso em relação às alterações na atividade locomotora gerada apenas pela STZ-icv, existem trabalhos que detectaram um aumento (MAYER; NITSCH; HOYER, 1995; CHEN et al., 2013) e trabalhos que não detectaram alterações (SAXENA; PATRO; NATH, 2011; SHARMA et al., 2012; TOTA et al., 2010; RAI et al., 2013). Provavelmente estes diferentes resultados estão relacionados com as diferentes doses de STZ utilizadas, a espécie de animal testada (rato ou camundongo) e também a janela de tempo em que a locomoção é avaliada.

O teste de reconhecimento de objeto está sendo cada vez mais utilizado como uma ferramenta para testar efeitos de drogas e para também compreender os mecanismos relacionados ao processo de formação de memória e aprendizado (BENGOETXEA; RODRIGUEZPERDIGON; RAMIREZ, 2015). Este teste consegue avaliar um comportamento espontâneo, com a vantagem de não necessitar de uma motivação externa, de punição ou de recompensa, tornando-se útil para explorar mecanismos relacionados a quadros demenciais como a DA e possíveis tratamentos (BENGOETXEA; RODRIGUEZ-PERDIGON; RAMIREZ, 2015). A redução do índice de reconhecimento do grupo STZ apresentada nesta tese também está consistente com a literatura que descreve déficits comportamentais no modelo STZ-icv. De forma mais específica, SHOHAM et al. (2007) e ESPINOSA et al. (2013) relataram uma piora significativa na memória de reconhecimento em ratos 
tratados com STZ-icv. Outro estudo comparativo entre camundongos triplo transgênicos (3xTg) e camundongos tratados com STZ-icv também relatou a existência de prejuízos na memória episódica de curto prazo em ambos os modelos e mostrou que os camundongos STZ-icv apresentaram alterações mais acentuadas que os camundongos transgênicos (CHEN et al., 2013). No que diz respeito ao efeito da nicotina na reversão dos déficits gerados pela STZ, este é o primeiro trabalho a mostrar este resultado. Alguns estudos mostram que o sistema colinérgico desempenha um importante papel na plasticidade sináptica nesta tarefa (WARBURTON et al., 2003). Neste contexto, existem trabalhos que comprovam o déficit no desempenho da tarefa de RO em modelos de DA e que tratamentos com inibidores da acetilcolinesterase tais como a galantamina - utilizados para tratar a DA na clinica - ou agonistas muscarínicos do tipo M1 conseguem reverter este déficit (USLANER et al., 2013; de Bruin; POUZET, 2006). Em relação ao efeito apenas da nicotina, o tratamento crônico por si só não altera a memória de reconhecimento. KENNEY et al. (2011) observaram o efeito da nicotina aguda, crônica e 24 h após o fim do tratamento e constataram que apenas a nicotina aguda prejudica a tarefa de reconhecimento de objeto. O efeito da nicotina em testes cognitivos e em processos de aprendizado não é universal e sim específico de cada tipo de tarefa, além de ser dependente da dose e do tempo do tratamento. De forma geral, tarefas hipocampo-dependentes - que apresentam uma melhora na presença de nicotina aguda - resultam em déficits durante a retirada da droga (DAVIS; GOULD, 2009). Este seria um dos motivos do tratamento com nicotina, ou a sua retirada, não ter alterado o índice de reconhecimento nos grupos NIC.

Adicionalmente, estudos mostram que déficits em diversos testes cognitivos em animais STZ-icv também estão associados com a redução da produção da colina acetiltransferase - ChAT (BLOKLAND; JOLLES, 1993; PRICKAERTS; FAHRIG; BLOKLAND, 1999). Em conjunto, estes dados corroboram a hipótese de que a redução na neurotransmissão colinérgica associada a prejuízos de plasticidade sináptica, pode ser uma das bases dos mecanismos relacionados aos resultados comportamentais observados neste trabalho. Além disso, é sugerido que o aumento da transmissão colinérgica gerada pela nicotina é capaz de reduzir os déficits observados. 


\subsection{Alterações na plasticidade sináptica}

Na análise de plasticidade sináptica, a STZ-icv gerou déficits tanto na indução quanto na manutenção da LTP no grupo STZ, independente do tempo. A curto prazo houve também uma redução do PPF e este efeito não ocorreu a longo prazo. Disfunções sinápticas em modelos transgênicos da DA já foram bem abordados na literatura (CLARK et al., 2015; SANCHETI et al., 2013; CHAKROBORTY et al., 2012). Já no modelo com STZicv, este trabalho é o primeiro a caracterizar a via CA1-CPFm in vivo. Estudos in vitro que pesquisaram a plasticidade na via colateral de Schaffer em modelos STZ-icv demonstraram que a LTP hipocampal é afetada pela STZ-icv (SHONESY et al., 2012; XU et al., 2014). SHONESY et al. (2012) também constataram que a STZ não é capaz de alterar o PPF na via colateral de Schaffer e sugeriram que a resistência de insulina cerebral, causada pela STZ, gera déficits devido a uma alteração da sinalização da via ILK-GSK-3 $\beta$. Os coautores deste trabalho também mencionaram que alteração desta via acarreta uma diminuição da expressão de receptores pós-sinápticos glutamatérgicos. XU et al. (2014), além da disfunção na LTP no hipocampo causada pela STZ-icv, mostraram que a droga gera uma diminuição da densidade de espinhos dendríticos. Além disso, constataram que a STZ-icv reduz o nível de GSK-3 $\beta$, PI3K e AKt fosforilada, o que indica uma alteração na via PI3/PkB - cascata de sinalização responsável por promover sobrevivência neuronal. Assim sendo, os achados eletrofisiológicos apresentados aqui corroboram a noção de que a STZ-icv produz perda de memória e uma redução da plasticidade sináptica de longa duração, sendo que a curto prazo houve também prejuízos na plasticidade pré-sináptica. Porém, mais estudos serão necessário para explicar o fato da STZ-icv gerar déficits pré e pós-sinápticos a curto prazo e apenas pós-sinápticos a longo prazo.

O declínio de memória associado à DA está relacionado com déficits na plasticidade, principalmente no hipocampo, e evidências sugerem que esta alteração antecede ao processo neurodegenerativo presente na doença (SELKOE, 2002). O hipocampo é essencial para consolidação e evocação de memórias declarativas (MOSER; ROWLAND; MOSER, 2015) e a comunicação existente entre o córtex prefrontal e o hipocampo é essencial para o desenvolvimento de funções relacionadas com tomadas de decisão, processamento de memória de trabalho e de memória espacial (VERTES, 2006). A LTP pode ser considerado um mecanismo que antecede ao processo de formação de memória (LAMPRECHT; LEDOUX, 2000). Apesar da importância da comunicação ente o hipocampo e o córtex pré-frontal em processos cognitivos, pouco se sabe sobre as alterações sínápticas que 
ocorrem na progressão da DA e também sobre a relação do sistema colinérgico nestas disfunções. Porém estudos mostram que a pilocarpina (um agonista muscarínico) é capaz de aumentar a plasticidade sináptica nesta via (LOPES-AGUIAR et al., 2008). Além disso, os déficits na LTP encontrado neste trabalho no modelo animal da DA, junto com trabalhos que mostram que a STZ-icv gera déficits tanto na memória de trabalho quanto na memória espacial (LANNERT; HOYER, 1998; SUN et al., 2015) é um forte indício de que - assim como nos pacientes com DA (BUCKNER, 2004) - as disfunções sinápticas estão modulando os déficits comportamentais neste modelo no estágio inicial da doença.

Existem evidências que relacionam disfunções mitocondriais e estresse oxidativo às alterações patológicas da DA (WANG et al., 2009). Estes eventos causam diminuição na sínteses da ATP que culmina em disfunções sinápticas devido à grande demanda de energia que esse processo exige (JüRGENSEN; FERREIRA, 2010). SAXENA et al. (2011) mostraram que animais STZ-icv apresentam disfunções mitocondriais, elevado influxo de $\mathrm{Ca}^{2+}$ e uma alta produção de radicais livres. SAXENA et al. (2011) também conseguiram mostrar que o tratamento crônico com nicotina nos animais STZ-icv desencadeou uma atividade neuroprotetora, capaz de prevenir as disfunções mitocondriais causadas pela STZ-icv - sem gerar alterações nos ratos saudáveis, em situação fisiológica normal. Seguindo esta linha de raciocínio, vários estudos relataram o papel neuroprotetor da nicotina na plasticidade sináptica (PICCIOTTO; ZOLI, 2002; LIU; ZHAO, 2004; FUJII; SUMIKAWA, 2001; UNGER et al., 2006; POORTHUIS et al., 2009). Porém, foi encontrado apenas um trabalho que investigou, através da LTP in vivo, o efeito do tratamento crônico com nicotina em um modelo animal da DA (SRIVAREERAT et al., 2011).Os pesquisadores deste estudo avaliaram um modelo animal da DA, induzido pela infusão do peptídeo beta-amilóide. Os animais foram tratados com nicotina e tiveram a memória avaliada em teste de labirinto radial aquático e posteriormente, registros eletrofisiológicos foram realizados durante a indução da LTP hipocampal sob anestesia com uretana. Os resultados apresentados por SRIVAREERAT et al. (2011) sugerem que a nicotina é capaz de prevenir os déficits de memória espacial e de curto prazo induzidos pela beta-amilóide sem afetar a memória em ratos saudáveis. A nicotina também conseguiu reverter os déficits induzidos pela beta-amilóide na LTP na via colateral de Schaffer e mostraram que a nicotina por si só não altera a indução da LTP em animais saudáveis. Apesar de não conseguirem explicar os mecanismos por trás do papel neuroprotetor da nicotina, SRIVAREERAT et al. (2011) sugerem que o tratamento gera maior expressão de receptores de nicotina, que possuem propriedades antioxidantes e protetoras contra a excitotoxicidade.

O tratamento com nicotina gera desensibilização seguido de uma maior expressão de 
receptores nicotínicos. Esta dessensibilização pode ser um dos responsáveis pelo papel neuroprotetor desempenhado pela nicotina (JONNALA; BUCCAFUSCO, 2001). O aumento no número de receptores nicotínicos é capaz também de aumentar a transmissão glutamatérgica em diversas regiões do cérebro, como o córtex pré-frontal (GRAY et al., 1996; WANG et al., 2006), e isso pode justificar a melhor eficiência na transmissão basal apresentada pelo grupo NIC a curto prazo (visto que esse aumento da expressão de receptores não é permanente).

Além do mais, pesquisas mostram que durante o período de abstinência de nicotina também existe aumento da expressão de receptores nicotínicos $\alpha 7$ nos interneurônios gabaérgicos de CA1, o que gera inibição dos neurônios piramidais desta região (KENNEY; GOULD, 2008). Este aumento da atividade inibitória no hipocampo durante a abstinência de nicotina pode ser a causa dos déficits pré-sinápticos gerados pela droga a curto prazo apenas no grupo NIC. Como a STZ gera déficits colinérgicos (BLOKLAND; JOLLES, 1993), é provável que animais STZ-icv também apresentem uma redução na expressão de receptores nicotínicos. Sendo assim, o grupo STZnic se tornaria menos suscetível ao efeito inibitório acarretado pela abstinência da nicotina. Este fato pode ser um dos motivos pelo o qual déficit pré-sináptico, mostrado pela redução do PPF, não está presente no grupo STZnic. Mas esta hipótese ainda precisaria ser testada.

A hipofunção colinérgica - indicada pela redução de marcadores colinérgicos tais como a ChAT, ACh, e AChR - entre o prosencéfalo basal e seus alvos no cortex e no hipocampo está correlacionada com déficits progressivos de memória já no estágio inicial da DA (HERNANDEZ; DINELEY, 2012; SCHLIEBS; ARENDT, 2006, 2011). Estas alterações levaram à formulação da hipótese colinérgica da disfunção de memória presentes na velhice e também na DA (BARTUS, 2000; CRAIG; HONG; MCDONALD, 2011). O aumento do nível de acetilcolina no cérebro pelo uso contínuo de drogas inibidoras da enzima acetilcolinesterase é o tratamento sintomático da DA atualmente aceito na clínica (ANAND; GILL; MAHDI, 2014). No entanto vários estudos indicam que a modulação direta das subunidades $\alpha 7$ e $\alpha 4 \beta 2$ do receptor colinérgico nicotínico (nAChR) é capaz de induzir uma melhora na transmissão sináptica e também na cognição (WALLACE; PORTER, 2011; ONDREJCAK et al., 2012; KROKER; RAST; ROSENBROCK, 2011). Neste contexto, uma nova abordagem terapêutica alternativa para o tratamento da DA e para outros distúrbios cognitivos vem emergindo visando o aumento da neurotransmissão colinérgica pela ativação direta dos receptores nicotínicos (HAYDAR; DUNLOP, 2010). A nicotina é um agonista que se liga com elevada afinidade às subunidades $\alpha 7$ e $\alpha 4 \beta 2$ dos nAChR e a ativação dessas subunidades é um possível mecanismo de neuroproteção 
mediada pela nicotina. Isto foi sugerido por estudos que conseguiram mostrar que os efeitos protetores da nicotina são bloqueados por antagonistas do nAChR (AKAIKE et al., 2010). Além disso, estes receptores podem modular a liberação de ACh e a homeostase do $\mathrm{Ca}^{2+}$, envolvidos nos processos de aprendizagem e de memória (SéGUéLA et al., 1993; MCGEHEE et al., 1995). Assim sendo,os achados eletrofisiológicos deste trabalho sugerem que a nicotina proporciona um efeito protetor contra a deterioração da memória em AD através do reforço colinérgico.

\subsection{Análises oscilatórias}

Os resultados das análises oscilatórias mostraram que a STZ-icv gera a curto prazo aumento das oscilações rápidas (Gama Alto) com redução das lentas (Delta Baixo). Porém, a longo prazo o resultado foi invertido, houve redução de Gama Alto e aumento de Delta Baixo em CA1. Neste caso, a nicotina não foi eficiente em reduzir as alterações geradas pela STZ em ambos os tempos. Além disso, a STZ-icv reduz o pico em Teta 2 (3-5Hz) no CPFm apenas a longo prazo, sem gerar alterações a curto prazo e a nicotina aumenta o pico em Teta 2 a curto prazo e reverte a redução gerada pela STZ a longo prazo.

Atividades oscilatórias como o ritmo teta tem sido o foco de estudo de vários trabalhos. O ritmo teta está associado a processos cognitivos e é considerado uma oscilação capaz gerar LTP (BUZSáKI, 2002; VERTES, 2005). Além do mais, uma correlação entre formação de memória e teta hipocampal foi demonstrada em diversos trabalhos tanto em animais quanto em humanos (LISMAN; REDISH, 2009; LEGA; JACOBS; KAHANA, 2012). As oscilações teta e gama também são descritas como componente importantes no processo de consolidação de memória e em funções executivas (BUZSáKI, 2002; LISMAN; BUZSáKI, 2008; COLGIN; MOSER, 2010). Mais recentemente foi demonstrado também que a magnitude do acoplamento entre teta e gama desempenham um papel importante no processo de aprendizado e memória em ratos, macacos e humanos (TORT et al., 2009; CANOLTY et al., 2010; AXMACHER et al., 2010). Também existem evidências que sugerem a alteração de atividade oscilatória em pacientes com DA, tanto em teta quanto em gama (MORETTI et al., 2010; van Deursen et al., 2008). Existem trabalhos que sugerem que essas alterações são gerada pela proteína beta-amilóide (SCOTT et al., 2012) e outros 
que indicam que ela precede à formação das placas amilóide (GOUTAGNY et al., 2013). Além do mais, alterações em teta tem sido consideradas como um possível preditor da DA (JELIC et al., 2000)). Porém, os mecanismos envolvendo essas alterações não são totalmente conhecidos, sendo necessários mais estudos para conseguir elucidar como essas disfunções são desencadeadas.

A oscilação gama é gerada por uma interação coordenada de ativação das células piramidais com inibição dos interneurônios (BUZSáKI; WANG, 2012) e disfunções nesse sincronismo podem acarretar alterações nesta oscilação. Trabalhos utilizando optogenética e camundongos knockout da subunidade NR1 dos receptores NMDA mostraram que a inativação de interneurônios parvalbuminérgicos aumenta a potência da oscilação gama e este aumento está associado a déficits em funções cognitivas (CARLéN et al., 2012; YIZHAR et al., 2011; KOROTKOVA et al., 2010). Esta inativação ou hipofunção dos receptores NMDA localizado nos interneurônios gera um aumento no balanço exitatório/inibitório existente entre interneurônios e células piramidais (YIZHAR et al., 2011). Desta forma pode-se sugerir que o aumento inicial de gama nos animais STZ-icv do Experimento 1 pode ser decorrente de uma disfunção nos interneurônios gabaérgicos localizados em CA1. Além disso, como a longo prazo a STZ gera redução do numero de espinhas dendríticas (XU et al., 2014), a lentificação do LFP nos animais do Experimento 2 - decorrente de aumento na potência de Delta Baixo e redução de potência de Gama Alto pode ser decorrente da redução da conectividade entre os neurônios.

As alterações observadas na oscilação teta indicam que a STZ-icv reduz o pico em Teta $2(3-5 \mathrm{~Hz})$ no CPFm apenas a longo prazo, sem gerar alterações a curto prazo. Em CA1 pode-se observar também que a longo prazo existe redução de Teta 2 nos animais STZ, apesar de não apresentar diferença estatística. KOROTKOVA et al. (2010) constataram que camundongos knockout para receptores NMDA, específico em interneurônios, apresentam redução na oscilação teta e déficits na memória de reconhecimento, além do aumento em gama mencionado anteriormente. SCOTT et al. 2012 também relataram redução em teta em modelos transgênicos da DA, mostrando que esta redução também é dependente do peptídeo beta-amilóide e também que aumenta ao decorrer do tempo. Considerando que a STZ desencadeia processos inflamatórios (SAXENA; PATRO; NATH, 2011) e redução na expressão de receptores de NMDA (RAI et al., 2013), o déficit em teta observado no grupo STZ, assim como o aumento em gama, pode ser decorrente de hipofunção dos receptores NMDA nos interneurônios, que possivelmente está relacionado com os déficits na LTP e na memória de reconhecimento. 
O tratamento com nicotina acarreta aumento na oscilação Teta 2 no CPFm a curto prazo (tanto no grupo NIC quanto no grupo STZnic) e consegue reverter a redução gerada pela STZ a longo prazo. Em CA1 a nicotina gera aumento neste pico apenas nos grupos STZnic. Tanto o sistema glutamatérgico quanto o colinérgico estão associados à oscilação teta e a ativação de receptores nicotínicos localizados em terminais de neurônios glutamatérgicos é capaz de aumentar a oscilação Teta Tipo 2 (KISS et al., 2013b; SIOK et al., 2006). Estes fatos, em conjunto, sugerem que o aumento da transmissão glutamatérgica gerada pelo tratamento com nicotina pode ser um dos fatores pelo qual a nicotina conseguiu reverter o déficit causado pela STZ na oscilação teta. A presença de correlação direta entre PPF e o pico de Teta 2 corrobora a idéia de que o sistema glutametérgico pode ser uma dos fatores que influenciam nas alterações da oscilação teta e a plasticidade sináptica neste trabalho.

\subsection{Resultados histológicos e imunohistoquímicos}

A seguir serão discutidos os resultados histológicos apresentados neste trabalho, assim como as correlações destes resultados com dados comportamentais e eletrofisiológicos. Entre os principais resultados está a redução da expressão de BDNF nos animais STZ e a sua reversão pela nicotina na região pré-límbica do córtex. Além disso, considerando apenas o efeito do tratamento com nicotina em animais controles, foi observado: papel neuroprotetor da nicotina na densidade neuronal, aumento da expressão de BDNF e de seu receptor no córtex entorrinal e redução da expressão de BDNF em CA1 compensada por um aumento na expressão de seu receptor.

A redução da densidade neuronal gerada pela STZ e pelo tratamento com nicotina a curto prazo pode ser decorrente de alguma condição transitória (como por exemplo processos inflamatórios), visto que não foram observadas estas alterações a longo prazo. O aumento da densidade neuronal do grupo NIC em relação aos demais é um forte indicador de que a nicotina a longo prazo apresentou um papel neuroprotetor em CA1, promovendo uma manutenção neuronal. Como a avaliação da densidade neuronal foi realizada por coloração com HE - que marca neurônios em varias fases do neurodesenvolvimento e glias - não se pode afirmar que de fato houve um aumento do numero de neurônios, para isso seria necessário fazer outras marcações mais especificas como NeuN (para neurônios 
maduros) e GFAP (para glias).

Neste trabalho foi constatada redução da expressão de BDNF em PL no grupo STZ e que o tratamento crônico com nicotina foi capaz de reverter este déficit, sem alterar a expressão desta proteína nos animais controles. O BDNF é capaz de ativar cascatas de sinalização que desempenham papeis críticos em processos de diferenciação neuronal, sobrevivência, plasticidade sináptica e cognição (BARTKOWSKA; TURLEJSKI; DJAVADIAN, 2010; ALDERSON et al., 1990; MINICHIELLO et al., 1999). A redução desta neurotrofina na região pré-límbica do CPFm no grupo STZ pode ser um dos mecanismos que explica os déficits na plasticidade verificados na via CA1-CPFm. Tendo em vista que a LTP nesta via requer ativação de receptores NMDA, antagonistas são capazes de inibir a indução da LTP (JAY; BURETTE; LAROCHE, 1995), consequentemente a diminuição da expressão desses receptores gera prejuízo na LTP desta via. Além disso, trabalhos mostram a insulina regula a expressão de receptores NMDA (SKEBERDIS et al., 2001) e que o glutamato também estimula a produção de BDNF (MATTSON, 2008). Em contrapartida, neurotrofinas como o BDNF também são capazes de regular tanto o RNAm quanto o número de proteínas das subunidades de receptores NMDA (CALDEIRA et al., 2007). Considerando que a STZ gera uma resistência à insulina (SALKOVIC-PETRISIC; HOYER, 2007), os fatos mencionados acima (juntamente com a menor expressão de BDNF observada nos animais STZ na região pré-límbica do CPFm) sugerem uma possível redução da expressão de receptores NMDA nos animais STZ. Esta redução pode estar associada aos déficits na LTP nesta via.

Além disso, a reversão induzida pela nicotina na diminuição de BDNF no PL, observada no grupo STZnic, reforça a hipótese da ativação glutamatérgica - desencadeada por tratamento crônico com nicotina (GRAY et al., 1996; WANG et al., 2006) - como responsável pelo aumento da expressão de BDNF e consequentemente melhora na LTP no grupo STZnic. Esta hipótese é reforçada pela correlação positiva obtida entre a expressão de BDNF no PL e a amplitude do $f P S P S_{1}$ durante a LTP.

O efeito que a nicotina exerce na expressão de neurotrofinas varia de acordo com a região do cérebro e janela de tempo analisada. No caso do BDNF, a nicotina agudamente promove redução, por outro lado, o tratamento crônico com nicotina aumenta a expressão dessa molécula e a abstinência retoma a redução da expressão em CA1 (KENNY; FILE; RATTRAY, 2000; VARANI; MOUTINHO; BALERIO, 2014). Este efeito parece ser dependente da subunidade $\alpha 7$ dos receptores nicotínicos visto que trabalhos mostram que antagonistas seletivos da subunidade $\alpha 7$ são capazes de aumentar a expressão de BDNF 
(FREEDMAN et al., 1993). Como mencionado anteriormente, durante o período de abstinência da nicotina existe aumento no número de receptores nos interneurônios gabaérgicos do hipocampo (KENNEY; GOULD, 2008). Este aumento da atividade inibitória gabaérgica - associada ao aumento do número de receptores nicotínicos - gera uma redução da expressão de BDNF durante a abstinência da nicotina (VARANI; MOUTINHO; BALERIO, 2014). Além disso, receptores GABA presentes em CA1 também estão associados às alterações tanto comportamentais quanto bioquímicas produzidas pela abstinência da nicotina (VARANI; MOUTINHO; BALERIO, 2015). Estes fatos podem sugerir que a redução da expressão de BDNF no grupo NIC em CA1 tenha sido gerada pelo aumento da atividade gabaérgica em interneurônios inibitórios, devido à retirada da nicotina.

KANDRATAVICIUS et al. (2014) em estudo com pacientes com epilepsia mesial do lobo temporal observaram aumento de TrkB acompanhado de redução de BDNF, em uma dinâmica compensatória entre a expressão do BDNF e seu receptor TrkB, na tentativa de manter as cascatas de sinalização ativadas pelo BDNF. De forma semelhante, nesse estudo tal dinâmica foi observada. Esta hipóteses é reforçada pela correlação positiva existente entre os receptores de BDNF e a eficiência basal do $f P S P_{1}$ em CA1, sugerindo que mesmo havendo uma redução de BDNF no grupo NIC, o receptor de BDNF continua contribuindo para a manutenção sináptica.

Ao avaliar o córtex entorrinal, foi observado que o tratamento com nicotina gerou aumento da expressão do BDNF, o qual foi acompanhado pelo aumento do seu receptor, TrkB. Neste caso, como o ENT é uma região menos suscetível aos efeitos da abstinência (KENNY; MARKOU, 2001) a expressão de BDNF e seu receptor tiveram um comportamento semelhante. As correlações positivas existentes entre a expressão de TrkB no ENT e em CA1 com a eficiência basal do $f P S P_{1}$ indica que as cascatas de sinalização ativadas pelos receptores de BDNF que estão associados à plasticidade sináptica nesta via, visto que o aumento da expressão de BDNF acompanhou o aumento da eficiência da plasticidade sináptica gerado pela nicotina.

Em suma, este trabalho mostra que o modelo animal da DA utilizando a STZ-icv desenvolve déficits cognitivos, eletrofisiológicos e histológicos que precedem à degeneração neuronal, provavelmente devido a resistência de insulina cerebral constatada neste modelo. Assim sendo, ele pode ser considerado um modelo útil pra compreender mecanismos que desencadeiam a doença em seu estágio inicial e propor novos tratamentos. Apesar das limitações inerente ao modelo animal utilizado, assim como as limitações do desenho experimental e das técnicas utilizadas neste trabalho, houve um esforço em correlacionar 
os achados comportamentais, eletrofisiológico e histológicos em diferentes intervalos de tempo. Sendo que as correlações encontradas podem sugerir a existência de uma relação causal entre elas. 


\section{Conclusões}

Neste estudo foi realizado uma caracterização eletrofisiológica do modelo farmacológico da DA. Além disso, também foi verificado - utilizando testes comportamentais e eletrofisiológico assim como análises histológicas e imunohistoquímicas, se o tratamento crônico de nicotina consegue reverter as patologias da DA presente neste modelo. Em resumo nossos principais achados indicam que a STZ-icv induziu déficits na memória de reconhecimento e na plasticidade sináptica na via CA1-CPFm e o tratamento crônico de nicotina conseguiu prevenir tanto os déficits de memória quanto os de plasticidade sem alterar a indução da LTP nos animais controles.

Entre os principais achados temos que a STZ-icv:

- Disfunção na memória de reconhecimento;

- Déficits na indução e manutenção da LTP na via CA1-CPFm;

- Aumento da oscilação Gama Baixo a curto prazo;

- Redução o pico da oscilação Teta a longo prazo;

- Redução da densidade neuronal no córtex entorrinal;

- Menor expressão de BDNF na região pré-límbica do córtex;

Em contrapartida, o tratamento crônico com nicotina gerou as seguintes alterações nos animais STZ-icv:

- Reverteu o déficit da memória de reconhecimento;

- Reduziu as disfunções na indução da LTP reverteu os déficits na manutenção da LTP;

- Aumentou o pico da oscilação teta;

- Reverteu a redução da expressão de BDNF na região pré-límbica do córtex; 
O presente trabalho foi o primeiro a registrar as alterações eletrofisiológicas in vivo na via CA1-CPFm no modelo STZ-icv. Traz também as primeiras evidências de que a modulação do sistema colinérgico, utilizando a nicotina, consegue prevenir algumas destas alteração, o que está de acordo com evidências presente na literatura que sugerem o papel neuroprotetor da nicotina. Tais resultados podem contribuir para elucidar os mecanismos que envolvem tanto o sistema colinérgico quanto a via CA1-CPFm na disfunção de memória que ocorre na DA.

Apesar da nicotina ser uma droga de toxicidade elevada e de gerar dependência psíquica e química, estudos utilizando a nicotina são úteis para modular os receptores colinérgicos nicotínicos e permitem que novas estratégias terapêuticas sejam consideradas no tratamento da DA. Além do mais, a compreensão de alterações na plasticidade sináptica da via CA1-CPFm fornece novas perspectivas para o entendimento das bases neuronais dos déficits de memória presentes nesta doença. 


\section{Referências}

AGRAWAL, R.; TYAGI, E.; SHUKLA, R.; NATH, C. Insulin receptor signaling in rat hippocampus: a study in stz (icv) induced memory deficit model. European Neuropsychopharmacology, v. 31, n. 3, p. 261-273, 2011.

AKAIKE, A.; TAKADA-TAKATORI, Y.; KUME, T.; IZUMI, Y. Mechanisms of neuroprotective effects of nicotine and acetylcholinesterase inhibitors: role of alpha4 and alpha7 receptors in neuroprotection. Journal of Molecular Neuroscience, v. 40, n. 1-2, p. 211-216, 2010.

ALBERT, M.; DEKOSKY, S.; DICKSON, D.; DUBOIS, B.; FELDMAN, H.; FOX, N.; GAMST, A.; HOLTZMAN, D.; JAGUST, W.; PETERSEN, R.; SNYDER, P.; CARRILLO, M.; THIES, B.; PHELPS, C. The diagnosis of mild cognitive impairment due to alzheimer's disease: recommendations from the national institute on aging-alzheimer's association workgroups on diagnostic guidelines for alzheimer's disease. Alzheimers Dementia, v. 7, n. 3, p. 270-279, 2011.

ALDERSON, R.; ALTERMAN, A.; BARDE, Y.; LINDSAY, R. Brain-derived neurotrophic factor increases survival and differentiated functions of rat septal cholinergic neurons in culture. Neuron, v. 5, n. 3, p. 508-517, 1990.

ALKADHI, A. A.; ALZOUBI, K. H.; SRIVAREERAT, M.; TRAN, T. T. Elevation of bace in an a $\beta$ rat model of alzheimerś disease: exacerbation by chronic stress and prevention by nicotine. International Journal of Neuropsychopharmacology, v. 15, n. 2011, p. 223-233, 2012 .

Alzheimer's Association. 2014 alzheimer's disease facts and figures. Alzheimers Dementia, v. 10, n. 2, p. 47-92, 2014.

Alzheimer's Disease International. World Alzheimer's Report 2009. 2009. Disponível em: $<$ https://www.alz.co.uk/research/files/WorldAlzheimerReport.pdf>. Acesso em: novembro 2015 .

Alzheimer's Disease International. World Alzheimer's Report 2015: The Global Impact of Dementia. 2015. Disponível em: $<$ https://www.alz.co.uk/research/WorldAlzheimerReport2015.pdf>. Acesso em: novembro 2015 . 
ANAND, R.; GILL, K. D.; MAHDI, A. A. Therapeutics of alzheimer's disease: Past, present and future. Neuropharmacology, v. 76, p. 27-50, 2014.

APOSTOLATOS, A.; SONG, S.; ACOSTA, S.; PEART, M.; WATSON, J.; BICKFORD, P.; COOPER, D.; PATEL, N. Insulin promotes neuronal survival via the alternatively spliced protein kinase c isoform. The Journal of Biological Chemistry, v. 287, n. 12, p. 9299-9310, 2012.

ARENDT, T. Synaptic degeneration in alzheimer's disease. Acta Neuropathol, v. 118, p. 167-179, 2009.

AXMACHER, N.; HENSELER, M.; JENSEN, O.; WEINREICH, I.; ELGER, C.; FELL, J. Cross-frequency coupling supports multi-item working memory in the human hippocampus. Proc Natl Acad Sci U S A, v. 107, n. 7, p. 3228-3233, 2010.

BARILAR, J.; KNEZOVIC, A.; GRüNBLATT, E.; RIEDERER, P.; SALKOVICPETRISIC, M. Nine-month follow-up of the insulin receptor signalling cascade in the brain of streptozotocin rat model of sporadic alzheimer's disease. Journal of Neural Transmission, v. 122, n. 4, p. 565-576, 2015.

BARTKOWSKA, K.; TURLEJSKI, K.; DJAVADIAN, R. Neurotrophins and their receptors in early development of the mammalian nervous system. Acta Neurobiologiae Experimentalis, v. 70, n. 4, p. 454-467, 2010.

BARTUS, R. On neurodegenerative diseases, models, and treatment strategies: lessons learned and lessons forgotten a generation following the cholinergic hypothesis. Experimental Neurology, v. 163, n. 2, p. 495-529, 2000.

BENGOETXEA, X.; RODRIGUEZ-PERDIGON, M.; RAMIREZ, M. Object recognition test for studying cognitive impairments in animal models of alzheimer's disease. Frontiers in Bioscience, v. 7, p. 10-29, 2015.

BLISS, T.; COLLINGRIDGE, G. A synaptic model of memory: long-term potentiation in the hippocampus. Nature, v. 361, n. 6407, p. 31-39, 1993.

BLISS, T.; COLLINGRIDGE, G.; MORRIS, R. Introduction. long-term potentiation and structure of the issue. Philos Trans R Soc Lond B Biol Sci., v. 358, n. 1432, p. 607-611, 2003.

BLISS, T.; LOMO, T. Long-lasting potentiation of synaptic transmission in the dentate area of the anaesthetized rabbit following stimulation of the perforant path. The Journal of Physiology, v. 232, n. 2, p. 331-356, 1973. 
BLOKLAND, A.; JOLLES, J. Spatial learning deficit and reduced hippocampal chat activity in rats after an icv injection of streptozotocin. Pharmacology Biochemistry and Behavior, v. 44, n. 2, p. 3992-3997, 1993.

BODENDORF, U.; DANNER, S.; FISCHER, F.; STEFANI, M.; STURCHLERPIERRAT, C.; WIEDERHOLD, K.; STAUFENBIEL, M.; PAGANETTI, P. Expression of human beta-secretase in the mouse brain increases the steady-state level of beta-amyloid. Journal of Neurochemistry, v. 80, n. 5, p. 799-806, 2002.

BUCKNER, R. Memory and executive function in aging and ad: multiple factors that cause decline and reserve factors that compensate. Neuron, v. 44, n. 1, p. 195-208, 2004.

BUZSáKI, G. Theta oscillations in the hippocampus. Neuron, v. 33, n. 3, p. 225-240, 2002.

BUZSáKI, G.; WANG, X. Mechanisms of gamma oscillations. Annual Review Neuroscience, v. 35, p. 203-225, 2012.

CAldeirA, M.; MElO, C.; PEREIRA, D.; CARVAlHO, R.; CORREIA, S.; BACKOS, D.; CARVAlHO, A.; ESTEBAN, J.; DUARTE, C. Brain-derived neurotrophic factor regulates the expression and synaptic delivery of alpha-amino-3-hydroxy-5-methyl4-isoxazole propionic acid receptor subunits in hippocampal neurons. The Journal of Biological Chemistry, v. 282, n. 17, p. 12619-12628, 2007.

CAMPION, D.; DUMANCHIN, C.; HANNEQUIN, D.; DUBOIS, B.; BELLIARD, S.; PUEL, M.; THOMAS-ANTERION, C.; MICHON, A.; MARTIN, C.; CHARBONNIER, F.; RAUX, G.; CAMUZAT, A.; PENET, C.; MESNAGE, V.; MARTINEZ, M.; CLERGET-DARPOUX, F.; BRICE, A.; FREBOURG, T. Early-onset autosomal dominant alzheimer disease: prevalence, genetic heterogeneity, and mutation spectrum. The American Journal of Human Genetics, v. 65, n. 3, p. 664-670, 1999.

CANOLTY, R.; GANGULY, K.; KENNERLEY, S.; CADIEU, C.; KOEPSELL, K.; WALLIS, J.; CARMENA, J. Oscillatory phase coupling coordinates anatomically dispersed functional cell assemblies. Proc Natl Acad Sci U S A, v. 107, n. 40, p. 17356-17361, 2010.

CARLéN, M.; MELETIS, K.; SIEGLE, J.; CARDIN, J.; FUTAI, K.; VIERLINGCLAASSEN, D.; RüHLMANN, C.; JONES, S.; DEISSEROTH, K.; SHENG, M.; MOORE, C.; TSAI, L. A critical role for nmda receptors in parvalbumin interneurons for gamma rhythm induction and behavior. Molecular Psychiatry - Nature, v. 17, n. 5, p. $537-548,2012$.

CAVANAUGH, S.; PIPPIN, J.; BARNARD, N. Animal models of alzheimer disease: Historical pitfalls and a path forward. ALTEX, p. 279-302, 2014. 
CHAKROBORTY, S.; KIM, J.; SCHNEIDER, C.; JACOBSON, C.; MOLGó, J.; STUTZMANN, G. Early presynaptic and postsynaptic calcium signaling abnormalities mask underlying synaptic depression in presymptomatic alzheimer's disease mice. Journal of Neuroscience, v. 32, n. 24, p. 8341-8353, 2012.

CHEN, Y.; LIANG, Z.; BLANCHARD, J.; DAI, C.; SUN, S.; LEE, M.; GRUNDKEIQBAL, I.; IQBAL, K.; LIU, F.; GONG, C. A non-transgenic mouse model (icv-stz mouse) of alzheimer's disease: similarities to and differences from the transgenic model (3xtg-ad mouse). Molecular Neurobiology, v. 47, n. 2, p. 711-725, 2013.

CHENG, C.; TSENG, V.; WANG, J.; WANG, D.; MATYAKHINA, L.; BONDY, C. Tau is hyperphosphorylated in the insulin-like growth factor-i null brain. Endocrinology, v. 146, n. 12, p. 5086-5091, 2005.

CHIU, S.; CHEN, C.; CLINE, H. Insulin receptor signaling regulates synapse number, dendritic plasticity, and circuit function in vivo. Neuron, v. 58, n. 5, p. 708-719, 2008.

CITRI, A.; MALENKA, R. Synaptic plasticity: multiple forms, functions, and mechanisms. Neuropsychopharmacology, v. 33, n. 1, p. 18-41, 2008.

CLARK, J.; FURGERSON, M.; CRYSTAL, J.; FECHHEIMER, M.; FURUKAWA, R.; WAGNER, J. Alterations in synaptic plasticity coincide with deficits in spatial working memory in presymptomatic 3xtg-ad mice. Neurobiology of Learning and Memory, v. 125, p. $152-162,2015$.

ClEMENT, E.; A., R.; THWAITES, M.; AILON, J.; PETERS, S.; DICKSON, C. Cyclic and sleep-like spontaneous alternations of brain state under urethane anaesthesia. PLos One, v. 3, n. 4, 2008.

COHEN, R.; REZAI-ZADEH, K.; WEITZ, T.; RENTSENDORJ, A.; GATE, D.; SPIVAK, I.; BHOLAT, Y.; VASILEVKO, V.; GLABE, C.; BREUNIG, J.; RAKIC, P.; DAVTYAN, H.; AGADJANYAN, M.; KEPE, V.; BARRIO, J.; BANNYKH, S.; SZEKELY, C.; PECHNICK, R.; TOWN, T. A transgenic alzheimer rat with plaques, tau pathology, behavioral impairment, oligomeric aß, and frank neuronal loss. Journal of Neuroscience, v. 33, n. 15, p. 6245-6256, 2013.

COLGIN, L.; MOSER, E. Gamma oscillations in the hippocampus. Physiology (Bethesda), v. 25, n. 5, p. 319-329, 2010.

COLLINGRIDGE, G.; PEINEAU, S.; HOWLAND, J.; WANG, Y. Long-term depression in the cns. Nature Reviews Neuroscience, v. 11, n. 7, p. 459-473, 2010.

CORREIA, S.; SANTOS, R.; PERRY, G.; ZHU, X.; MOREIRA, P.; SMITH, M. Insulinresistant brain state: the culprit in sporadic alzheimer's disease? Ageing Research Reviews, v. 10, n. 2, p. 264-273, 2011. 
CRAFT, S. Insulin resistance and alzheimer's disease pathogenesis: potential mechanisms and implications for treatment. Current Alzheimer Research, v. 4, n. 2, p. 147-152, 2007.

CRAIG, L.; HONG, N.; MCDONALD, R. Revisiting the cholinergic hypothesis in the development of alzheimer's disease. Neuroscience and Biobehavioral Reviews, v. 35, n. 6, p. 1397-1409, 2011.

DAMASIO, A. Time-locked multiregional retroactivation: a systems-level proposal for the neural substrates of recall and recognition. Cognition, v. 33, n. 1-2, p. 25-62, 1989.

DANI, J.; BERTRAND, D. Nicotinic acetylcholine receptors and nicotinic cholinergic mechanisms of the central nervous system. Annual Review of Pharmacology and Toxicology, v. 47, p. 699-729, 2007.

DAVIS, J.; GOULD, T. Hippocampal nachrs mediate nicotine withdrawal-related learning deficits. Psychopharmacology (Berl), v. 19, n. 8, p. 551-561, 2009.

de Bruin, N.; POUZET, B. Beneficial effects of galantamine on performance in the object recognition task in swiss mice: deficits induced by scopolamine and by prolonging the retention interval. Pharmacology Biochemistry and Behavior, v. 85, n. 1, p. 253-260, 2006.

DE LA MONTE, S. Type 3 diabetes is sporadic alzheimer's disease: Mini-review. European Neuropsychopharmacology, v. 24, p. 1954-1960, 2014.

DE LA MONTE, S.; TONG, M. Brain metabolic dysfunction at the core of alzheimer's disease. Biochemical Pharmacology, v. 88, p. 548-559, 2014.

DE LA MONTE, S.; WANDS, J. Review of insulin and insulin-like growth factor expression, signaling, and malfunction in the central nervous system: Relevance to alzheimer's disease. Journal of Alzheimers Disease, v. 7, p. 45-61, 2005.

DE LA MONTE, S.; WANDS, J. Alzheimer's disease is type 3 diabetes - evidence reviewed. Journal of Diabetes Science and Technology, v. 2, n. 6, p. 1101-113, 2008.

DREVER, B.; RIEDEL, G.; PLATT, B. Hippocampal synaptic loss in early alzheimer's disease and mild cognitive impairment. Behavioural Brain Research, v. 221, n. 2, p. 505$514,2011$.

DUDAI, Y.; MORRIS, R. Memorable trends. Neuron, v. 80, n. 3, p. 742-750, 2013.

DUYCKAERTS, C.; DELATOUR, B.; POTIER, M. Classification and basic pathology of alzheimer disease. Advances in Medical Sciences, v. 118, n. 1, p. 5-36, 2009. 
DUYCKAERTS, C.; POTIER, M.; DELATOUR, B. Alzheimer disease models and human neuropathology: similarities and differences. Acta Neuropathologica, v. 115, n. 1, p. 5-38, 2008 .

ESPINOSA, J.; ROCHA, A.; NUNES, F.; COSTA, M.; SCHEIN, V.; KAZLAUCKAS, V.; KALININE, E.; SOUZA, D.; CUNHA, R.; PORCIúNCULA, L. Caffeine consumption prevents memory impairment, neuronal damage, and adenosine a2a receptors upregulation in the hippocampus of a rat model of sporadic dementia. Journal of Alzheimers Disease, v. 34, n. 2, p. 509-518, 2013.

FARRER, L.; CUPPLES, L. A.; HAINES, J.; HYMAN, B.; KUKULL, W.; MAYEUX, R.; MYERS, R.; PERICAK-VANCE, M.; RISCH, N.; VANDUIJN, C. Effects of age, sex, and ethnicity on the association between apolipoprotein e genotype and alzheimer disease. a meta-analysis. apoe and alzheimer disease meta analysis consortium. JAMA, v. 279, n. 16, p. 1349-1356, 1997.

FISHER, A. Cholinergic modulation of amyloid precursor protein processing with emphasis on m1 muscarinic receptor: perspectives and challenges in treatment of alzheimer's disease. Journal of Neurochemistry, v. 120, n. 1, p. 22-33, 2012.

FLORESCO, S.; SEAMANS, J.; PHILLIPS, A. Selective roles for hippocampal, prefrontal cortical, and ventral striatal circuits in radial-arm maze tasks with or without a delay. Journal of Neuroscience, v. 17, n. 5, p. 1880-1890, 1997.

FRANCO, R.; CEDAZO-MINGUEZ, A. Successful therapies for alzheimer's disease: why so many in animal models and none in humans? Frontiers in Pharmacology, v. 5, n. 146, 2013.

FREEDMAN, R.; WETMORE, C.; STRöMBERG, I.; LEONARD, S.; OLSON, L. Alphabungarotoxin binding to hippocampal interneurons: immunocytochemical characterization and effects on growth factor expression. The Journal of Neuroscience, v. 13, n. 5, p. 1965-1975, 1993.

FRöLICH, L.; BLUM-DEGEN, D.; BERNSTEIN, H.; ENGELSBERGER, S.; HUMRICH, J.; LAUFER, S.; MUSCHNER, D.; THALHEIMER, A.; TüRK, A.; HOYER, S.; ZöCHLING, R.; BOISSL, K.; JELLINGER, K.; RIEDERER, P. Brain insulin and insulin receptors in aging and sporadic alzheimer's disease. Journal of Neural Transmission, v. 105, p. 423-438, 1998.

FRöLICH, L.; Blum-Degen, D.; RIEDERER, P.; HOYER, S. A disturbance in the neuronal insulin receptor signal transduction in sporadic alzheimer's disease. Annals of the New York Academy of Science, v. 893, p. 290-293, 1999. 
FUJII, S.; SUMIKAWA, K. Acute and chronic nicotine exposure reverse age-related declines in the induction of long-term potentiation in the rat hippocampus. Brain Research, v. 894 , n. 2, p. 347-353, 2001.

FUNG, Y.; SCHMID, M.; ANDERSON, T.; LAU, Y. Effects of nicotine withdrawal on central dopaminergic systems. Pharmacology Biochemistry and Behavior, v. 53, n. 3, p. 635-640, 1996.

GAUTHIER, S.; LEUZY, A.; RACINE, E.; ROSA-NETO, P. Diagnosis and management of alzheimer's disease: Past, present and future ethical issues. Progress in Neurobiology, v. 110, p. 102-103, 2013.

GOATE, A. Segregation of a missense mutation in the amyloid beta-protein precursor gene with familial alzheimer's disease. Journal of Alzheimers Disease, v. 9, n. 3, p. 341-347, 2006.

GOH, J. J.; MANAHAN-VAUGHAN, D. Spatial object recognition enables endogenous ltd that curtails ltp in the mouse hippocampus. Cerebral Cortex, v. 10, n. 1093, 2012.

GOUTAGNY, R.; GU, N.; CAVANAGH, C.; JACKSON, J.; CHABOT, J.; QUIRION, R.; KRANTIC, S.; WILLIAMS, S. Alterations in hippocampal network oscillations and theta-gamma coupling arise before abeta overproduction in a mouse model of alzheimer's disease. European Journal of Neuroscience, v. 37, n. 12, p. 1896-1902, 2013.

GRAY, R.; RAJAN, A.; RADCLIFFE, K.; YAKEHIRO, M.; DANI, J. Facilitation of glutamate release by nicotine involves the activation of a ca2+/calmodulin signaling pathway in rat prefrontal cortex nerve terminals. Nature, v. 383, n. 6602, p. 713-716, 1996.

GRAY, S.; MEIJER, R.; BARRETT, E. Insulin regulates brain function, but how does it get there? Diabetes, v. 63, n. 12, p. 3992-3997, 2014.

GRüNBLATT, E.; SALKOVIC-PETRISIC, M.; OSMANOVIC, J.; RIEDERER, P.; S., H. Brain insulin system dysfunction in streptozotocin intracerebroventricularly treated rats generates hyperphosphorylated tau protein. Pharmacology Biochemistry and Behavior, v. 101, n. 3, p. 751-770, 2007.

HASSELMO, M. A model of prefrontal cortical mechanisms for goal-directed behavior. Journal of Cognitive Neuroscience, v. 17, n. 7, p. 1115-1129, 2005.

HAYDAR, S.; DUNLOP, J. Neuronal nicotinic acetylcholine receptors - targets for the development of drugs to treat cognitive impairment associated with schizophrenia and alzheimer's disease. Current Topics in Medicinal Chemistry, v. 10, p. 144-152, 2010.

HEBB, D. The Organization of Behavior: A Neuropsychological Theory. New York: John Wiley and Sons, 1949. 
HERNANDEZ, C.; DINELEY, K. $\alpha 7$ nicotinic acetylcholine receptors in alzheimer's disease: neuroprotective, neurotrophic or both? Current Drug Targets, v. 13, n. 5, p. 613-622, 2012 .

HIRONAKA, N.; TANAKA, K.; IZAKI, Y.; HORI, K.; NOMURA, M. Memory-related acetylcholine efflux from rat prefrontal cortex and hippocampus: a microdialysis study. Journal of Cognitive Neuroscience, v. 901, n. 1-2, p. 143-150, 2001.

HOYER, S. Is sporadic alzheimer disease the brain type of non-insulin dependent diabetes mellitus? a challenging hypothesis. Journal of Neural Transmission, v. 105, p. 415-422, 1998.

HOYER, S. The brain insulin signal transduction system and sporadic (type ii)alzheimer disease: an update. European Journal of Pharmacology, v. 109, p. 341-360, 2002.

HOYER, S. Glucose metabolism and insulin receptor signal transduction in alzheimer disease. European Journal of Pharmacology, v. 490, p. 115-125, 2004.

HOYER, S.; LANNERT, H. Long-term abnormalities in brain glucose energy metabolism after inhibition of the neuronal insulin receptor: implication of tau-protein. Journal of Neural Transmission, v. 72, p. 195-202, 2007.

HUANG, y.; MUCKE, L. Alzheimer mechanisms and therapeutic strategies. Cell, v. 148, n. 6, p. 1204-1222, 2015.

ISHRAT, T.; HODA, M.; KHAN, M.; YOUSUF, S.; AHMAD, M.; KHAN, M.; AHMAD, A.; ISLAM, F. Amelioration of cognitive deficits and neurodegeneration by curcumin in rat model of sporadic dementia of alzheimer's type (sdat). European Neuropsychopharmacology, v. 19, n. 9, p. 636-647, 2009.

ITO, M.; KANO, M. Long-lasting depression of parallel fiber-purkinje cell transmission induced by conjunctive stimulation of parallel fibers and climbing fibers in the cerebellar cortex. Neuroscience Letters, v. 33, n. 3, p. 253-258, 1982.

JACK, C. J.; HOLTZMAN, D. Biomarker modeling of alzheimer's disease. Neuron, v. 80, n. 6, p. 1347-1358, 2013.

JAVED, H.; KHAN, M.; AHMAD, A.; VAIBHAV, K.; AHMAD, M.; KHAN, A.; ASHAFAQ, M.; ISLAM, F.; SIDDIQUI, M.; SAFHI, M.; ISLAM, F. Rutin prevents cognitive impairments by ameliorating oxidative stress and neuroinflammation in rat model of sporadic dementia of alzheimer type. Neuroscience, v. 210, p. 340-352, 2012.

JAY, T. M.; BURETTE, F.; LAROCHE, S. Nmda receptor-dependent long-term potentiation in the hippocampal afferent fibre system to the prefrontal cortex in the rat. European Journal of Neuroscience, v. 7, n. 2, p. 247-250, 1995. 
JEFFERSON, A.; BEISER, A.; HIMALI, J.; SESHADRI, S.; O'DONNELL, C.; MANNING, W.; WOLF, P.; AU, R.; BENJAMIN, E. Low cardiac index is associated with incident dementia and alzheimer disease: the framingham heart study. Circulation, v. 131, n. 15, p. 1333-1342, 2015.

JELIC, V.; JOHANSSON, S.; ALMKVIST, O.; SHIGETA, M.; JULIN, P.; NORDBERG, A.; WINBLAD, B.; WAHLUND, L. Quantitative electroencephalography in mild cognitive impairment: longitudinal changes and possible prediction of alzheimer's disease. Journal of Neural Transmission, v. 21, n. 4, p. 533-540, 2000.

JONES, E. Santiago ramon y cajal and the croonian lecture, march 1894. Trends Neurosciences, v. 17, n. 5, p. 190-192, 1994.

JONNALA, R.; BUCCAFUSCO, J. Relationship between the increased cell surface alpha7 nicotinic receptor expression and neuroprotection induced by several nicotinic receptor agonists. Journal of Neuroscience Research, v. 66, n. 4, p. 565-572, 2001.

JüRGENSEN, S.; FERREIRA, S. Nicotinic receptors, amyloid-beta, and synaptic failure in alzheimer's disease. Journal of Molecular Neuroscience, v. 40, n. 1-2, p. 221-229, 2010.

KALARIA, R. Vascular basis for brain degeneration: faltering controls and risk factors for dementia. Nutrition Review, v. 68, n. 2, p. 74-87, 2010.

KANDRATAVICIUS, L.; HALlAK, J. E.; CARLOTTI, C. G.; ASSIRATI, J. A. J.; LEITE, J. P. Neurotrophin receptors expression in mesial temporal lobe epilepsy with and without psychiatric comorbidities and their relation with seizure type and surgical outcome. Acta Neuropathol Commun, v. 81, n. 2, 2014.

KANDRATAVICIUS, L.; MONTEIRO, M.; ASSIRATI, J. A. J.; CARLOTTI, C. G. J.; HALLAK, J. E.; LEITE, J. P. Neurotrophins in mesial temporal lobe epilepsy with and without psychiatric comorbidities. J Neuropathol Exp Neuro, v. 72, n. 11, p. 1029-1042, 2013.

KENNEY, J.; GOULD, T. Modulation of hippocampus-dependent learning and synaptic plasticity by nicotine. Molecular Neurobiology, v. 38, n. 1, p. 101-121, 2008.

KENNY, P.; FILE, S.; RATTRAY, M. Acute nicotine decreases, and chronic nicotine increases the expression of brain-derived neurotrophic factor mrna in rat hippocampus. Molecular Brain Research, v. 85, n. 1-2, p. 234-238, 2000.

KENNY, P.; MARKOU, A. Acute nicotine decreases, and chronic nicotine increases the expression of brain-derived neurotrophic factor mrna in rat hippocampus. Pharmacology Biochemistry and Behavior, v. 70, n. 4, p. 531-549, 2001. 
KHAN, T.; ALKON, D. Peripheral biomarkers of alzheimer's disease. Journal of Alzheimer's Disease, v. 49, n. 3, p. 729-744, 2013.

KISS, T.; FENG, J.; HOFFMANN, W.; SHAFFER, C.; HAJóS, M. Rhythmic theta and delta activity of cortical and hippocampal neuronal networks in genetically or pharmacologically induced n-methyl-d-aspartate receptor hypofunction under urethane anesthesia. Neuroscience, v. 237, p. 255-267, 2013.

KISS, T.; FENG, J.; HOFFMANN, W.; SHAFFER, C.; HAJóS, M. Rhythmic theta and delta activity of cortical and hippocampal neuronal networks in genetically or pharmacologically induced n-methyl-d-aspartate receptor hypofunction under urethane anesthesia. Neuroscience, v. 237, p. 255-267, 2013.

KISS T.AND HOFFMANN, W. E.; HAJóS, M. Delta oscillation and short-term plasticity in the rat edial prefrontal cortex: modelling nmda hypofunction of schizophrenia. International Journal of Neuropsychopharmacology, v. 14, n. 1, p. 29-42, 2011.

KOROTKOVA, T.; FUCHS, E.; PONOMARENKO, A.; ENGELHARDT, J. von; MONYER, H. Nmda receptor ablation on parvalbumin-positive interneurons impairs hippocampal synchrony, spatial representations, and working memory. Nature, v. 68, n. 3, p. 557-569, 2010.

KROKER, K.; RAST, G.; ROSENBROCK, H. Differential effects of subtype-specific nicotinic acetylcholine receptor agonists on early and late hippocampal ltp. European Journal of Pharmacology, v. 671, n. 1-7, p. 26-32, 2011.

KUMAR, A.; SINGH, A.; EKAVALI. A review on alzheimer's disease pathophysiology and its management: an update. Pharmacological Reports, v. 67, p. 195-203, 2015.

LAMPRECHT, R.; LEDOUX, J. Structural plasticity and memory. Nature Reviews Neuroscience, v. 5, n. 1, p. 45-54, 2000.

LANNERT, H.; HOYER, S. Intracerebroventricular administration of streptozotocin causes long-term diminutions in learning and memory abilities and in cerebral energy metabolism in adult rats. Behavioral Neuroscience, v. 112, n. 5, p. 1199-1208, 1998.

LAROCHE, S.; DAVIS, S.; JAY, T. Plasticity at hippocampal to prefrontal cortex synapses: dual roles in working memory and consolidation. Hippocampus, v. 10, n. 4, p. 438-446, 2000.

LAROCHE, S.; JAY, T.; THIERRY, A. Long-term potentiation in the prefrontal cortex following stimulation of the hippocampal ca1/subicular region. Neuroscience Letters, v. 114, n. 2, p. 184-190, 1990. 
LEGA, B.; JACOBS, J.; KAHANA, M. Human hippocampal theta oscillations and the formation of episodic memories. Hippocampus, v. 22, n. 4, p. 748-761, 2012.

LEIBSON, C.; ROCCA, W.; HANSON, V.; CHA, R.; KOKMEN, E.; O'BRIEN, P.; PALUMBO, P. The risk of dementia among persons with diabetes mellitus: a populationbased cohort study. Annals of New York Academy of Science, v. 26, n. 826, p. 422-427, 1997.

LEISER, S.; BOWLBY, M.; COMERY, T.; DUNLOP, J. A cog in cognition: how the alpha 7 nicotinic acetylcholine receptor is geared towards improving cognitive deficits. Pharmacology and Therapeutics, v. 122, n. 3, p. 302-311, 2009.

LESTER-COLL, N.; RIVERA, E.; SOSCIA, S.; DOIRON, K.; WANDS, J.; DE LA MONTE, S. Intracerebral streptozotocin model of type 3 diabetes: relevance to sporadic alzheimer's disease. Journal of Alzheimers Disease, v. 9, n. 1, p. 13-33, 2006.

LEVIN, E. alpha7-nicotinic receptors and cognition. Current Drug Targets, v. 13, n. 5, p. 602-606, 2012.

LEWCZUK, P.; MROCZKO, B.; FAGAN, A.; KORNHUBER, J. Biomarkers of alzheimer's disease and mild cognitive impairment: A current perspective. Advances in Medical Sciences, v. 60, p. 76-82, 2015.

LI, S.; TOPCHIY, I.; KOCSIS, B. The effect of atropine administered in the medial septum or hippocampus on high- and low-frequency theta rhythms in the hippocampus of urethane anesthetized rats. Synapse, v. 61, n. 6, p. 412-419, 2007.

LIPTON, S. The molecular basis of memantine action in alzheimer's disease and other neurologic disorders: low-affinity, uncompetitive antagonism. Current Alzheimer Research, v. 331 , p. $155-165,2005$.

LISMAN, J.; BUZSáKI, G. A neural coding scheme formed by the combined function of gamma and theta oscillations. Schizophrenia Bulletin, v. 34, n. 5, p. 974-980, 2008.

LISMAN, J.; REDISH, A. Prediction, sequences and the hippocampus. Philos Trans $R$ Soc Lond B Biol Sci, v. 364, n. 1521, p. 1193-11201, 2009.

LIU, Q.; ZHAO, B. Nicotine attenuates beta-amyloid peptide-induced neurotoxicity, free radical and calcium accumulation in hippocampal neuronal cultures. British Journal of Pharmacoly, v. 141, p. 746-754, 2004.

LOPES-AGUIAR, C.; BUENO-JUNIOR, L. S.; RUGGIERO, R. N.; ROMCY-PEREIRA, R. N.; LEITE, J. P. Nmda receptor blockade impairs the muscarinic conversion of subthreshold transient depression into long-lasting ltd in the hippocampus-prefrontal cortex 
pathway in vivo: correlation with gamma oscillations. Neuropharmacology, v. 65 , p. 143$155,2013$.

LOPES-AGUIAR, C.; ROMCY-PEREIRA, R. N.; SZAWKA, R. E.; GALVIS-ALONSO, O. Y.; ANSELMO-FRANCI, J. A.; LEITE, J. P. Muscarinic acetylcholine neurotransmission enhances the late-phase of long-term potentiation in the hippocampal-prefrontal cortex pathway of rats in vivo: a possible involvement of monoaminergic systems. Neuroscience, v. 153, n. 4, p. 1309-1319, 2008.

MARTIN, S.; MORRIS, R. New life in an old idea: the synaptic plasticity and memory hypothesis revisited. Hippocampus, v. 12, n. 5, p. 609-636, 2002.

MATTSON, M. Glutamate and neurotrophic factors in neuronal plasticity and disease. Annals of the New York Academy of Sciences, v. 1144, p. 97-112, 2008.

MAYER, G.; NITSCH, R.; HOYER, S. Effects of changes in peripheral and cerebral glucose metabolism on locomotor activity, learning and memory in adult male rats. Brain Research, v. 532, p. 95-100, 1995.

MCGEHEE, D.; HEATH, M.; GELBER, S.; DEVAY, P.; ROLE, L. Nicotine enhancement of fast excitatory synaptic transmission in cns by presynaptic receptors. Science, v. 269, p. 1692-1696, 1995.

MEHLA, J.; PAHUJA, M.; GUPTA, Y. Streptozotocin-induced sporadic alzheimer's disease: selection of appropriate dose. Journal of Alzheimers Disease, v. 33, n. 1, p. 17-21, 2013.

MINICHIELLO, L.; KORTE, M.; WOLFER, D.; KüHN, R.; UNSICKER, K.; CESTARI, V.; ROSSI-ARNAUD, C.; LIPP, H.; BONHOEFFER, T.; KLEIN, R. Essential role for trkb receptors in hippocampus-mediated learning. Neruon, v. 24, n. 2, p. 401-414, 1999.

MIWA, J.; FREEDMAN, R.; LESTER, H. Neural systems governed by nicotinic acetylcholine receptors: emerging hypotheses. Neuron, v. 70, n. 1, p. 20-33, 2011.

MORETTI, D.; PIEVANI, M.; GEROLDI, C.; BINETTI, G.; ZANETTI, O.; ROSSINI, P.; FRISONI, G. Eeg markers discriminate among different subgroup of patients with mild cognitive impairment. Proc Natl Acad Sci U S A, v. 25, n. 1, p. 58-73, 2010.

MOSER, M.; ROWLAND, D.; MOSER, E. Place cells, grid cells, and memory. Science, v. 7, n. 2,2015 .

MUCKE, L.; MASLIAH, E.; YU, G.; MALLORY, M.; ROCKENSTEIN, E.; TATSUNO, G.; HU, K.; KHOLODENKO, D.; JOHNSON-WOOD, K.; MCCONLOGUE, L. Highlevel neuronal expression of abeta 1-42 in wild-type human amyloid protein precursor 
transgenic mice: synaptotoxicity without plaque formation. Journal of Neuroscience, v. 20, n. 11, p. 4050-4058, 2000.

NATHANSON, N. Synthesis, trafficking, and localization of muscarinic acetylcholine receptors. Pharmacology and Therapeutics, v. 119, n. 1, p. 33-43, 2008.

NICOLAKAKIS, N.; ABOULKASSIM, T.; ONGALI, B.; LECRUX, C.; FERNANDES, P.; ROSA-NETO, P.; TONG, X.; HAMEL, E. Complete rescue of cerebrovascular function in aged alzheimer's disease transgenic mice by antioxidants and pioglitazone, a peroxisome proliferator-activated receptor gamma agonist. Journal of Neuroscience, v. 28, n. 37, p. 9287-9296, 2008.

NOMIKOS, G.; HILDEBRAND, B.; PANAGIS, G.; SVENSSON, T. Nicotine withdrawal in the rat: role of alpha7 nicotinic receptors in the ventral tegmental area. Neuroreport, v. 10, n. 4, p. 697-702, 1999.

ODDO, S.; CACCAMO, A.; SHEPHERD, J.; MURPHY, M.; GOLDE, T.; KAYED, R.; METHERATE, R.; MATTSON, M.; AKBARI, Y.; LAFERLA, F. Triple-transgenic model of alzheimer's disease with plaques and tangles: intracellular abeta and synaptic dysfunction. Neuron, v. 39, n. 3, p. 409-421, 2003.

ONDREJCAK, T.; WANG, Q.; KEW, J.; VIRLEY, D.; UPTON, N.; ANWYL, R.; ROWAN, M. Activation of $\alpha 7$ nicotinic acetylcholine receptors persistently enhances hippocampal synaptic transmission and prevents a $\beta$-mediated inhibition of ltp in the rat hippocampus. European Journal of Pharmacology, v. 677, n. 1-3, p. 63-70, 2012.

PALOP, J.; MUCKE, L. Amyloid-beta-induced neuronal dysfunction in alzheimer's disease: from synapses toward neural networks. Nature Neuroscience, v. 13, n. 10, p. 812-818, 2010.

PAXINOS, G.; WATSON, C. The Rat Brain in Stereotaxic Coordinates. London: Academic Press, 2007.

PENDLEBURY, S.; ROTHWELL, P. Prevalence, incidence, and factors associated with pre-stroke and post-stroke dementia: a systematic review and meta-analysis. The Lancet Neurology, v. 8, n. 11, p. 1006-1018, 2013.

PHIEL, C.; WILSON, C.; LEE, V.; KLEIN, P. Gsk-3alpha regulates production of alzheimer's disease amyloid-beta peptides. Nature, v. 423, n. 6938, p. 435-439, 2003.

PICCIOTTO, M.; ZOLI, M. Nicotinic receptors in aging and dementia. Journal of Neurobiology, v. 53, n. 4, p. 641-655, 2002.

PLASSMAN, B.; HAVLIK, R.; STEFFENS, D.; HELMS, M.; NEWMAN, T.; DROSDICK, D.; PHILLIPS, C.; GAU, B.; WELSH-BOHMER, K.; BURKE, J.; GURALNIK, 
J.; BREITNER, J. Documented head injury in early adulthood and risk of alzheimer's disease and other dementias. Neurology, v. 55, n. 8, p. 1158-1166, 2010.

POOLER, A.; NOBLE, W.; HANGER, D. P. A role for tau at the synapse in alzheimer's disease pathogenesis. Neuropharmacology, v. 76, p. 1-8, 2014.

POORTHUIS, R.; GORIOUNOVA, N.; COUEY, J.; MANSVELDER, H. Nicotinic actions on neuronal networks for cognition: general principles and long-term consequences. Biochemical Pharmacology, v. 78, n. 7, p. 668-676, 2009.

PRICKAERTS, J.; FAHRIG, T.; BLOKLAND, A. Cognitive performance and biochemical markers in septum, hippocampus and striatum of rats after an i.c.v. injection of streptozotocin: a correlation analysis. Behavioural Brain Research, v. 102, n. 1-2, p. 73-88, 1999.

RACCHI, M.; MAZZUCCHELLI, M.; PORRELLO, E.; LANNI, C.; GOVONI, S. Acetylcholinesterase inhibitors: novel activities of old molecules. Pharmacological Research, v. 50, n. 4, p. 441-451, 2004.

RAFII, M.; AISEN, P. Advances in alzheimer's disease drug development. BMC Medicine, v. 13, n. 62, p. 231-246, 2015.

RAI, S.; KAMAT, P.; NATH, C.; SHUKLA, R. A study on neuroinflammation and nmda receptor function in stz (icv) induced memory impaired rats. Journal of Neuroimmunology, v. 254, p. $1-9,2013$.

REITZ, C.; BRAYE, C.; MAYEUX, R. Epidemiology of alzheimer's disease. Nature Reviews Neurology, v. 7, n. 2, p. 137-152, 2011.

ROMCY-PEREIRA, R. N.; PAVILDES, C. Distinct modulatory effects of sleep on the maintenance of hippocampal and medial prefrontal cortex ltp. European Journal of Neuroscience, v. 20, n. 12, p. 3453-3462, 2004.

ROSENMANN, H. Immunotherapy for targeting tau pathology in alzheimer's disease and tauopathies. Current Alzheimer Research, v. 10, n. 3, p. 217-228, 2013.

SALKOVIC-PETRISIC, M.; HOYER, S. Central insulin resistance as a trigger for sporadic alzheimer-like pathology: an experimental approach. Journal of Neural Transmission, v. 72 , p. 217-233, 2007.

SALKOVIC-PETRISIC, M.; KNEZOVIC, A.; HOYER, S.; RIEDERER, P. What have we learned from the streptozotocin-induced animal model of sporadic alzheimer's disease, about the therapeutic strategies in alzheimer's research. Journal of Neural Transmission, v. 120, n. 1, p. 233-252, 2013. 
SALKOVIC-PETRISIC, M.; OSMANOVIC-BARILAR, J.; BRüCKNER, M.; HOYER S. ARENDT, T. R. P. Cerebral amyloid angiopathy in streptozotocin rat model of sporadic alzheimer's disease: a long-term follow up study. Journal of Neural Transmission, v. 118, n. 5 , p. 290-293, 2011.

SALKOVIC-PETRISIC, M.; TRIBL, F.; SCHMIDT M. HOYER, S. R. P. Alzheimerlike changes in protein kinase $\mathrm{b}$ and glycogen synthase kinase-3 in rat frontal cortex and hippocampus after damage to the insulin signalling pathway. Journal of Neurochemistry, v. 96, n. 4, p. 1005-1015, 2006.

SANCHETI, H.; AKOPIAN, G.; YIN, F.; BRINTON, R.; WALSH, J.; CADENAS, E. Age-dependent modulation of synaptic plasticity and insulin mimetic effect of lipoic acid on a mouse model of alzheimer's disease. PLoS One, v. 8, n. 7, p. e69830, 2013.

SARAVANARAMAN, P.; CHINNADURAI, R.; BOOPATHY, R. Why calcium channel blockers could be an elite choice in the treatment of alzheimer's disease: a comprehensive review of evidences. Reviews in the Neurosciences, v. 25, n. 2, p. 231-246, 2014.

SAXENA, G.; PATRO, I. K.; NATH, C. Icv stz induced impairment in memory and neuronal mitochondrial function:a protective role of nicotinic receptor. Behavioural Brain Research, v. 224, n. 2011, p. 50-57, 2011.

SCHEFF, S.; PRICE, D.; SCHMITT, F.; MUFSON, E. Hippocampal synaptic loss in early alzheimer's disease and mild cognitive impairment. Neurobiology of Aging, v. 27, n. 10, p. 1372-1384, 2006.

SCHLIEBS, R.; ARENDT, T. The significance of the cholinergic system in the brain during aging and in alzheimer's disease. Pharmacological ResearchJournal of Neural Transmission, v. 113, n. 11, p. 1625-1644, 2006.

SCHLIEBS, R.; ARENDT, T. The cholinergic system in aging and neuronal degeneration. Behavioural Brain Research, v. 221, n. 2, p. 555-563, 2011.

SCOTT, L.; FENG, J.; KISS, T.; NEEDLE, E.; ATCHISON, K.; KAWABE, T.; MILICI, A.; HAJóS-KORCSOK, E.; RIDDELL, D.; HAJóS, M. Age-dependent disruption in hippocampal theta oscillation in amyloid-beta overproducing transgenic mice. Neurobiology of Aging, v. 33, n. 7, p. 1481.e13-23, 2012.

SEAMANS, J.; FLORESCO, S.; PHILLIPS, A. Functional differences between the prelimbic and anterior cingulate regions of the rat prefrontal cortex. Behavioral Neuroscience, v. 109, n. 6, p. 1063-1073, 1995.

SELKOE, D. Alzheimer's disease is a synaptic failure. Science, v. 298, n. 5594, p. 789-791, 2002. 
SéGUéLA, P.; WADICHE, J.; DINELEY-MILLER, K.; DANI, J.; PATRICK, J. Molecular cloning, functional properties, and distribution of rat brain alpha 7: a nicotinic cation channel highly permeable to calcium. Journal of Neuroscience, v. 13, p. 596-604, 1993.

SHAH, K.; DESILVA, S.; ABBRUSCATO, T. The role of glucose transporters in brain disease: diabetes and alzheimer's disease. International Journal of Molecular Sciences, v. 13, n. 10, p. 12629-12655, 2012.

SHARMA, V.; BALA, A.; DESHMUKH, R.; BEDI, K.; SHARMA, P. Neuroprotective effect of ro-20-1724-a phosphodiesterase4 inhibitor against intracerebroventricular streptozotocin induced cognitive deficit and oxidative stress in rats. Pharmacology Biochemistry and Behavior, v. 101, n. 2, p. 239-245, 2012.

SHONESY, B.; THIRUCHELVAM, K.; PARAMESHWARAN, K.; RAHMAN, E.; KARUPPAGOUNDER, S.; HUGGINS, K.; PINKERT, C.; AMIN, R.; DHANASEKARAN, M.; SUPPIRAMANIAM, V. Central insulin resistance and synaptic dysfunction in intracerebroventricular-streptozotocin injected rodents. Neurobiology of Aging, v. 33, p. 430e5-430e18, 2012.

SIOK, C.; ROGERS, J.; KOCSIS, B.; HAJóS, M. Activation of alpha7 acetylcholine receptors augments stimulation-induced hippocampal theta oscillation. European Journal of Neuroscience, v. 23, n. 2, p. 570-574, 2006.

SKEBERDIS, V.; LAN, J.; ZHENG, X.; ZUKIN, R.; BENNETT, M. Insulin promotes rapid delivery of n-methyl-d- aspartate receptors to the cell surface by exocytosis. Proc Natl Acad Sci U S A, v. 98, n. 6, p. 3561-3566, 2001.

SRIVAREERAT, M.; TRAN, T.; SALIM, S.; ALEISA, A.; ALKADHI, K. Chronic nicotine restores normal a $\beta$ levels and prevents short-term memory and e-ltp impairment in a $\beta$ rat model of alzheimer's disease. Neurobiology of Aging, v. 32, n. 5, p. 834-844, 2011.

SUN, P.; KNEZOVIC, A.; PARLAK, M.; CUBER, J.; KARABEG, M.; DECKERT, J.; RIEDERER, P.; HUA, Q.; SALKOVIC-PETRISIC, M.; SCHMITT, A. Long-term effects of intracerebroventricular streptozotocin treatment on adult neurogenesis in the rat hippocampus. Current Alzheimer Research, v. 12, n. 8, p. 772-784, 2015.

SZKUDELSKI, T. The mechanism of alloxan and streptozotocin action in b cells of the rat pancreas. Physiological Research, v. 50, n. 6, p. 537-546, 2001.

SZUTOWICZ, A.; BIELARCZYK, H.; JANKOWSKA-KULAWY, A.; PAWELCZYK, T.; RONOWSKA, A. Acetyl-coa the key factor for survival or death of cholinergic neurons in course of neurodegenerative diseases. Neurochemical Research, v. 38, n. 8, p. 1523-1542, 2013. 
TAKADA, J.; MACHADO, M.; PERES, S.; BRITO, L.; Borges-Silva, C.; COSTA, C.; Fonseca-Alaniz, M.; ANDREOTTI, S.; LIMA, F. Neonatal streptozotocin-induced diabetes mellitus: a model of insulin resistance associated with loss of adipose mass. Metabolism Clinical and Experimental, v. 56, n. 7, p. 977-984, 2007.

TAKITA, M.; IZAKI, Y.; JAY, T. M.; KANEKO, H.; SUZUKI, S. S. Induction of stable long-term depression in vivo in the hippocampal-prefrontal cortex pathway. European Journal of Neuroscience, v. 11, n. 11, p. 4145-4148, 1999.

TORT, A.; KOMOROWSKI, R.; MANNS, J.; KOPELL, N.; EICHENBAUM, H. Thetagamma coupling increases during the learning of item-context associations. Proc Natl Acad Sci U S A, v. 106, n. 49, p. 20942-20947, 2009.

TOTA, S.; AWASTHI, H.; KAMAT, P.; NATH, C.; HANIF, K. Protective effect of quercetin against intracerebral streptozotocin induced reduction in cerebral blood flow and impairment of memory in mice. Behavioural Brain Research, v. 209, n. 1, p. 239-245, 2010.

TOTA, S.; KAMAT, P.; SHUKLA, R.; NATH, C. Improvement of brain energy metabolism and cholinergic functions contributes to the beneficial effects of silibinin against streptozotocin induced memory impairment. Behavioural Brain Research, v. 221, p. 207$215,2011$.

UNGER, C.; SVEDBERG, M.; YU, W.; HEDBERG, M.; NORDBERG, A. Effect of subchronic treatment of memantine, galantamine, and nicotine in the brain of tg2576 (appswe) transgenic mice. Journal of Pharmacology and Experimental Therapeutic, v. 317, p. 30-36, 2006.

United Nations. Policy Brief for Heads of Government: The Global Impact of Dementia 2013 - 2050. 2013. Disponível em: <http://www.un.org/en/development/desa/population/publications/pdf/ageing/ WorldPopulationAgeing2013.pdf>. Acesso em: novembro 2015.

USLANER, J.; EDDINS, D.; PURI, V.; CANNON, C.; SUTCLIFFE, J.; CHEW, C.; PEARSON, M.; VIVIAN, J.; CHANG, R.; RAY, W.; KUDUK, S.; WITTMANN, M. The muscarinic $\mathrm{m} 1$ receptor positive allosteric modulator pqca improves cognitive measures in rat, cynomolgus macaque, and rhesus macaque. Psychopharmacology, v. 225, n. 1, p. 21-30, 2013.

van Deursen, J.; VUURMAN, E.; VERHEY, F.; van Kranen-Mastenbroek, V.; RIEDEL, $\mathrm{W}$. Increased eeg gamma band activity in alzheimer's disease and mild cognitive impairment. Journal of Neural Transmission, v. 115, n. 9, p. 1301-1311, 2008. 
VARANI, A.; MOUTINHO, M.; BALERIO, G. Baclofen prevented the changes in cfos and brain-derived neutrophic factor expressions during mecamylamine-precipitated nicotine withdrawal in mice. Synapse, v. 68, n. 11, p. 508-517, 2014.

VARANI, A.; MOUTINHO, M.; BALERIO, G. Lack of gabab receptors modifies behavioural and biochemical alterations induced by precipitated nicotine withdrawal. Neuropharmacology, v. 90, p. 90-101, 2015.

VERRET, L.; MANN, E.; HANG, G.; BARTH, A.; COBOS, I.; HO, K.; DEVIDZE, N.; MASLIAH, E.; KREITZER, A.; MODY, I.; MUCKE, L.; PALOP, J. Inhibitory interneuron deficit links altered network activity and cognitive dysfunction in alzheimer model. Cell, v. 149, n. 3, p. 708-721, 2012.

VERTES, R. Hippocampal theta rhythm: a tag for short-term memory. Hippocampus, v. 15, n. 7, p. 923-983, 2005.

VERTES, R. Interactions among the medial prefrontal cortex, hippocampus and midline thalamus in emotional and cognitive processing in the rat. Neuroscience, v. 142, n. 1, p. $1-20,2006$.

VILLEMAGNE, V. L.; BURNHAM, S.; BOURGEAT, P.; BROWN, B.; ELLIS, K. A.; SALVADO, O.; SZOEKE, C.; MACAULAY, S. L.; MARTINS, R.; MARUFF, P.; AMES, D.; ROWE, C.; MASTERS, C. Amyloid $\beta$ deposition, neurodegeneration, and cognitive decline in sporadic alzheimer's disease: a prospective cohort study. The Lancet Neurology, v. 12, n. 4, p. 357-367, 2013.

WALLACE, T.; PORTER, R. Targeting the nicotinic $\alpha 7$ acetylcholine receptor to enhance cognition in disease. Biochemical Pharmacology, v. 82, n. 8, p. 891-903, 2011.

WANG, B.; LIAO, W.; CHANG, C.; WANG, S. Facilitation of glutamate release by nicotine involves the activation of a ca2+/calmodulin signaling pathway in rat prefrontal cortex nerve terminals. Synapse, v. 59, n. 8, p. 491-501, 2006.

WANG, X.; SU, B.; ZHENG, L.; PERRY, G.; SMITH, M.; ZHU, X. The role of abnormal mitochondrial dynamics in the pathogenesis of alzheimer's disease. Journal of Neurochemistry, v. 109, p. 153-159, 2009.

WARBURTON, E.; KODER, T.; CHO, K.; MASSEY, P.; DUGUID, G.; BARKER, G.; AGGLETON, J.; BASHIR Z, I.; BROWN, M. Cholinergic neurotransmission is essential for perirhinal cortical plasticity and recognition memory. Neuron, v. 38, n. 6, p. 987-996, 2003.

WATSON, G.; CRAFT, S. The role of insulin resistance in the pathogenesis of alzheimer's disease: implications for treatment. CNS Drugs, v. 17, n. 1, p. 27-45, 2003. 
WATSON, G.; CRAFT, S. Modulation of memory by insulin and glucose: neuropsychological observations in alzheimer's disease. European Journal of Pharmacology, v. 490, p. 97-113, 2004.

World Health Organization; Alzheimer's Disease International. Dementia: a public health priorit. 2012. Disponível em: < http :

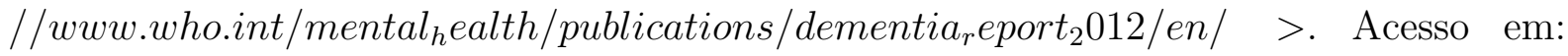
novembro 2015.

XU, T.-Y.; GUO, L.-L.; WANG, P.; SONG, J.; LE, Y.-Y. e. a. Chronic exposure to nicotine enhances insulin sensitivity through $\alpha 7$ nicotinic acetylcholine receptor-stat3 pathway. PLoS ONE, v. 7, n. 12, 2012.

XU, Z.; LI, L.; BAO, J.; WANG, Z.; ZENG, J.; LIU, E.; LI, X.; HUANG, R.; GAO, D.; LI, M.; ZHANG, Y.; LIU, G.; WANG, J. Magnesium protects cognitive functions and synaptic plasticity in streptozotocin-induced sporadic alzheimer's model. PLoS One, v. 9, n. 9, p. e108645, 2014.

YAGER, L.; GARCIA, A.; WUNSCH, A.; FERGUSON, S. The ins and outs of the striatum: role in drug addiction. Neuroscience, v. 30, n. 301, p. 529-541, 2015.

YIZHAR, O.; FENNO, L.; PRIGGE, M.; SCHNEIDER, F.; DAVIDSON, T.; O'SHEA, D.; SOHAL, V.; GOSHEN, I.; FINKELSTEIN, J.; PAZ, J.; STEHFEST, K.; FUDIM, R.; RAMAKRISHNAN, C.; HUGUENARD, J.; HEGEMANN, P.; DEISSEROTH, K. Neocortical excitation/inhibition balance in information processing and social dysfunction. Nature, v. 477, n. 7363, p. 171-178, 2011.

ZEMEK, F.; DRTINOVA, L.; NEPOVIMOVA, E.; SEPSOVA, V.; KORABECNY J. KLIMES, J.; K., K. Outcomes of alzheimer's disease therapy with acetylcholinesterase inhibitors and memantine. Expert Opinion on Drug Safety, v. 13, n. 6, p. 759-774, 2014. 